$b 20226615$

QP

535

into

2010

\title{
IN-VIVO MEASUREMENT OF STRONTIUM INCORPORATION AND RETENTION IN HUMAN BONE USING AN X-RAY FLUORESCENCE SYSTEM
}

\author{
By \\ Helen Moise \\ B.Sc. Concordia University, 2001 \\ Montréal, Québec
}

A thesis

presented to Ryerson University

in partial fulfillment of the

requirements for the degree of

Master of Science

in the Program of

Biomedical Physics

Toronto, Ontario, Canada, 2010

(c) Helen Moise, 2010 


\section{Author's Declaration}

I hereby declare that I am the sole author of this thesis.

I authorize Ryerson University to lend this thesis to other institutions or individuals for the purpose of scholarly research.

I further authorize Ryerson University to reproduce this thesis by photocopying or by other means, in total or in part, at the request of other institutions or individuals for the purpose of scholarly research. 


\section{Abstract}

"In-Vivo Measurement of Strontium Incorporation and Retention in Human Bone Using an X-Ray Fluorescence System". Helen Moise, M. Sc. Biomedical Physics, Ryerson University, Toronto, 2010.

Strontium ( $\mathrm{Sr}$ ), found in nature and the human skeleton, exerts beneficial or detrimental effects, depending on levels. Previous strontium studies in humans and animals showed bone mineral density and bone strength increases. However, its exact mechanism of therapeutic action is not fully understood. The purpose of this study was to investigate strontium incorporation and retention over time, in healthy and osteoporotic/osteopenic individuals, using the non-invasive, in-vivo X-Ray Fluorescence (IVXRF) system developed and optimized by Pejović-Milić 2004 and Zamburlini 2008.

Nineteen individuals, self-supplementing with strontium, were recruited and measured at their finger and ankle, representing cortical and trabecular bone. Using ${ }^{125}$ I brachytherapy seeds as the radiation photon source, each measurement lasted thirty minutes. All individuals showed an initial rapid uptake of strontium within 2-5 months followed by slower increases, suggesting that strontium incorporation and retention is a result of two different mechanisms and is dependent on the bone remodeling cycle. 


\section{Acknowledgements}

In completing my thesis work, there are a number of individuals I would like to thank that made this learning experience an enriching one. I would like to thank my supervisor and professor, Dr. Ana Pejović-Milić for her expertise, support and guidance she has shown me. Her passion and dedication not only to this research project but to the field of medical physics is inspiring. I would also like to thank Dr. David Chettle of McMaster University, one of my supervisory committee members and future supervisor, for his valuable insight and enthusiastic support. To Dr. Michael Kolios, of Ryerson University, my second committee supervisory member, for imparting his guidance and knowledge and for the mobile ultrasound device necessary for this research study. To Dr. Colin Webber, of McMaster University, for his professional input and insight in this study. With much appreciation to Christopher Heirwegh, M.Sc, for his time and introducing me to this research study. His patience and guidance to my endless questions is sincerely appreciated!

To the tandem accelerator building staff at McMaster University for making my thesis work flow smoothly; Jason Falladown and Scott McMaster for their technical assistance and Fiona Ahlang, Department Administrator for her help. To McMaster graduate student Elstan DeSouza for his countless energy, time and valuable help. To Mira Sibai, fellow colleague and Ryerson University graduate student for her assistance when requested.

To the program administrator, Mary Neelands, physics administrative staff at Ryerson University; Tess and Sally, and physics faculty and technical staff for their assistance, and Ryerson graduate students, Mehrnaz Tabibi and others who made my experience at Ryerson a 
good one.

To the volunteers participating in this study, for your time and dedication- thank you!

But most of all, special thanks goes to Marjorie Filice, a friend, for her warm

encouragement, dedication and time devoted to this research study. To my wonderful parents, brother and aunt for their love and support, who encouraged me to work through difficult times and never give up. I couldn't have made it this far without you!

Thank you! 


\section{Table of Contents}

AUTHOR'S DECLARATION............................................... II

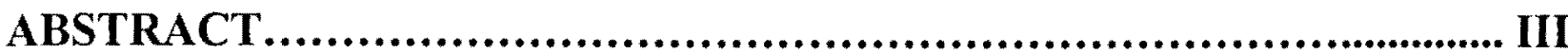

ACKNOWLEDGEMENTS ................................................... IV

TABLE OF CONTENTS..................................................................................

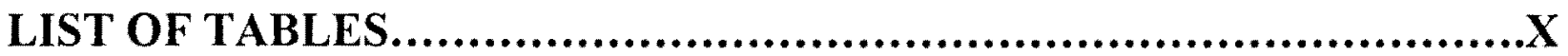

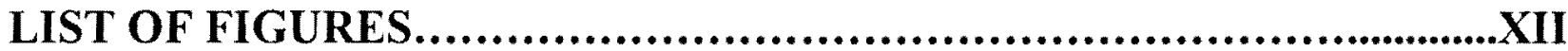

LIST OF APPENDICES....................................................

CHAPTER 1 INTRODUCTION................................................... 1

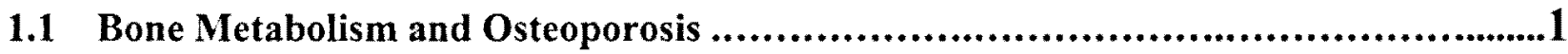

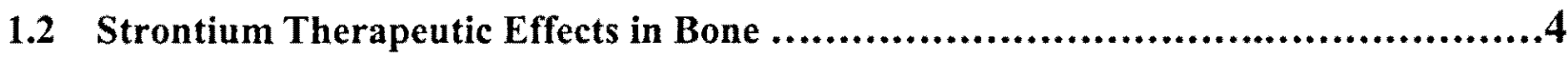

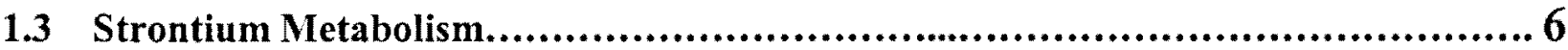

1.4 In-Vivo X-Ray Fluorescence (IVXRF) System to Measure Bone Strontium Level:

Technique Development and Previous Work .............................................12

1.4.1 Strontium Signal Attenuation by Overlying Soft Tissue...........................13

1.4.2 Coherent Normalization of Bone Strontium Signal $\quad$................................17

1.4.3 IVXRF Pilot Study of Human Bone Strontium Measurements .......................20 


\section{CHAPTER 2 FURTHER DEVELOPMENT OF THE IVXRF}

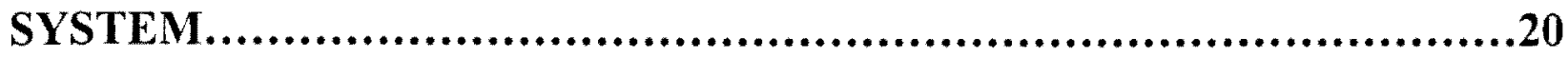

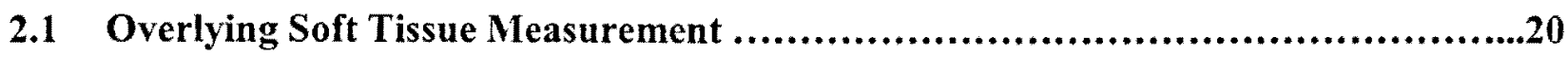

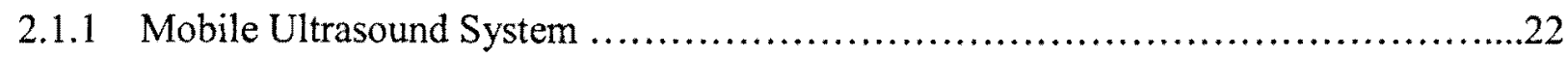

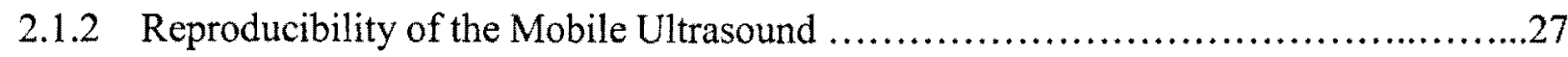

2.1.3 Average Overlying Soft Tissue Measurement at Two Anatomical Sites ...............28

2.1.4 Sources of Error Associated with Ultrasound Imaging ...............................29

2.2 Excitation Source Positioning During Bone Strontium Measurements ................ 29

2.2.1 Effects of Source Positioning on Bone Strontium IVXRF Measurement................34

\section{CHAPTER 3 STRONTIUM INCOPORATION INTO BONE..............40}

3.1 Quantification of Strontium in Human Bone by Dual Photon Absorptiometry.........40

3.2 In-Vivo X-Ray Fluorescence to Measure Bone Strontium: Previous Human

Studies.......................................................................................40

3.3 IVXRF Bone Strontium Measurements: Experimental Set-Up and Measurement

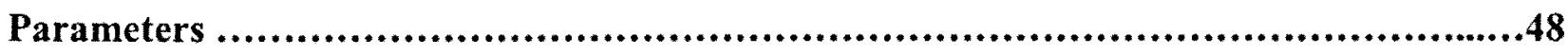

3.4 Bone Strontium Baseline Study of Individuals taking Strontium Supplements.........49

3.4.1 Results of the Bone Strontium Baseline Study of Individuals Taking Strontium

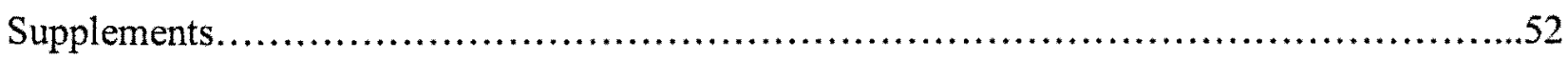

3.4.2 Discussion of the Bone Strontium Baseline Study Individuals taking Strontium

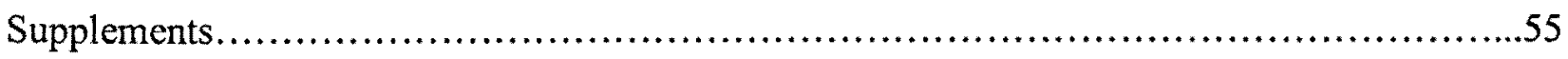

3.5 Time Dependant Incorporation of Strontium in Bone: Initial Baseline Case Study....58 
3.7 Bone Strontium Levels in African Subject Measured with the IVXRF System..........67

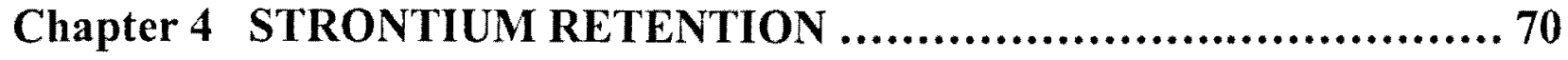

4.1 Long Term Strontium Retention in Human Bone....................................70

4.2 Initial Retention Study Using the IVXRF System.....................................73

4.3 Human Bone Strontium Measurements ............................................83

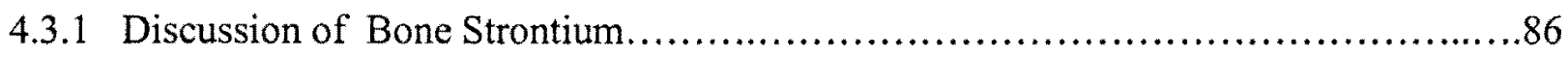

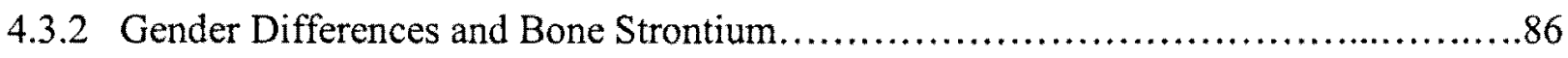

4.3.3 Influence of Dosage and Duration of Treatment on Bone Strontium....................89

4.4 Strontium Levels and Bone Mineral Density ......................................... 93

\section{CHAPTER 5 IN-VIVO MEASUREMENT OF STRONTIUM \\ INCORPORATION AND RETENTION IN HUMAN BONE USING AN}

IVXRF SYSTEM.....................................................97

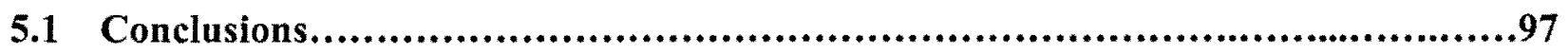

5.1.1 Excitation Source Positioning and Mobile Ultrasound System ......................99

5.1.2 Bone Strontium Levels in African Subject Measured with the IVXRF System ........101

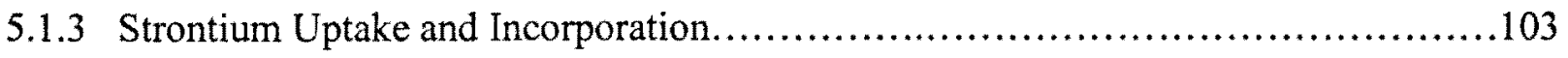

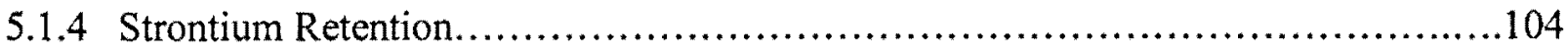

5.1.5 Use of Strontium K-alpha and K-beta Peaks to Determine Bone Health...............106 
5.2.1 Improvement of Subject Positioning Undergoing the IVXRF Bone Strontium

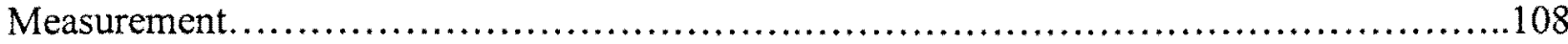

5.2.2 New Generation of Silicon-Based Detectors for Bone Strontium Measurements......113

5.2.3 Creation of a New Set of Calibration Standards...................................115

5.2.4 Modeling of IVXRF Human Bone Strontium Data..............................117

REFERENCES............................................................. 


\section{List of Tables}

Table 1-1: Table 1-1: The WHO Classification of Osteoporosis and Osteopenia According to BMD. Note that the T-score is the number of units or standard deviations (SD) that an individual's bone density is above or below the average. T-score is usually compared to a

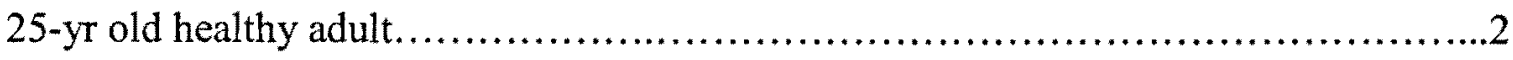

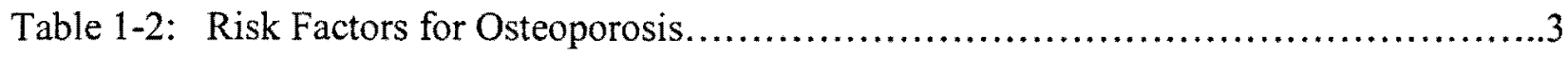

Table 1-3: Distribution of Strontium, Calcium and Magnesium in Reference Man (70Kg)

(Nielsen, 2004) ..............................................................

Table 1-4: Summary of Bone Strontium Concentrations Depending on Skeletal Site (C):

Cortical bone; (T): Trabecular Bone. (Zamburlini, 2008) .........................10

Table 2-1: Image Modality Accuracy Results. Note: \% Accuracy= 100 *(Accuracy, mm)/

$(3.79 \mathrm{~mm})$. Tissue thickness estimates from seven cadaver fingers suggests an average

population index finger soft tissue thickness of $3.79 \mathrm{~mm}$ (Heirwegh, 2008) ............21

Table 2-2: Ultrasound Parameters Used in Imaging for the Determination of Overlying

Soft -Tissue Thickness

Table 2-3: Summary of Reproducibility Measurements obtained with the Mobile Ultrasound.27

Table 2-4: Summary of Overall Soft-Tissue Thickness (in mm) of Individuals. N=19 represents the combined total number of individuals (male and female) measured with the $10 \mathrm{MHz}$ mobile ultrasound. $\mathrm{N}=16$ represents the number of female participants and $\mathrm{N}=3$

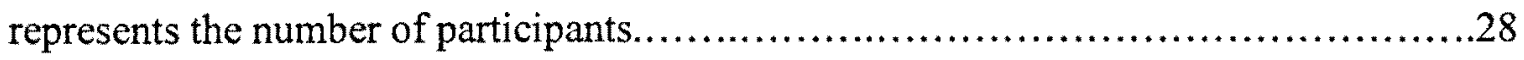

Table 2-5: Peak Parameters Used to Run the Finger Phantom. Rise Time, Cusp, Flat-top, Width, and Tilt peak parameters were previously optimized by Zamburlini et al.,(2008)..31 
Table 3-1: Average Normalized Strontium Signal for Asian and Caucasian Individuals

Table 3-2: Profile of Baseline Subjects Recruited. Note that all baseline individuals are females. All are Caucasian with the exception of one who is South American. The median age of recruitants is 66 years old

Table 3-3: Summary of Strontium K-alpha Levels in Finger (Cortical Bone) at Major Points of Interest for All Baseline Subjects (including initial baseline subject \#1). The ratio refers to the strontium k-alpha to k-beta peak ratio. The error represents statistical uncertainty in the measurement.

Table 3-4: Summary of Strontium Levels in the Ankle (Trabecular Bone) at Major Points of Interest for All Baseline Subjects (including initial baseline subject \#1). The ratio refers to the strontium $\mathrm{k}$-alpha to k-beta peak ratio. The error represents statistical uncertainty in the measurement. .55

Table 4-1: Profile of Additional Subjects Recruited. Note that all individuals are Caucasian and have a history of strontium supplementation. The median age of recruitants is 66 years old

Table 4-2: Summary of K-alpha Bone Strontium Levels in Female and Male Participants after 4 years of Strontium Supplementation. The Caucasian individuals participating in the 2006 pilot study, had an average normalized k-alpha strontium signal of $0.43 \pm 0.08$ for the finger bone and $0.40 \pm 0.13$ for the ankle bone. Subjects 12,13 and 17 's levels are compared to these values. The error is associated with statistical uncertainty. NA=not available .88 
Table 4-3: Average Change in Bone Strontium Measurements with Decreasing Strontium Dosage. Note subject \#17 had initially supplemented with strontium carbonate and recently switched to strontium citrate supplements. Calculations are based on two bone strontium measurements in which strontium supplementation was reduced. The calculation for subject \#10, in the ankle did not utilize visits 1 and 2 due to a positioning error during measurement taking.

Table 4-4: Bone Mineral Density Changes with Strontium Citrate. Note that names have been changed.

Table 5-1: X-Ray Emission Lines (K-level and L-level) Similar to Strontium Alpha and Beta Peaks. Note that $k$-alpha is designated as $k_{\alpha}$ and $k$-beta is designated as $k_{\beta}$. (http://www.bedwani.ch/xrf/emission/XEmission.htm).

Table 5-2: Plaster of Paris (poP) Phantoms used in IVXRF Measurements. .115 


\section{List of Figures}

Figure 1-1: Chemical Structure of Strontium ranelate. The molecular formula is:

C12H6N2O8SSr2 (Valaciclovir, 2010) ..........................................

Figure 1-2: Side view of human finger phantom positioning.............................

Figure 1-3: Detector and measurement setup using $180^{\circ}$ interaction geometry (head-on view).17

Figure 2-1: Ultrasound Image of Finger: Transverse View (with gel pad). The soft tissue thickness is determined as the distance from the bone surface to the skin surface. Scale

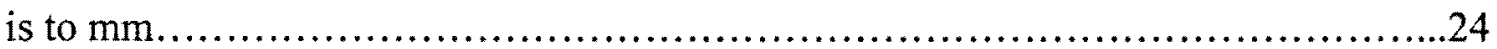

Figure 2-2: Ultrasound Image of Finger: Transverse View with A) Gel pad and B) Without

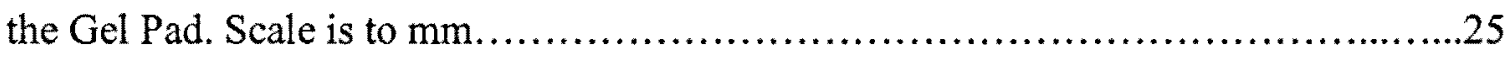

Figure 2-3: Ultrasound Image of Ankle: Transverse View with A) Gel pad and B) Without

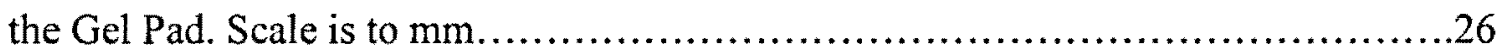

Figure 2-4: Experimental Set-Up of Source and Phantom Positioning. Note that the set-up is the same as during a human finger measurement; the phantom is positioned to simulate a human finger measurement......................................................

Figure 2-5: Typical Spectrum Obtained for the Bone Strontium Phantom using the IVXRF System. Strontium K-alpha and K-beta peaks are seen at $14.16 \mathrm{KeV}$ and $15.8 \mathrm{KeV}$

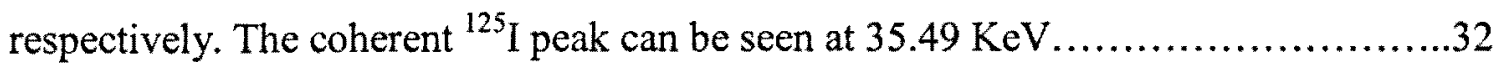


Figure 2-6: Various Directions of Movement. The strontium bone phantom was moved in various directions with respect to the ${ }^{125}$ I seed excitation source. The up and down directions are defined as the vertical distance (y-plane), forward and backward ( $\mathrm{x}$-plane)

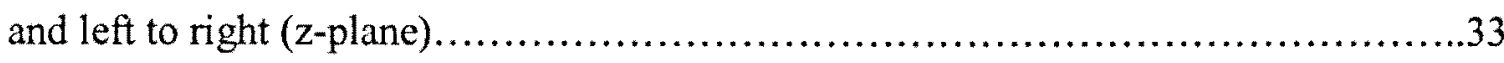

Figure 2-7: Typical Spectrum Obtained for the Bone Strontium Phantom using the IVXRF System. Strontium K-alpha and K-beta peaks are seen at $14.16 \mathrm{keV}$ and $15.8 \mathrm{keV}$ respectively. The coherent ${ }^{125}$ I peak can be seen at $35.49 \mathrm{keV}$

Figure 2-8: Variation of IVXRF Measurement as a Function of Source Positioning in the Xplane (Horizontal Movement: forward and backward). Position $(0,0)$ represents positioned bone strontium phantoms in front of the excitation seeds. A) Strontium Peaks were normalized to the ${ }^{125}$ I coherent peak localized at $35.49 \mathrm{keV}$ and B) NonNormalized

Figure 2-9: Variation of IVXRF Measurement as a Function of Source Positioning Source Positioning in the Y-plane (Vertical Movement: upwards and downwards). Position $(0,0)$ represents positioned bone strontium phantoms in front of the excitation seeds. A) Strontium Peaks were normalized to the ${ }^{125} \mathrm{I}$ coherent peak localized at $35.49 \mathrm{keV}$ and

B) Non-Normalized .36

Figure 2-10: Variation of IVXRF Measurement as a Function of Source Positioning Source Positioning in the Z-plane (Sideways Movement: left and right). Position $(0,0)$ represents positioned bone strontium phantoms in front of the excitation seeds. A) Strontium Peaks were normalized to the ${ }^{125}$ I coherent peak localized at $35.49 \mathrm{keV}$ and B) Non-Normalized 
Figure 2-11: Variation of IVXRF Measurement as a Function of Seed Angle. The strontium peaks were normalized to the ${ }^{125} \mathrm{I}$ coherent peak localized at $35.49 \mathrm{keV} \ldots \ldots \ldots \ldots \ldots . . .38$

Figure 3-1: Normalized Strontium Alpha Peak in Finger Measurement. Note that the uncertainty represents the statistical uncertainty (Zamburlini et al., 2007).

Figure 3-2: Normalized Strontium Alpha Peak in Ankle Measurement. Note that the uncertainty represents the statistical uncertainty (Zamburlini et al., 2007)

Figure 3-3: Pilot Study; Correlation of the Normalization Strontium Peaks for Finger Measurements of the 22 Subjects. Note the errors are associated with the statistical uncertainty (Zamburlini et al, 2007)

Figure 3-4: Strontium Spectra of Finger for Caucasian, Continental Asian and Strontium Supplementing Individual. Note that in this spectrum, the Caucasian and Asian Individual had the same overlying soft tissue thickness. The self-supplementing individual had a thicker overlying soft tissue thickness (Zamburlini et al., 2007)

Figure 3-5: Strontium IVXRF Results of Self-Supplementing Individual Compared to NonSupplementing Caucasian and Asian Individual. Note that the control group refers to the group of the twenty two subjects (Zamburlini et al., 2007).

Figure 3-6: Strontium Measurement over Time of Baseline Subject \#2 in A) Finger and B) Ankle. The subject is a $72 \mathrm{yr}$ old female, diagnosed with osteoporosis. Day zero represents the baseline measurement of subject's natural bone strontium level prior to strontium supplementation. Errors are associated with the statistical uncertainty 53 
Figure 3-7: Baseline Case Study \#1 Strontium Measurement over Time in A) Finger and B) Ankle. The subject is a 68 yr old Caucasian female, diagnosed with Osteoporosis. Day zero represents the baseline measurement of natural, pre-treatment bone strontium levels. Errors are associated with the statistical uncertainty

Figure 3-8: Incorporation of Strontium and its Influence in the Bone Remodeling Cycle. The plus $(+)$ and minus $(-)$ sign indicates activation or inhibition by strontium on the corresponding stage (Marie PJ, 2006).

Figure 4-1: Global Bone Strontium Content over Time in Post- Menopausal Women Administrated with Strontium Ranelate Medication. Note that the authors express the global bone strontium content as the total (cortical+trabecular). The number, $\mathrm{n}$, represents the number of bone samples.

Figure 4-2: Subject \#10's strontium levels in A) Finger (Cortical bone) and B) Ankle (Trabecular bone) six months after strontium supplementation. Note that strontium concentration is reported as arbitrary units and is proportional to the strontium signal observed. The error represents the uncertainty associated with the measurement (Heirwegh, 2008)

Figure 4-3: Subject \#1's Strontium Levels in the Finger Bone (Cortical bone). Note that normalized strontium peak area is proportional to the strontium signal observed. The error is associated with statistical uncertainty .78

Figure 4-4: Highlighted Subject \#1's Strontium Levels in the Finger Bone (Cortical bone). Note that normalized strontium peak area is proportional to the strontium signal observed. The error is associated with statistical uncertainty . .78 
Figure 4-5: Subject \#1's Strontium Levels in the Ankle Bone (Trabecular bone). Note that normalized strontium peak area is proportional to the strontium signal observed. The Error is associated with statistical uncertainty. ....

Figure 4-6: Highlighted Subject \#1's Strontium Levels in the Finger Bone (Cortical bone).

Note that normalized strontium peak area is proportional to the strontium signal observed. The error is associated with statistical uncertainty

Figure 4-7: Subject \#10's Bone Strontium Measurements in A) the Finger and B) the Ankle. Note that normalized strontium peak area is proportional to the strontium signal observed. The error is associated with statistical uncertainty.

Figure 4-8: Retention Subject \#11; Strontium Measurement over Time in A) Finger and B) Ankle. Subject is a $61 \mathrm{yr}$ old Caucasian male, diagnosed with Osteopenia of the Spine, Neck and Hip. Note that normalized strontium peak area is proportional to the strontium signal observed. The error is associated with statistical uncertainty .84

Figure 4-9: Retention Subject\#14; Strontium Measurement over Time in A) Finger and B) Ankle. Subject is a 53 yr old Caucasian female, diagnosed with osteoporosis. The initial value denotes time of her first measurement before she resumed taking strontium supplements after an absence of six months. Note that normalized strontium peak area is proportional to the strontium signal observed. The error is associated with statistical

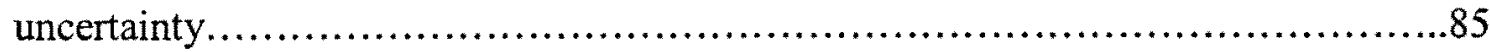

Figure 5-1: Human Finger Measurement (Heirwegh, 2008) ................................109 
Figure 5-2: Proposed Finger Positioning (Front View); Additional Enhancements. The finger is represented by the yellow horizontal bar and two side mirrors are attached to the top of the detector. A clamp would further mobilize and keep the finger straight; may be adjustable to accommodate variances in finger thickness. The same wooden hand support base as shown in Figure 5-1, along with a bean bag may be used.

Figure 5-3: Proposed Ankle Positioning; Front View

Figure 5-4: Finger Bone Lead Measurement with a Germanium Detector (16mm)

(Börjesson and Mattsson, 2007)

Figure 5-5: Optical system at $78.1 \mathrm{~cm}$ away from the $\mathrm{x}$-ray tube. Note that coherent normalization is not done (Sibai, unpublished work)

Figure 5-6: Calibration Curve of poP phantoms. The error relates to statistical uncertainty within the strontium peak area...

Figure AI-1: Strontium Measurement over Time Baseline Subject \#3 in A) Finger and B) Ankle. Subject is a 66 yr old female, diagnosed with osteoporosis and osteopenia. Day zero represents the baseline measurement of subject's natural bone strontium level prior to strontium supplementation. Errors are associated with the statistical uncertainty....122

Figure AI-2: Strontium Measurement over Time Baseline Subject \#4 in A) Finger and B) Ankle. Subject is a 75 yr old Caucasian female, diagnosed with osteoporosis of the spine and osteopenia of the neck. Day zero represents the baseline measurement of subject's natural bone strontium level prior to strontium supplementation. Errors are associated with the statistical uncertainty 
Figure AI-3: Strontium Measurement over Time Baseline Subject \#5 in A) Finger and B) Ankle. Subject is a $67 \mathrm{yr}$ old South American female, diagnosed with osteopenia of the hip. Note that normalized strontium peak area is proportional to the strontium signal observed. The error is associated with statistical uncertainty

Figure AI-4: Strontium Measurement over Time Baseline Subject \#5 in A) Finger and B) Ankle. Subject is a $57 \mathrm{yr}$ old Caucasian female, diagnosed with osteopenia of the spine. Note that normalized strontium peak area is proportional to the strontium signal observed. The error is associated with statistical uncertainty.....

Figure AI-5: Strontium Measurement over Time Baseline Subject \#6 in A) Finger and B) Ankle. Subject is a 74 yr old Caucasian female, diagnosed with osteopenia of the spine. Note that normalized strontium peak area is proportional to the strontium signal observed. The error is associated with statistical uncertainty....

Figure AI-6: Strontium Measurement over Time Baseline Subject \#8 in A) Finger and B) Ankle. Subject is a 53 yr old Caucasian female, diagnosed with osteoporosis of the spine and osteopenia of the hip. Note that normalized strontium peak area is proportional to the strontium signal observed. The error is associated with statistical uncertainty

Figure AI-7: Strontium Measurement over Time Baseline Subject \#9 in A) Finger and B) Ankle. Subject is a 63 yr old Caucasian female, diagnosed with osteopenia of the spine and hip. Note that normalized strontium peak area is proportional to the strontium signal observed. The error is associated with statistical uncertainty .128 
Figure AII-1: Strontium Measurement over Time Baseline Subject \#15 in A) Finger and B) Ankle. Subject is a 51 yr old Caucasian female, diagnosed with osteopenia of the spine. At time of first measurement, subject had been supplementing for 6 months (341 mg daily). Note that normalized strontium peak area is proportional to the strontium signal observed. The error is associated with statistical uncertainty

Figure AII-2: Strontium Measurement over Time Baseline Subject \#16 in A) Finger and B) Ankle. Subject is a 55 yr old Caucasian female, diagnosed with osteopenia of the spine. At time of first measurement, subject had been supplementing for 6 months (341 mg daily). Note that normalized strontium peak area is proportional to the strontium signal observed. The error is associated with statistical uncertainty

Figure All-3: Strontium Measurement over Time Baseline Subject \#17 in A) Finger and B) Ankle. Subject is a 69 yr old Caucasian female, diagnosed with Osteopenia. Doses varied according to visit as: first visit; $1020 \mathrm{mg} /$ day, second visit: $680 \mathrm{mg} /$ day. She then discontinued strontium supplements after her second visit. A time lapse of 72 days occurred between visits and at the time of her third visit she had resumed strontium supplements to $341 \mathrm{mg} /$ day. Note that normalized strontium peak area is proportional to the strontium signal observed. The error is associated with statistical uncertainty.131

Figure AII-4: Subject \#19 in A) Finger and B) Ankle.. Subject is a 76 year old Caucasian female diagnosed with osteoporosis of the spine. Subject took one bottle of strontium supplements before stopping 4 months ( $341 \mathrm{mg}$ daily) prior to joining the study. Note that normalized strontium peak area is proportional to the strontium signal observed. The error is associated with statistical uncertainty. 132 


\section{List of Appendices}

Appendix I IVXRF Bone Strontium Measurements of Baseline Subjects.................122

Appendix II IVXRF Bone Strontium Measurements of Retention Subjects.................129 


\section{Chapter 1 Introduction}

\subsection{Bone Metabolism and Osteoporosis}

In the human body, bone serves to fulfill many functions vital to health. Bone is a composite material, consisting of inorganic and organic components as well as the cellular elements. Its function is to provide structural support, protection of internal organs, enable movement, act as a reservoir of minerals, help maintain acid-base balance and play a role in hematopoiesis (Peel, 2008). There are two types of bone: trabecular bone and cortical bone, with differing proportions of the two at different skeletal sites (Peel, 2008). Trabecular bone, also known as cancellous bone is the inner, softer portion of bone, representing approximately $20 \%$ of the skeleton. The second type, cortical bone is the outer, harder layer of bone, representing approximately $80 \%$ of the skeleton (Peel, 2008). Bone shape, growth and health are influenced by the bone remodeling process, which allows for repair of bone fractures, maintenance of calcium homoeostasis and acid-base balance (Peel, 2008). An imbalance in the bone remodeling process may lead to bone diseases such as osteoporosis.

Osteoporosis, according to the Merck Manual of Medical Information (1997) is defined as a progressive disease in the density of bones that causes weakness and an increased risk of fractures. Osteopenia, on the other hand, is a low bone mass and will eventually lead to osteoporosis. The World Health Organization (WHO) classifies Osteoporosis and Osteopenia based on bone mineral density (BMD) scores. Table 1-1, summarizes these classifications according to BMD score. 


\begin{tabular}{|l|l|}
\hline \multicolumn{1}{|c|}{ T-score } & \multicolumn{1}{c|}{ Classification } \\
\hline Between 0 and -1 & Normal \\
\hline Between -1 and -2.5 & $\begin{array}{l}\text { Osteopenia } \\
\text { Low bone mass, does not yet meet criteria for osteoporosis } \\
\text { but may lead to osteoporosis; increased fracture risk. }\end{array}$ \\
\hline Below -2.5 & $\begin{array}{l}\text { Osteoporosis } \\
\text { High risk for fractures; advanced stages leading to bone } \\
\text { pain. }\end{array}$ \\
\hline
\end{tabular}

Table 1-1: The WHO Classification of Osteoporosis and Osteopenia According to BMD. Note that the T-score is the number of units or standard deviations (SD) that an individual's bone density is above or below the average. T-score is usually compared to a 25-yr old healthy adult.

The National Osteoporosis Foundation (2008), estimated that 44 million Americans were affected with osteoporosis and low bone mass. The WHO classifies osteoporosis as one of the leading health issues worldwide. One in four women and one in eight men will be diagnosed with osteoporosis during their lifetime (Osteoporosis Canada, 2008). While the cause of osteoporosis still remains unclear, there are several risk factors that make an individual prone to getting the disease, as indicated in Table 1-2. 


\begin{tabular}{|c|c|}
\hline Risk & Factors Associated with Risk \\
\hline Biological & $\begin{array}{l}\text { - } \text { Age (Increases with Risk) } \\
\text { - Gender (More Prevalent in Females) } \\
\text { - } \text { Family History } \\
\text { - } \text { Low Body Weight/ Thin Frame } \\
\text { - } \text { History of broken bones } \\
\text { - Early Menopause } \\
\text { - Low Sex Hormones (estrogen, missing } \\
\quad \text { periods, testosterone) }\end{array}$ \\
\hline Diet and Lifestyle & $\begin{array}{l}\text { - Low calcium, vit } D \text { and phosphorus } \\
\text { intake } \\
\text { - Mineral and vitamin deficiencies } \\
\text { - High protein and caffeine intake } \\
\text { - High sodium diet } \\
\text { - Spinach and Wheat Bran (if taken with } \\
\text { calcium rich foods, will prevent the } \\
\text { body from absorbing calcium) } \\
\text { - Smoking and alcohol } \\
\text { - Being inactive }\end{array}$ \\
\hline Drugs & - Prolonged use of Corticosteroids \\
\hline Health Diseases & $\begin{array}{l}\text { - Anorexia and eating disorders } \\
\text { - } \text { Celiac disease } \\
\text { - Multiple Myeloma } \\
\text { - } \text { Inflamerparathyroidsm, hyperthyroidism } \\
\text { - Organ Transplant History } \\
\text { - Rheumatoid Arthritis }\end{array}$ \\
\hline
\end{tabular}

Table 1-2: Risk Factors for Osteoporosis

Osteoporosis occurs when there is uneven rate of activity between osteoclasts and osteoblasts, such that bone loss occurs. As bone is constantly being remodeled, with one bone remodeling cycle taking approximately 120 days for completion (Marie et al., 2001), there is a continuous uptake of old bone (resorption) followed by the deposition of new bone. The osteoblasts cells are 
the cells responsible for laying down new bone and osteoclasts are cells responsible for the breakdown of old bone. To keep bones healthy, which includes repairing any minor damage that may occur with wear and tear, the activity of the osteoclasts and osteoblasts must be kept in balance. When there is a mismatch between these cells' activities, possibly due to factors such as aging, hormonal changes, low calcium and Vitamin D, then osteoporosis may occur. As a result, of this mismatch, the osteoclasts will out-perform the osteoblasts and as a consequence, more bone is broken down than is deposited, leading to thinner bones, lower bone density and mass, decreased bone strength and an increased risk of fractures. The trabecular bone would be most affected by this mismatch as it undergoes turnover at a quicker rate than cortical bone. Areas in the body where there is a higher ratio of trabecular bone to cortical bone include the spine, the wrist and the hips, thus these areas may be affected much more rapidly than other bone sites in the body. Treatment for osteoporosis is aimed at rebalancing the bone cells' activity through resorption reduction and increasing bone strength and density. Therapy includes prescribed drugs, such as drugs belonging to the bisphosphonates group, dietary and lifestyle changes and supplements. Strontium supplementation, in addition to calcium and vitamin D is one current therapy that is gaining attention and popularity.

\subsection{Strontium Therapeutic Effects in Bone}

Nielsen (2004) suggests that the first observation that strontium may be used to treat bone diseases, such as osteoporosis came from Shorr and Carter (1952), who showed that after a moderate dose of strontium lactate, the deposition of calcium in bone was greater than total calcium storage when calcium was given without strontium. In another preliminary study, as 
stated by Neilson (2004), the same agent, strontium lactate was shown to reduce bone pain in osteoporotic individuals with radiological sign improvement, such as thicker bone. In rats, strontium ranelate was shown to reduce resorption and long bone loss induced by hind leg immobilization (Bain et al., 2008). Furthermore, in ovariectomized rats, strontium ranelate was shown to induce positive effects on intrinsic bone properties, decrease bone resorption, maintain bone formation, prevent bone loss, and increase in bone strength (Neuprez et al., 2008). In humans, one of the largest long term international trials involving strontium ranelate, was initiated in 1996 which included two extensive clinical trials for the treatment of established osteoporosis: the SOTI (Spinal Osteoporosis Therapeutic Intervention), to evaluate strontium ranelate effect on the risk of vertebral fractures and TROPOS (TReatment Of Peripheral Osteoporosis) which evaluated strontium ranelate and non-spinal fractures (Neuprez et al., 2008). In this double-blind randomized placebo controlled trial involving post-menopausal, osteoporotic women, strontium ranelate was shown to reduce the number of new vertebral and peripheral fractures, compared to the placebo group. It also was shown to increase the bone mineral density (BMD) at the spine and femur levels (Bärenholdt et al., 2009). In addition to use of this medication, other strontium supplements that could produce similar effects include strontium gluconate, strontium carbonate and strontium citrate. In North America, strontium ranelate, as shown in figure 1-1, is not available and/or approved by the American FDA(Food and Drug Administration) and the Canadian Ministry of Health for treatment of osteoporosis, thus, strontium citrate is the most commonly available strontium salt. 
<smiles>N#Cc1c(N(CC(=O)[O-])CC(=O)[O-])sc(C(=O)[O-])c1CC(=O)[O-]</smiles>

Figure 1-1: Chemical Structure of Strontium ranelate. The molecular formula is:

C12H6N2O8SSr2 (Valaciclovir, 2010)
Although, previous studies have focused on the effects of strontium ranelate, the effects of the other strontium supplements are expected to be similar, as the difference between the supplements is related to the carrier molecule, such as ranelate

or citrate. And although, there is some debate that one carrier molecule may be superior to others in terms of strontium absorption that is yet to be determined.

\subsection{Strontium Metabolism}

The element strontium belongs to the group two elements of the periodic table, which includes elements calcium and magnesium, it forms divalent cations in biological fluids and the protein binding of strontium in serum or plasma is approximately the same order of magnitude as calcium (Neilson, 2004). As a trace metal in the human body, strontium balance data for the reference man is as follows: intake through foods and fluids of $1.9 \mathrm{mg}$ strontium/day; urinary loss of $0.34 \mathrm{mg}$; feces loss of $1.5 \mathrm{mg}$ strontium/day and other bodily loss (such as sweat, hair,etc) of $0.02 \mathrm{mg}$ strontium/day or less (Neilson, 2004). In humans, more than $99 \%$ of the strontium burden can be found in the skeleton (Schroeder et al., 1972). This depends on diet, as strontium can be found in dark leafy green vegetables, legumes, whole grains, rice and in seafood, such as shrimps. Strontium is taken up via the gastrointestinal tract through our diet. Dietary strontium is absorbed from the jejunum portion of the GI tract. The absorption of strontium and calcium from 
the GI tract is carried out by the same mechanisms; thus the body handles strontium in a similar way to calcium, in that it is absorbed from the gut, concentrated in bone and excreted mainly in urine (Dahl et al., 2001). The concentration of strontium in drinking water is usually $<1 \mathrm{mg} / \mathrm{L}$ and a normal diet contains between $2-4 \mathrm{mg}$ strontium/day, most of it coming from vegetables and cereals (Marie et al., 2001). Hence, the amount of strontium in the western diet is neglible compared to calcium intake, as the intake of strontium depends on the strontium content of the diet. In plants, strontium is taken up via the plant roots through the soil, the main source of strontium. And similarly, for plants, the concentration of strontium correlates with the strontium content of the soil, which again is much lower than calcium. Furthermore, in plants, strontium is a growth stimulant and can replace calcium required by Chlorella (Nielsen, 2004). Furthermore, Comar and colleagues (1957) have suggested that plants may be able to distinguish marginally between strontium and calcium. Hence, as Nielsen (2004) indicates, plants usually contain the same strontium to calcium ratio as their corresponding soil extracts. In humans, in tissues and bodily fluids, the strontium to calcium ratio is much lower than that of plants, perhaps due to the preferential uptake of calcium over strontium. This preferential uptake of calcium over strontium has to do with the issue of the calcium binding protein, which binds strontium to a lesser degree than calcium and also due to the smaller size of the calcium atom; hence, GI absorption of strontium may be hindered (Schrooten et al., 1998). Thus, in humans, for strontium to be preferentially absorbed from the GI tract, calcium and strontium must be taken separately due to the competition between strontium and calcium for intestinal absorption.

In humans, the ratio of strontium is 0.032 of the calcium content in the skeleton. Table 1-3 shows the relative amount of strontium compared to other similar divalent cations in the body. 


\begin{tabular}{lllcl}
\hline Flement & $\begin{array}{l}\text { Atomic } \\
\text { number }\end{array}$ & $\begin{array}{l}\text { Afomic } \\
\text { weight }\end{array}$ & $\begin{array}{l}\text { A momt } \\
(\mathrm{g})\end{array}$ & $\begin{array}{l}\text { \% of hody } \\
\text { mass }\end{array}$ \\
\hline $\mathrm{Mg}$ & 12 & 24.32 & 19 & 0.027 \\
$\mathrm{Ca}$ & 20 & 40.08 & 1000 & 1.4 \\
$\mathrm{Sr}$ & 38 & 87.63 & 0.32 & 0.00044 \\
\hline
\end{tabular}

Table 1-3: Distribution of Strontium, Calcium and Magnesium in Reference Man (70Kg) (Nielsen, 2004).

Studies using radioactive labeled strontium and calcium have shown that radiostrontium and radiocalcium both have strong bone seeking properties. Strontium- 85 , for example, passes the walls of the Haversian capillaries to reach bone extracellular fluid through the process of diffusion. Administered strontium is almost exclusively deposited in bone (Neilson, 2004). Furthermore, in long term studies, after incorporation into bone, strontium and calcium behaved identically (Neilson, 2004). This implies that strontium may exert an effect on the calcification process or bone remodeling cycle.

MacDonald et al. (1951), observed a rapid decrease in calcium/strontium ratio in rat and mouse femur during the first day of oral administration of strontium chloride in drinking water, followed by a much slower decrease in the calcium/strontium ratio during 6-8 weeks. Hence, they postulated, that strontium is taken up into bone by two different mechanisms. The first mechanism, a rapid phase, occurs at the bone surface area that is in direct contact with the blood supply, and it involves strontium being taken up by ionic exchange with bone calcium, binding of the strontium to preosteoid proteins or a combination of these. Second, there is a slower mechanism involving incorporation of strontium into the crystal lattice of the bone mineral. This is also known as ionic substitution in which the strontium is slowly migrated into the bone volume through an exchange with the calcium ion. This slower process is also the dominant 
mechanism of trace element uptake in adulthood (Boivin et al., 1996). The idea of bone surface exchange and absorption of strontium was investigated by Boivin et al. (1996). This group looked into the biodistribution of strontium after administration of the agent, strontium ranelate to monkeys, using X-ray diffraction and Raman microspectroscopy. They observed that strontium was not only incorporated into the bone mineral of trabecular and compact bone in a dose dependent manner, but mainly it was incorporated into new bone and trabecular bone. They observed that in old bone, absorption and exchange at the crystal surface was the main route of strontium incorporation whereas in new bone, strontium was incorporated not only with absorption and exchange but through ionic substitution with calcium, as well into the hydroxyapatite matrix. Furthermore, when the strontium ranelate was withdrawn, the strontium concentration in bone decreased rapidly. However, there were no changes in the crystal lattice, crystallinity or crystal structure of the calcium hydroxyapatite matrix. They also observed that less than one calcium ion out of 10 was substituted for by one strontium atom in each crystal. Long term studies, using rats, confirmed the dose dependency, with dose-related increments in trabecular bone volume mineralized, osteoblastic surface and reduction in osteoclasts number, but similarly, the osteoid thickness was not affected (Neilson, 2004). Thus, this may explain how strontium is incorporated into bone and has the ability to affect the crystal lattice.

However, the relative strontium bone concentration varies depending on skeletal site and according the Dahl et al. (2001), there are several factors that influence the incorporation of strontium into bone. These factors include strontium dosage, gender, plasma strontium levels, duration of strontium intake and skeletal site. With respect to determining the amount of strontium in the skeleton, there have been many studies attempting to quantify the bone 
strontium concentration throughout the skeleton. Table 1-4 taken from Zamburlini (2008) gives a summary of these studies.

In contrast to the two different phases of strontium incorporation in bone, the elimination of strontium is a combination of three processes. Dahl et al. (2001) indicated that strontium may be eliminated through: 1) clearance from the exchangeable pools of bone, 2) displacement of strontium (presumably by calcium) from sites within the apatite crystal by long term exchange processes and 3) by volume removal from the mineral phase and the matrix by osteoclastic resorption. Furthermore, unlike calcium, (Neilson, 2004), strontium is not under homeostatic control. However, it is possible that strontium levels are influenced by calcium and hormones.

\begin{tabular}{|c|c|c|c|c|}
\hline Source & $\mathrm{Y}$ & Bone site & $\begin{array}{c}\text { Age of } \\
\text { Individual }\end{array}$ & Concentration \\
\hline ICRP $23(1975)$ & 150 & Rib & $\mathrm{N} / \mathrm{A}$ & 32 " g Sr g bone \\
\hline \multirow[t]{4}{*}{ Hodges et al. (1950) } & 20 & Parietal & $(8$ nos -75 yts.) & $230 \mu \mathrm{g} \mathrm{Sr} \mathrm{g}$ bone ash \\
\hline & & Rib & & $220 \mu \mathrm{g} \mathrm{Sr} g$ bone ash \\
\hline & & Vertebrae & & $220 \mu \mathrm{g} \mathrm{Sr} g$ bone ash \\
\hline & & Fenur & & $220 \mu \mathrm{g} \mathrm{Sr} g$ bone ash \\
\hline Thuber er al. (1958) & & Various & & $450 \mu \mathrm{g} \mathrm{Srg} \mathrm{Ca}$ \\
\hline \multirow[t]{4}{*}{ Zaichick (2006) } & 81 & Thas crest & $(15-55 \mathrm{yss})$ & $308=18 \mu \mathrm{g}$ Sr $g$ dry bone(C) \\
\hline & & & & $235=18 \mu \mathrm{g}$ Srg dry bone $(\mathrm{T})$ \\
\hline & & Femoral neck & $(15-55 \mathrm{yrs})$ & $260=18 \mu \mathrm{g} \mathrm{Sr} g \mathrm{dry}$ bone $(\mathrm{C})$ \\
\hline & & & & $212 \pm 20 \mu \mathrm{g} S \mathrm{gr} \mathrm{dry}$ bone( ( ) \\
\hline Carvalho et al (1998) & 60 & Shall & $\mathrm{N} / \mathrm{A}$ & $147=55 \mu g \mathrm{Sr} g \mathrm{dry}$ bone \\
\hline Rosenthal et al. (1972) & $3-5$ & $\begin{array}{l}\text { Clavicle, tibia, } \\
\text { ulna }\end{array}$ & $(40-60$ yss $)$ & $460=50 \mu \mathrm{g} \mathrm{Sr} g$ boue ash \\
\hline \multirow{2}{*}{$\begin{array}{l}\text { Saunudralwar and } \\
\text { Robertson (1993) }\end{array}$} & 12 & $\mathrm{Rib}$ & $(60-82$ yrs. $)$ & $62 \pm 18 \mu \mathrm{g}$ Sr $g$ dry bone $(\mathrm{C})$ \\
\hline & & & & $58 \pm 17 \mu g$ Srig dry boue $(\mathrm{T})$ \\
\hline Turekian and Kulp (1956) & 277 & $\mathrm{~N} / \mathrm{A}$ & $\mathrm{NA}$ & $600 \mu \mathrm{g} \mathrm{Sr} g$ bone ash \\
\hline Aras et al. $(2000)$ & $\begin{array}{c}12(\mathrm{C}) \\
9(\mathrm{~T})\end{array}$ & Iliac Crest & $(15-50)$ & $110 \pm 22 \mu \mathrm{g} \mathrm{Sr} g \mathrm{dry}$ bone \\
\hline
\end{tabular}

Table 1-4: Summary of Bone Strontium Concentrations Depending on Skeletal Site (C): Cortical bone; (T): Trabecular Bone. (Zamburlini, 2008). 
In order to further understand the biological role and importance of strontium in the human body, there have been various animal and human studies in recent years. Strontium has never been shown to be an essential element, in other words, a deficiency or absenteeism of strontium will not cause death. On a molar basis, strontium seems less biologically active than calcium and toxicity of strontium is not pronounced (Neilson, 2004). However, although strontium is known to be less toxic than calcium in animals, at high doses, it has been shown to have adverse effects. In rats, high dietary strontium levels were shown to have rachitic lesions, especially when calcium intake was low. Neilson (2004) explains that the cause for this may be due to a combination of impaired intestinal absorption of calcium and reduced renal production of $1,25-$ dihydroxycholecalciferol. Other studies, have reported similar toxic effects of high strontium levels. In pregnant mice, given high levels of strontium and calcium, the amount of calcium binding protein was reduced in both the maternal intestine and placenta, leading to hypomineralization of the fetal skeleton. In human studies, similar adverse effects have been observed. Ozgur et al. (1996) reported a correlation between the incidence of rickets and high levels of strontium in soil, in Turkey. As cited by Neilson (2004), a direct effect of high strontium levels, in vitro, in bone was reported by Verberkmoes et al. (2004), who found evidence of deficient hydroxyapatite formation at high levels of strontium. Furthermore, in patients undergoing dialysis for kidney failure, there is also an increase in prevalence of osteomalacia, perhaps due to the high concentration of strontium in dialysis fluid (Nielsen, 2004). The adverse effects of strontium on bone structure have been theorized to be caused from a distortion of strontium on the crystal lattice. Cristofferson et al.(1997) suggested that the ionic substitution of strontium for calcium in the hydroxyapatite (HAp) matrix would cause 
subsequent lattice expansion, due to the larger strontium radius, and hence instability of the HAp structure. This in turn weakens the overall crystal structure. However, at low levels of strontium, the opposite holds true. Verberkmoes et al. (2004) also noted that at low levels of strontium, there was little to no expansion of the crystal lattice and thus this may subsequently improve bone strength, due to the greater surface area and hence overall bone rigidity. Thus, at low levels, strontium may exert beneficial effects in bone. In studies, using strontium ranelate, improvements in bone mineral density, bone fracture risk and osteoporotic symptoms were reported.

However, despite these positive results obtained from the strontium ranelate trials, there still remain questions to be answered on strontium kinetics, such as how strontium is incorporated and retained in human bone and how fast does it clear from the skeleton and body once strontium supplementation stops. The development and use of an x-ray fluorescence system developed by Pejović-Milić and colleagues (2004), may help to provide these answers as this diagnostic tool is non-invasive and has been demonstrated to be sensitive and capable of measuring strontium, invivo, in human bone.

\subsection{In-Vivo X-Ray Fluorescence (IVXRF) System to Measure Bone Strontium \\ Level: Technique Development and Previous Work}

The in-vivo $\mathrm{x}$-ray fluorescence (IVXRF) system has been developed to measure strontium in bone, in-vivo in human subjects. The IVXRF system compromises of a EG \& G Ametek -AMT $\mathrm{Si}(\mathrm{Li})(\mathrm{Ortec} \otimes, \mathrm{USA})$ detector with a $16 \mathrm{~mm}$ active area window with $5.65 \mathrm{~mm}$ of sensitive 
crystal thickness. X-ray fluorescence is based on the exposure of an organ to an external source of photons adapt to undergo photoelectric absorption with the element under investigation. The excitation source are I-125 Prostaseed $®$ brachytherapy seeds (Core Oncology, USA) having an approximate activity of $30 \mathrm{MBq}$. The data were analyzed using ORTEC DSPEC Plus ${ }^{\mathrm{TM}}$ and the Maestro ${ }^{\mathrm{TM}}$ software. The subsequent spectra obtained with the system, were then analysed using a modified in-house nonlinear least squares, Marquardt based, fitting routine. Of importance in measuring the strontium levels are the strontium $\mathrm{x}$-ray peaks observed at $14.16 \mathrm{keV}$ and 15.16 $\mathrm{keV}$ as these peaks correspond to the strontium $\mathrm{k}$-alpha and strontium $\mathrm{k}$-beta peaks, respectively.

\subsubsection{Strontium Signal Attenuation by the Overlying Soft Tissue}

To measure human bone strontium measurements, the measurement of the dorsal side of the middle phalanx of the index finger and the measurement of the middle of the medial malleolus of the ankle are taken to determine bone strontium levels in an individual. However, since the IVXRF system is used for these measurements, consideration of soft tissue photon attenuation overlying measured bone sites must be taken into account. Soft tissue photon attenuation is especially a concern when dealing with low energy photons in the order of $20 \mathrm{keV}$ or less. Furthermore, strontium $\mathrm{x}$-rays are more likely to be absorbed in soft tissue compared to coherently scattered photons at $35.49 \mathrm{keV}$, and also considering that the average adult finger total thickness (soft tissue and cortical bone) is between 2.0 and $4.8 \mathrm{~mm}$, the attenuation of the strontium x-rays is expected to be substantial (Zamburlini, 2008). Berger et al., (2005) estimated values for linear attenuation coefficients and mean free path (the distance at which $63 \%$ of the original signal is attenuated) for strontium $x$-rays as follows: in skin $\left(\rho=1.09 \mathrm{~g} / \mathrm{cm}^{3}\right)$, the linear 
attenuation coefficient $(u)$ of the strontium $k$-alpha and strontium k-beta rays are $0.215 \mathrm{~mm}^{-1}$ and $0.158 \mathrm{~mm}^{-1}$ and the corresponding mean free paths $(\lambda)$ are 4.6 and $6.3 \mathrm{~mm}$, respectively. In cortical bone $\left(\rho=1.82 \mathrm{~g} / \mathrm{cm}^{3}\right)$, the linear attenuation coefficient $(u)$ of the strontium $\mathrm{k}$-alpha and strontium k-beta rays are $1.98 \mathrm{~mm}^{-1}$ and $1.48 \mathrm{~mm}^{-1}$ and the corresponding mean free paths $(\lambda)$ are 0.51 and $0.70 \mathrm{~mm}$, respectively. Thus, it is expected that larger skin thicknesses will produce an increase in the fraction of coherently scattered photons, originating from the skin. In order to obtain the strontium signal, soft tissue thickness must be taken into account and used to correct for the attenuation of outgoing strontium signals in soft tissue. The correction method proposed by Zamburlini (2008) was used throughout the strontium measurements performed in this work, to determine strontium levels in bone. Equations 1-1 and 1-2, represent the soft-tissue attenuation correction equations for the $\mathrm{k}$-alpha and $\mathrm{k}$-beta photon attenuation in soft tissue:

$$
\begin{aligned}
& K_{\alpha}: \ln \left(\frac{I}{I_{0}}\right)=(-3.58 \pm 0.04) T+(0.156 \pm 0.006) \\
& K_{\beta}: \ln \left(\frac{I}{I_{0}}\right)=(-2.86 \pm 0.04) T+(0.162 \pm 0.006)
\end{aligned}
$$

where $\mathrm{I}_{0}$ is the intensity of the strontium $\mathrm{x}$-rays emitted from the bone surface, $\mathrm{I}$ is the initial intensity of strontium $\mathrm{x}$-rays after passage through the soft tissue and $\mathrm{T}$ is the soft tissue thickness in (cm). The negative values of 3.58 and 2.86 for the strontium $\mathrm{k}$-alpha and $\mathrm{k}$-beta peaks respectively represent the total linear attenuation coefficient values (in $\mathrm{cm}^{-1}$ ) and take into account primary beam attenuation as well as emerging strontium $\mathrm{x}$-rays. The uncertainties reported in equations 1-1 and 1-2 are derived from a model Zamburlini used to determine softtissue thickness. 
More information about modeling of bone strontium measurement using the Electron Gamma Shower 5 (EGS5) Monte Carlo simulation is available in the literature (Zamburlini et al., 2006 and Zamburlini et al., 2008). The soft tissue thickness could be measured using different imaging modalities such as US, CT or MRI. However, apart from the soft tissue correction relationship used to correct for strontium k-alpha and strontium k-beta attenuation, another correction is required which relates to the number of detected $\mathrm{x}$-rays.

The second correction step, which is discussed further in the second chapter, relates to the normalization of the strontium peak observed to the coherent ${ }^{125}$ I peak at $35.49 \mathrm{keV}$. As the number of detected strontium $\mathrm{x}$-rays is proportional to the strontium level in bone, it will be affected by experimental conditions such as source to detector distance and source positioning.

The coherent normalization of the strontium peaks, best source selection, geometry, ideal anatomical bone sites for measurement and tissue correction factors have been previously reported by Pejović-Milić (2004), Zamburlini(2008) and Heirwegh (2008).

\subsubsection{Coherent Normalization of Bone Strontium Signal}

In IVXRF, the number of counts or number of detected strontium $\mathrm{x}$-rays is proportional to the strontium level in bone; however, there are several factors that affect the number of $\mathrm{x}$-rays detected outside a human body. One such factor is the bone to excitation source distance. Other factors that affect the IVXRF measurement, as reported by Zamburlini (2008) include:

(i) The amount of bone volume that is measured, which in turn is determined by bone size and shape, as well as the source collimation and detector positioning; 
(ii) Overlying tissue thickness between the radiation source and the bone surface, and the tissue thickness between the detector and bone surface;

(iii) Experimental factors such as source strength, duration of measurement and detector size.

Thus, to correct for these factors, coherent normalization to the ${ }^{125} \mathrm{I}$ peak at $35.49 \mathrm{KeV}$ is suggested. The coherent peak as a mean of normalization, as indicated by Zamburlini et al. (2008) must rely on four conditions:

(a) The coherent and $\mathrm{x}$-ray photons exhibit similar absorption through soft tissue

(b) They are produced by the same incident fluence

(c) The coherent signal arises from the same region where the $\mathrm{x}$-ray signal originates

(d) The coherent cross section is uniform about the scattering angle

However, since the $35.49 \mathrm{KeV}$ peak is not able to accurately correct for soft tissue thickness (condition (i) does not hold) in human measurements, a soft tissue correction is made before the coherent normalization (Zamburlini et al., 2008). Thus, a two step correction method is used to determine the strontium levels in human bone, (1) correction for signal attenuation by soft tissue and (2) the coherent normalization. The coherent normalization can correct well for factors (i) and (iii) mentioned above. The effect of coherent normalization on the strontium signal and the effect of subject positioning is discussed in chapter two. 


\subsubsection{IVXRF Pilot Study of Human Bone Strontium Measurements}

Using the set-up as shown in Figures 1-2 and 1-3, an initial pilot study of 22 healthy volunteers was conducted in spring of 2006, by Zamburlini and colleagues (2007a).

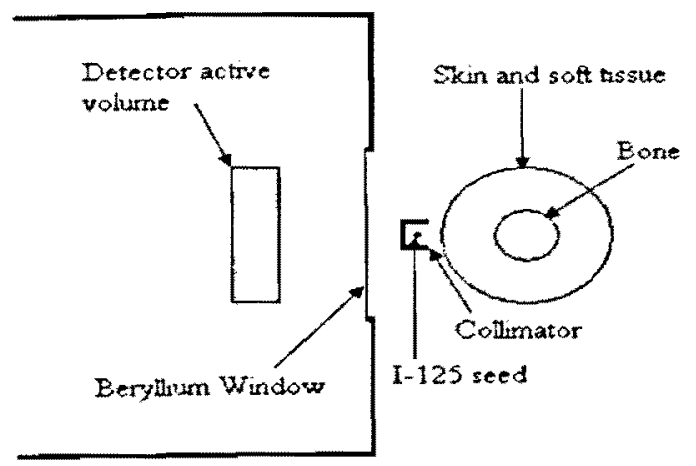

Figure 1-2: Side view of human finger phantom positioning

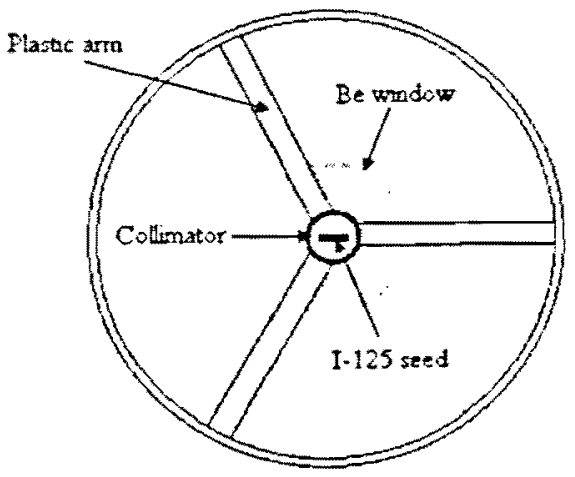

Figure 1-3: Detector and measurement setup using $180^{\circ}$ interaction geometry (head-on view)

Two interesting observations were made: 1) Asian people tended to have a higher bone strontium level compared to Caucasian people and 2) the strontium signal observed was higher in ankle 
(trabecular bone) than in finger (cortical bone). A preliminary measurement of two osteoporotic subjects who were self- supplementing with strontium citrate was also done by Zamburlini (2008) and it was observed that their bone strontium levels were much higher than the 22 healthy non-supplementing volunteers. This observation was confirmed in another case study that both Zamburlini and Heirwegh followed until 2008 (Heirwegh, 2008). Four individual measurements over a six month period on an osteoporotic subject was performed and the higher strontium trabecular concentration was confirmed, but he also noted that at the last measurement, the subject's finger and ankle measurement decreased. This was consistent with the fact the subject had stopped strontium supplementation for two months at the time of visit. This outcome of the sensitivity of the IVXRF system to measure bone strontium levels. While these initial findings confirm the observations from previous animal studies that human trabecular bone has a higher bone strontium concentration than cortical bone, it does not explain how strontium may be incorporated and retained in human bone over time. There is no published literature on bone strontium incorporation and retention to date. This information could be used to develop a kinetic model of strontium in bone and help answer the question of whether an individual must continue to take strontium for the rest of his/her life, as well as the optimum dosage.

Therefore, in this work the IVXRF system was used to investigate strontium uptake and retention in-vivo, in the human bone. By measuring osteoporotic and/or osteopenic individuals who have never taken strontium supplements and following them as they self-administered strontium supplements on a regular basis, more information was obtained in an attempt to better understand the uptake and/or retention of strontium in human bone. In addition, other individuals with either high or low strontium doses were included, although, pre-treatment bone strontium 
levels were not available at the time of this study.

In chapter two, the use of a new portable ultrasound system to determine soft tissue thickness is discussed which is followed by positioning analysis and the effect of coherent normalization on the strontium signal Both forward mentioned topics represent further development of the IVXRF system. In chapter three, incorporation of strontium in the bone of individuals with no prior history of strontium intake (baseline study) are presented. In the same chapter, two case studies of of an individual taking strontium for more than 15 months and natural bone strontium levels in an African black male subject are also included. Study of individuals with prior history of strontium intake, either via medications or supplements is included in the bone retention study, in chapter four. Chapter five concludes results of this work and opens up new questions and directions for future work. 


\section{Chapter 2 Further Development of the IVXRF System}

An initial set of experiments, prior to launching a human study to investigate incorporation and retention of strontium in bone, focused on further development and optimization of the IVXRF system. These experiments could be divided into two subsets: 1) testing of a new mobile $10 \mathrm{MHz}$ US imaging modality to measure overlying soft tissue thickness at the bone sites where the bone strontium concentration was measured, and 2) assessment of the excitation source positioning with respect to the bone site, which was investigated using a bone mimicking phantom. They are discussed in this chapter.

\subsection{Overlying Soft-Tissue Measurement}

The strontium in-vivo $\mathrm{x}$-ray fluorescence system involves the measurement of $\mathrm{K}$-shell $\mathrm{x}$ rays that travel through soft-tissue overlying bone; therefore one of the issues to take into consideration is the soft tissue attenuation and the effect it has on travelling photons. In section 1.4 , values for the linear attenuation coefficient and mean free paths for skin and cortical bone were discussed. Since, the strontium signal arises from the interaction of strontium x-rays within the bone, the mean free path values indicate that the IVXRF system is more likely to detect the photons emitted from the strontium atoms nearer the bone surface than those emitted from deeper within the bone matrix. Furthermore, the mean free paths for strontium $\mathrm{k}$-alpha and $\mathrm{k}$-beta photons are 4.6 and $6.3 \mathrm{~mm}$ in skin, respectively (Berger, 2005). Thus, $35 \%$ of the strontium kalpha $\mathrm{x}$-rays are attenuated by only $2 \mathrm{~mm}$ of skin and $64 \%$ are attenuated by $4.8 \mathrm{~mm}$ of skin 
(Heirwegh, 2008). This statistically significant signal attenuation illustrates the need in obtaining soft-tissue thickness to correct for the bone strontium signal tissue attenuation. Several imaging modalities can be used to determine soft-tissue thicknesses. Such modalities include CT, MR, and Ultrasound. Calipers may also be used to determine soft tissue thickness. Heirwegh (2008) imaged seven cadaver index fingers using MRI, CT and 55, 25 and $8 \mathrm{MHz}$ ultrasound. All modalities were able to distinguish bone surface from tendon and the bone surface was clearly visible in all images. Table 2-1 summarizes accuracy range and present relative error obtained using these imaging modalities.

\begin{tabular}{ccc}
\hline Modality & $\begin{array}{c}\text { Accuracy Range } \\
(\mathrm{mm})\end{array}$ & $\begin{array}{c}\text { \% Accuracy Range } \\
\text { (\% Relative Error) }\end{array}$ \\
\hline Caliper & 0.261 & 6.9 \\
US-55 MHz & 0.121 & 3.2 \\
US-25 MHz & 0.205 & 5.4 \\
US-8 MHz & 0.251 & 6.6 \\
MR & 0.164 & 4.3 \\
CT & 0.269 & 7.1 \\
\hline
\end{tabular}

Table 2-1: Image Modality Accuracy Results. Note: \% Accuracy $=100$ *(Accuracy, $\mathbf{m m}) /$ $(3.79 \mathrm{~mm})$. Tissue thickness estimates from seven cadaver fingers suggests an average population index finger soft tissue thickness of $3.79 \mathrm{~mm}$ (Heirwegh, 2008).

The Ultrasound System at the $55 \mathrm{MHz}$ frequency had the least relative error compared to the 
other modalities. However, the $8 \mathrm{MHz}$ ultrasound had a reasonable \% relative error. Though, Zamburlini (2008) reported the need for more in vivo studies to determine to which extent the use of different ultrasound machines affect the estimation of soft tissue thickness, Heirwegh (2008) concluded that among the three tested frequencies: $8 \mathrm{MHz}, 25 \mathrm{MHz}$ and $55 \mathrm{MHz}$, the highest frequency of $55 \mathrm{MHz}$ with three dimensional data reconstruction provided a twofold better accuracy in determining finger soft tissue thickness compared to the $8 \mathrm{MHz}$ ultrasound (Table 2-1). The estimated uncertainty for the $55 \mathrm{MHz}$ ultrasound was determined to be $3.2 \%$. Taking this into account, and the unavailability of other imaging modalities (CT and MR), and the limited resources for higher frequency ultrasound, in this work, a mobile $10 \mathrm{MHz}$ ultrasound system was used to determine soft-tissue thickness to correct for the bone strontium signal.

\subsubsection{Mobile Ultrasound System}

A portable, mobile ultrasound system, made available by the Department of Physics at Ryerson University, was used to determine the soft tissue thickness. Previously, prior to the Fall of 2008, individuals were taken to the Mohawk-McMaster Institute of Applied Health Sciences on the McMaster Campus for ultrasound measurements. The portable ultrasound system allows for the measurement of individuals on site without depending on external resources. The portable system consists of a Telemed EchoBlaster 128 EXT-1Z kit with a linear HL 9.0/40/1Z8Z probe of $10 \mathrm{MHz}$ frequency (Telemed, Lithuania). The corresponding software included the EchoWave 2.94 software from which images were recorded (standard $800 \times 600$ software window). The ultrasound parameters used throughout this work to image overlying soft tissue are provided in Table 2-2. 


\begin{tabular}{|l|l|}
\hline Probe & HL 9.0/40/128 \\
\hline Probe Frequency & $10.0 \mathrm{MHz}$ \\
\hline Frame Rate & $15 \mathrm{fps}$ \\
\hline Depth & $50 \mathrm{~mm}$ \\
\hline Frame Averaging & 5 frames \\
\hline Dynamic Range & $56 \mathrm{~dB}$ \\
\hline Power & $39 \%$ \\
\hline Gain & $40 \%$ \\
\hline Zoom & $100 \%$ \\
\hline
\end{tabular}

Table 2-2: Ultrasound Parameters Used in Imaging of Bone Sites for the Determination of Overlying Soft -Tissue Thickness.

Ultrasound measurements were performed prior to the XRF measurements and soft-tissue thickness measurements were taken at two sites:

(1) Finger: on the dorsal surface of the index finger (left hand) in the centre of the middle phalanx and

(2) Ankle: at the ankle joint at the most prominent part of the medial malleolus of the tibia (left foot)

For each site, four measurements were taken in two transducer planes; sagittal and transverse.

Two measurements in each plane using a gel pad and two measurements without the use of a gel pad were taken per site. The averages of the four readings were used to estimate the soft tissue thickness at the measurement site. The gel pad was placed between the measuring site and the 
transducer. The purpose of the gel pad is to reduce reverberation artifacts and help minimize the pressure exerted by the transducer on the skin, which may otherwise result in an underestimation of the measured skin thickness (Zamburlini 2008). Figure 2-1 illustrates anatomical points of interest for determining soft tissue thickness in the human bone. In figure 2-1, the top arrow points to the skin surface overlying bone, the middle arrow refers to tendon and the third bottom arrow refers to the bone surface. The soft tissue thickness is taken as the distance between the skin surface and the bone surface, which is shown through the vertical white arrows in figures 2 2 and 2-3. Figure 2-2 show sample ultrasound images of the same individual with the gel pad and without the gel pad, respectively, for the finger. For the ankle, this is shown in figure 2-3.

Nevertheless, as seen in figures 2-2 and 2-3, the gel pad images produced a clearer image and that enabled distinguishing the bone surface from tendon.

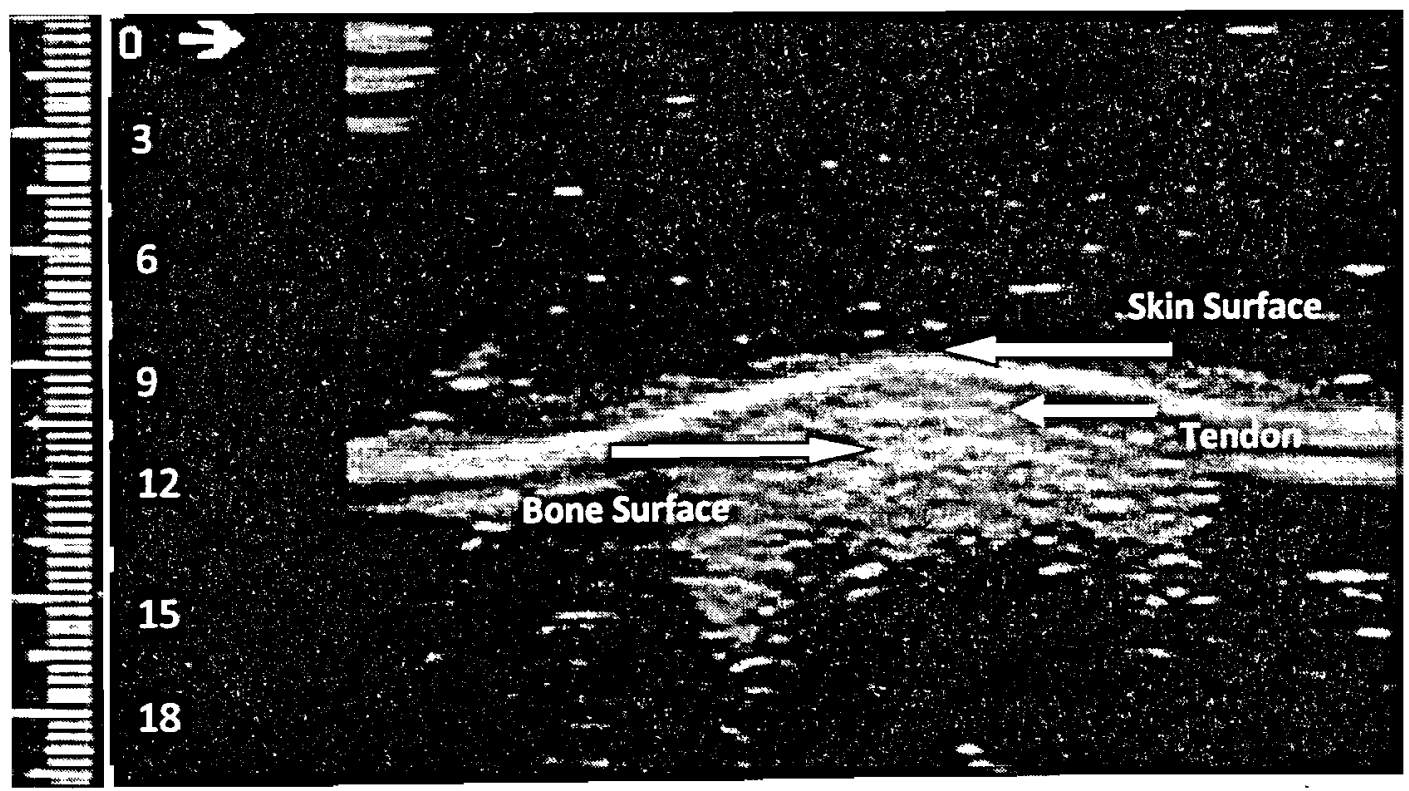

Figure 2-1: Ultrasound Image of Finger: Transverse View (with gel pad). The soft tissue thickness is determined as the distance from the bone surface to the skin surface. Scale is to mm. 
transducer. The purpose of the gul pad is to reduce reverberation artifacis and help mininize the pressure exerted by the transducer on the skin. which may otherwise result in an underestimation of the measured skin thickness (Zamburlini 2008). Figure 2-1 illustrates anatomical points of interest for determining soft tissue thickness in the human bone In figure 2-1, the top arrow' points to the skin surface overlying bone, the middle arrow refers to tendon and the third buttom arrow refers to the bone surface. The soft tissue thickness is taken as the distance between the skin surface and the bone surface, which is shown through the vertical white arrows in figures 22 and 2-3. Figure 2-2 show sample ultrasound images of the same individual with the gel pad and without the gel pad, respectively, for the finger. For the ankie, this is shown in figure 2-3.

Nevertheless, as secn in figures 2-2 and 2-3. the gel pad images produced a clearer image and that enabled distinguishing the bone surface from tendon.

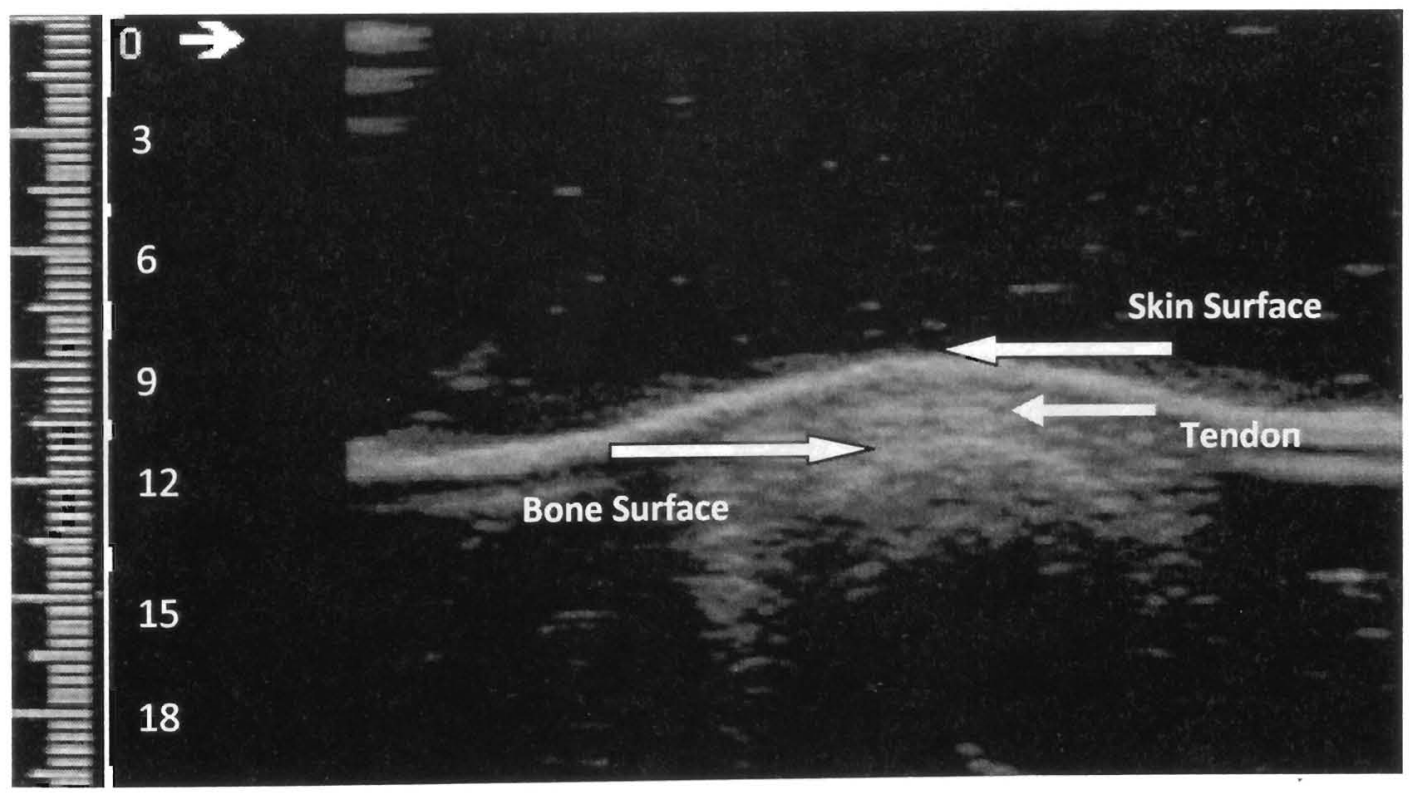

Figure 2-1: Cltrasound Image of Finger: Transverse View (with gel pad). The soft tissue thickness is determined as the distance from the bone surface to the skin surface. Scale is to mm. 

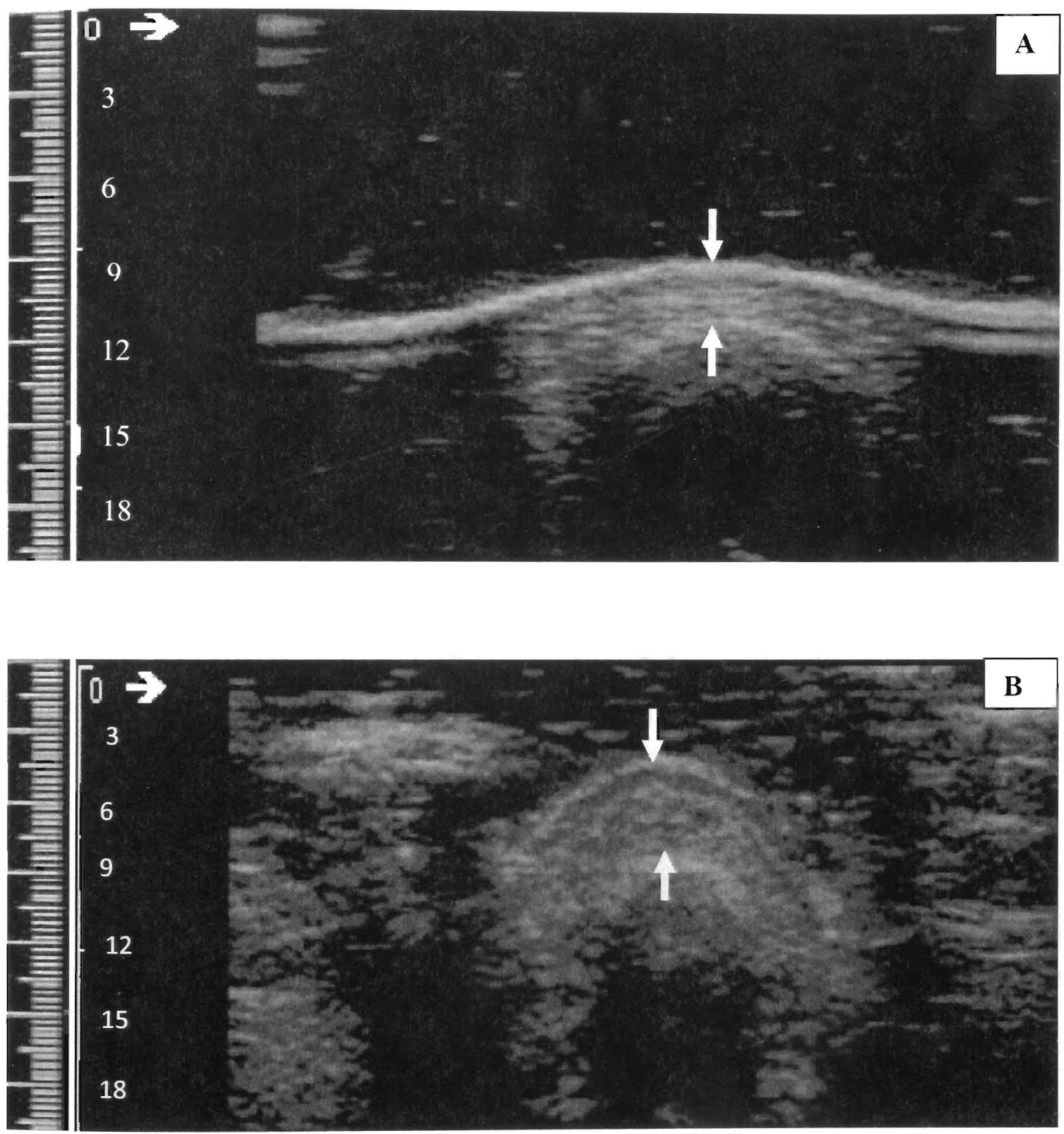

Figure 2-2: Cltrasound Image of Finger: Transverse View with A) Gel pad and B) Without the Gel Pad. Scale is to $\mathrm{mm}$. 

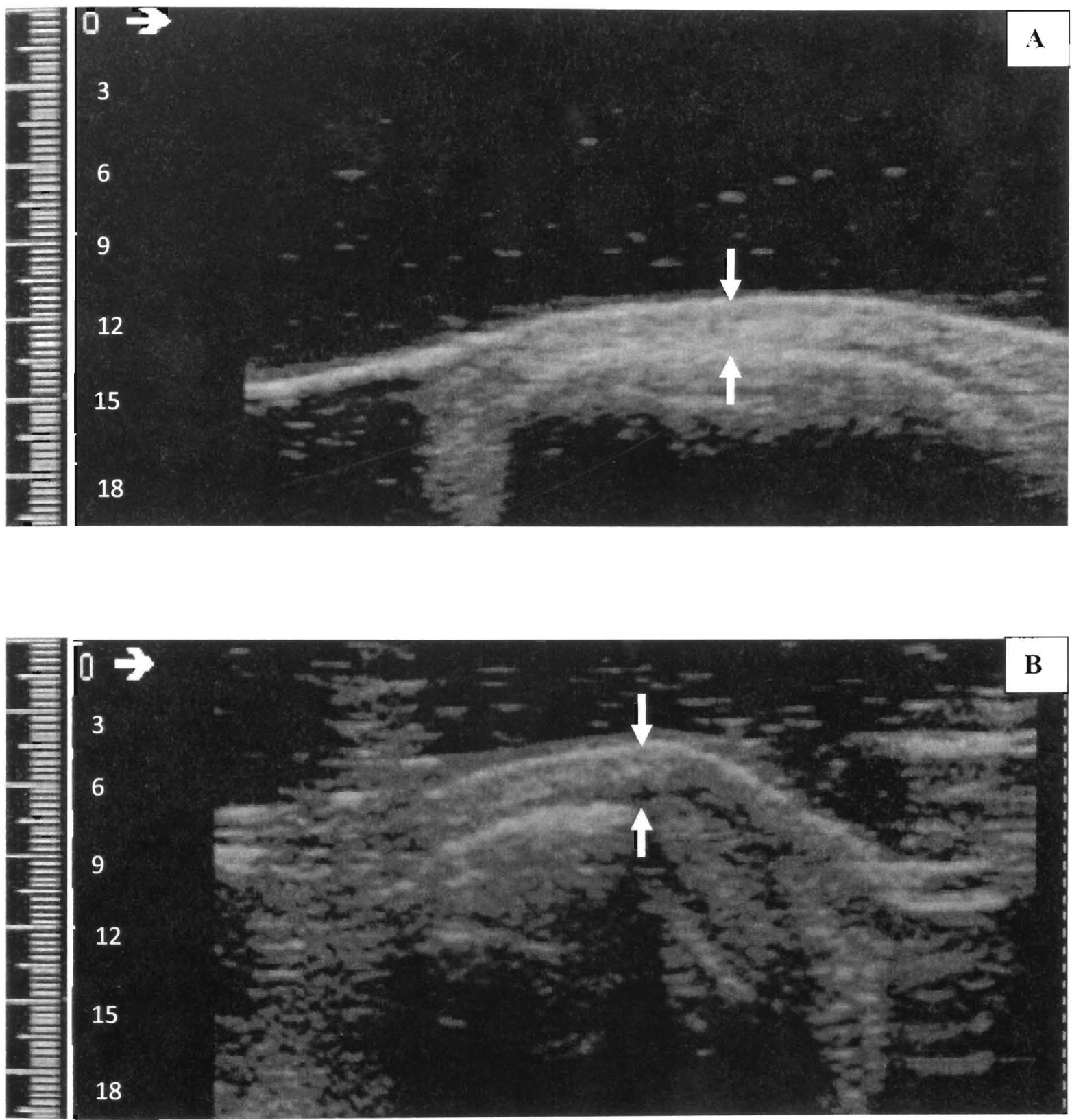

Figure 2-3: Litrasound Image of Ankle: Transverse View with A) Gel pad and B) Without the Gel Pad. Scale is to $\mathrm{mm}$. 


\subsubsection{Reproducibility of the Mobile Ultrasound}

To determine the reproducibility of the mobile ultrasound, soft tissue thicknesses at both bone sites, the finger and ankle, were measured 12 times in an individual, on different days, repositioning between each measurement, with the gel pad and without the gel pad. Table 2-3 summarizes the results of the measurements.

\section{GEL PAD}

\section{WITHOUT GEL PAD}

\begin{tabular}{llll}
$\begin{array}{c}\text { Finger } \\
(\text { Mean } \pm \text { SD })\end{array}$ & $\begin{array}{c}\text { Ankle } \\
(\text { Mean } \pm \text { SD })\end{array}$ & $\begin{array}{c}\text { Finger } \\
(\text { Mean } \pm \text { SD })\end{array}$ & $\begin{array}{c}\text { Ankle } \\
(\text { Mean } \pm \text { SD })\end{array}$ \\
\hline$(3.12 \pm 0.39) \mathrm{mm}$ & $(1.89 \pm 0.068) \mathrm{mm}$ & $(3.01 \pm 0.44) \mathrm{mm}$ & $(1.82 \pm 0.084) \mathrm{mm}$
\end{tabular}

Table 2-3: Summary of Reproducibility Measurements of One Individual obtained with the Mobile Ultrasound.

The coefficient of variance (CV) obtained with the finger reading is: $12.6 \%$ (gel pad) compared to a $\mathrm{CV}$ of $14.6 \%$ (without the gel pad) and for the ankle, the CV are: $3.6 \%$ (gel pad) and $4.6 \%$ (without gel pad). Thus, the lower $\mathrm{CV}$ obtained for the gel pad readings and the ankle indicate that the gel pad readings are easier to measure and give more reliable results. The lower $\mathrm{CV}$ of the ankle may be attributed to the flatter bone surface at this bone site, which makes it easier to measure the overlying soft tissue thickness. However, the overlying thicknesses with and without the gel pad agree within the uncertainty and are not expected to change in an individual, unless there has been some weight loss or weight gain. 


\subsubsection{Average Overlying Soft Tissue Measurement at Two Anatomical Sites}

Table 2-4 summarizes the results of tissue thicknesses at two bone sites, finger and ankle, for additional individuals who were recruited to participate in bone strontium measurements. A total of 19 individuals were measured on bone strontium levels in this work. Of the 19 individuals, 16 were female participants and 3 were male participants. All participants were measured with the $10 \mathrm{MHz}$ mobile ultrasound system.

\begin{tabular}{|c|c|c|c|c|c|}
\hline \multicolumn{2}{|c|}{$\begin{array}{c}\begin{array}{c}\text { Overall Average } \\
N=19\end{array} \\
\text { c }\end{array}$} & \multicolumn{2}{|c|}{$\begin{array}{l}\text { Female } \\
N=16\end{array}$} & \multicolumn{2}{|c|}{$\begin{array}{l}\text { Male } \\
\mathbf{N}=\mathbf{3}\end{array}$} \\
\hline $\begin{array}{l}\text { Finger } \\
(\text { Mean } \pm \text { SD })\end{array}$ & $\begin{array}{c}\text { Ankle } \\
(\text { Mean } \pm \text { SD) }\end{array}$ & $\begin{array}{l}\text { Finger } \\
(\text { Mean } \pm \text { SD) }\end{array}$ & $\begin{array}{l}\text { Ankle } \\
(\text { Mean } \pm \text { SD })\end{array}$ & $\begin{array}{l}\text { Finger } \\
\text { (Mean } \pm \text { SD) }\end{array}$ & $\begin{array}{l}\text { Ankle } \\
(\text { Mean } \pm \text { SD) }\end{array}$ \\
\hline $0.28 \pm 0.04$ & $0.26 \pm 0.05$ & $0.26 \pm 0.04$ & $0.21 \pm 0.06$ & $0.29 \pm 0.04$ & $0.31 \pm 0.04$ \\
\hline
\end{tabular}

Table 2-4: Summary of Overall Soft-Tissue Thickness (in $\mathrm{mm}$ ) of All Individuals. $\mathrm{N}=19$ represents the combined total number of individuals (male and female) measured with the $10 \mathrm{MHz}$ mobile ultrasound. $\mathrm{N}=16$ represents the number of female participants and $\mathrm{N}=3$ represents the number of male participants.

The ankle soft-tissue thickness is thinner than on the finger. The mobile ultrasound system based on the presented results, and taking into account the work done by Heirwegh (2008) and Zamburlini (2008) have been shown to be a reliable system to determine soft tissue thickness. The estimated level of accuracy for the $10 \mathrm{MHz}$ mobile ultrasound is $6.6 \%$ (Heirwegh, 2008). The accuracy calculation for ultrasound imaging modalities is well documented by Heirwegh (2008). The use of a higher frequency ultrasound in conjunction with a water bath sound propagation medium was suggested as a means to improve the accuracy of soft tissue thickness measurement. However, the images and reproducibility of the data obtained with the $10 \mathrm{MHz}$ 
ultrasound system are very good. Considering its low cost and portability should continue to be used in determining the soft tissue thicknesses, after taking into account possible sources of error and uncertainty associated with these measurements.

\subsubsection{Sources of Error Associated with the Ultrasound Imaging}

The main source of error introduced in the ultrasound images relate to anatomical points of reference. As shown in figure 2-1, being able to clearly distinguish between the bone surface and tendon may be a source of error, such that mistaking tendon for the bone surface would result in an underestimation of soft-tissue thickness. Another possible source of error is the erroneous determination of skin thickness. The skin thickness may be altered depending on the pressure exerted by the transducer. Hence, to correct for these two main sources of error, a gel pad should be used with minimal transducer pressure in conjunction with transducer gel, followed by careful subsequent analysis of the bone surface image. In this way, a more accurate reading of the overlying soft tissue thickness could be achieved. Once the soft tissue thickness is determined by the ultrasound measurement, the Zamburlini soft tissue correction method (Zamburlini,2008) is applied to the strontium signal to correct for soft tissue attenuation, as discussed in chapter one.

\subsection{Excitation Source Positioning During Bone Strontium Measurements}

The next step of IVXRF system optimization was to investigate the effects of source positioning and the use of coherent normalization on the strontium signal. Therefore, the bone mimicking phantom was made of a plaster of Paris (poP) material: $\mathrm{Ca} \mathrm{SO}_{4} \cdot 1 / 2 \mathrm{H}_{2} \mathrm{O}$, with a concentration of $119.84 \mathrm{ppm}$ strontium to calcium ratio. Figure 2-4 depicts the experimental 
set-up of the ${ }^{125} I$ excitation source and the bone phantom during these experiments.

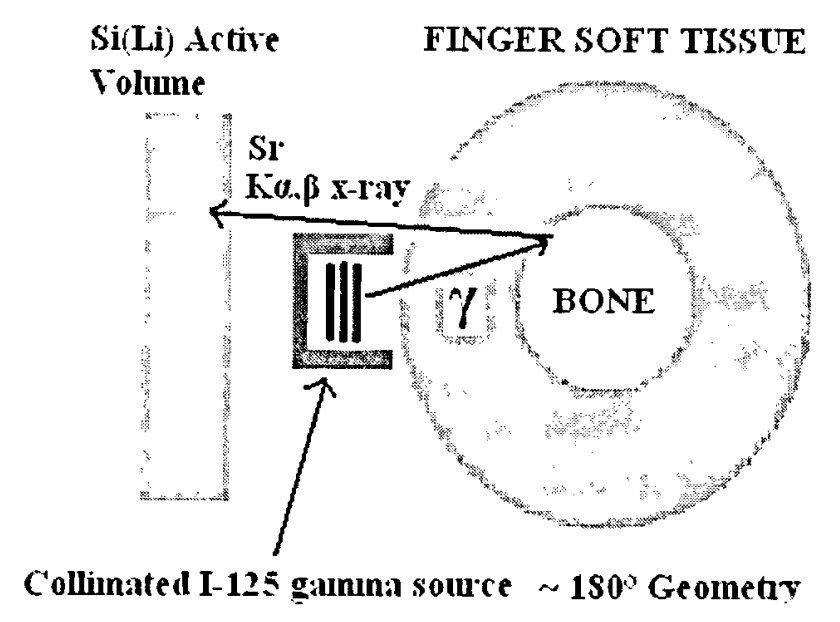

Figure 2-4: Experimental Set-Up of Source and Phantom Positioning. Note that the set-up is the same as during a human finger measurement; the phantom is positioned to simulate a human finger measurement.

As mentioned before, Prostaseed $\otimes{ }^{125}$ I brachytherapy seeds (Core Oncology, USA) were used as the excitation source, having an approximate activity of $30 \mathrm{MBq}$. An Ortec $®$ Ametek-AMT $\mathrm{Si}(\mathrm{Li})$ detector with a $16 \mathrm{~mm}$ diameter crystal and energy resolution of $230 \mathrm{eV}$ (Ortec, 2010) was used as in all measurements. Table 2-5 summarizes the peak parameters used to run all experiments discussed in this work. 
set-up of the ${ }^{125}$ I excitation source and the bone phantom during these experiments.

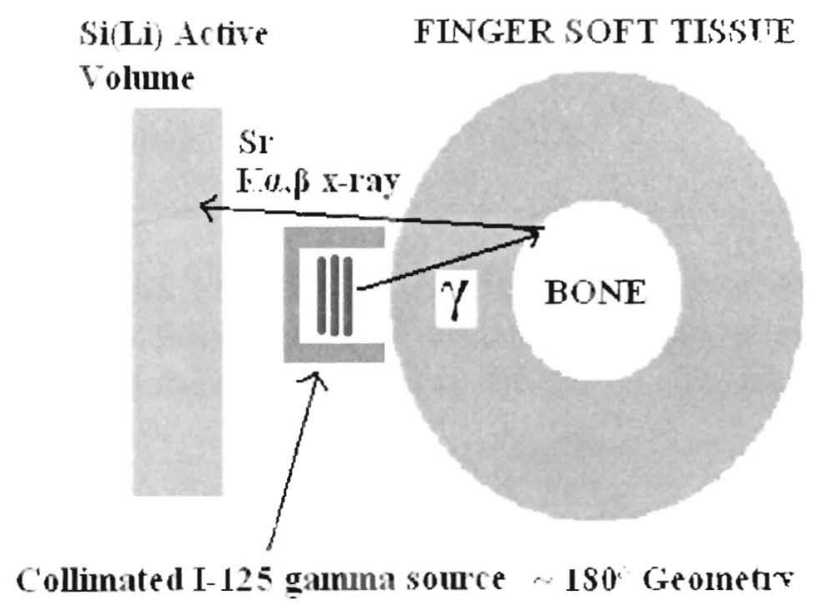

Figure 2-4: Experimental Set-Up of Source and Phantom Positioning. Note that the set-up is the same as during a human finger measurement; the phantom is positioned to simulate a human finger measurement.

As mentioned before, Prostaseed ${ }^{\circledR}{ }^{125}$ I brachytherapy seeds (Core Oncology, USA) were uscd as

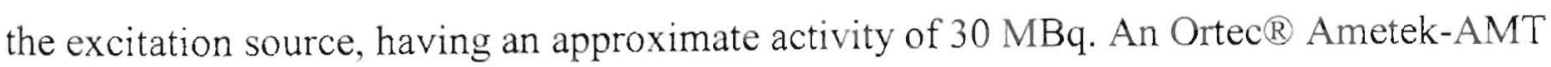
$\mathrm{Si}(\mathrm{Li})$ detector with a $16 \mathrm{~mm}$ diameter crystal and energy resolution of $230 \mathrm{eV}$ (Ortec, 2010) was used as in all measurements. Table 2-5 summarizes the peak parameters used to run all experiments discussed in this work. 


\begin{tabular}{ll}
\hline Parameter & Value \\
\hline Peak Rise time & $10 \mu \mathrm{s}$ \\
Peak Cusp & 0.80 \\
Peak Flat Top & 0.80 \\
Peak Width & 0.80 \\
Peak Tail & 0.00 \\
Dead Time (Pop bone phantoms) & $15-30 \%$ \\
\hline
\end{tabular}

Table 2-5: Peak Parameters Used for the Finger Phantom Experiments. Rise Time, Cusp, Flat-top, Width, and Tilt peak parameters of the detector were previously optimized by Zamburlini et al., (2008). Note there are no units for the peak cusp, flat top, width and tail.

The pulse processing and count sorting was done using Ortec $®$ DSPEC PLUS ${ }^{\mathrm{TM}}$ Digital Gamma Ray Spectrometer and Maestro ${ }^{\mathrm{TM}}$ software respectively. Figure 2-5 shows an example of a typical phantom spectrum obtained with the IVXRF system. The bone phantom was measured for 1800 seconds real time, at various directions and positions with respect to the source. For each distance, the experiment was performed three times and the averages of the three trials were used in analyzing the results.

Possible positioning includes three different geometrical planes: $\mathrm{x}, \mathrm{y}$ and $\mathrm{z}$, corresponding to horizontal, vertical and sideway positioning respectively. Figure 2-6 illustrates the three directions that the phantom was moved in this experiment. 


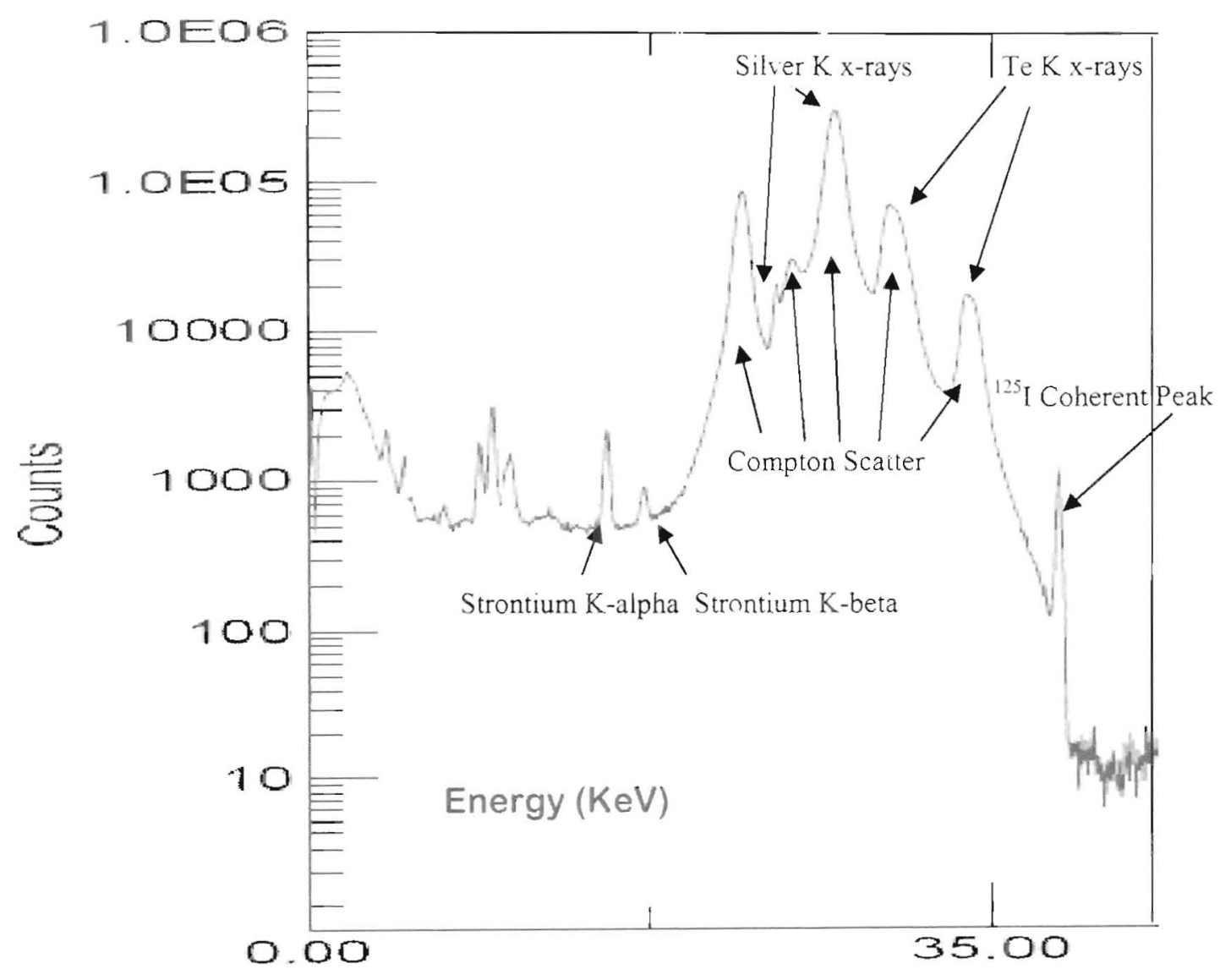

Figure 2-5: Typical Spectrum Obtained for the Bone Strontium Phantom using the IVXRF System. Strontium K-alpha and K-beta peaks are seen at $14.16 \mathrm{keV}$ and $15.8 \mathrm{keV}$ respectively. The coherent ${ }^{125} \mathrm{I}$ peak can be seen at $35.49 \mathrm{keV}$. 


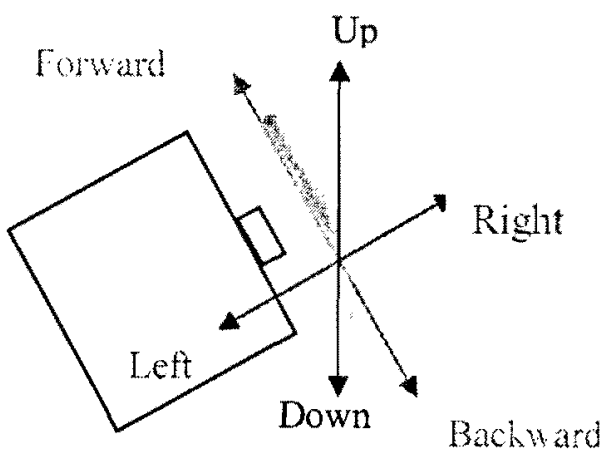

Figure 2-6: Various Directions of Movement. The strontium bone phantom was moved in various directions with respect to the ${ }^{125}$ I seed excitation source. The up and down directions are defined as the vertical distance ( $y$-plane), forward and backward ( $x$-plane) and left to right (z-plane).

To fit the strontium alpha and beta peaks, an in-house non-linear least squares method program was used to extract strontium peak parameters. The program used for the fitting, fits two Gaussian curves to these strontium k-alpha and k-beta peaks and approximates the background as a slowly increasing exponential background (Zamburlini, 2008). Figure 2-7 illustrates a filled spectrum obtained by measuring the bone phantom. 


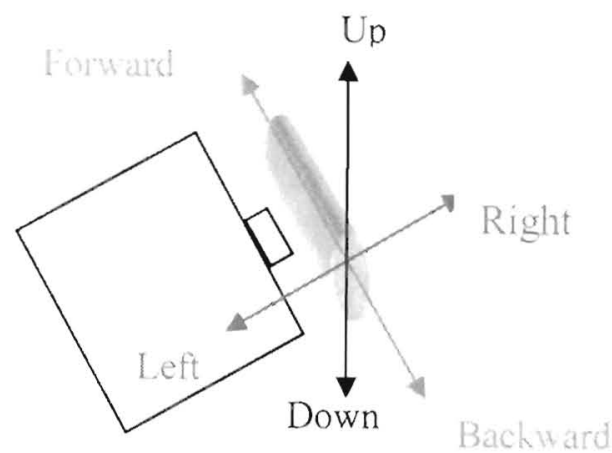

Figure 2-6: Various Directions of Movement. The strontium bone phanton was moved in various directions with respect to the ${ }^{125}$ I seed excitation source. The up and down directions are defined as the vertical distance (y-plane), forward and backward (x-plane) and left to right (z-plane).

To fit the strontium alpha and beta peaks. an in-house non-linear least squares method program. was used to extract strontium peak parameters. The program used for the fitting, fits two Gaussian curves to these strontium k-alpha and k-beta peaks and approximates the background as a slowly increasing exponential background (Zamburlini, 2008). Figure 2-7 illustrates a filled spectrum obtained by measuring the bone phantom. 


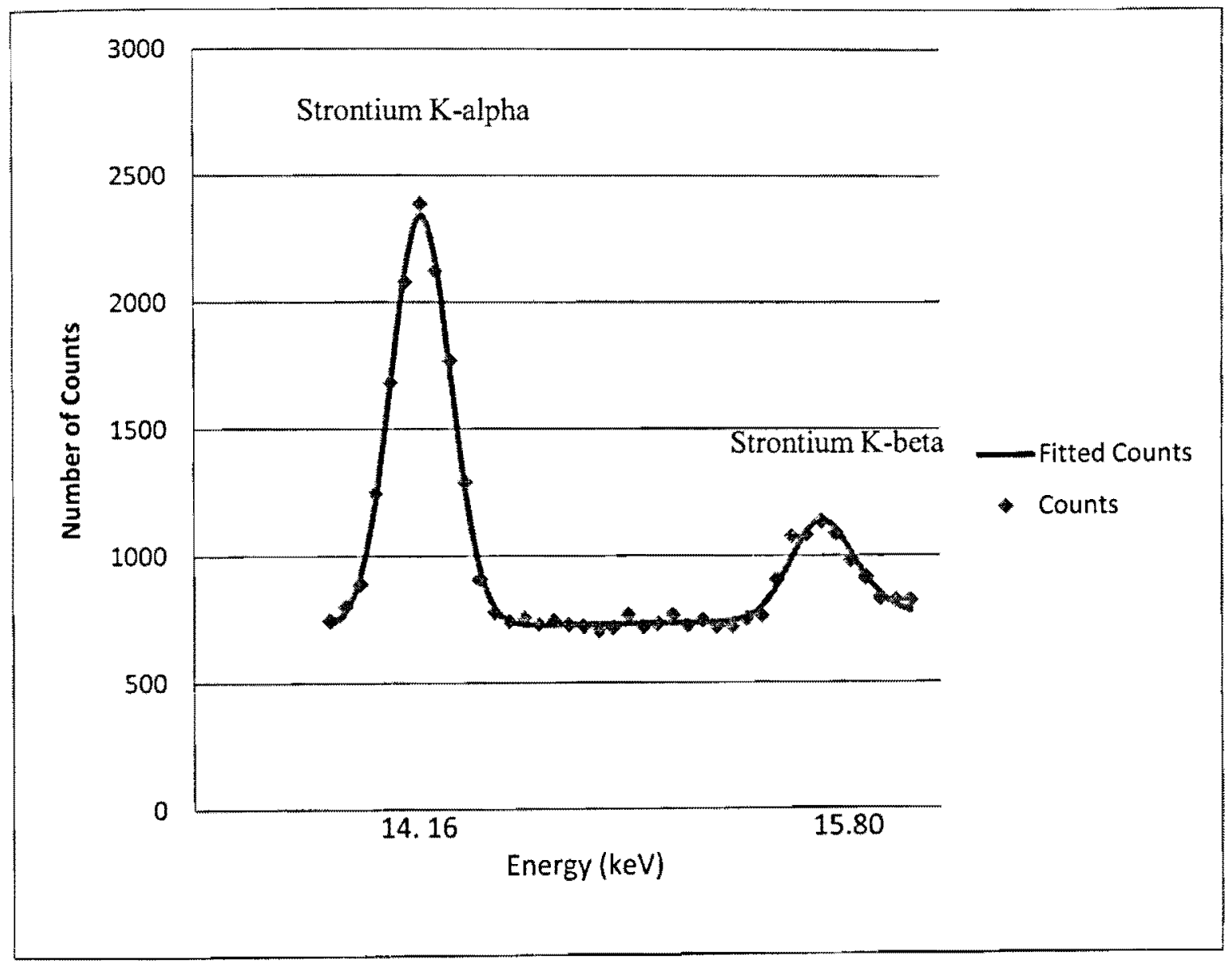

Figure 2-7: Typical Spectrum of the Bone Strontium Phantom after Fitting Using an InHouse Non-Linear Least Squares Method.

\subsubsection{Effects of Source Positioning on Bone Strontium IVXRF Measurement}

The graphical results obtained at various distances and seed angles are shown in Figures 2-8 to 211. 


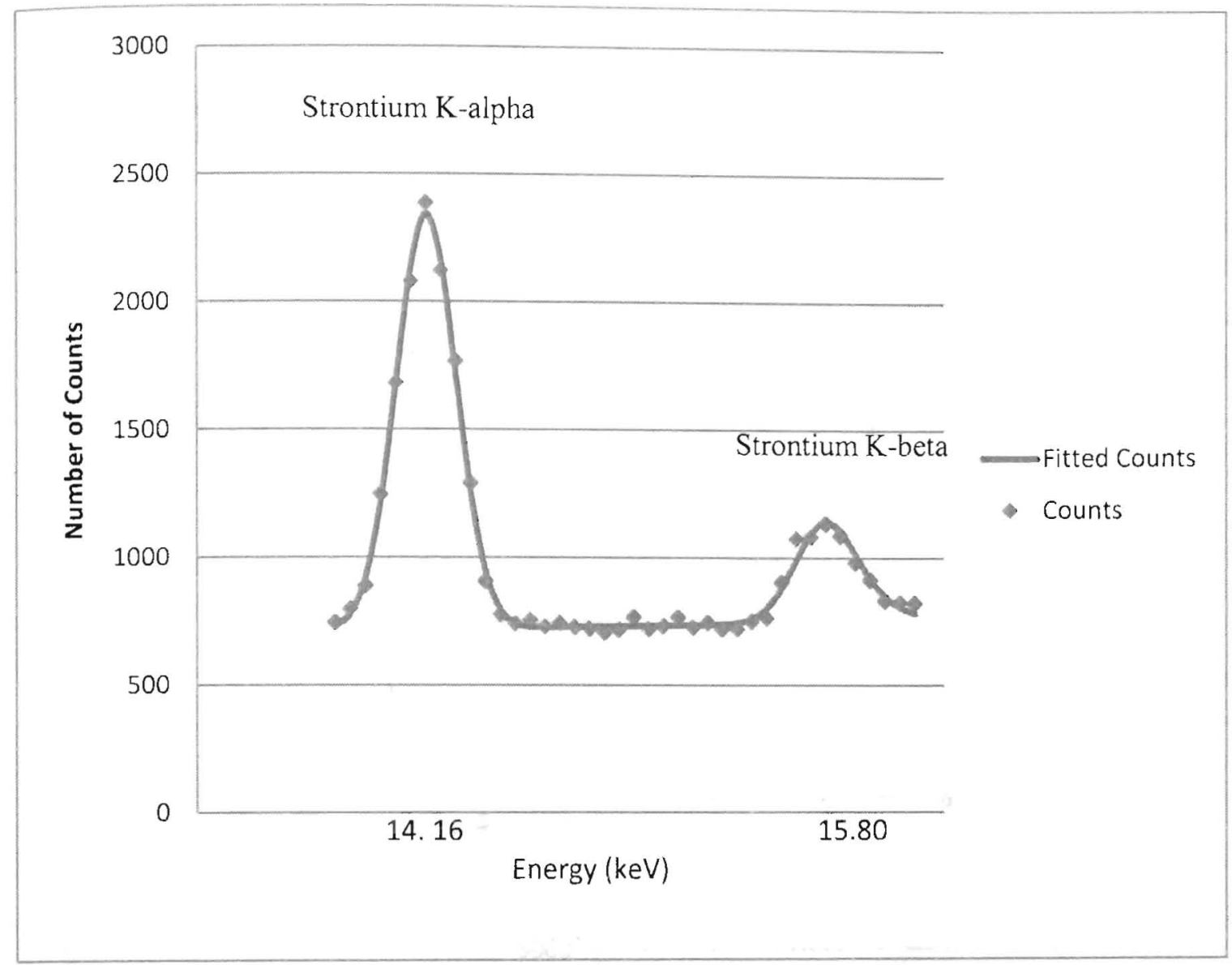

Figure 2-7: Typical Spectrum of the Bone Strontium Phantom after Fitting Using an InHouse Non-Linear Least Squares Method.

\subsubsection{Effects of Source Positioning on Bone Strontium IVXRF Measurement}

The graphical results obtained at various distances and seed angles are shown in Figures 2-8 to 211. 

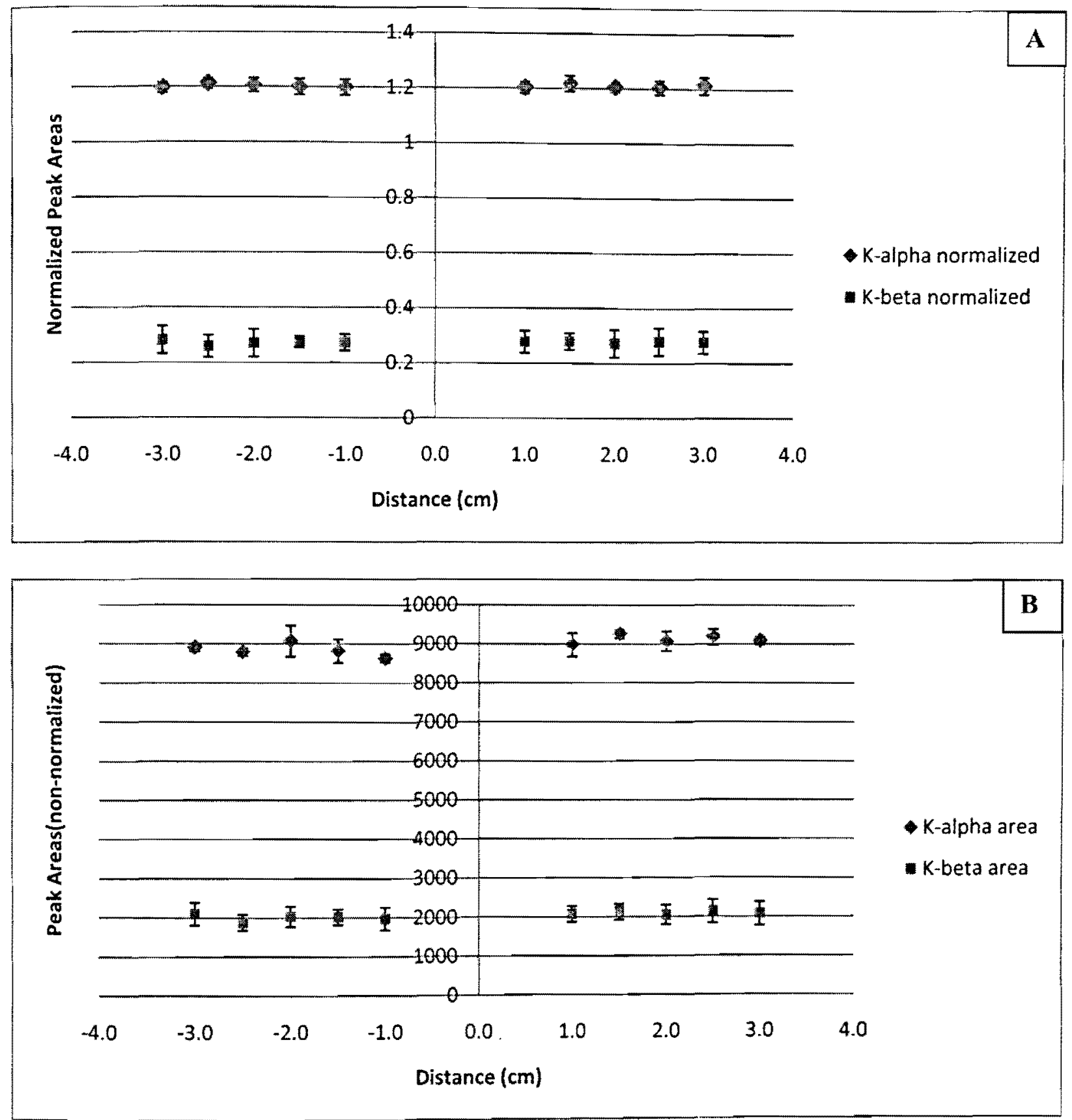

Figure 2-8: Variation of IVXRF Measurement as a Function of Source Positioning in the $X$ plane (Horizontal Movement: forward and backward). Position $(0,0)$ represents positioned bone strontium phantoms in front of the excitation seeds. A) Strontium Peaks were normalized to the ${ }^{125}$ I coherent peak localized at $35.49 \mathrm{keV}$ and B) Non-Normalized. 

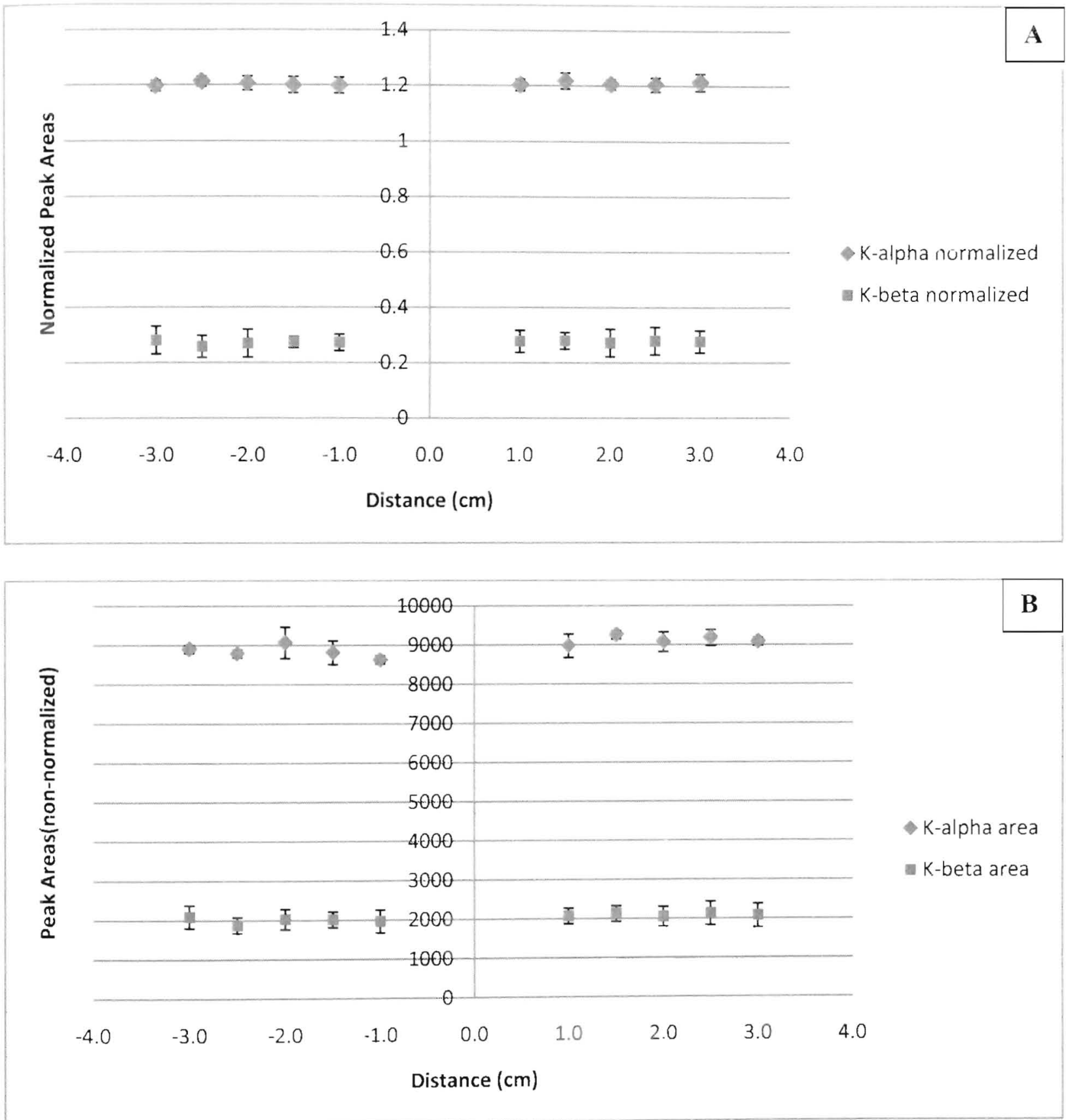

Figure 2-8: Variation of IVXRF Measurement as a Function of Source Positioning in the Xplane (Horizontal Movement: forward and backward). Position $(0,0)$ represents positioned bone strontium phantoms in front of the excitation seeds. A) Strontium Peaks were normalized to the ${ }^{125}$ I coherent peak localized at $35.49 \mathrm{keV}$ and B) Non-Normalized. 

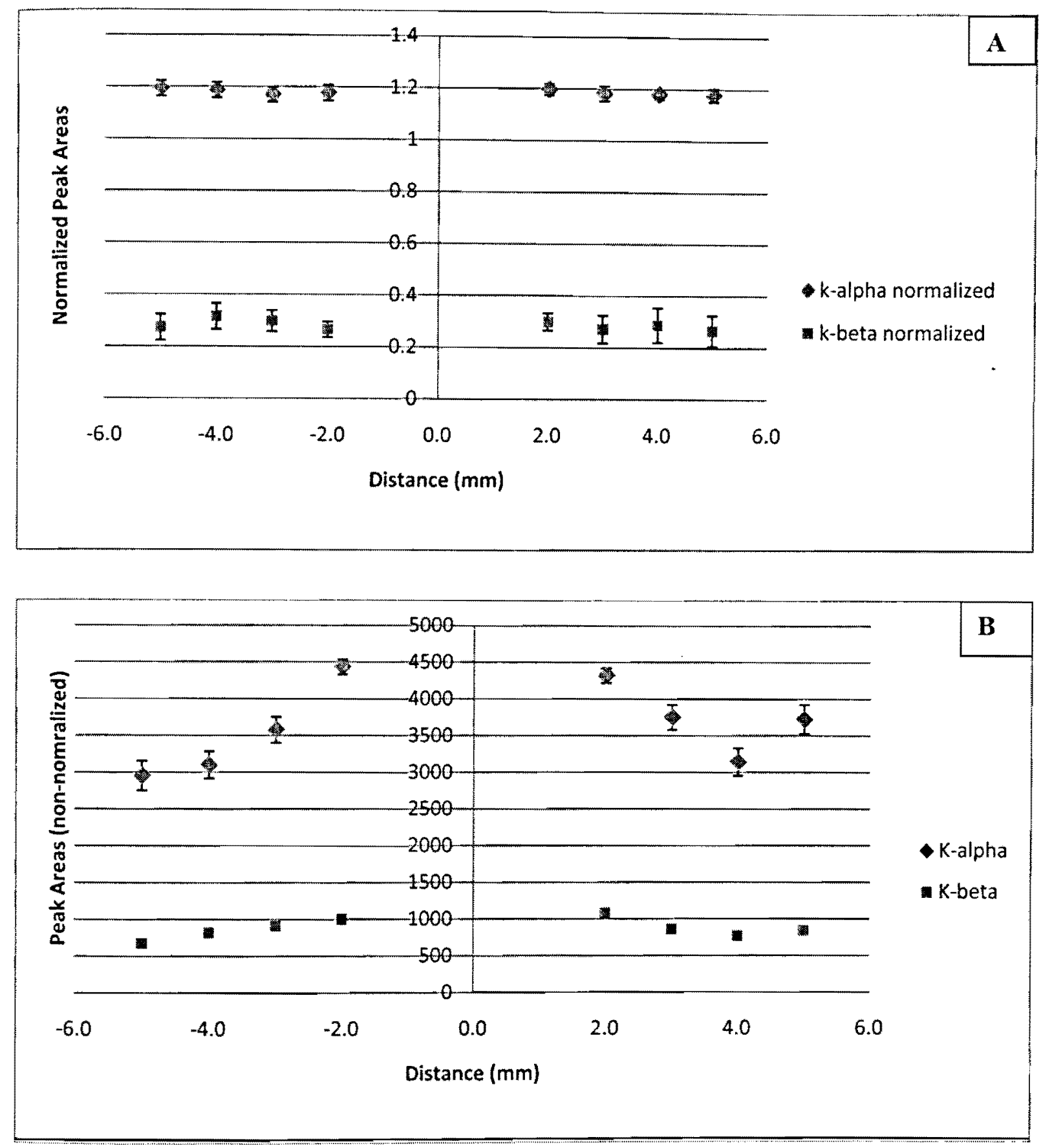

Figure 2-9: Variation of IVXRF Measurement as a Function of Source Positioning Source Positioning in the Y-plane (Vertical Movement: upwards and downwards). Position (0,0) represents positioned bone strontium phantoms in front of the excitation seeds. A) Strontium Peaks were normalized to the ${ }^{125}$ I coherent peak localized at $35.49 \mathrm{keV}$ and B) Non-Normalized. 


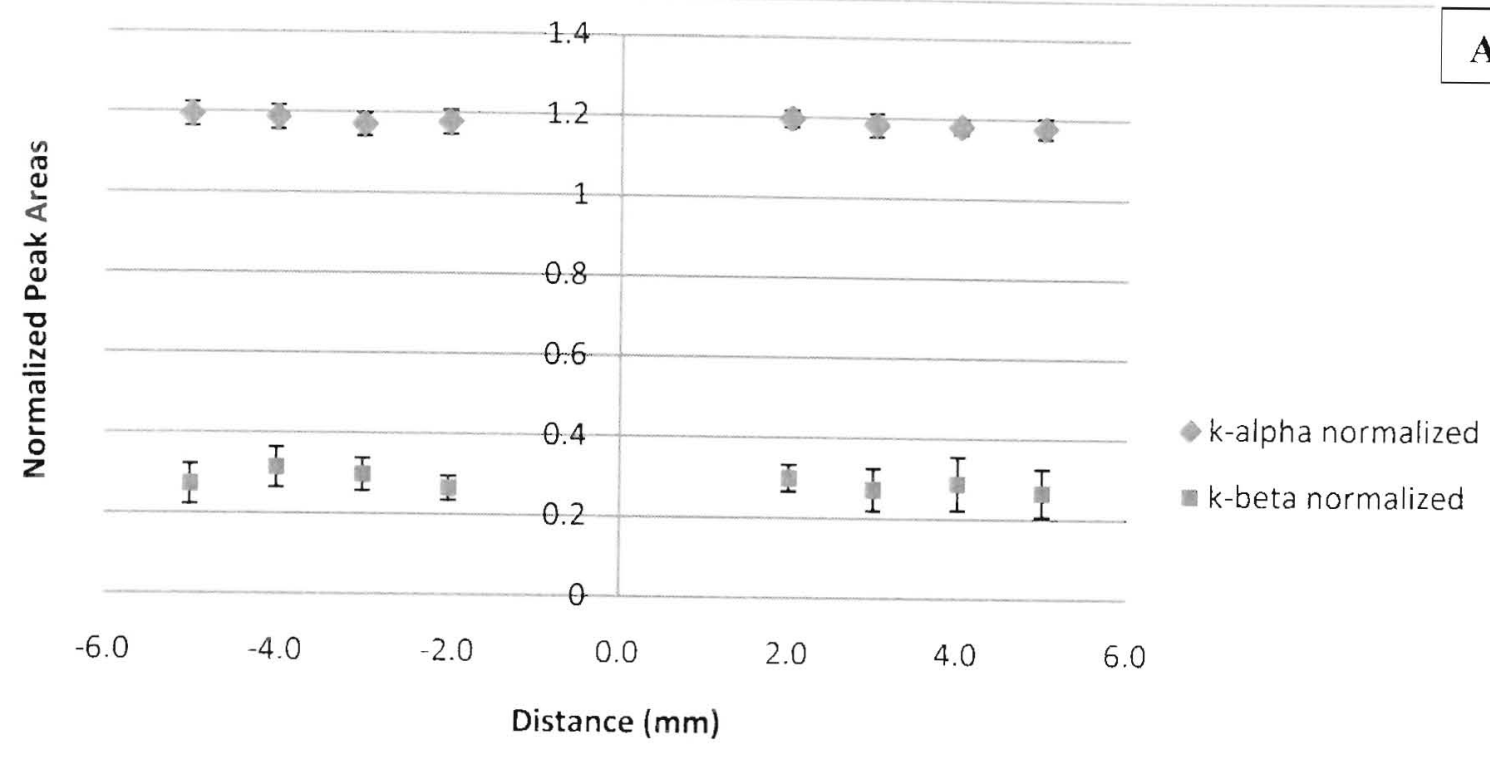

A

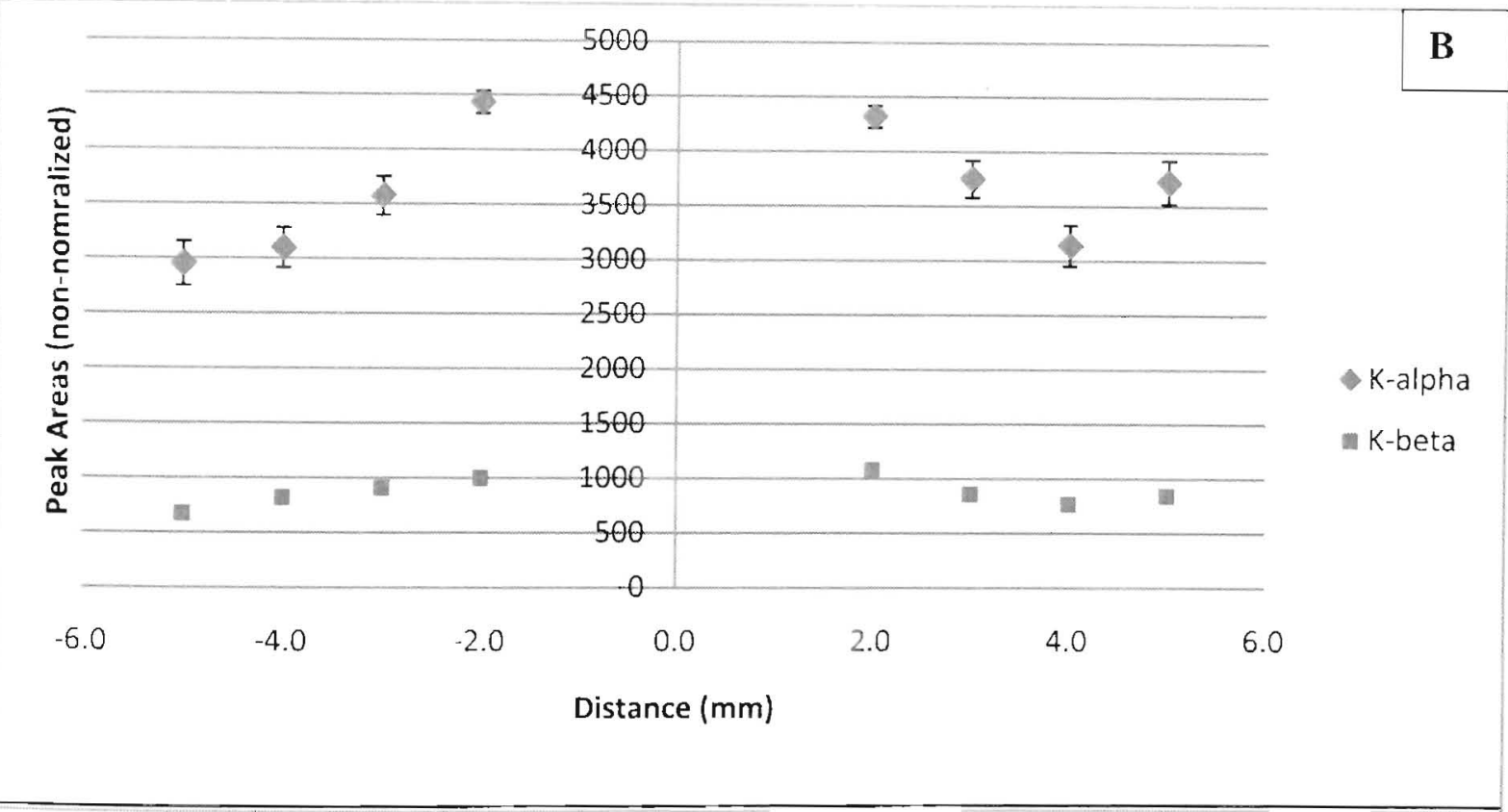

Figure 2-9: Variation of IVXRF Measurement as a Function of Source Positioning Source Positioning in the $\mathrm{Y}$-plane (Vertical Movement: upwards and downwards). Position $(0,0)$ represents positioned bone strontium phantoms in front of the excitation seeds. A) Strontium Peaks were normalized to the ${ }^{125}$ I coherent peak localized at $35.49 \mathrm{keV}$ and B) Non-Normalized. 

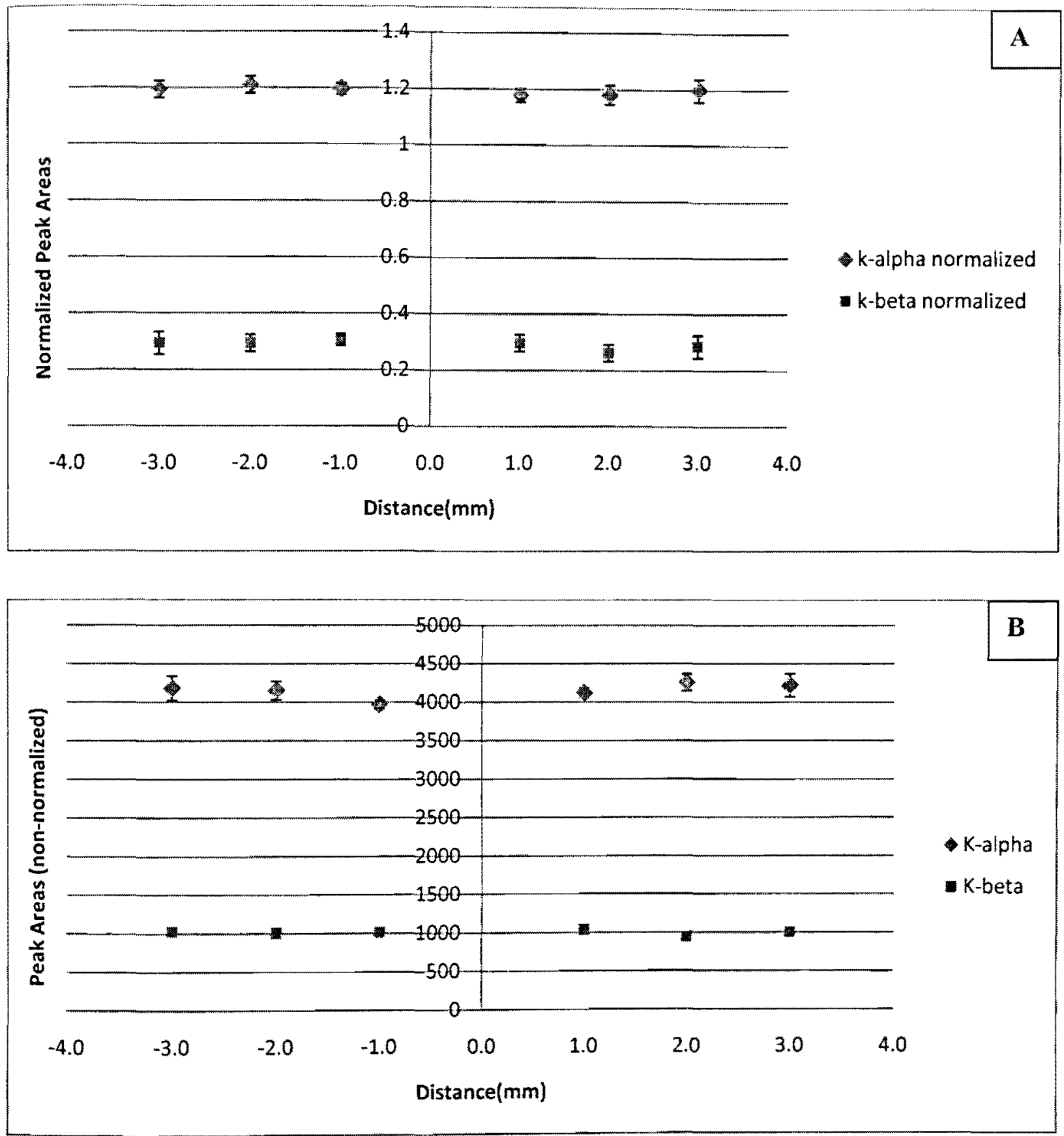

Figure 2-10: Variation of IVXRF Measurement as a Function of Source Positioning Source Positioning in the Z-plane (Sideways Movement: left and right). Position $(0,0)$ represents positioned bone strontium phantoms in front of the excitation seeds. A) Strontium Peaks were normalized to the ${ }^{125} \mathrm{I}$ coherent peak localized at $35.49 \mathrm{keV}$ and B) Non-Normalized. 

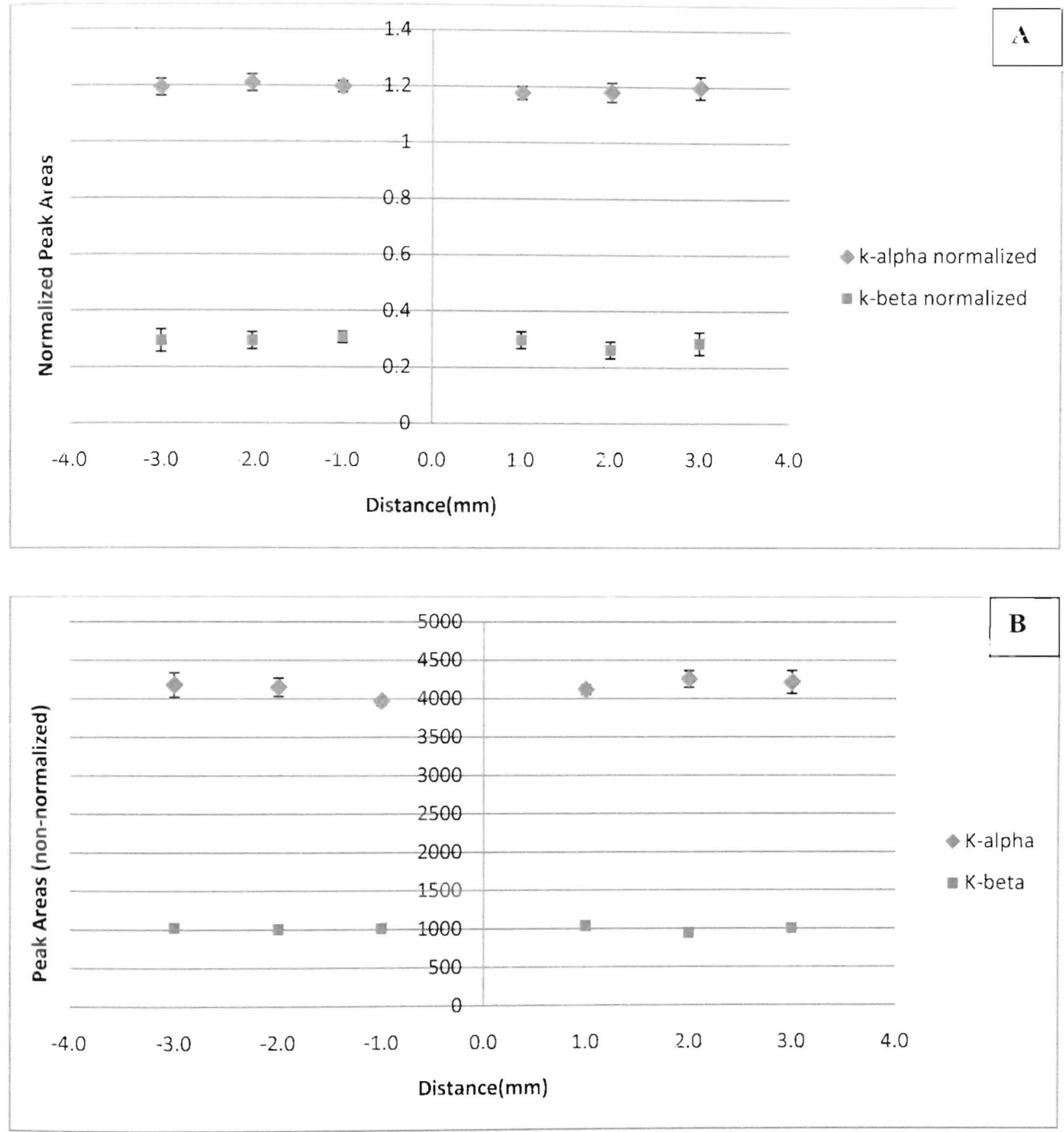

Figure 2-10: Variation of IVXRF Measurement as a Function of Source Positioning Source Positioning in the Z-plane (Sideways Movement: left and right). Position $(0,0)$ represents positioned bone strontium phantoms in front of the excitation seeds. A) Strontium Peaks were normalized to the ${ }^{125}$ I coherent peak localized at $35.49 \mathrm{keV}$ and B) Non-Normalized. 


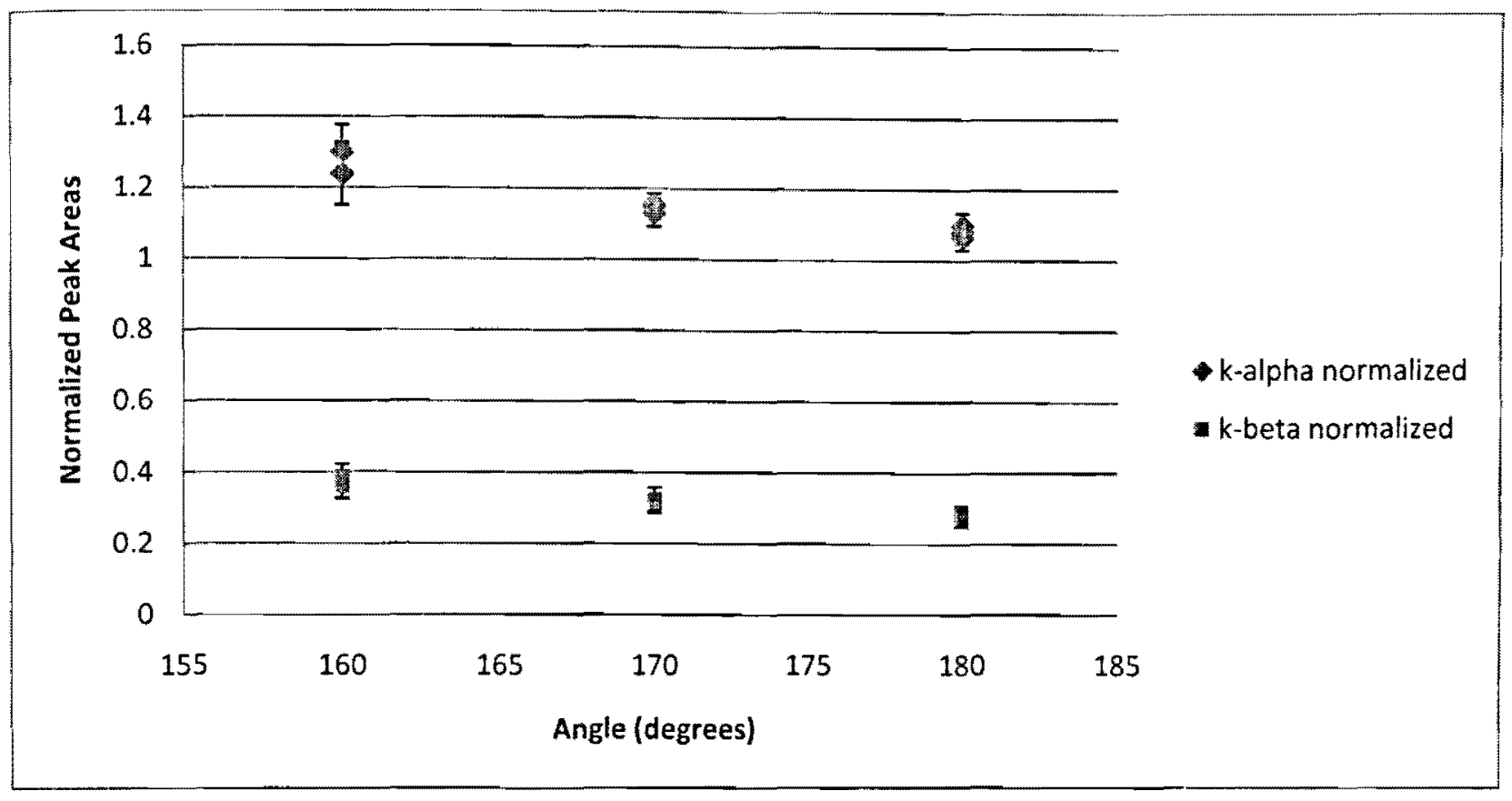

Figure 2-11: Variation of IVXRF Measurement as a Function of Seed Angle. The strontium peaks were normalized to the ${ }^{125}$ I coherent peak localized at $35.49 \mathrm{keV}$.

As mentioned before, it is expected that the strontium signal is dependent on source position, as observed in Figures $2-8(\mathrm{~B}), 2-9(\mathrm{~B})$ and $2-10(\mathrm{~B})$. However, the results indicate, in all cases, that the normalization of the strontium $\mathrm{k}$-alpha and $\mathrm{k}$ - beta peaks to the coherent ${ }^{125} \mathrm{I}$ peak improved the consistency of the strontium signal observed between changes in positioning. It was observed that the largest change of strontium signal occurred when the bone strontium phantom was moved in vertical direction (phantom height placement with respect to the source). Without normalization of the strontium k-alpha and k-beta peaks to the coherent ${ }^{125}$ I peak, the range of the $\mathrm{k}$-alpha strontium signal was determined to be $27.3 \pm 0.06 \%$ for the positions examined. This was calculated using the highest and lowest observed strontium signals. However, the coherent normalization of strontium k-alpha peak reduced the change of strontium 


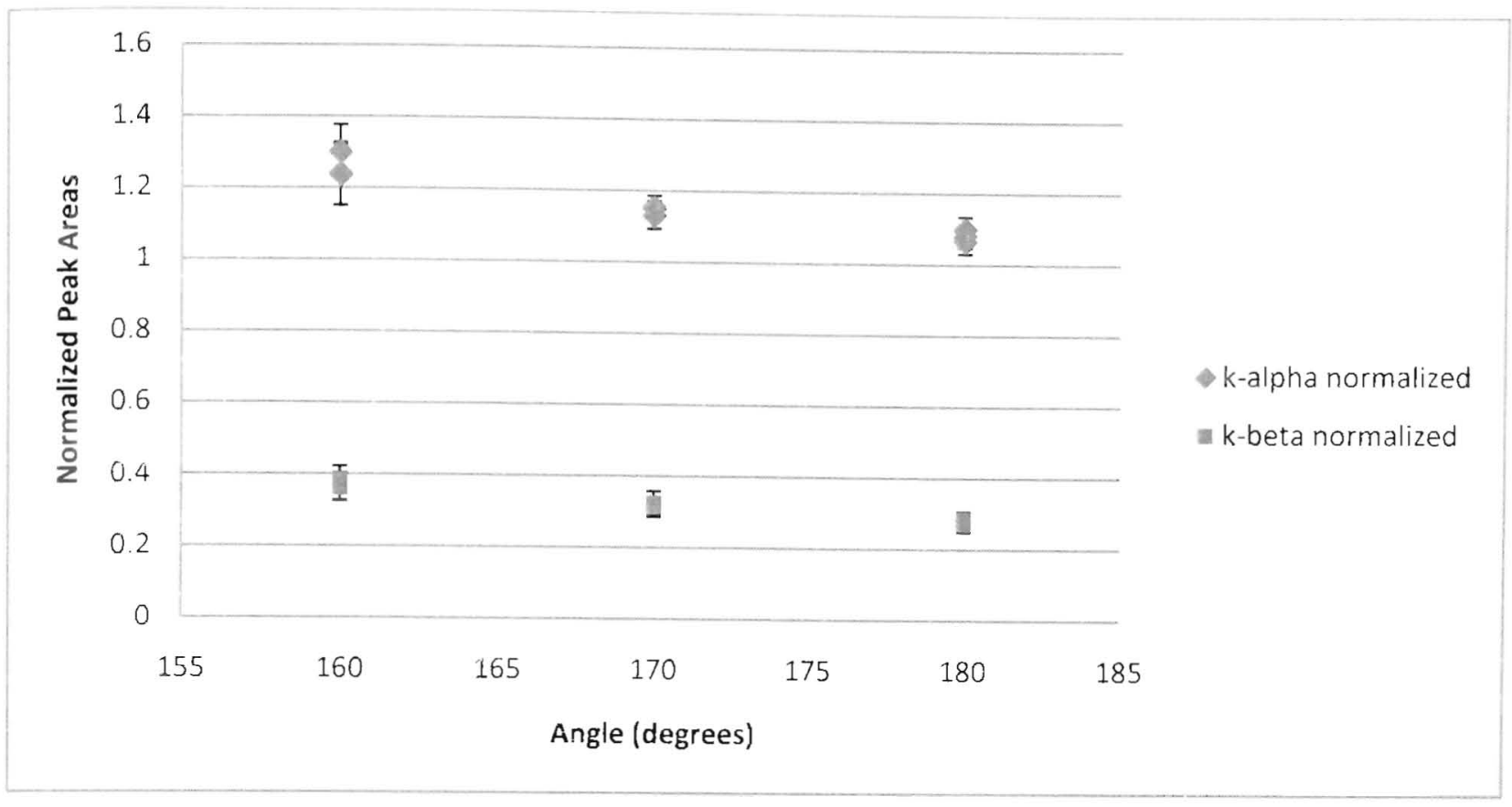

Figure 2-11: Variation of IVXRF Measurement as a Function of Seed Angle. The strontium peaks were normalized to the ${ }^{125}$ I coherent peak localized at $35.49 \mathrm{keV}$.

As mentioned before, it is expected that the strontium signal is dependent on source position, as observed in Figures 2-8(B), 2-9(B) and 2-10(B). However, the results indicate, in all cases, that the normalization of the strontium $\mathrm{k}$-alpha and $\mathrm{k}$ - beta peaks to the coherent ${ }^{125} \mathrm{I}$ perak improved the consistency of the sirontium signal observed between changes in positioning. It was observed that the largest chanye of strontium signal occurred when the bone strontium phantom was moved in vertical direction (phantom height placement with respect to the source).

Without normalization of the strontium k-alpha and k-beta peaks to the coherent ${ }^{125} \mathrm{I}$ peak, the range of the $\mathrm{k}$-alpha strontium signal was determined to be $27.3 \pm 0.06 \%$ for the positions examined. This was calculated using the highest and lowest observed strontium signals.

However, the coherent normalization of strontium $\mathrm{k}$-alpha peak reduced the change of strontium 
signals to $2.64 \pm 0.08 \%$. This trend was also observed for bone phantom positioning in the other directions. The average non-normalized strontium signal change in the $\mathrm{x}$-plane (bone phantom placed left to right of the source) and z-plane (bone phantom moved further away from the source) were $3.08 \pm 0.03 \%$ and $3.35 \pm 0.03 \%$, respectively, whereas coherent normalization improved the results to $1.15 \pm 0.01 \%$ and $1.16 \pm 0.02 \%$, respectively.

The effect of the coherent normalization on the strontium signal arises because normalization corrects for various conditions that would otherwise affect the strontium signal observed. As mentioned by Zamburlini (2008), normalization using the coherent peak has also been used in other studies involving X-ray fluorescence systems; notably ${ }^{57} \mathrm{Co}$-based $\mathrm{K}$ shell $\mathrm{U}$ and $\mathrm{Pb}$ systems, and "has been shown to correct reasonably well for differences in bone size and soft tissue thicknesses in the ranges expected during an in vivo measurement" (O'Meara et al, $1997,2001)$. Hence, the effect of coherent normalization of strontium peaks and soft-tissue attenuation correction of bone strontium signal makes the IVXRF system feasible for use to measure bone strontium in-vivo. 


\title{
Chapter 3 Strontium Incorporation Into Human Bone
}

\subsection{Quantification of Strontium in Human Bone by Dual Photon}

\begin{abstract}
Absorptiometry
To date, there have been several studies investigating the effects of strontium in both human and animals. In the past, two strontium diagnostic tools have been reported. One was based on dual photon absorptiometry (DPA) (Neilson et al.,2004 and Bärenholdt et al.,2009) and the second one on X-ray fluorescence (XRF) (Snyder and Secord, 1983, Weilopolski et al., 1984 and Pejović-Milić et al., 2004).
\end{abstract}

The DPA method, which was proposed by Neilson and colleagues (2004) to measure strontium in vivo, involved the measurement of the strontium hydroxyapatite crystals in the bone matrix based on the different attenuation properties of $59.5 \mathrm{keV}$ and $365 \mathrm{keV}$ photons emitted by ${ }^{241} \mathrm{Am}$ and ${ }^{133} \mathrm{Ba}$ in strontium and calcium. It also necessitated immersing the measurement site, the arm, in a water bath, assuming that water has similar attenuation properties to soft tissue. As a result, the DPA method is an indirect method to measure natural strontium levels in bone invivo. Furthermore, this diagnostic tool did not provide sufficient sensitivity to measure bone strontium levels in the population. In addition, the high measurement uncertainties made it unfeasible to measure strontium in-vivo.

\subsection{In-Vivo X-Ray Fluorescence to Measure Bone Strontium: Previous}

\section{Human Studies}

The first attempts to use IVXRF to measure bone strontium levels in-vivo were performed 
in the 1980's using animals and humans. Snyder and Secord (1982) used XRF on rabbit skull, while Wielopolski et al., (1983) proposed a similar method to measure bone strontium levels in the tibial shaft of human cadaver legs. However, in both cases strontium quantification was not reported, because Snyder and Secord's focus was not on the quantification of strontium in absolute terms but rather on obtaining a time dependent curve. On the other hand, Wielopolski and colleagues (1983), did not report the absolute strontium concentration because they did not measure the overlying soft tissue thickness at the tibial shaft, and hence were not able to correct for the signal attenuation through the soft tissue.

The IVXRF system originally developed by Pejović-Milić and colleagues (2004) was initially tested on ten healthy subjects and the detection limit of $110 \mu \mathrm{g}$ strontium/g calcium was reported. After further technique development, improvement in the detection limit of $22.9 \pm 0.6$ $\mu \mathrm{g}$ strontium/g calcium (Zamburlini et al., 2006) was reported. The second human study of twenty two healthy subjects followed, confirming the sensitivity of the IVXRF system to measure bone strontium levels in various individuals (Zamburlini et al., 2007a).

Among the twenty two healthy subjects that participated in the study in 2006, the group consisted of both Caucasian and Asian ethnicities of both genders (eleven males and eleven females). The age of the group varied between 26 and 68 years old, with the median age of the group being 31 years of age. None of the subjects measured had bone disease and none were taking strontium supplements or strontium based drugs. Only one subject was taking calcium supplements at the time of this study.

Prior to their measurements, subjects underwent ultrasound measurements to determine the overlying soft tissue thickness at the finger and ankle bone sites where the measurement would 
take place. In addition, a marker (tested to be free of strontium content) was used to mark the site at the ultrasound measurement. This mark also corresponded as the reference point for the IVXRF bone measurement. For the twenty two subjects, ultrasound measurements, using a gel pad, were done using a Philips HDI ultrasound machine of $12 \mathrm{MHz}$ frequency and a L12-5 linear probe. This ultrasound machine has an uncertainty of $1 \%$ on each measured thickness (Zamburlini, 2008). The bone strontium measurements were performed at:

(1) The finger at a point on the dorsal surface of the index finger (right hand) in the centre of the middle phalanx,

and

(2) The ankle joint at the most prominent part of the medial malleolus of the tibia of the right foot.

However, one person had to be measured at the medial tibial location due to the presence of a surface superficial vein that interfered with the measurement. For all subjects, a thirty minute measurement (1800 seconds clock time) was performed at both finger and ankle sites. The finger was placed at approximately $3 \mathrm{~mm}$ from the collimator face (source to finger distance was approximately $5 \mathrm{~mm}$ ) and the seed activity ranged from 24 to $39 \mathrm{MBq}$. The ankle was placed approximately $1 \mathrm{~mm}$ from the collimator face (source to ankle distance was approximately $3 \mathrm{~mm}$ ) and the corresponding seed activity ranged from $12-26 \mathrm{MBq}$. Note that the smaller source activity was chosen for the ankle to keep the detector dead time from being above $50 \%$. Data were acquired and processed using an ORTEC DSPEC Plus ${ }^{\mathrm{TM}}$ multichannel analyzer operating 
with Maestro ${ }^{\mathrm{TM}}$ software. The maximum effective dose delivered was $64 \times 10^{-6} \mathrm{mSv}$ for the finger and $76 \times 10^{-6} \mathrm{mSv}$ for the ankle in a 30 minute measurement (Zamburlini et al, 2007a). Figures 3-1 and 3-2 illustrate the strontium k-alpha signal normalized by the coherent peak of the twenty two subjects.

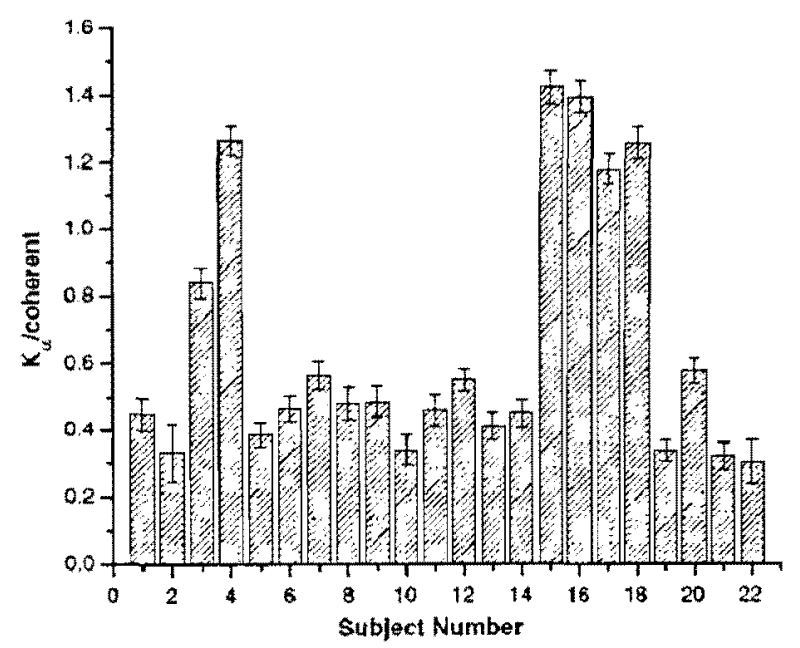

Figure 3-1: Normalized Strontium Alpha Peak in Finger Measurement. Note that the uncertainty represents the statistical uncertainty of the number of recorded photons (Zamburlini et al., 2007a).

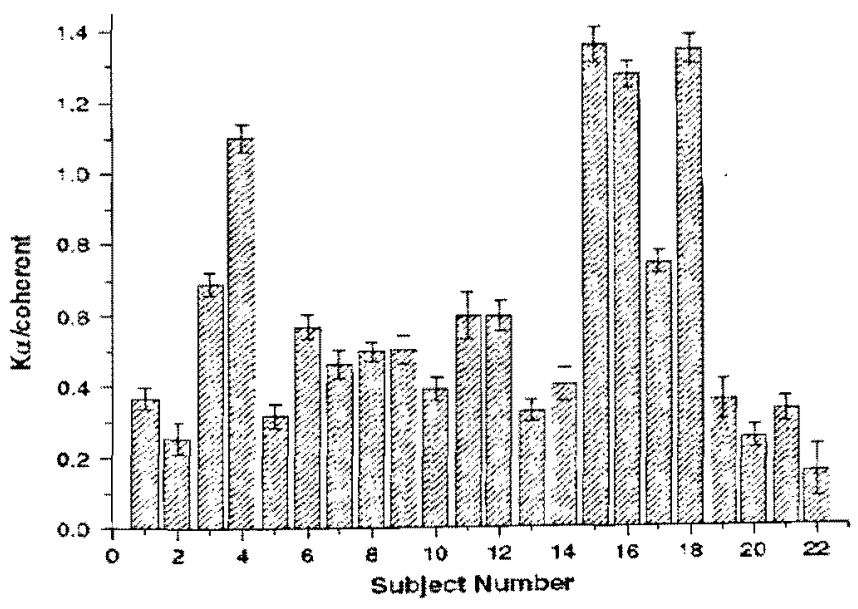

Figure 3-2: Normalized Strontium Alpha Peak in Ankle Measurement. Note that the uncertainty represents the statistical uncertainty of the number of recorded photons (Zamburlini et al., 2007a). 
The correlation between the finger and ankle was found to be significant $(p<0.0001)$ (Zamburlini et al., 2007a). This result is important because it demonstrated that the IVXRF system was capable to provide a quantitative measurement of bone strontium levels in healthy individuals and had enough sensitivity to measure strontium levels in each of the twenty two individuals in which the strontium intake was only through diet.

Interestingly, the results also indicated that strontium levels, on average, were much higher in the ankle bone than in the finger bone. This suggests that the strontium concentration is higher in trabecular bone than in cortical bone and this finding agrees with the same observation reported by Dahl and colleagues (2001). The correlation between the $\mathrm{k}$-alpha and $\mathrm{k}$-beta strontium peaks in both the finger and ankle cases indicated it to be significant $(\mathrm{p}<0.0001)$. When a plot of the $\mathrm{k}-$ beta versus $k$-alpha values were performed as shown in figure 3-3, Zamburlini and colleagues (2007a) noted that the intercept was greater than zero, due to the probability of emission of the strontium $\mathrm{K}$-alpha photon being seven times larger than the probability of emission for the strontium K-beta photon.

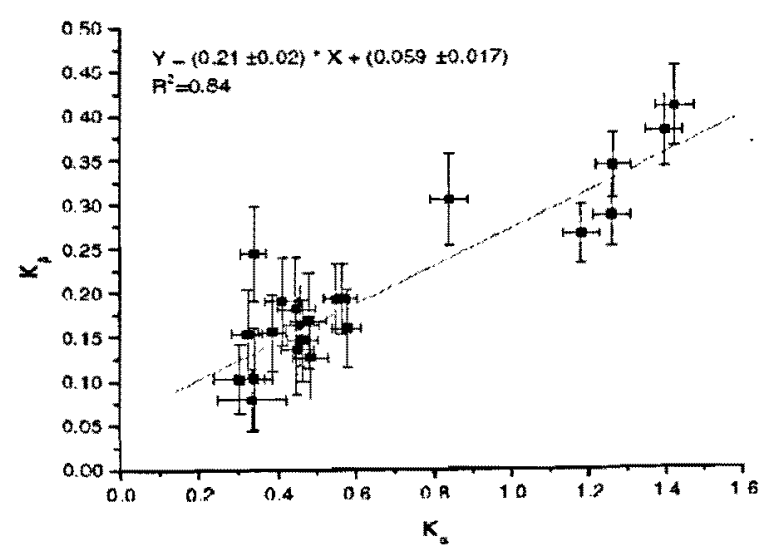

Figure 3-3: Pilot Study; Correlation of the Normalization Strontium Peaks for Finger Measurements of the 22 Subjects. Note the errors are associated with the statistical uncertainty of the number of recorded photons (Zamburlini et al, 2007a) 
The correlation between the finger and ankle was found to be significant $(\mathrm{p}<0.0001)$ (Zamburlini et al., 2007a). This result is important because it demonstrated that the IVXRF system was capable to provide a quantitative measurement of bone strontium levels in healthy individuals and had enough sensitivity to measure strontium levels in each of the twenty two individuals in which the strontium intake was only through diet.

Interestingly, the results also indicated that strontium levels, on average, were much higher in the ankle bone than in the finger bone. This suggests that the strontium concentration is higher in trabecular bone than in cortical bone and this finding agrees with the same ubservation reported by Dahl and colleagues (2001). The correlation between the k-alpha and $\mathrm{k}$-beta strontium peaks in both the finger and ankle cases indicated it to be significant $(\mathrm{p}<0.0001)$. When a plot of the $\mathrm{k}-$ beta versus $\mathrm{k}$-alpha values were performed as shown in figure 3-3, Zamburlini and colleagues (2007a) noted that the intercept was greater than zero, due to the probability of emission of the strontium K-alpha photon being seven times larger than the probability of emission for the strontium K-beta photon.

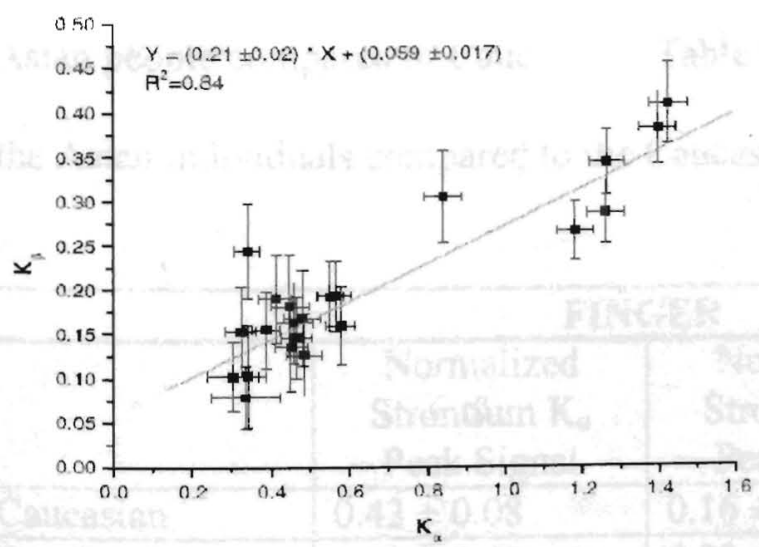

Figure 3-3: Pilot Study; Correlation of the Normalization Strontium Peaks for Finger Measurements of the 22 Subjects. Note the errors are associated with the statistical uncertainty of the number of recorded photons (Zamburlini et al, 2007a) 
Theoretically, the alpha to beta ratio is 7 ; however, if the strontium is assumed to be uniformly distributed in bone (hydrated cortical bone) then this ratio value is lowered to 5.2. However, Zamburlini and colleagues (2007a) found the alpha to beta ratio among the twenty two subjects to be $2.9 \pm 0.7$ for the finger bone and $2.7 \pm 0.1$ for the ankle bone, lower than the predicted 5.2 value. The lower ratio values observed suggested non-uniform distribution of strontium in bone, but further investigation by Zamburlini and colleagues (2007a) in five cadaver fingers, using particle induced X-ray emission (PIXE) to study bone strontium depth distribution showed strontium to be uniformly distributed. This discrepancy needs to be resolved, and will be further discussed in section 3.5 of this chapter.

Another interesting observation that Zamburlini and colleagues (2007) made was that the bone strontium concentration between the continental Asian and non-Asian people was different. The larger normalized k-alpha values for both bone sites belonged to the continental Asian people (fig. 3-1 and 3-2, subjects 3, 4, 15, 16, 17 and 18). A two sample t-test, assuming normal variances $(p<0.001$ and $\mathrm{p}=0.003$ for the finger and ankle, respectively) showed a significant difference of the strontium levels. The strontium levels were about two to three times higher in Asian people compared to Caucasians. Table 3-1 summarizes the strontium levels observed in the Asian individuals compared to the Caucasian individuals.

\begin{tabular}{|l|c|c|c|c|}
\hline & \multicolumn{2}{|c|}{ FINGER } & \multicolumn{2}{c|}{ ANKLE } \\
\hline & $\begin{array}{c}\text { Normalized } \\
\text { Strontium } \mathrm{K}_{\alpha} \\
\text { Peak Signal }\end{array}$ & $\begin{array}{c}\text { Normalized } \\
\text { Strontium } \mathrm{K}_{\beta} \\
\text { Peak Signal }\end{array}$ & $\begin{array}{c}\text { Normalized } \\
\text { Strontium } \mathrm{K}_{\alpha} \\
\text { Peak Signal }\end{array}$ & $\begin{array}{c}\text { Normalized } \\
\text { Strontium } \mathrm{K}_{\beta} \\
\text { Peak Signal }\end{array}$ \\
\hline Caucasian & $0.43 \pm 0.08$ & $0.16 \pm 0.04$ & $0.40 \pm 0.13$ & $0.16 \pm 0.05$ \\
\hline $\begin{array}{l}\text { Continental } \\
\text { Asian }\end{array}$ & $1.03 \pm 0.40$ & $0.33 \pm 0.06$ & $1.09 \pm 0.30$ & $0.33 \pm 0.08$ \\
\hline
\end{tabular}

Table 3.1: Average Normalized Strontium Signal for Asian and Caucasian Individuals. 
Although the reason for the higher strontium levels in the Asian individuals is unknown, there may be various factors explaining this observation. The authors suggested that race, genetics or dietary influences may play a role in higher strontium levels in these individuals. If the hypothesis that race and genetics play a role in strontium levels, then variances in other ethnic groups, such as American-Africans, Middle Eastern and Indian groups, should be observed as well. Zamburlini (2008) also reported that Schroeder and colleagues (1972) observed that strontium levels vary among races, by reporting higher strontium concentration in ex-vivo bone samples from Far Eastern people than from American people. Furthermore, the prevalence of osteoporosis among Asian people is smaller compared to Caucasians (Barrett-Connor et al., 2005). Thus, whether the risk of osteoporosis is linked to lower bone strontium levels is a hypothesis that needs to be addressed.

The excellent sensitivity of the IVXRF system and its ability to distinguish bone strontium levels among various individuals, led to the next human study such as a pilot measurement of a person that was self-administering with strontium citrate. This person, a Caucasian, was on 454 mg of strontium citrate per day for approximately three months before the measurement and the person's strontium level was compared with that of the three healthy individuals without known and deliberate administration of strontium tablets but received strontium through their diets (figure 3-4). 


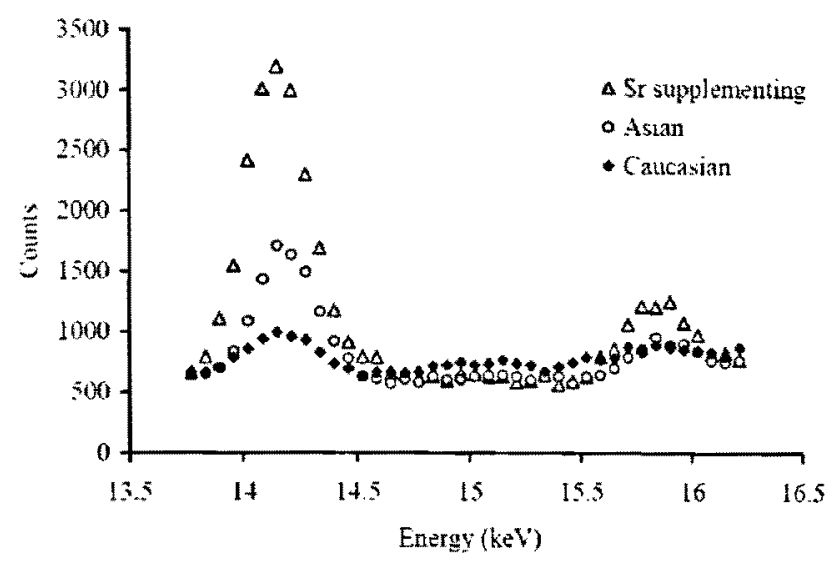

Figure 3-4: Strontium Spectra of Finger for Caucasian, Continental Asian and Strontium Caucasian Supplementing Individual. Note that in this spectrum, the Caucasian and Asian individuals had the same overlying soft tissue thickness, so correction was not applied. (Zamburlini et al., 2007a).

Measurements were also taken at two and five month intervals for the self-administrating individual. Figure 3-5 summarizes these results.

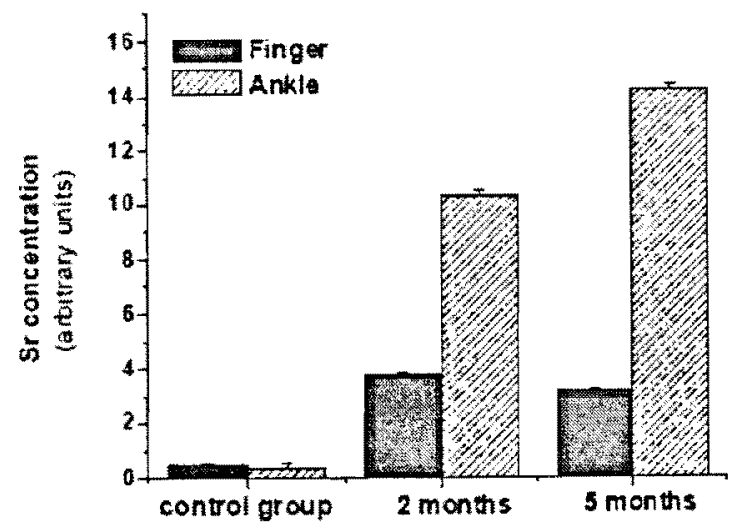

Figure 3-5: Strontium IVXRF Results of Self-Supplementing Individual Compared to NonSupplementing Caucasian and Asian Individual. Note that the control group refers to the group of the twenty two subjects (Zamburlini et al., 2007a).

These pilot results indicate not only that the IVXRF system is capable of measuring strontium levels in individuals over time, but it produced the observation that the self-administered 


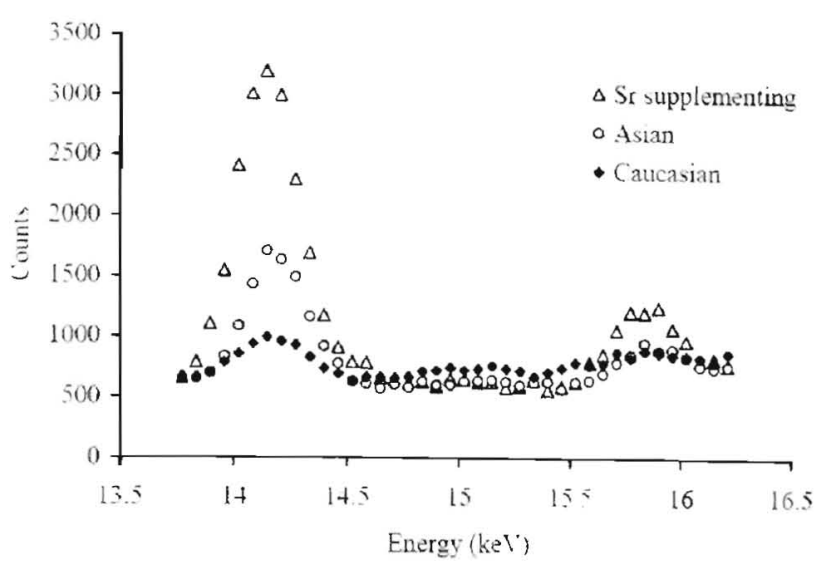

Figure 3-4: Strontium Spectra of Finger for Caucasian, Continental Asian and Strontium Caucasian Supplementing Individual. Note that in this spectrum, the Caucasian and Asian individuals had the same overlying soft tissue thickness, so correction was not applied. (Zamburlini et al., 2007a).

Measurements were also taken at two and five month in ervals for the self-administrating individual. Figure 3-5 summarizes these results.

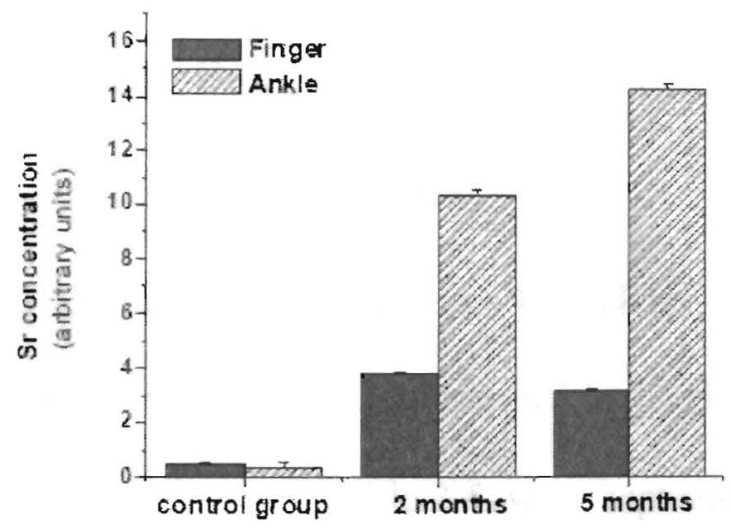

Figure 3-5: Strontium IVXRF Results of Self-Supplementing Individual Compared to NonSupplementing Caucasian and Asian Individual. Note that the control group refers to the group of the twenty two subjects (Zamburlini et al., 2007a).

These pilot results indicate not only that the IVXRF system is capable of measuring strontium levels in individuals over time, but it produced the observation that the self-administered 
strontium individual had higher bone strontium levels at both the finger and ankle bone compared to the Asian and Caucasian individuals. Based on this result, Zamburlini and colleagues (2007a) emphasized the need to continue with human studies conducted by the same research group.

Several questions arise from the human studies performed by Pejović-Milić and colleagues (2004) and Zamburlini and colleagues (2007a) related to strontium kinetics. The first question is is how is strontium taken up in bone and incorporated. The second question is how strontium is retained in bone; will it plateau at some point in time or will it increase indefinitely. To date there are no reports present in the literature, thus the focus of this work and results described in this thesis revolve around these two questions. Furthermore, for the first time, an African black male was measured with the IVXRF system.

\subsection{IVXRF Bone Strontium Measurements: Experimental Set-Up and}

\section{Measurement Parameters}

All the human bone strontium IVXRF measurements in this work were performed using the same experimental set-up as described in the pilot human studies. The peak shaping parameters, as previously shown in Table $2-5$, were kept constant. The detector dead time was maintained

between $30-50 \%$ for both bone sites. Prostaseed ${ }^{125} \mathrm{I}$ brachytherapy seeds (CoreOncology, USA) were used as the excitation source, having an approximate activity of $30 \mathrm{MBq}$. Bone strontium measurements were taken at the left index finger at the center of the middle phalanx, and left ankle at the most prominent part of the medial malleolus of the tibia bone with the IVXRF 
system for 30 minutes (1800 seconds live time) at each site. The finger to source distance was between $4-5 \mathrm{~mm}$ and the ankle to source distance was between $2-3 \mathrm{~mm}$. The whole body effective dose for the finger and ankle measurement was approximately $49.08 \pm 0.05 \times 10^{-6} \mathrm{mSv}$ and $49.08 \pm 0.05 \times 10^{-6} \mathrm{mSv}$, respectively. This is equivalent to approximately three minutes of natural background radiation; in North America the natural background radiation is approximately $3000 \mu \mathrm{Sv} / \mathrm{year}$. Prior to the XRF measurements, a portable ultrasound machine with a maximum frequency of $10 \mathrm{MHz}$ was used to determine the overlying soft tissue thickness at both bone sites. The ultrasound imaging was done to monitor any changes in skin and softtissue thickness, which in turn may have an effect on the strontium readings. Data acquisition and processing were obtained, as previously explained, with the ORTEC DSPEC Plus ${ }^{\mathrm{TM}}$ multichannel analyser operating with Maestro ${ }^{\mathrm{TM}}$ software.

\subsection{Bone Strontium Baseline Study of Individuals taking Strontium}

\section{Supplements}

To help answer the first questions posed previously, after obtaining ethics approvals from the McMaster University (REB \# 07-402) and Ryerson University (REB \# 2007-212-1) Research Ethics Boards, individuals suffering from either osteoporosis or osteopenia were recruited to join the "McMaster and Ryerson University Strontium in Bone Research Study" to be regularly monitored over a prolong period of time (minimum 1 year), while taking strontium supplements of their choice. The goal was to recruit and measure individuals who did not have any prior history of strontium supplementation or strontium based treatments. Thus, an initial 
participant, subject \#1 was recruited to join this research study through her bone specialist. However, to recruit additional participants, an amendment was made to both the McMaster University (REB \# 07-402) and Ryerson University (REB \# 2007-212-1) Research Ethics Board approved application to allow for media recruitment of participants in addition to physician referrals.

Two categories of individuals were therefore recruited. The first category includes baseline individuals, who were the individuals that have no prior intake of strontium supplements or strontium based treatments. The advantage with these individuals was that the measurement of their natural strontium levels have been obtained prior to starting administration of strontium supplements, followed by the next bone strontium measurement $24 \mathrm{hr}$ after their very first intake of strontium supplements. This would give information on strontium uptake by bone that may not otherwise be obtained with individuals who have already taken strontium. The second categories of individuals were those who already had a history of strontium supplementation and were continuing to take strontium based salts. Due to their prior history of strontium supplementation, therefore, no baseline measurements of their natural bone strontium levels were obtained.

A total of 18 volunteers were recruited. Of this total, 9 were classified as the baseline subjects and 9 were the second category subjects. In this chapter, the results of the baseline subjects are reported, followed by the individual results of subject \#1, whom was the first baseline subject to be recruited and thus followed the longest for over a year. In the next chapter, the second category of subjects is examined. However it should be noted that DEXA measurements were not planned in this study, due to lack of resources. Table 3-2 profiles the 
baseline subjects recruited, for the bone strontium baseline study.

\begin{tabular}{|llll|}
\hline Gender & Age & Diagnosis & $\begin{array}{l}\text { Supplement Dosage } \\
\text { (Strontium Citrate) }\end{array}$ \\
\hline $\begin{array}{l}\text { Female } \\
\text { (Subject \#1) }\end{array}$ & 68 & Osteoporosis(Spine) & $682 \mathrm{mg} /$ day \\
\hline $\begin{array}{l}\text { Female } \\
\text { (Subject \#2) }\end{array}$ & 72 & Osteoporosis(Spine) & $341 \mathrm{mg} /$ day \\
\hline $\begin{array}{l}\text { Female } \\
\text { (Subject \#3) }\end{array}$ & 66 & $\begin{array}{l}\text { Osteoporosis (Spine) } \\
\text { Osteopenia (Hip) }\end{array}$ & $341 \mathrm{mg} /$ day \\
\hline $\begin{array}{l}\text { Female } \\
\text { (Subject \#4) }\end{array}$ & 75 & $\begin{array}{l}\text { Osteoporosis (Spine) } \\
\text { Osteoporosis (Hip) }\end{array}$ & $341 \mathrm{mg} /$ day \\
\hline $\begin{array}{l}\text { Female } \\
\text { (South American) } \\
\text { (Subject \#5) }\end{array}$ & 67 & Osteopenia (Hip) & $341 \mathrm{mg} /$ day \\
\hline $\begin{array}{l}\text { Female } \\
\text { (Subject \#6) }\end{array}$ & 57 & Osteopenia (Spine) & $341 \mathrm{mg} /$ day \\
\hline $\begin{array}{l}\text { Female } \\
\text { (Subject \#7) }\end{array}$ & 74 & Osteopenia (Spine) & $341 \mathrm{mg} /$ day \\
\hline $\begin{array}{l}\text { Female } \\
\text { (Subject \#8) }\end{array}$ & 53 & $\begin{array}{l}\text { Osteoporosis (Spine) } \\
\text { Osteopenia (Hip) }\end{array}$ & $341 \mathrm{mg} /$ day \\
\hline $\begin{array}{l}\text { Female } \\
\text { (Subject \#9) }\end{array}$ & 63 & $\begin{array}{l}\text { Osteopenia } \\
\text { (Spine and Hip) }\end{array}$ & $341 \mathrm{mg} /$ day \\
\hline
\end{tabular}

Table 3-2: Profile of Baseline Subjects Recruited. Note that all baseline individuals are females. All are Caucasian with the exception of one who is South American. The median age of recruitants is 66 years old.

Of the individuals recruited, all expressed concern about the progression of their bone disease and their interest in trying strontium supplements as an alternative and preventive therapy.

Of the 18 volunteers recruited, only three indicated a family history of osteoporosis. The 
remaining volunteers were unsure of their family history, as their parents, born in the early 1900's were not tested for bone disease. All the individuals recruited for this study had at least one risk factor. The most common risk factor among the participants was being fair skinned and having a small thin body frame.

\subsubsection{Results of the Bone Strontium Baseline Study of Individuals Taking Strontium}

\section{Supplements}

Tables 3-3 and 3-4 summarize the bone strontium levels for all baseline subjects according to three characteristic points: natural strontium baseline, at $24 \mathrm{hrs}$ after the first strontium intake, and at the time of rapid increase of bone strontium. A sample result of one individual (subject \#2) who has been measured for approximately five months, is shown in figure 3-6 (A) and (B). The remaining results of the baseline subjects may be seen in Appendix I. 

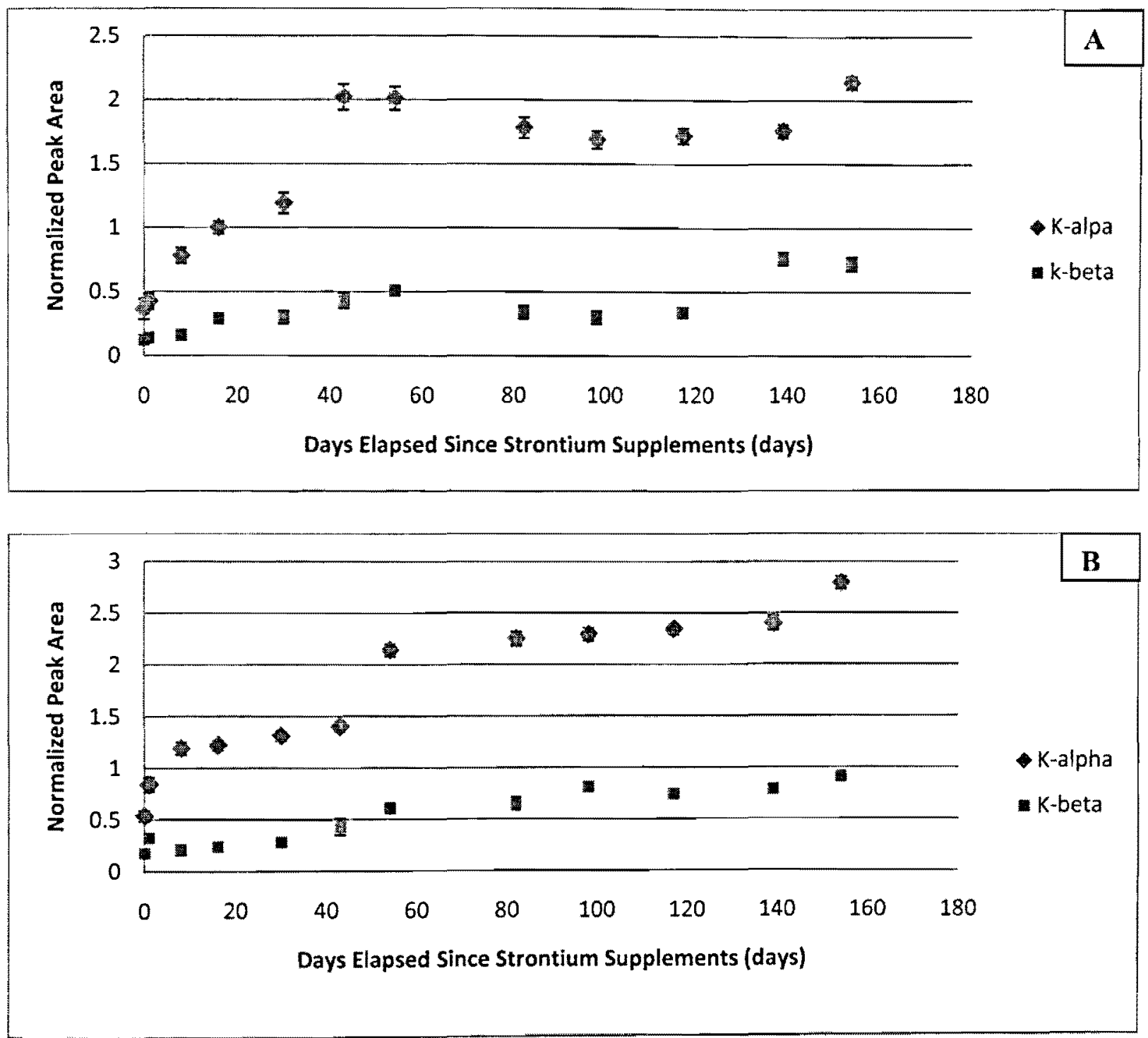

Figure 3-6: Strontium Measurement over Time of Baseline Subject \#2 in A) Finger and B) Ankle. The subject is a $72 \mathrm{yr}$ old female, diagnosed with osteoporosis. Day zero represents the baseline measurement of subject's natural bone strontium level prior to strontium supplementation. Errors are associated with the statistical uncertainty. 


\begin{tabular}{|ccccccc|}
\hline Subject \# & Baseline & Ratio & 24 hrs & Ratio & $\begin{array}{c}\text { Second } \\
\text { Increase } \\
\text { (in days) }\end{array}$ & Ratio \\
\hline $\mathbf{1}$ & $0.35 \pm 0.05$ & $2.1 \pm 0.7$ & $0.62 \pm 0.14$ & $2.9 \pm 1.3$ & $\begin{array}{c}68 \mathrm{~d} \\
1.70 \pm 0.11\end{array}$ & $4.4 \pm 0.2$ \\
\hline $\mathbf{2}$ & $0.36 \pm 0.08$ & $3.0 \pm 1.0$ & $0.42 \pm 0.04$ & $3.1 \pm 0.9$ & $\begin{array}{c}43 \mathrm{~d} \\
2.02 \pm 0.10\end{array}$ & $4.7 \pm 0.7$ \\
\hline $\mathbf{3}$ & $0.34 \pm 0.06$ & $3.4 \pm 0.5$ & $0.49 \pm 0.02$ & $3.4 \pm 1.9$ & $\begin{array}{c}96 \mathrm{~d} \\
1.29 \pm 0.05\end{array}$ & $5.7 \pm 0.2$ \\
\hline $\mathbf{4}$ & $0.35 \pm 0.05$ & $2.3 \pm 0.7$ & $0.62 \pm 0.11$ & $2.4 \pm 0.7$ & $\begin{array}{c}58 \mathrm{~d} \\
1.37 \pm 0.05\end{array}$ & $4.9 \pm 0.3$ \\
\hline $\mathbf{5}$ & $0.41 \pm 0.05$ & $2.3 \pm 0.4$ & $0.53 \pm 0.03$ & $2.5 \pm 0.5$ & $\begin{array}{c}42 \mathrm{~d} \\
1.06 \pm 0.09\end{array}$ & $4.6 \pm 0.3$ \\
\hline $\mathbf{6}$ & $0.45 \pm 0.05$ & $3.5 \pm 0.6$ & $0.70 \pm 0.05$ & $4.6 \pm 1.0$ & $\begin{array}{c}34 \mathrm{~d} \\
2.10 \pm 0.11\end{array}$ & $5.9 \pm 0.6$ \\
\hline $\mathbf{7}$ & $0.38 \pm 0.07$ & $2.6 \pm 0.5$ & $0.52 \pm 0.03$ & $2.8 \pm 0.6$ & $\begin{array}{c}122 \mathrm{~d} \\
1.79 \pm 0.08\end{array}$ & $4.2 \pm 0.3$ \\
\hline $\mathbf{8}$ & $0.36 \pm 0.08$ & $3.0 \pm 1.0$ & $0.66 \pm 0.04$ & $3.3 \pm 0.8$ & $\begin{array}{c}74 \mathrm{~d} \\
1.07 \pm 0.05\end{array}$ & $4.7 \pm 0.8$ \\
\hline $\mathbf{9}$ & $0.39 \pm 0.05$ & $2.4 \pm 0.4$ & $0.61 \pm 0.03$ & $2.5 \pm 0.3$ & $\begin{array}{c}113 \mathrm{~d} \\
1.93 \pm 0.10\end{array}$ & $5.2 \pm 0.2$ \\
\hline Average & $0.38 \pm 0.06$ & $2.7 \pm 0.6$ & $0.57 \pm 0.04$ & $3.1 \pm 0.8$ & $\begin{array}{c}(72 \pm 11) \mathrm{d} \\
4.9 \pm 0.6\end{array}$ \\
\hline
\end{tabular}

Table 3-3: Summary of Strontium K-alpha Levels in Finger (Cortical Bone) at Major Points of Interest for All Baseline Subjects (including initial baseline subject \#1). The ratio refers to the strontium $k$-alpha to $k$-beta peak ratio. The error represents statistical uncertainty in the measurement. 


\begin{tabular}{|ccccccc|}
\hline Subject & Baseline & Ratio & $\mathbf{2 4}$ hrs & Ratio & $\begin{array}{c}\text { Second } \\
\text { Increase } \\
\text { (in days) }\end{array}$ & Ratio \\
\hline $\mathbf{1}$ & $0.39 \pm 0.10$ & $2.3 \pm 0.7$ & $0.45 \pm 0.12$ & $2.9 \pm 1.0$ & $\begin{array}{c}141 \mathrm{~d} \\
2.91 \pm 0.09\end{array}$ & $4.4 \pm 0.3$ \\
\hline $\mathbf{2}$ & $0.54 \pm 0.05$ & $2.9 \pm 0.6$ & $0.84 \pm 0.07$ & $3.0 \pm 1.0$ & $\begin{array}{c}54 \mathrm{~d} \\
2.14 \pm 0.06\end{array}$ & $3.5 \pm 0.3$ \\
\hline $\mathbf{3}$ & $0.36 \pm 0.08$ & $3.0 \pm 1.0$ & $0.58 \pm 0.04$ & $5.4 \pm 2.0$ & $\begin{array}{c}110 \mathrm{~d} \\
1.75 \pm 0.04\end{array}$ & $4.8 \pm 0.3$ \\
\hline $\mathbf{4}$ & $0.33 \pm 0.06$ & $3.3 \pm 0.7$ & $0.69 \pm 0.06$ & $3.4 \pm 0.6$ & $\begin{array}{c}72 \mathrm{~d} \\
1.52 \pm 0.05\end{array}$ & $5.5 \pm 0.7$ \\
\hline $\mathbf{5}$ & $0.44 \pm 0.05$ & $2.3 \pm 0.4$ & $0.74 \pm 0.09$ & $2.5 \pm 0.5$ & $\begin{array}{c}38 \mathrm{~d} \\
1.39 \pm 0.06\end{array}$ & $3.6 \pm 0.2$ \\
\hline $\mathbf{6}$ & $0.41 \pm 0.06$ & $3.5 \pm 0.7$ & $0.68 \pm 0.04$ & $4.6 \pm 1.0$ & $\begin{array}{c}34 \mathrm{~d} \\
2.10 \pm 0.11\end{array}$ & $3.8 \pm 1.0$ \\
\hline $\mathbf{7}$ & $0.40 \pm 0.08$ & $2.6 \pm 0.5$ & $0.69 \pm 0.03$ & $2.8 \pm 0.6$ & $\begin{array}{c}108 \mathrm{~d} \\
1.82 \pm 0.09\end{array}$ & $4.6 \pm 0.5$ \\
\hline $\mathbf{8}$ & $0.39 \pm 0.08$ & $3.0 \pm 1.0$ & $0.76 \pm 0.06$ & $3.3 \pm 0.8$ & $\begin{array}{c}88 \mathrm{~d} \\
1.05 \pm 0.09\end{array}$ & $4.9 \pm 0.4$ \\
\hline $\mathbf{9}$ & $0.37 \pm 0.07$ & $2.5 \pm 0.4$ & $0.84 \pm 0.05$ & $3.5 \pm 0.3$ & $\begin{array}{c}99 \mathrm{~d} \\
2.23 \pm 0.13\end{array}$ & $5.9 \pm 0.3$ \\
\hline Average & $0.41 \pm 0.13$ & $2.8 \pm 0.7$ & $0.69 \pm 0.05$ & $3.5 \pm 0.5$ & $\begin{array}{c}(83 \pm 12) \mathrm{d} \\
1.94 \pm 0.10\end{array}$ & $4.6 \pm 0.3$ \\
\hline & & & & & & \\
\hline & & & & & & \\
\hline
\end{tabular}

Table 3-4: Summary of Strontium Levels in the Ankle (Trabecular Bone) at Major Points of Interest for All Baseline Subjects (including initial baseline subject \#1). The ratio refers to the strontium $\mathrm{k}$-alpha to k-beta peak ratio. The error represents statistical uncertainty in the measurement.

\subsubsection{Discussion of the Bone Strontium Baseline Study Individuals Taking Strontium}

\section{Supplements}

The average percentage increase after the $24 \mathrm{hr}$ of first intake of strontium supplementation was $63.2 \%$ in the ankle bone, whereas in the finger bone the average percent increase was 
$47.6 \%$. This indicates that the uptake of strontium is more rapid by trabecular bone, perhaps due to the larger surface area and blood flow, allowing for exchange of strontium atoms for calcium at the bone surface. When the average natural baseline strontium is compared to the average value of strontium in the Caucasian, healthy individuals of the pilot (the control group, table 3-1) done in 2006 , it is seen that the results (tables 3-3 and 3-4) agree within uncertainty and are not statistically different (two sample t-test, $\mathrm{p}=0.31$ and $\mathrm{p}=0.48$ for the finger and ankle, respectively). However, after $24 \mathrm{hrs}$ of the first strontium intake, strontium levels are higher at the ankle bone site compared to day $0(\mathrm{p}=0.033)$ but may not suggest a statistical difference for the finger bone site $(\mathrm{p}=0.058)$. Furthermore, the average ankle bone strontium level was higher (table 3-6) compared to the Caucasian control group (two sample t-test, $\mathrm{p}=0.004$ ), suggesting that strontium is deposited where the bone turnover rate is greatest.

As discussed earlier in this chapter, the strontium k-alpha to k-beta ratio may be used as an indication to determine strontium depth distribution in bone. The probability of emission for a strontium k-alpha photon is 7 times larger than the probability of emission for a k-beta photon; however, if it is assumed that strontium is homogeneously distributed in cortical bone, the kalpha to k-beta ratio is expected to be 5.2 or larger. If the k-alpha to k-beta ratio is smaller than 5.2, this implies non-uniform strontium distribution in bone (Zamburlini et al., 2007b). However, the ratio results included in tables 3-5 and 3-6 show that at the baseline and $24 \mathrm{hr}$ time points, the $\mathrm{k}$-alpha to $\mathrm{k}$-beta ratio was smaller than the expected ratio of 5.2. Zamburlini (2008) reported kalpha to k-beta ratios among the Caucasian individuals who participated in the 2006 pilot study 
to be $2.9 \pm 0.7$ and $2.7 \pm 1.0$, for the finger and ankle bone, respectively. Similarly, Heirwegh (2008) found the k-alpha to k-beta ratio on intact cadaver fingers to be between 2.6 and 3.2 , after the soft tissue correction.

The ratios in tables 3-3 and 3-4 suggest that as individuals self-supplement strontium, the kalpha and $\mathrm{k}$-beta ratios are increased in comparison to baseline ratios. In finger, the average $\mathrm{k}$ alpha to k-beta ratio of $(3.1 \pm 0.8)$ and in ankle of $(3.5 \pm 0.5)$ was obtained. These two ratios are significantly higher ( $p=0.027$ and $p=0.033$, for the finger and ankle, respectively) at day 0 . The average ratio at the natural bone strontium levels in the finger and ankle was found to be (2.8 \pm 0.6$)$ and (2.8 \pm 0.7$)$. Thus, the baseline ratio in the 9 individuals participating in this study agrees within uncertainty to the two ratios reported by our research group.

At the time of rapid bone strontium increase, the average ratio increased to $(4.8 \pm 0.6)$ and (4.6 \pm 0.3 ), suggesting change in the strontium depth distribution on bone. This observation is in agreement within uncertainty, with the results reported by Heirwegh (2008), who found the average ratio of $(5.52 \pm 0.62)$ and $(5.24 \pm 0.15)$ for the finger and ankle, respectively, in two individuals on strontium supplements. Thus, it may be concluded that strontium is initially deposited on the outer bone surface. However, further investigation in the ratio values obtained for the individuals over time, is required to fully address this observation and investigate whether this ratio may be used to indicate bone health.

Dahl and colleagues (2001) report that other factors, in addition to gender and age, have been identified to influence strontium incorporation into bone. These factors include strontium dose, plasma strontium level, skeletal site and the duration of treatment. In terms of dosage, it is expected that the strontium content in bone increases with administered dose and at higher dose 
levels, as observed by Dahl and colleagues (2001) in animal studies, strontium content tends to reach a plateau level. This is likely due to saturation of the GI absorption mechanism. The second factor, plasma strontium levels relate to the amount of strontium in blood available for exchange at bone surfaces (Dahl et al., 2001). Strontium incorporation is expected to be higher in trabecular bone than in cortical bone due to higher bone turnover and higher regional blood flow. The last factor, the duration of treatment, influences the strontium made available in the body, such that once strontium supplementation is discontinued, plasma strontium levels, and hence bone strontium levels should decrease.

\subsection{Time Dependant Incorporation of Strontium in Bone: Initial Individual}

\section{Baseline Case Study}

Subject \#1, the initial baseline subject recruited joined this study in December 2008 and was followed for more than a year. She was diagnosed with severe osteoporosis of her lumbar spine, having a $\mathrm{T}$ score of -3.2 , as classified using the WHO classification system as discussed in chapter one. Her hip, however, classified as normal, with a corresponding T-score of -0.9. After having taking the prescribed bone medication, Fosamax, for several years, subject \#1 decided to try an alternative therapy. Subject \#1 had read about the promising effects of strontium supplements on bone mineral density and the beneficial effects in reducing osteoporotic symptoms; therefore she decided to self-supplement strontium citrate under the direction of her bone specialist. Though, the studies published to date have all looked at the administration of 
strontium ranelate, it is not known whether other strontium salts, such as strontium citrate and strontium carbonate, will exert any or similar outcomes on bone as strontium ranelate does. Subject 1 was recruited to join the study prior to starting the strontium citrate, therefore, a baseline reading of her natural bone strontium levels was obtained. This reading was obtained in December 2008 and was recorded as Day 0. Following this first bone strontium measurement, she started taking strontium supplements in January 2009. She self-administered two strontium citrate pills, each of $341 \mathrm{mg}$ for a daily dose of $682 \mathrm{mg}$ per day, and currently continues to do so. The next bone strontium measurement was performed $24 \mathrm{hrs}$ after the first strontium supplement dose. She was then followed twice a week, for four weeks, progressing to once a week over the next second month and then once every two weeks for four months, and currently monthly. Each measurement was performed in the morning, with her last dose taken the morning the day before. The parameters and conditions used to measure all subject \#l's bone strontium levels were the same as for all human measurements meaning thirty minute measurements of her finger and ankle were taken (see section 3.2). Figures 3-7 (A) and (B) show subject \#1's bone strontium levels at the finger and ankle bone sites, respectively. The normalized peak area refers to strontium either $\mathrm{k}$-alpha or $\mathrm{k}$-beta $\mathrm{x}$-ray peaks after the coherent normalization is applied. 

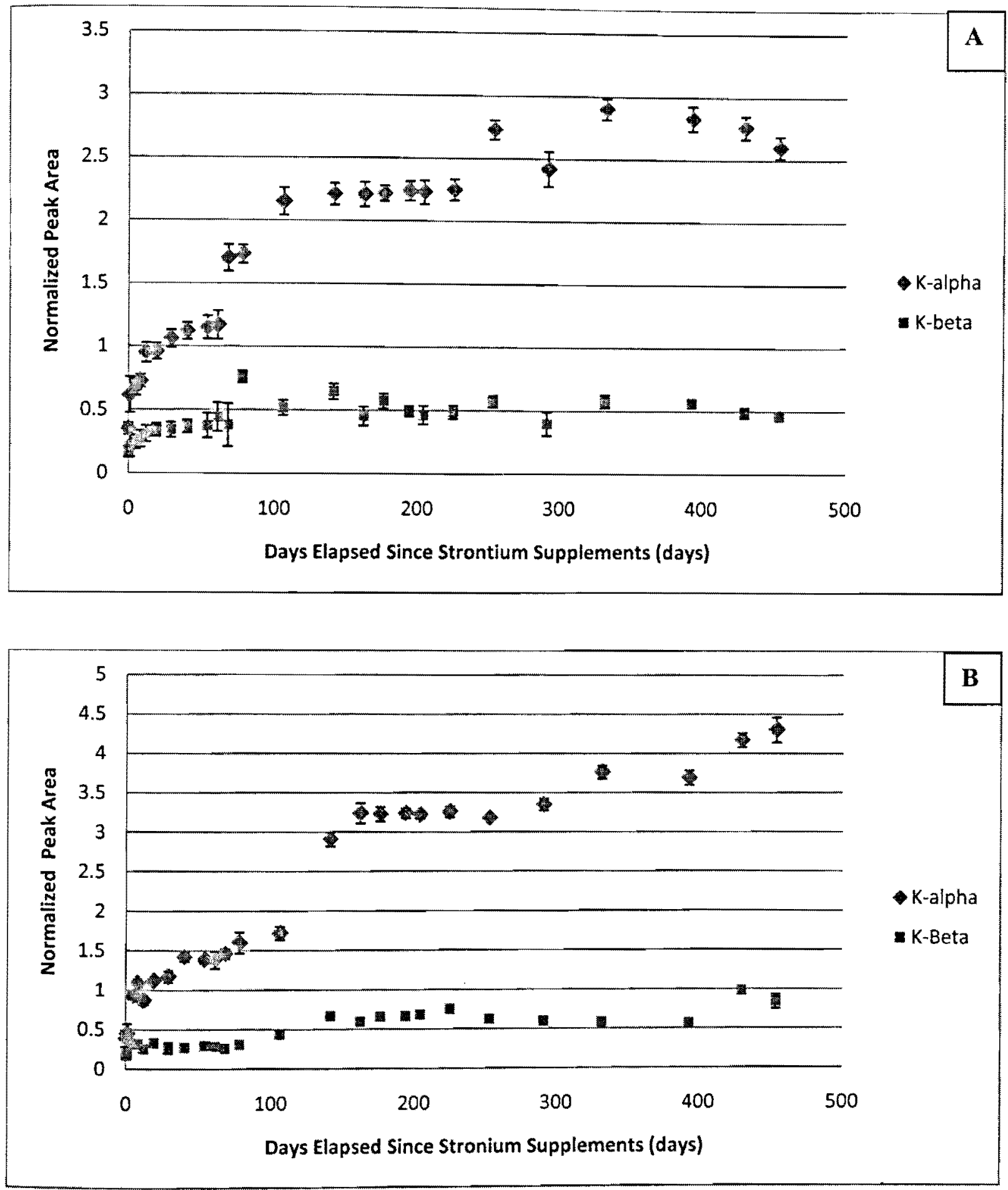

Figure 3-7: Baseline Case Study \#1 Strontium Measurement over Time in A) Finger and B) Ankle. The subject is a 68 yr old Caucasian female, diagnosed with Osteoporosis. Day zero represents the baseline measurement of natural, pre-treatment bone strontium levels. Errors are associated with the statistical uncertainty. 
The bone strontium levels of subject \#1 show that ankle (trabecular bone) shows a higher strontium level than (cortical bone), which is in agreement with published observations. A paired $t$-test on subject \#1's results after the first intake of strontium supplements at 24 hrs was performed to determine whether the bone strontium levels at the two sites were still different. The result of the test shows that the bone strontium level between the ankle and finger are statistically different $(p=0.011)$. However, if subject \#1's natural bone strontium levels at (Day 0 ) were compared to the natural bone strontium levels observed in Caucasians of the twenty-two individuals in the 2006 study, the results indicate no statistical difference between the two bone sites ( $\mathrm{p}=0.52$ and $\mathrm{p}=0.37$ for the finger and ankle, respectively). This important conclusion disagrees with the statement that natural bone strontium levels (measured at the hip) are lower in osteoporotic individuals compared to healthy individuals (Bayan et al.,2009).

More interesting is the pattern of strontium incorporation that is observed at both the finger and ankle sites. During the first few weeks of strontium supplementation, the strontium levels continue to increase slowly until the 141 th day, when there is a significant increase in the bone strontium levels at both bone sites. Another significant increase is seen after the $330^{\text {th }}$ day, with the increase being more pronounced in ankle (trabecular bone). However, while it may seem that strontium levels plateau after a certain time period; after the third month in the finger and fifth month in the ankle, additional measurements taken after this plateau time indicate bone strontium levels continue to rise, with the effect more pronounced in the ankle bone (trabecular bone). In his observation of a strontium supplementing individual, Heirwegh (2008), suggested strontium bone levels reached a plateau after two and six months in the finger and ankle respectively. Continuing measurement of subject $\# 1$, indicate that her most recent $454^{\text {th }}$ day 
measurement have shown another increase of bone strontium levels in ankle (trabecular bone) but finger levels decreased slightly. On the $450^{\text {th }}$ day, subject \#1's strontium k-alpha signal was $(4.28 \pm 0.16)$ in ankle and $(2.63 \pm 0.088)$ in finger. Compared to the control Caucasian individuals of the twenty two subjects, subject \#1's bone strontium level is eleven times higher in ankle and six times higher in finger. If her finger and ankle bone strontium levels are compared to the natural bone strontium levels that were measured on day 0 , they are seven and eleven times higher, respectively (paired $t$-test, $\mathrm{p}=0.0124$ and $\mathrm{p}=0.0084$ ). Strontium increases bone mineral density (Neuprez et al., 2008), and the increase in bone mineral density is observed in subject \#1's most recent bone mineral density test (November, 2009). The spine T-score reported a percentage increase of $4.17 \%$, compared to the previous measurement (October 2008). However, an increase was not reported in the hip bone. This bone mineral density result is consistent with the observation of increased spine bone mineral density readings and reduced vertebral fractures, in the European trials involving administration of strontium ranelate to osteoporotic women (Neuprez et al., 2008).

\subsection{Mechanisms of Strontium Uptake}

The observed baseline results suggest that strontium uptake in an individual, after the very first strontium supplement, is higher in trabecular bone $(\mathrm{p}=0.027)$ compared to cortical bone $(0.69 \pm 0.05)$ versus $(0.57 \pm 0.04)$. Bärenholdt et al, report that strontium uptake into bone is likely to vary from one individual to another, and the uptake of strontium is a result of several factors that include intestinal absorption, bone turnover, and excretion from the body, which all considerably vary between individuals. Interestingly, a rapid increase in bone strontium levels in 
the baseline individuals has been observed to occur at $(72 \pm 11)$ days and $(83 \pm 12)$ days in finger and ankle, respectively. Given that it takes approximately 120 days for a single bone remodeling cycle to be completed (Marie, P.J, 2006a), this likely suggests the strontium incorporation in bone is influenced by the bone remodeling cycle. The variance in the kinetics of bone strontium uptake is expected as it depends on the stage of the bone remodeling cycle at the time of treatment. The pattern observed in the baseline individuals suggests that strontium is initially slowly incorporated into bone until a rapid uptake of strontium occurs coincident with the bone remodeling cycle. In-vivo studies involving strontium ranelate, strontium exerts its action on the bone remodeling cycle by uncoupling bone turnover in favor of bone formation by both stimulating bone formation and decreasing bone resorption (Marie, P.J, 2006b), as illustrated in Figure 3-8.

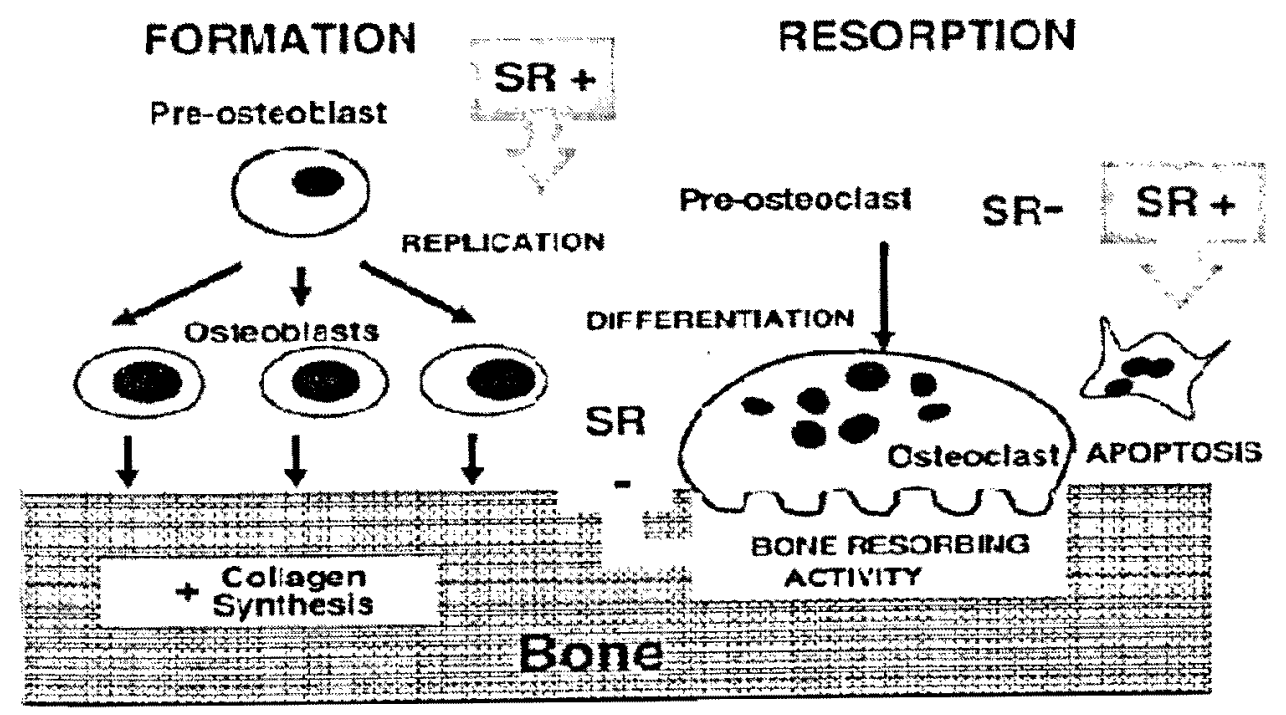

Figure 3-8: Incorporation of Strontium and its Influence in the Bone Remodeling Cycle. The plus $(+)$ and minus $(-)$ sign indicates activation or inhibition by strontium on the corresponding stage (Marie PJ, 2006). 
the baseline individuals has been observed to occur at (72 \pm 11$)$ days and $(83 \pm 12)$ days in finger and ankle, respectively. Given that it takes apprcximately 120 days for a single bone remodeling cycle to be completed (Marie, P.J, 2006a), this likely suggests the strontium incorporation in bone is influenced by the bone remodeling cycle. The variance in the kinetics of bone strontium uptake is expected as it depends on the stage of the bone remodeling cycle at the time of treatment. The pattern observed in the baseline individuals suggests that strontium is initially slowly incorporated into bone until a rapid uptake of strontium occurs coincident with the bone remodeling cycle. In-vivo studies involving strontium ranelate, strontium exerts its action on the bone remodeling cycle by uncoupling bone turnover in favor of bone formation by both stimulating bone formation and decreasing bone resorption (Marie, P.J, 2006b), as illustrated in Figure 3-8.

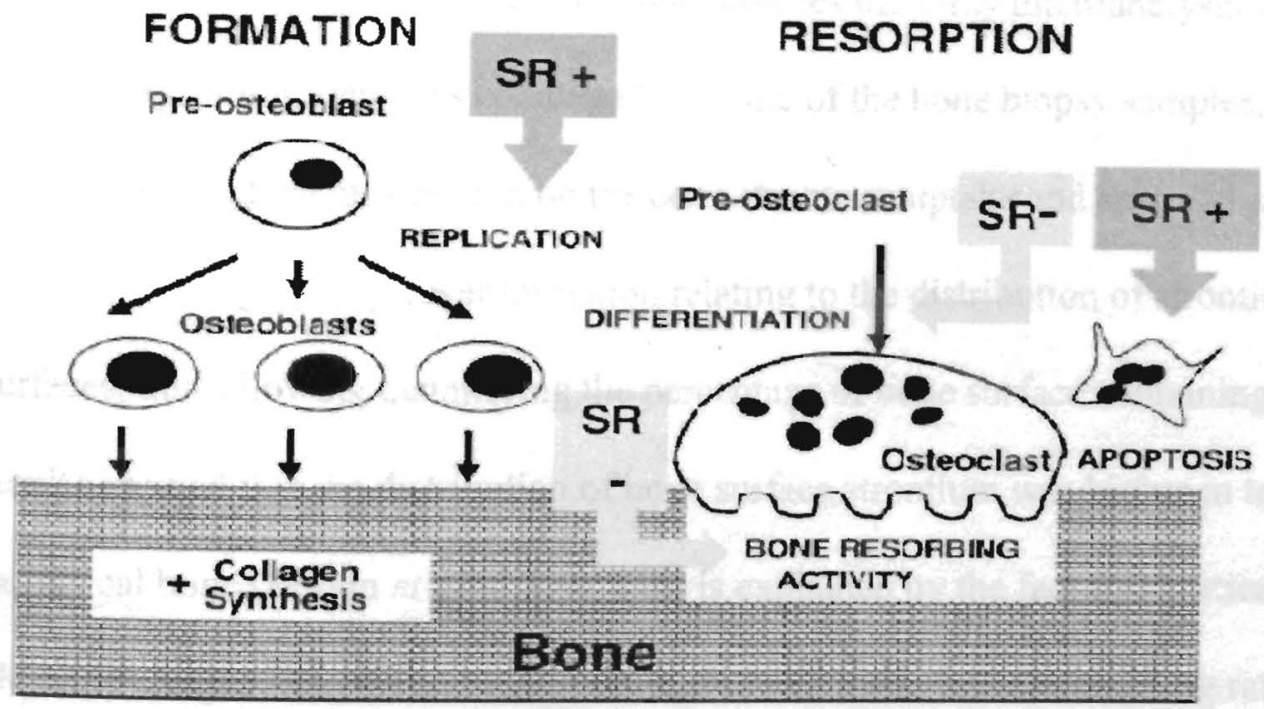

Figure 3-8: Incorporation of Strontium and its Influence in the Bone Remodeling Cycle. The plus (+) and minus (-) sign indicates activation or inhibition by strontium on the corresponding stage (Marie PJ, 2006). 
Hence, as strontium increases osteoblastic activity and decreases resorption, it is then expected to increase the bone mineral density by increasing the bone thickness. However, strontium is likely only to be deposited in new bone, as the study by Boivin and colleagues (2009) suggests based on the lack of strontium deposition in old interstitial bone. The incorporation of strontium into the bone matrix initially takes place mainly by exchange at the crystal surface (Dahl et al., 2001). This mechanism is an initial rapid mode, which depends on osteoblastic activity, that eventually is saturated and whereby strontium is taken up by ionic exchange with bone calcium, binding of strontium to preosteoid proteins, or a combination of these.

Boivin and colleagues (2009), investigated the interaction between strontium and bone mineral and its effect on mineralization in osteoporotic women treated with strontium ranelate. The iliac bone biopsy samples of post-menopausal osteoporotic women, treated with strontium ranelate for three years, participating in phases II and III of the SOTI and TROPOS trials were obtained (Boivin et al., 2009). On all bone biopsies the $\mathrm{x}$-ray microanalysis was performed, while $\mathrm{x}$-ray cartography was conducted on some of the bone biopsy samples. The X-ray microanalysis gives information on the bone strontium uptake and spatial distribution, whereas the X-ray cartography gives information relating to the distribution of strontium on the sample surfaces, thus allowing quantifying the percentage of bone surface containing strontium. The results showed that the distribution of bone surface strontium was higher in trabecular bone than in cortical bone (Boivin et al., 2009). This is explained by the fact that cortical bone is richer in old bone compared to the trabecular bone, due to a lower bone remodeling rate. This observation agrees with the findings seen in this study, in which the ankle (trabecular bone) showed higher strontium levels. Furthermore, in the bone biopsy of the same individual, at 2 and 36 months of 
strontium ranelate treatment, the cartography of strontium in bone showed that the number of new bone structural units (BSU) containing strontium was higher after 36 months than after two months of treatment (Boivin et al., 2009). The percentage of bone surfaces containing strontium varied over time with a mean of $2.2 \%$ after two months and $37 \%$ after 36 months (Boivin et al., 2009). The strontium was observed in osteons and packets formed during treatment reflected the bone surfaces involved in the bone remodeling process. However, they reported that old interstitial bone did not contain strontium, and it was seen only in newly formed bone. Thus, the degree of bone mineralization is influenced by the activity of the bone remodeling cycle on which strontium theoretically exerts its positive actions.

Correlating these findings and the suggested mechanism of strontium uptake, based on Boivin and colleagues (2009) work, a higher bone strontium concentration is expected to be measured just after two months of strontium supplementation, followed by further increases after 36 months. Relating this finding to the baseline individuals measured in this work, it is expected then that the baseline individuals' strontium levels will continue to increase, even after two years. If this is the case, hypothetically, the baseline individuals' strontium bone levels should continue to exhibit an increase even after a year, while taking strontium supplements. This is observed only in subject \#1's results in which a second increase in her ankle bone strontium levels is seen by the $454^{\text {th }}$ day. Taking into account that a bone remodeling cycle takes approximately 120 days to complete, this increase is expected to occur within every three to four months. However, if this is the case, one question that arises is whether bone strontium levels will continue to increase indefinitely or will they at some point in time plateau. As will be seen in the next chapter, there have been various conflicting time frames, suggested in both animal 
and human studies, for when bone strontium levels are seen to plateau. Given that the baseline subjects in this study, have shown significant increase in bone strontium levels within $60-150$ days, it can be suggested, that strontium citrate could have similar mechanism of action as strontium ranelate on bone.

The suggested mechanism of strontium uptake by Marie and colleagues (2006b) and Boivin and colleagues (2009), provide an explanation of increased bone mineral density that has been observed in other individuals on strontium ranelate. In a Taiwanese study by Twang and colleagues (2008), involving 125 post-menopausal osteoporotic women, given either 2 grams of strontium ranelate or a placebo, it was found that the strontium ranelate group exhibited a significant change in bone mineral density at 6 and 12 months in the lumbar spine, femoral neck and total hip compared to the placebo group. Furthermore, two serum bone markers, bonespecific alkaline phospatase (BSAP) and C-telopeptide cross-links (CTX) were also analyzed using a chemiluminescence immunoradiometric assay and an electrochemiluminiscence immunoassay. These two serum bone markers are an indication of bone turnover activity. Results of the bone serum marker analysis showed an increase of both markers at 6 and 12 months indicating formation of new bone. Mean plasma strontium levels were also monitored at the 6 and 12 month mark. Twang and colleagues (2008) noted that their observation was consistent with the SOTI and TROPOS trials, reporting significant bone mineral density differences between the placebo and strontium supplementing individuals. According to these studies, the increase in bone mineral density is attributed to the effect strontium ranelate has on the bone remodeling cycle and formation of new bone. Since the Taiwanese and European studies did not measure bone mineral density changes regularly, but at two fixed points of 6 and 
12 months, it is uncertain whether the bone mineral density increases may have been observed earlier in the treatment. Thus, the lack of data between the 6 and 12 month period in their study, does not explain how strontium is incorporated into bone over time. An increase in bone mineral density value is likely to correspond to an increase in bone strontium levels. Kendler and colleagues (2008), state that the greater increases in bone mineral density are in part due to combined anti-catabolic and bone anabolic effects of strontium ranelate and in part due to higher atomic number of strontium in bone compared to calcium. However, the issue of strontium having a higher mass atomic number than calcium is an important artifact and thus a limit of dual energy $\mathrm{x}$-ray absorptiometry (DEXA), which is further discussed in chapter four. In conclusion, the baseline study using the IVXRF system discussed in this chapter presented unique insight into bone strontium incorporation, in terms of monitoring strontium bone levels, non-invasively, over a time that has not yet been reported in literature work to date.

\subsection{Bone Strontium Levels in African Subject Measured with the IVXRF}

\section{System}

Unlike the initial human studies in which only Asian and Caucasian individuals were measured, using this IVXRF system, in this work, for the first time, an African black male's bone strontium levels were measured. The male individual, visiting scholar from Nairobi, Kenya, was a healthy male, without known bone disease, who has never taken any strontium supplements, nor any strontium based drugs. Furthermore, this individual stated having a diet rich in vegetables and grains. Bone strontium measurements were done at the finger and ankle sites and the soft tissue thicknesses at these sites were determined by the $10 \mathrm{MHz}$ mobile 
ultrasound. His finger and ankle bone strontium levels are given in Table 3-5.

FINGER

ANKLE

\begin{tabular}{|l|l|l|l|l|}
\hline & $\begin{array}{c}\text { Normalized } \\
\text { Strontium } \mathbf{K}_{\boldsymbol{\alpha}} \\
\text { Peak Signal }\end{array}$ & $\begin{array}{c}\text { Normalized } \\
\text { Strontium } \mathbf{K}_{\boldsymbol{\beta}} \\
\text { Peak Signal }\end{array}$ & $\begin{array}{c}\text { Normalized } \\
\text { Strontium } \mathbf{K}_{\boldsymbol{\alpha}} \\
\text { Peak Signal }\end{array}$ & $\begin{array}{c}\text { Normalized } \\
\text { Strontium } \mathbf{K}_{\boldsymbol{\beta}} \\
\text { Peak Signal }\end{array}$ \\
\hline African & $1.93 \pm 0.08$ & $0.39 \pm 0.04$ & $2.15 \pm 0.53$ & $0.78 \pm 0.09$ \\
\hline
\end{tabular}

Table 3-5: Normalized Strontium Peak Values for African Male Subject. The error is associated with statistical uncertainty in measurement.

Comparing this result to the results from the individuals who participated in the 2006 human study (Table 3-1), it is interesting to note that this subject shows much higher levels than the Asian individuals (assuming unequal variances, $p<0.001$ and $p=0.022$ for the finger and ankle, respectively). Compared to the Asian and Caucasian individuals, at the finger, the African male's strontium k-alpha levels are 1.87 and 4.48 times higher, respectively. Similarly, the ankle, the African male's k-alpha strontium levels were 1.97 and 5.38 times higher compared to the Asian and Caucasian subjects, respectively.

The higher bone strontium signal observed in the African male could be partially explained by his race, place of origin and diet. In particular, high Rubidium/Strontium concentration (ppm) ratios $(\sim 0.1$ to 0.8$)$ have been found in xenolithic alkaline rocks from Kenya (Heumann and Davies, 2002). In another study, bone samples from one human and from species such as fauna and wild and domesticated animals were collected near a waterhole, located in a desert area north and east of Lake Turkana, close to the Ethiopian border and analyzed for bone strontium concentration. The results of strontium (ppm) in bone ash, showed human bone to have $827 \mathrm{ppm}$ 
(Price, 2006), which is about 8 times higher than the median human average of $110 \mathrm{ppm}$ and $100 \mathrm{ppm}$ for vertebral and rib bone respectively (Clayton, 2007). Thus, in addition to genetics, race, geographical location and dietary habits could play a role in strontium levels, as discussed in chapter one, in which higher strontium levels were seen in individuals living in Turkey. However, this intriguing result needs more attention in the future in order to make any conclusive statements. 


\section{Chapter 4 Strontium Retention}

\subsection{Long Term Strontium Retention in Human Bone}

In the previous chapter, baseline measurements of strontium levels in bone was discussed and it was observed that after $24 \mathrm{hrs}$ after the first intake of strontium supplementation, strontium bone levels increased by $47.6 \%$ in the finger and $63.2 \%$ in the ankle. Continued measurements showed that strontium levels continued to increase slowly until within the next two to five months, when a significant increase was seen at both sites. This increase was attributed to the bone remodeling cycle and thus, further significant increases are expected to be seen within the next two to five months, as seen in chapter three for subject \#1. However, the question that arises is whether strontium levels will continue to increase over time or whether strontium levels will eventually plateau at some point in time. When strontium levels plateau, this is likely due to the saturation of the gastrointestinal absorption mechanism (Dahl et al., 2001), which is not yet fully understood.

In both animal and human studies involving strontium chloride or strontium ranelate administration, different time frames for when strontium levels appear to have plateaued are given. These times range from as short as four weeks in animal studies (Dahl et al., 2001), to as long as three years in human studies (Neuprez et al., 2008, Hwang et al.,2009, Cortet, 2009 and Boivin $e$ al.,2009). These studies used methods such as bone biopsies of the iliac crest, X-ray cartography and serum biomarker analysis to determine bone strontium levels and corresponding time of plateau. 
Boivin and colleagues (2009), obtained transiliac bone biopsies of osteoporotic women who were enrolled in phases two and three of the STRATOS, SOTI and TROPOS studies. The STRATOS study, which lasted for two years, involved three groups of osteoporotic women receiving various doses of strontium ranelate, in addition to a placebo group. Strontium ranelate doses ranged from $0.5,1$ and $2 \mathrm{~g}$ per day, and about six to eight biopsies were obtained per group. For the SOTI and TROPOS, phase three trials, strontium ranelate was given in $2 \mathrm{~g}$ per day and treatment lasted for three years. Fifteen biopsies were taken from this group and the placebo group. The bone biopsies were analyzed by X-ray microanalysis for bone strontium uptake and focal distribution and by quantitative micro radiography for degree of mineralization. X-ray cartography was also performed on some samples for strontium distribution on bone surface. They found that global bone strontium content reached a plateau after three years of treatment with strontium ranelate and that the strontium deposition depended on the dose with higher focal content in new bone structural units than old ones. However, using this data, Cortet (2009), concluded that bone strontium levels plateau after two years. Even though slightly higher strontium bone values were obtained after three years, the difference was not significant. Figure 4-1, taken from Boivin and colleague (2009), illustrates their finding. 


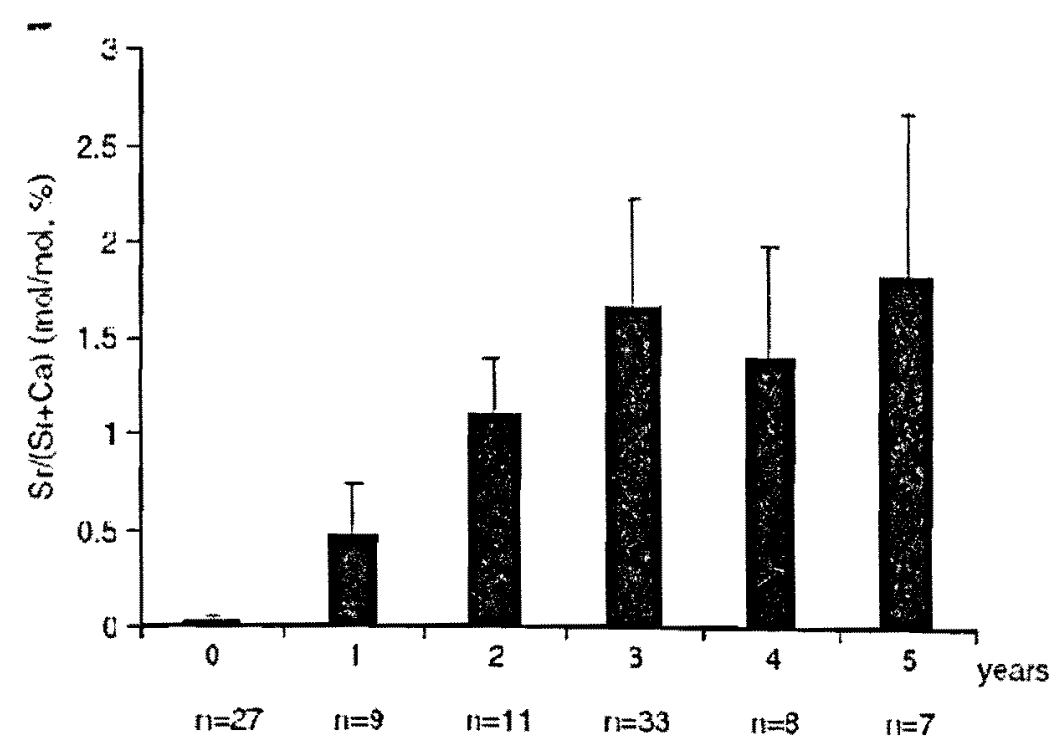

Figure 4-1: Global Bone Strontium Content over Time in Post- Menopausal Women Administrated with Strontium Ranelate Medication. Note that the authors express the global bone strontium content as the total (cortical+trabecular). The number, $n$, represents the number of bone samples.

Furthermore to the observation that global bone strontium content plateau within 2-3 years, Boivin and colleagues (2009), observed that strontium was taken up by bone tissue, but heterogeneously distributed and exclusively present in bone during treatment. The strontium content was always higher in trabecular bone $(44 \pm 5 \%)$ than in cortical bone $(29 \pm 6 \%)$. Boivin and colleagues (2009) explained this result due to the fact that cortical bone is richer in old bone than trabecular bone due to a decreased remodeling rate (Boivin et al.,2009).

Although the SOTI, TROPOS and STRATOS studies focused on strontium ranelate administration to post-menopausal osteoporotic women (Neuprez et al., 2008), one question is whether similar results would have been seen in male osteoporotic individuals. Dahl and colleagues (2001) reported that oral administration of strontium ranelate in female rats showed lower bone strontium contents than their male counterparts. The higher strontium concentrations 
in the male rats were attributed to differences in the gastrointestinal absorption of strontium between the male and female rats. However, they also observed that in cynomolgus monkeys, that this difference was less pronounced. Nevertheless, they reported that there has been no evidence of a similar gender difference in humans and suggest that gender will not have an influence in strontium incorporation and retention in human bone. This remains to be investigated further.

Considering Dahl and colleague's (2001) five factors that determine the kinetics of strontium incorporation, as discussed in the previous chapter, the first part of this work involving baseline subject measurements with the IVXRF system to determine whether the skeletal site influenced strontium uptake. The focus of the work reported in this chapter has been on investigating the retention of strontium in human bone using the IVXRF system.

\subsection{Initial Retention Study using the IVXRF System}

After the initial pilot study results of the twenty two subjects showed that the IVXRF system was sensitive to determine bone strontium levels in various individuals, Zamburlini and colleagues (2006) measured strontium supplementing individuals with the IVXRF system, as discussed in chapter three (figure 3-5) which further confirmed the sensitivity of the IVXRF system and the observation that strontium levels were higher in strontium supplementing individuals. This was followed by Heirwegh (2008) who measured a strontium supplementing individual on four different occasions for 6.5 months.

Using approval from the McMaster University (REB \# 04-702) and Ryerson University (REB \# 2007-12) Research Ethics Board to conduct human bone strontium measurements, 
Heirwegh (2008), in April 2008, recruited a self-supplementing individual, whom is referred to as Subject \#10, based on a referral from a bone specialist. The procedure Heirwegh used to measure the strontium supplementing individual, was based on the same IVXRF system set-up as earlier described in this work. However, the soft tissue thicknesses for the finger and ankle bone sites were determined using the resources of the McMaster-Mohawk Health Sciences Centre. A certified ultrasonographer used a $12 \mathrm{MHz}$ ultrasound to acquire the finger and ankle bone images. Subject \#10 was diagnosed with osteoporosis of the spine and hip and was selfsupplementing with three strontium citrate tablets of $227 \mathrm{mg}$ daily and first started taking strontium supplements in October of 2007. Subject \#10 reported that she occasionally missed her daily dose and was about $70 \%$ regular in her habitual intake. After the first initial measurement of subject \#10 in April, subject $\# 10$ was measured her three more times in early May, early June and late October of 2008. However, in between subject \#10's June and October measurement, she reported that she had stopped taking strontium citrate completely in mid-August, due to a medical procedure, and thus the October measurement, she was off her strontium supplements by approximately over two months. 
Subject \#10's finger and ankle bone strontium levels are shown in Figures 4-2(A) and (B).

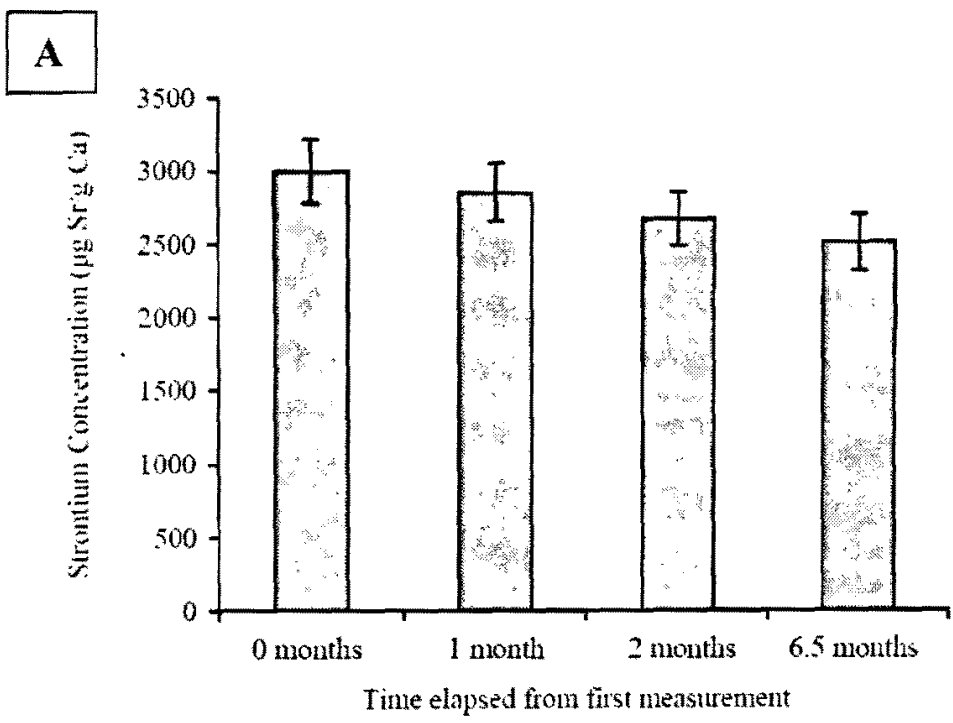

B

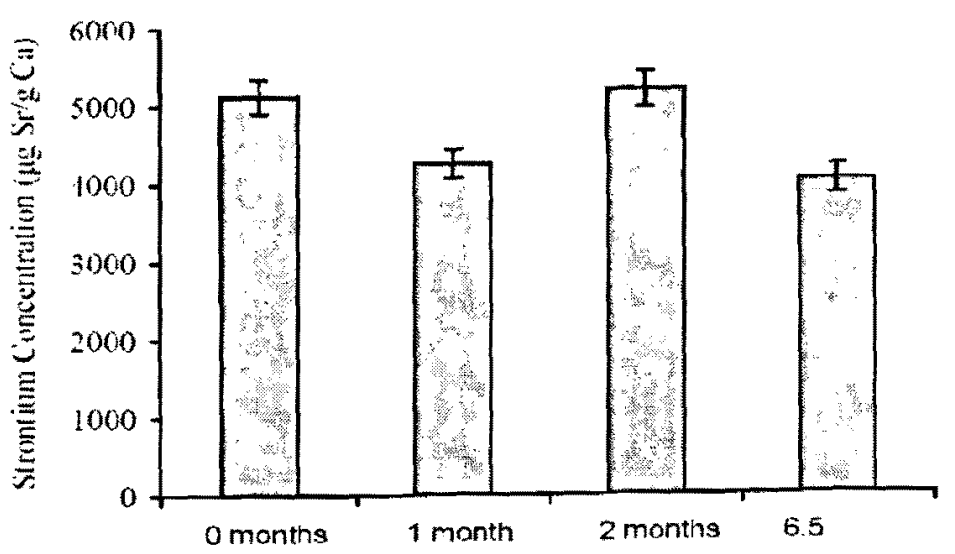

Time elapsed after medication period began

Figure 4-2: Subject \#10's strontium levels in A) Finger (Cortical bone) and B) Ankle (Trabecular bone) six months after strontium supplementation. Note that strontium concentration is reported as arbitrary units and is proportional to the strontium signal observed. The error represents the uncertainty associated with the measurement (Heirwegh, 2008) 
Subject \#10's finger and ankle bone strontium levels are shown in Figures 4-2(A) and (B).

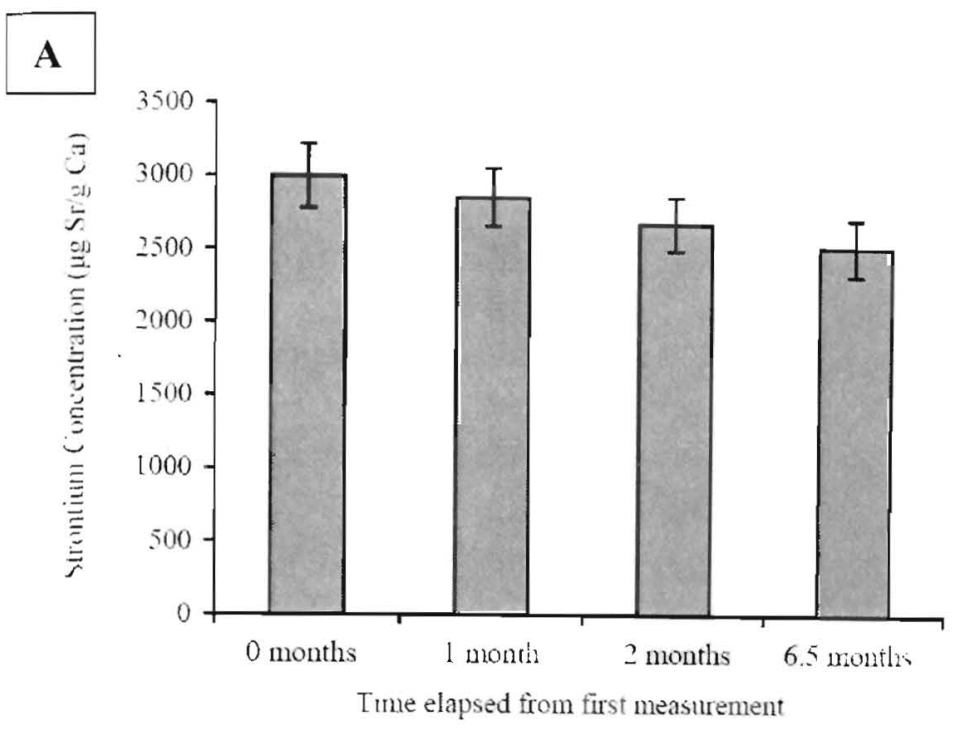

B

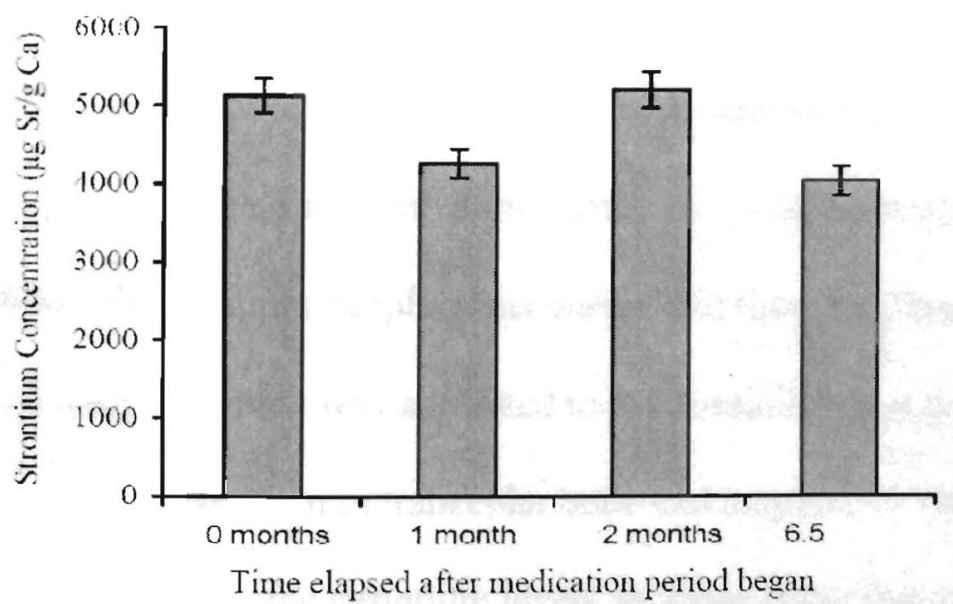

Figure 4-2: Subject \#10's strontium levels in A) Finger (Cortical bone) and B) Ankle (Trabecular bone) six months after strontium supplementation. Note that strontium concentration is reported as arbitrary units and is proportional to the strontium signal observed. The error represents the uncertainty associated with the measurement (Heirwegh, 2008) 
Thus, Heirwegh (2008) observed that subject \#10's cortical and trabecular bone levels, in comparison with the average Caucasian population from the twenty two subjects of the pilot study in 2006 , were $(4.4 \pm 0.8)$ and $(7.4 \pm 1.6)$ times greater, with the assumption that strontium is evenly distributed in trabecular and cortical bone of the population. Furthermore, it is suggested subject \#10's strontium levels have reached a plateau or are marginally beginning to decrease, taking into account the uncertainty for each measurement. Thus, subject \#10's bone strontium levels were believed to already plateau at the time of her first measurement, which occurred six months after the strontium citrate administration period had started. The same conclusion was suggested for her ankle bone measurements. As illustrated in Figure 4-3, Heirwegh reported that her strontium measurement in the ankle appeared similar to that of the first visit. However, he also noted that the second measurement showed a decrease to which he attributed to an error in the measurement, since subject $\# 10$ confirmed she continued to take her strontium supplements regularly. The fourth measurement, at 6.5 months was a result of her discontinuing the strontium supplements two months prior to the measurement. Comparing this last measurement with the finger bone measurement at the same time point, he suggested that despite subject \#10 having been off strontium supplements during that time, her finger bone strontium level remained unchanged, which was attributed to the possibility that the strontium clearance from cortical bone is slower than in trabecular bone and may not be visible until several months afterwards. In the ankle bone, the strontium levels decrease faster due to the fact that ankle is predominantly trabecular bone and receives a greater blood flow, thereby accelerating the exchange of ions at the bone surface. Likewise, to the finger bone measurement, it is also suggested that the strontium levels in the ankle were already at a plateau at the time of the first 
measurement. Thus, based on this case study of one individual it seemed that bone strontium levels would reach a plateau at both bone sites by six months or less.

Since only three measurements were acquired while subject \#10 was taking strontium supplements, there was not enough information to conclude that her levels have already reached a plateau. This preliminary hypothesis is not consistent with the findings observed in the baseline individuals measured with the same IVXRF system (chapter three, section 3.4). For example, if subject \#1's baseline results from the previous chapter is compared in this manner using only four measurements within the same time frame (i.e six months after strontium supplementation has started), then the same conclusion that subject \#1's bone strontium levels have already reached a plateau could be incorrectly arrived at. This is illustrated in figures 4-3 and 4-5 using subject \#1's results, in which this time frame is highlighted. It is also interesting to note here that subject \#1 and subject \#10, at the time of measurements were both taking $681 \mathrm{mg}$ of strontium citrate per day and both are osteoporotic. 


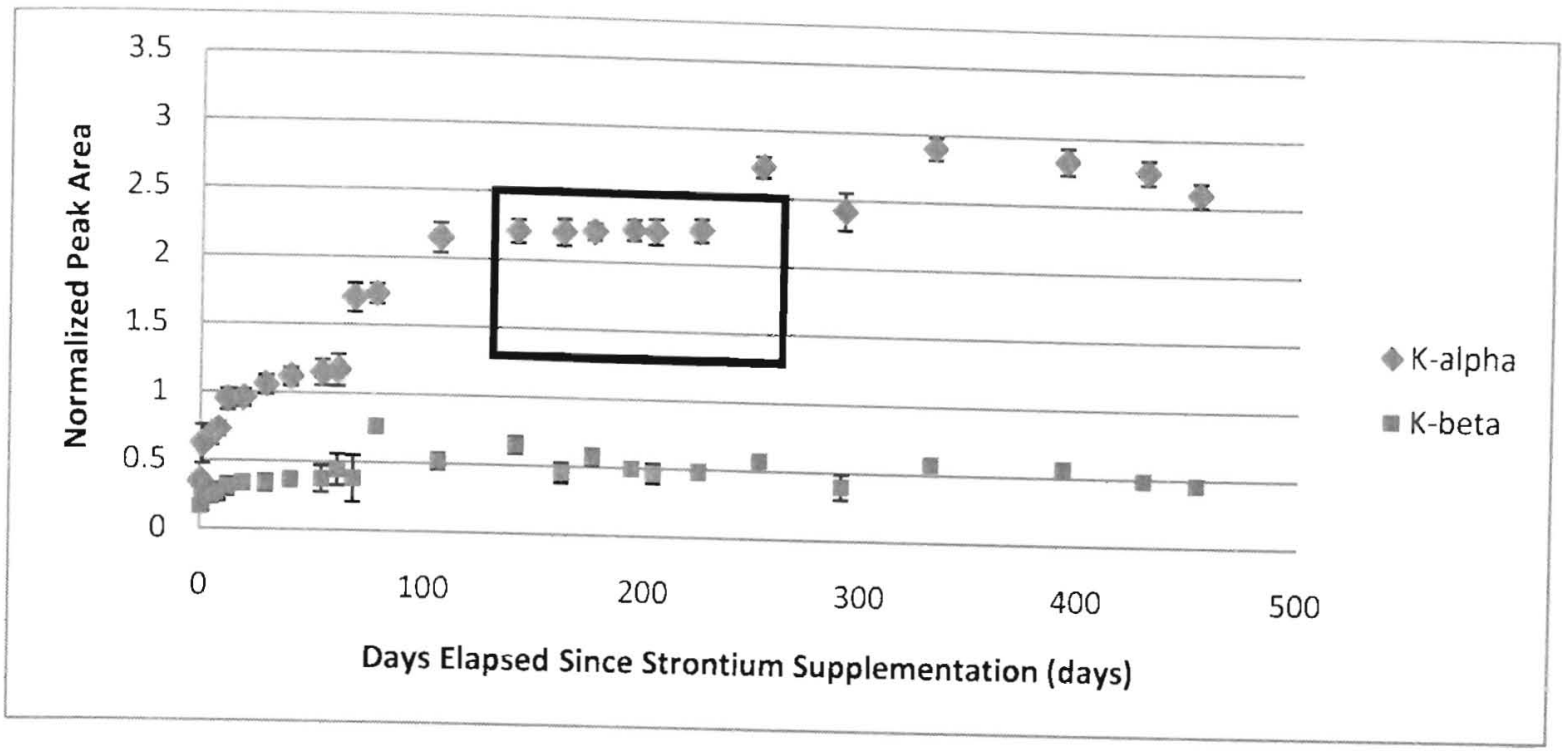

Figure 4-3: Subject \#1's Strontium Levels in the Finger Bone (Cortical bone). Note that normalized strontium peak area is proportional to the strontium signal observed. The error is associated with statistical uncertainty.

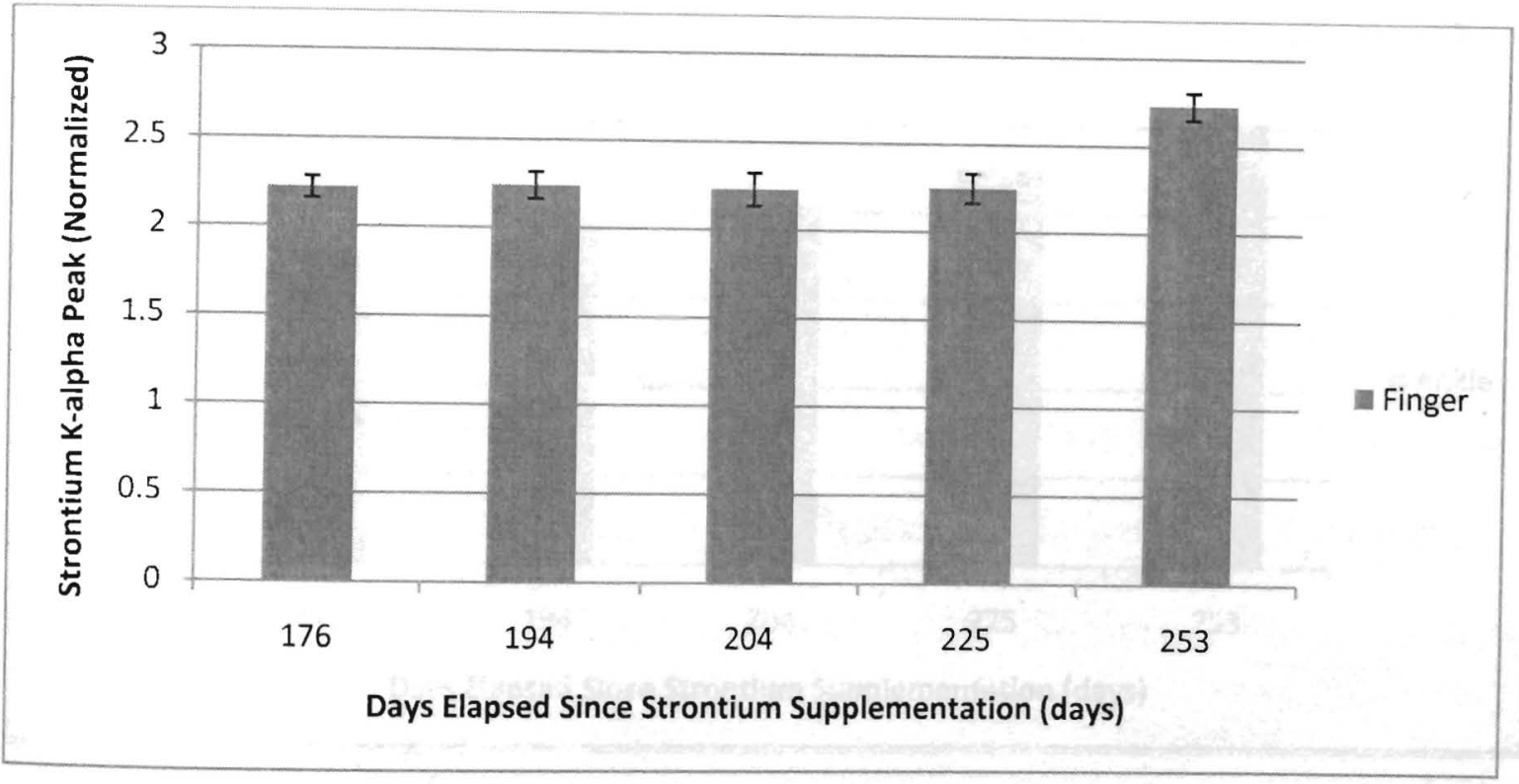

Figure 4-4: Highlighted Subject \#1's Strontium Levels in the Finger Bone (Cortical bone). Note that normalized strontium peak area is proportional to the strontium signal observed. The error is associated with statistical uncertainty. 


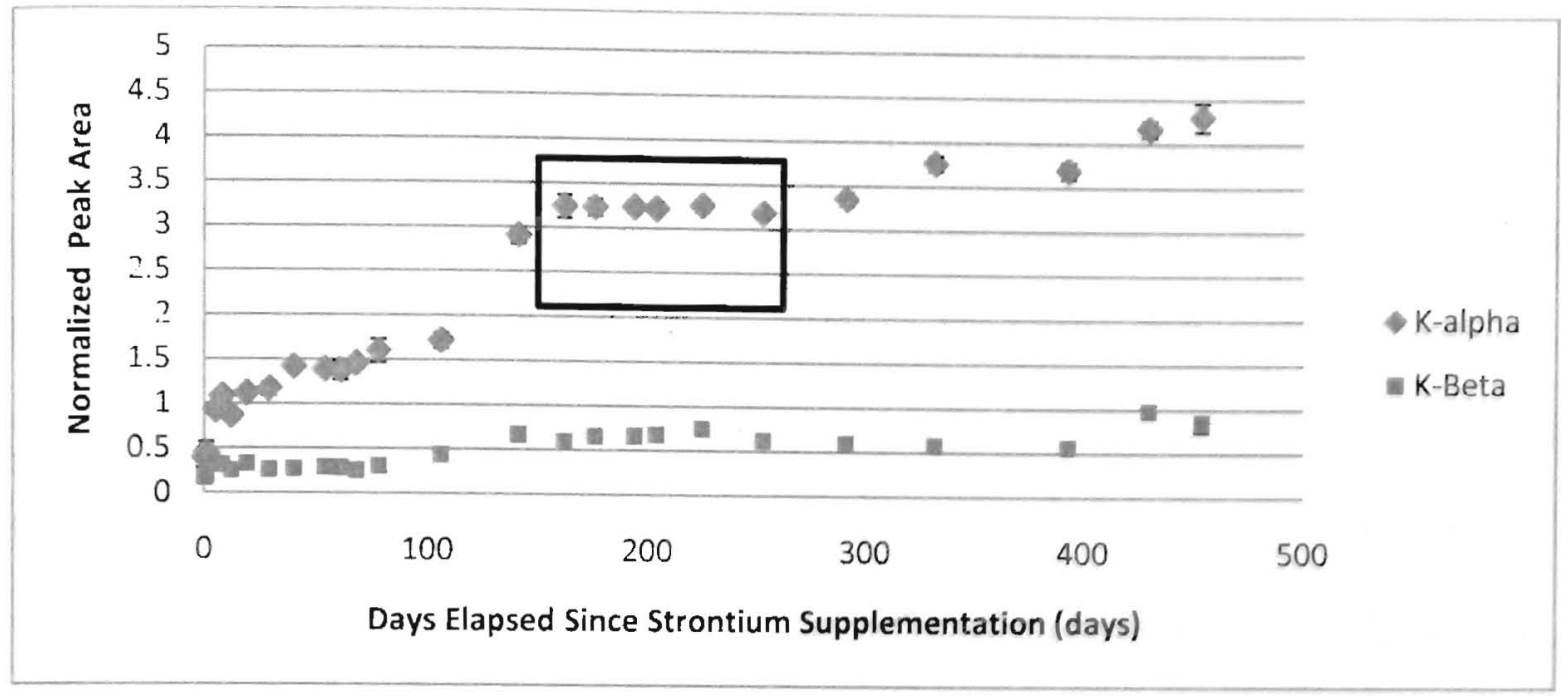

Figure 4-5: Subject \#1's Strontium Levels in the Ankle Bone (Trabecular bone). Note that normalized strontium peak area is proportional to the strontium signal observed. The Error is associated with statistical uncertainty.

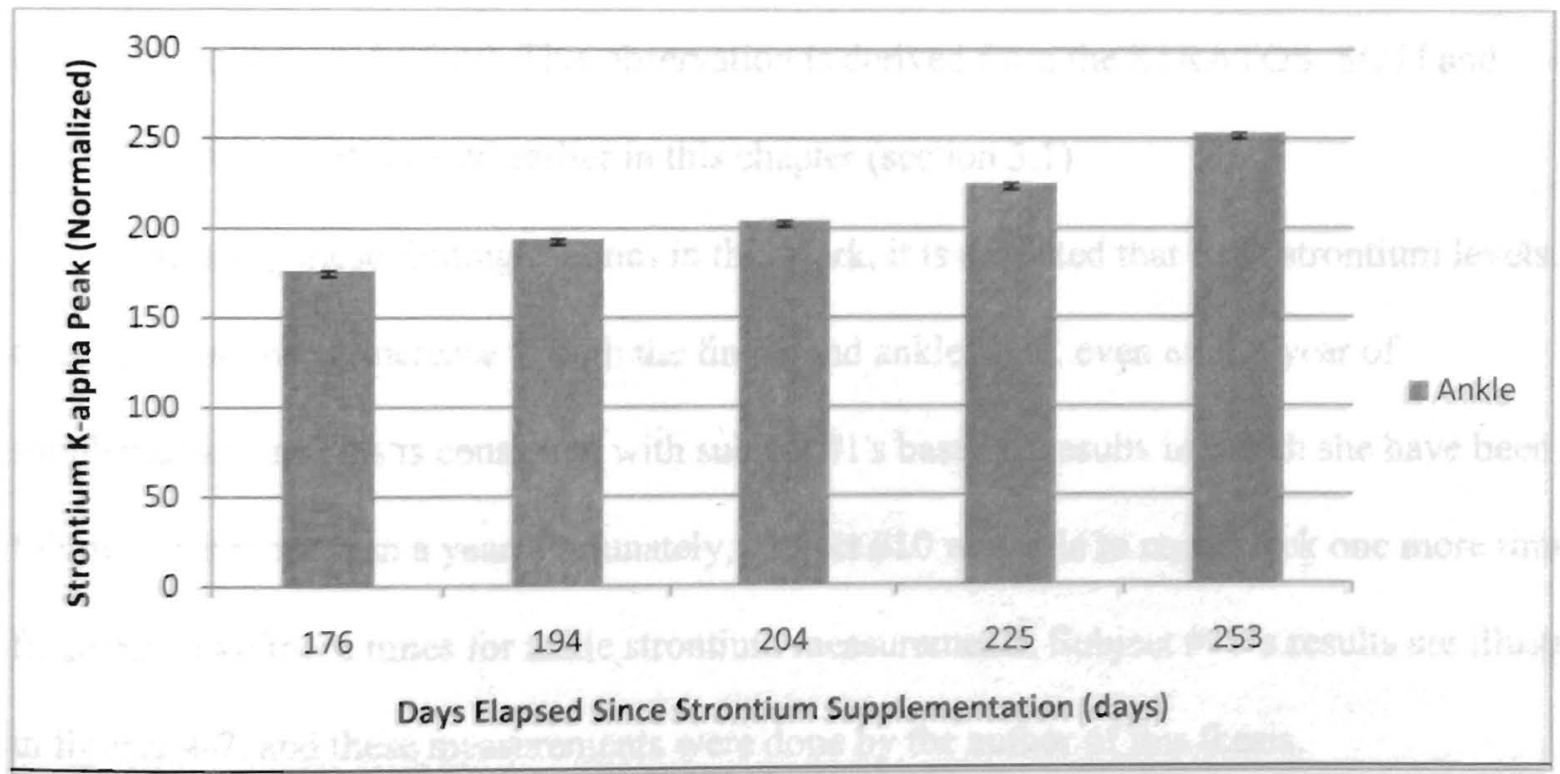

Figure 4-6: Highlighted Subject \#1's Strontium Levels in the Ankle Bone (Cortical bone). Note that normalized strontium peak area is proportional to the strontium signal observed. The error is associated with statistical uncertainty. 
However, further measurements indicate that this is not the case, as there is a further increase of bone strontium at approximately 253 and 332 days in finger and ankle, respectively.

Unfortunately, whether this same pattern would have been observed in subject \#10's case could not be determined, as the disadvantage here was that subject \#10 had discontinued taking strontium supplements by her fourth visit, so whether a further increase would have been seen after her fourth visit remains unknown. Thus, it seems that Heirwegh's suggestion of bone strontium levels having already reached a plateau are based on insufficient data. Though he suggests that it is in agreement with Dahl and colleagues' (2001), observation of three to four weeks, in male cynomolgus monkies, it is in disagreement with the human studies of osteoporotic women involving strontium ranelate administration, at which the time taken for strontium levels to plateau in bone was 36 months or three years (Neuprez et al, 2009, Cortet, 2009 and Boivin et al, 2009). This observation is derived from the STRATOS, SOTI and TROPOS trials, as discussed earlier in this chapter (section 3.1).

Comparing these findings to ones in this work, it is expected that bone strontium levels will continue to show an increase in both the finger and ankle bone, even after a year of supplementation. This is consistent with subject \#1's baseline results in which she have been followed for more than a year. Fortunately, subject $\# 10$ was able to come back one more time for finger and two more times for ankle strontium measurements. Subject \#10's results are illustrated in figures 4-7, and these measurements were done by the author of this thesis. 

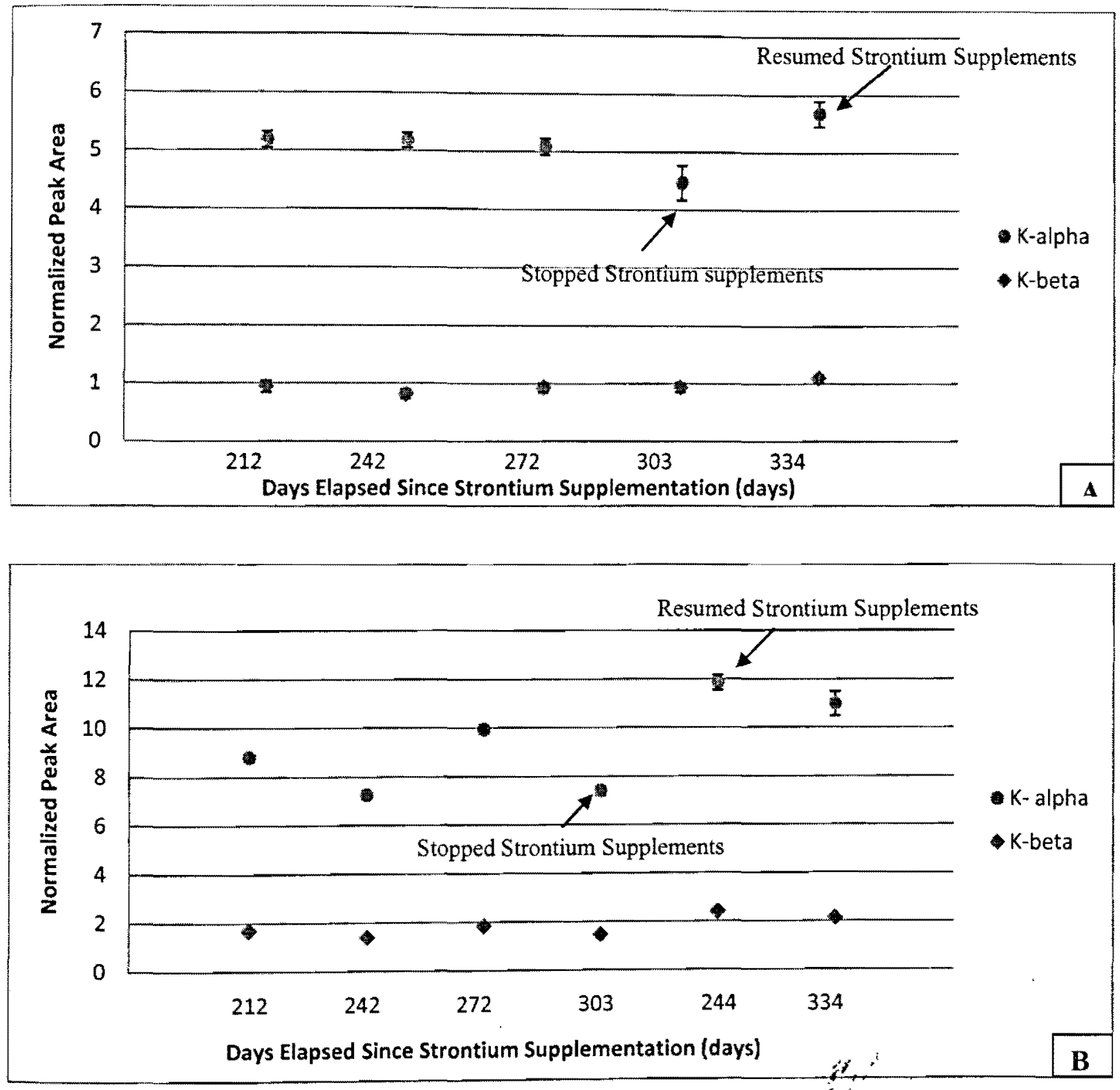

Figure 4-7: Subject \#10's Bone Strontium Measurements in A) the Finger and B) the Ankle. Note that normalized strontium peak area is proportional to the strontium signal observed. The error is associated with statistical uncertainty. 
It is interesting to see that her strontium levels have increased significantly from the fourth measurement obtained by Heirwegh. On 240 days, the fifth measurement indicates the time that she had resumed taking strontium supplementation between the fourth and fifth visit. As of the fifth visit, she had resumed strontium citrate supplements for approximately eight months. An increase in strontium levels of $27.1 \%$ in her finger and $60.2 \%$ in her ankle was observed. This is a remarkable increase after resuming strontium supplementation, indicating that strontium is quickly taken up by trabecular bone compared to cortical bone even when higher amounts of this element are already present in bone. Unfortunately, no earlier measurements could be obtained to determine whether there were any other previous increases. However, since she has went by occasionally for a week without taking strontium supplements and has been taking her strontium supplements on and off, her results are difficult to compare with other individuals. However, it does demonstrate the sensitivity of the IVXRF system to determine the changes in bone strontium levels over time. These changes also agree with the observation that strontium level uptake are influenced by the dosage and duration of time (Dahl et al., 2001), which is discussed further in this chapter. To help investigate strontium levels retention in bone over time, in addition, to subject $\# 10$, other subjects were also measured. These subjects, as briefly outlined in chapter three, are the second category, meaning that a baseline measurement of their natural strontium levels could not be obtained at the time of recruitment, as they already had a prior history of strontium based supplementation or were already taking strontium supplements. 


\subsection{Human Bone Strontium Retention Measurements}

As outlined in chapter three (section 3.5), once an amendment to recruit participants outside of physicians' offices was requested and approved (McMaster University REB \# 07-402 and Ryerson University REB \# 2007-212-1) from the Research Ethics Board at Ryerson and McMaster University, participants were recruited to be measured on a biweekly or monthly basis at McMaster University. The subjects were measured with the IVXRF system in the same manner as the baseline subjects (section 3. 2) and their profile are shown in Table 4-1.

\begin{tabular}{|llll|}
\hline Gender & Age & Diagnosis & $\begin{array}{l}\text { Supplement Dosage } \\
\text { (Strontium Citrate) }\end{array}$ \\
\hline $\begin{array}{l}\text { Male } \\
\text { (Subject \#11) }\end{array}$ & 61 & $\begin{array}{l}\text { Osteopenia (Spine, } \\
\text { Neck and Hip) }\end{array}$ & $\begin{array}{l}341 \mathrm{mg} / \text { day, reduced } \\
\text { to } 341 \mathrm{mg} / \text { thrice } \\
\text { weekly }\end{array}$ \\
\hline $\begin{array}{l}\text { Male } \\
\text { (Subject \#12) }\end{array}$ & 82 & Osteopenia (Hip) & $\begin{array}{l}682 \mathrm{mg} / \text { day reduced to } \\
341 \mathrm{mg} / \text { day }\end{array}$ \\
\hline $\begin{array}{l}\text { Female } \\
\text { (Subject \#13) }\end{array}$ & 79 & $\begin{array}{l}\text { Osteoporosis (Spine) } \\
\text { Osteopenia (Hip) }\end{array}$ & $\begin{array}{l}682 \mathrm{mg} / \text { day reduced to } \\
341 \mathrm{mg} / \text { day }\end{array}$ \\
\hline $\begin{array}{l}\text { Female } \\
\text { (Subject \#14) }\end{array}$ & 53 & Osteoporosis (Spine) & $341 \mathrm{mg} /$ day \\
\hline $\begin{array}{l}\text { Female } \\
\text { (Subject \#15) }\end{array}$ & 51 & Osteopenia (Spine) & $341 \mathrm{mg} /$ day \\
\hline $\begin{array}{l}\text { Female } \\
\text { (Subject \#16) }\end{array}$ & 55 & Osteopenia (Spine) & $341 \mathrm{mg} /$ day \\
\hline $\begin{array}{l}\text { Female } \\
\text { (Subject \#17) }\end{array}$ & 69 & Osteopenia(Hip) & $341 \mathrm{mg} /$ day to \\
\hline $\begin{array}{l}\text { Female } \\
\text { (Subject \#18) }\end{array}$ & 72 & Osteopenia (Hip) & $341 \mathrm{mg} /$ day \\
\hline $\begin{array}{l}\text { Female } \\
\text { (Subject \#19) }\end{array}$ & 76 & Osteoporosis (Spine) & $341 \mathrm{mg} /$ day \\
\hline
\end{tabular}

Table 4-1: Profile of Additional Subjects Recruited. Note that all individuals are Caucasian and have a history of strontium supplementation. The median age of recruitants is 66 years old. 
Two representative results are shown for these individuals (figures 4-8 and 4-9). The remaining results are shown in the Appendix II section.
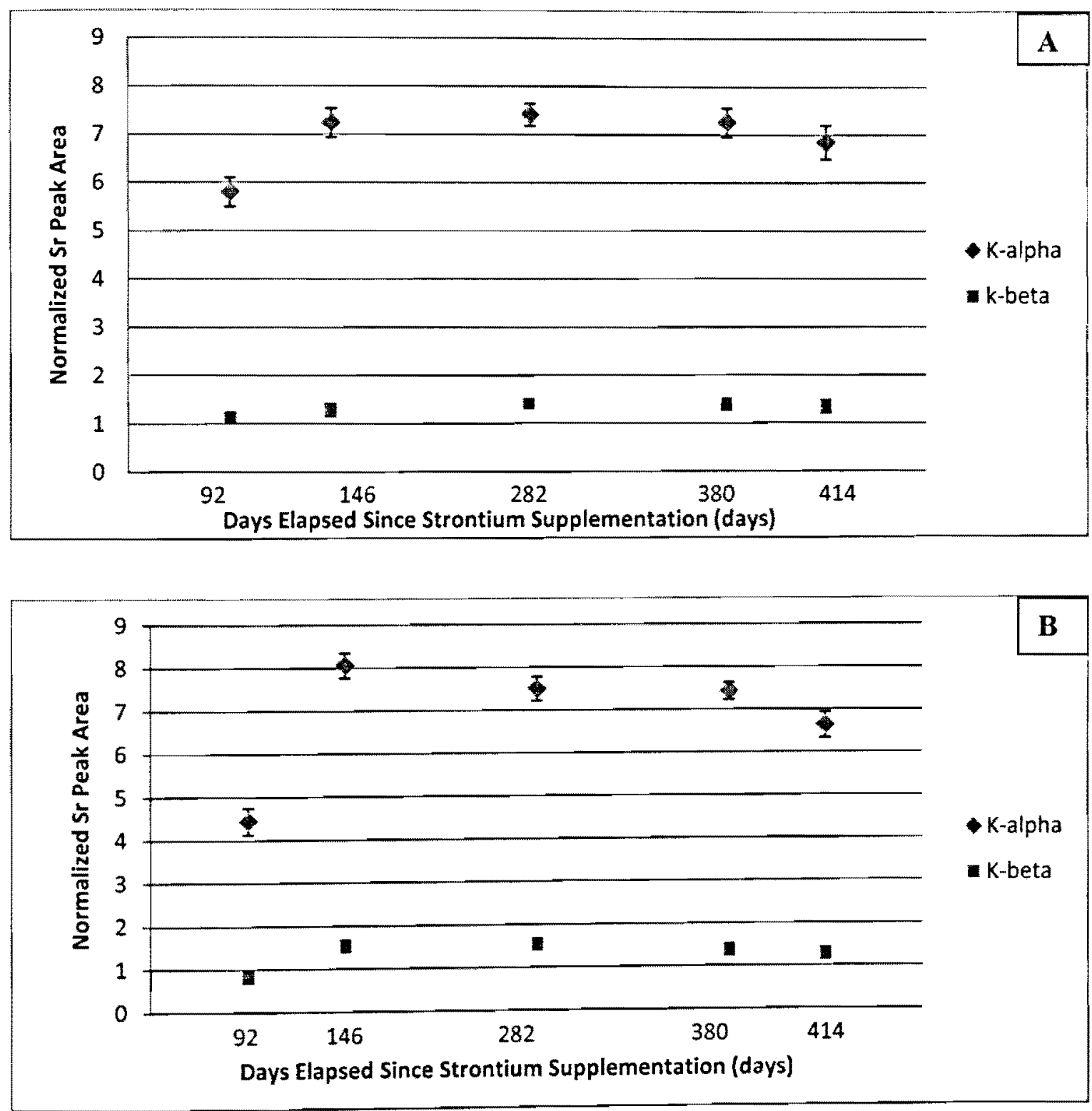

Figure 4-8: Retention Subject \#11; Strontium Measurement over Time in A) Finger and B) Ankle. Subject is a 61 yr old Caucasian male, diagnosed with Osteopenia of the Spine, Neck and Hip. Note that normalized strontium peak area is proportional to the strontium signal observed. The error is associated with statistical uncertainty. 

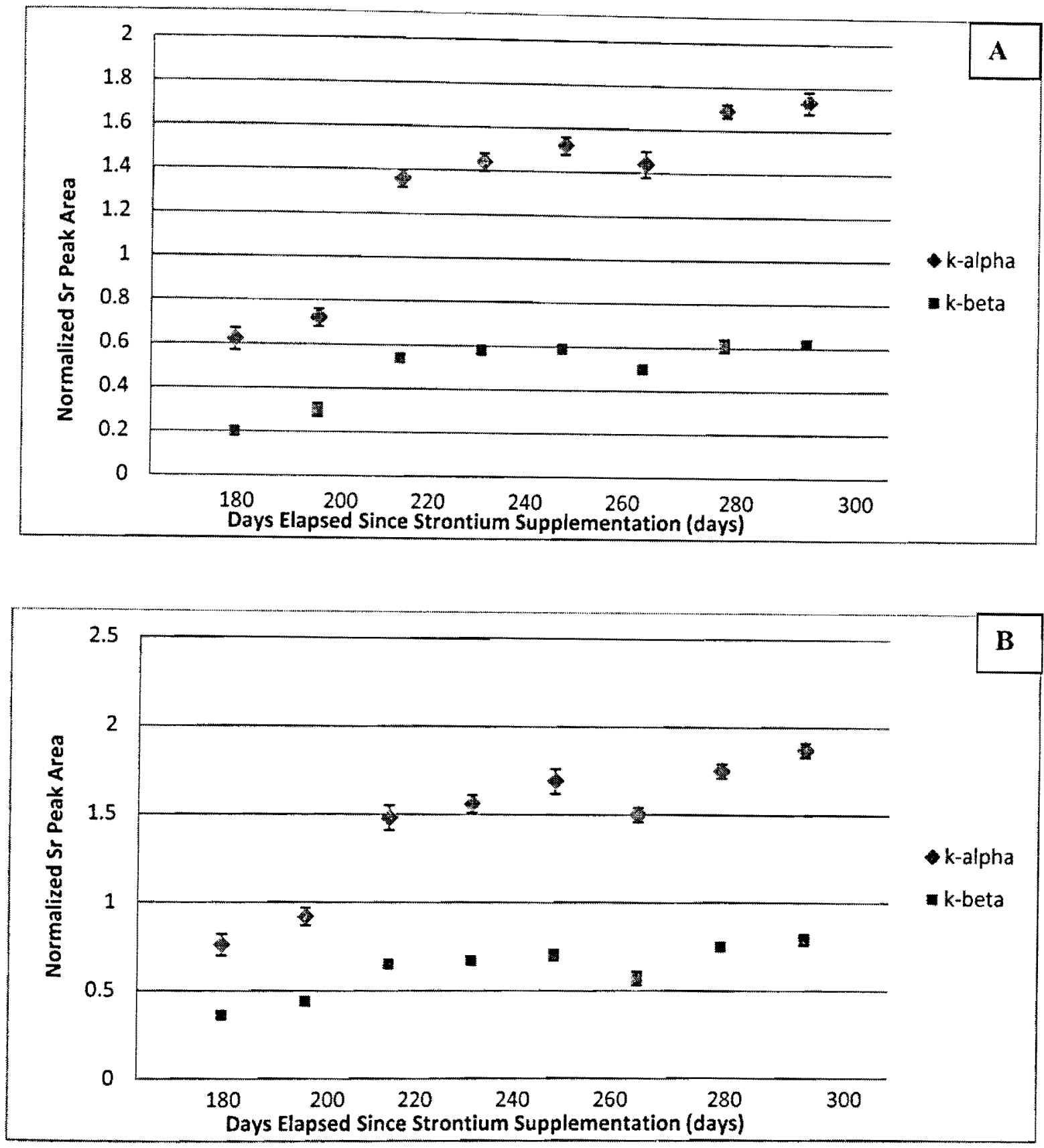

Figure 4-9: Retention Subject\#14; Strontium Measurement over Time in A) Finger and B) Ankle. Subject is a $53 \mathrm{yr}$ old Caucasian female, diagnosed with osteoporosis. The initial value denotes time of her first measurement before she resumed taking strontium supplements after an absence of six months. Note that normalized strontium peak area is proportional to the strontium signal observed. The error is associated with statistical uncertainty. 


\subsubsection{Discussion of Bone Strontium}

In the previous chapter, the baseline results suggested strontium incorporation occurred by an initial rapid mechanism by which strontium is taken up by ionic exchange with bone calcium, that takes place at the bone surface in direct contact with the blood supply. However, the results presented in this chapter show that over time, within 200 days, strontium levels seemingly plateau at both bone sites, as discussed previously. This suggests a second mechanism, which is slower, and involves the incorporation of strontium into the crystal lattice of the bone mineral. Also known as ionic substitution, during this mechanism, strontium is slowly migrated into the bone volume through an exchange with the calcium ion. However, less than one calcium ionout of ten is substituted for by one strontium atom in each crystal (Boivin et al.,1996). The results observed for the retention individuals presented in this chapter (Appendix II) suggest that this second process is dominant, as seen by the slower increases in strontium levels over time. It is also expected that if the individuals are consistent with their strontium supplementation and dosage, that global bone strontium levels will evidently plateau within three years as reported by Cortet (2009).

\subsubsection{Gender Differences and Bone Strontium}

If gender differences, being the second factor, influenced strontium levels, then the strontium levels among the male subjects should be higher than the female subjects. As discussed in section 4.1, Dahl and colleagues (2001) suggested that despite the fact that strontium uptake in rats was influenced by gender, in humans; there has been no similar evidence, which does not agree with the observations in this study. 
The number of male subjects participating in this study is limited; however, some preliminary patterns could be suggested. One time bone strontium measurements were performed on a married couple who started strontium citrate supplementation at the same time, approximately four years ago. The male subject, subject \# 12 (Table 4-1), is a 82 year old male, diagnosed with osteopenia of the hip, having a reported T-score of -1.7, whereas his wife, subject \#13 (Table 41) who is 79 years old was diagnosed with osteopenia of the hip and osteoporosis of the spine, with reported T-scores of -1.7 and -2.6 respectively. Initially, until November 2009 , they were taking $681 \mathrm{mg}$ per day but reduced their dosage after November 2009, after reading and being concerned about the detrimental effects of high levels of strontium. Although, only one measurement could be obtained, a finger measurement could not be obtained for the wife, due to technical difficulties. A comparison of the results show that the male had a measured normalized strontium (K-alpha) signal of $(9.07 \pm 1.03)$ and $(20.16 \pm 0.77)$ in the finger and ankle bones respectively. Whereas, the female had a measured normalized strontium (K-alpha) signal of (47 $\pm 0.96)$ in her ankle. Thus, those two cases show that the wife had higher strontium levels $(\mathrm{p}=0.06)$ compared to her husband's levels. Interestingly, another subject, participating in this retention study, shows a similar strontium history. Similar to the married couple, subject \#17, also took strontium citrate ( $682 \mathrm{mg}$ daily) four years ago and shares the same diagnosis of osteopenia in the hip. Subject \#17's results (Appendix II) show the last bone strontium signal in finger and ankle bones to be $(12.04 \pm 0.41)$ and $(31.05 \pm 0.68)$, respectively. Table 4-2 summarizes subject 12's, 13's and 17's results and increase in their bone strontium levels to the Caucasian levels in the individuals participating in the 2006 pilot study. 


\begin{tabular}{|lcccc|}
\hline Subject \# & $\begin{array}{c}\text { Finger } \\
\text { (Normalized k- } \\
\text { alpha strontium } \\
\text { signal) }\end{array}$ & $\begin{array}{c}\text { Ankle } \\
\text { (Normalized k- } \\
\text { alpha strontium } \\
\text { signal) }\end{array}$ & $\begin{array}{c}\text { Number of } \\
\text { Times Higher } \\
\text { (Finger) }\end{array}$ & $\begin{array}{c}\text { Number of } \\
\text { Times Higher } \\
\text { (Ankle) }\end{array}$ \\
\hline $\begin{array}{l}\mathbf{1 2} \\
\text { (Male) }\end{array}$ & $9.07 \pm 1.03$ & $20.16 \pm 0.77$ & 21 & 50 \\
\hline $\begin{array}{l}\mathbf{1 3} \\
\text { (Female) }\end{array}$ & NA & $47 \pm 0.96$ & NA & 118 \\
\hline $\begin{array}{l}\mathbf{1 7} \\
\text { (Female) }\end{array}$ & $12.04 \pm 0.42$ & $31.05 \pm 0.68$ & 28 & 78 \\
\hline
\end{tabular}

Table 4-2: Summary of K-alpha Bone Strontium Levels in Female and Male Participants after 4 years of Strontium Supplementation. The Caucasian individuals participating in the 2006 pilot study, had an average normalized $k$-alph a strontium signal of $(0.43 \pm 0.08)$ for the finger bone and $(0.40 \pm 0.13)$ for the ankle bone. Subjects \# 12,13 and 17 's levels are compared to these values. The error is associated with statistical uncertainty. $\mathrm{NA}=$ not available.

Thus, if we compare all three subjects in table 4-2, in terms of gender and strontium levels, the results suggests females to have higher strontium levels than males.

However, it should be noted here, that although there were two males participating in this study (Subject \#11 and \#12), the results for the other male (subject \#11) were not included in this discussion as he does not share the same strontium history or dosage.

The lower strontium signal observed in the male subject may be attributed to his condition of osteopenia compared to his wife's condition, whom has both osteopenia and osteoporosis. There may be other factors influencing bone strontium levels such as age and overall health. Therefore, further investigation is needed to determine if there is indeed a gender difference in strontium uptake. Apart from gender differences influencing strontium uptake, from all nineteen individuals participating in this study, it was observed that the strontium dosage and duration of 
treatment influenced the bone strontium levels. These results clearly document that IVXRF is a useful tool to address these observed differences in the future.

\subsubsection{Influence of Dosage and Duration of Treatment on Bone Strontium}

In three individuals, two females (subject \#10 and 17) and one male (subject \#11), it was noted that their strontium levels fluctuated compared to other participants who showed slower increases of strontium levels over time. This fluctuation was noted in individuals who changed their strontium supplement dosage, such that whenever their dosage is decreased or increased, their corresponding bone strontium levels decreased or increased. Furthermore, the longer a person took higher doses of strontium over time, the higher bone strontium level was observed. This is in agreement with Dahl and colleagues (2001), who reported that strontium uptake and incorporation depends on strontium dosage and duration of treatment among other factors. This observation of strontium levels in bone being dose dependant have also been reported by Boivin and colleagues (2009) and Hwang and colleagues (2009), who also observed that lumbar bone mineral density results were dependant on strontium ranelate dosage in osteoporotic women. Table 4-3 illustrates how strontium levels changed in three individuals as they changed their strontium dosage. 


\begin{tabular}{|lccc|}
\hline Subject \# & Dosage & $\begin{array}{c}\text { Average \% Decrease } \\
\text { (Finger) }\end{array}$ & $\begin{array}{c}\text { Average \% Decrease } \\
\text { (Ankle) }\end{array}$ \\
\hline Subject \# 11 & $\begin{array}{c}341 \mathrm{mg} / \text { day to } \\
170 \mathrm{mg} / \text { day }\end{array}$ & $\begin{array}{c}-5.6 \% \\
\text { (visits 2 and 5) }\end{array}$ & $\begin{array}{c}-10.7 \% \\
\text { (visits 2 and 5) }\end{array}$ \\
\hline Subject \# 10 & $\begin{array}{c}-1.74 \% \\
\text { occasional weekly } \\
\text { missed dose }\end{array}$ & $\begin{array}{c}-7.33 \% \\
\text { (Visits } 1 \text { and 2) }\end{array}$ & $\begin{array}{c}\text { (visits } 5 \text { and 6) } \\
\text { Subject \# 17 }\end{array}$ \\
$\begin{array}{c}1020 \mathrm{mg} / \text { day to } \\
\text { 680mg/day }\end{array}$ & $\begin{array}{c}-13.8 \% \\
\text { (visits 1 and 2) }\end{array}$ & $\begin{array}{c}-1.9 \% \\
\text { (visits 1 and 2) }\end{array}$ \\
\hline
\end{tabular}

Table 4-3: Average Change in Bone Strontium Measurements with Decreasing Strontium Dosage. Note subject \#17 had initially supplemented with strontium carbonate and recently switched to strontium citrate supplements. Calculations are based on two bone strontium measurements in which strontium supplementation was reduced. The calculation for subject \# 10, in the ankle did not utilize visits 1 and 2 due to a positioning error during measurement taking.

Although, it is interesting to note that compared to subjects 10 and 11 , subject 17 's ankle measurement showed a smaller increase when her dosage was decreased. Although this observation is unexpected due to the higher bone turnover at the ankle, it may be a result of subject 17's supplementation history, which in turn affected her strontium levels. This is further discussed later in this chapter. Thus, this indicates that if strontium levels are dose dependant, then it signifies that an individual probably has to continue taking strontium supplements for the rest of their life to maintain the beneficial effects of strontium. It also indicates that once an individual stops taking strontium, strontium will be rapidly eliminated from trabecular bone in comparison to cortical bone, as seen in subject \#10. However, it should be noted here that for subject $\# 17$, this trend of a faster clearance rate in trabecular bone once strontium supplementation stops was not seen. This may be attributed to subject \#17's excess use of 
additional supplements in addition to strontium which may have interfered with strontium elimination from bone.

The elimination of strontium depends on other agents as shown by Dahl and colleagues (2001), who observed that in strontium-labeled rats fed a low calcium diet and injected 24, $25(\mathrm{OH}) 2 \mathrm{D}_{3}$ or clodronate for two weeks, that clodronate significantly decreased strontium output during both sampling weeks as a result of decreased bone resorption, however, 24 , $25(\mathrm{OH}) 2 \mathrm{D}_{3}$, resulted in an increased strontium output, as a result of an increase in bone resorption. Thus, Dahl and colleagues (2001) concluded strontium bone levels will not only be affected by bone turnover but by other agents that an individual may be taking. And this may be the case with subject \# 17; the additional supplements she takes most probably influence bone strontium levels differently and thus, the trend of a faster strontium clearance from trabecular bone is not observed.

As discussed before once subject $\# 10$ discontinued taking strontium supplements at the time for her fourth measurement, which was taken just over two months past the day of her last dose, the finger measurement shows that her strontium level at this site did not change by much. This could be attributed to the rate of bone turnover in cortical bone, which is slower than in trabecular bone and had subject $\# 10$ been continuously measured, a significant decrease in her finger strontium levels may not have been observed until after a few weeks. Contrarily, her ankle measurement during the fourth visit decreased by about $22 \%$ compared to her previous third measurement. Based on her decrease in the ankle bone measurement, Heirwegh (2008), estimated the biological half life to be $(193 \pm 72)$ days, using the ratio of observed intensities of the ankle measurements during the third and fourth visit, and a time difference of 70 days, which 
correspond to the number of days between the third and fourth measurement, which agrees with the reported biological half-life for osteoporotic individuals of 178 days (Smith et al, 1967) A biological half-life was not calculated for her finger measurement due to the high errors likely caused by positioning, associated with the measurement.

Using a similar approach for subject \#11, taking into account a time difference of 34 days, which corresponded to the number of days between the fourth and fifth visit, the biological half life is estimated to be $(390 \pm 88)$ days for the ankle and $(515 \pm 65)$ days for the finger. The biological half-life estimated based on subject \#11 bone strontium levels does not agree with Heirwegh's (2008) and Smith's (1967) values. However, a longer biological half-life has been reported in previous literature. Newton and colleagues (1977) estimated the biological half-life of the long term compartment (representing cortical bone) corresponding to strontium release from the bone matrix to be (1118 4450$)$ days, as cited by Heirwegh (2008).

In conclusion, the results of this study suggest that once strontium supplementation is discontinued, a rapid decrease in bone strontium levels from the skeleton should occur and the elimination of deeper incorporated bone is expected to be much slower as it depends on the bone remodeling activity (Kendler et al, 2009). Furthermore, decreases are expected to be more rapid in ankle bone compared to finger bone. 


\subsection{Strontium Levels and Bone Mineral Density}

The high bone strontium levels due to high strontium citrate doses seen for the three individuals, subject \#12,13 and 17 (Table 4-2) suggest that high strontium bone levels should also affect bone mineral density tests results. Bone mineral density test results were obtained from two additional individuals (subject \# 16 and 13, in addition to subject \#1, who was introduced in chapter three. All of these individuals are Caucasian females who have been supplementing with strontium citrate supplements for over a year. Table 4-4 summarizes the results for these women.

\begin{tabular}{|lcc|}
\hline Subject and Dosage & $\begin{array}{c}\text { Lumbar Spine } \\
(\% \text { change })\end{array}$ & $\begin{array}{c}\text { Total Hip } \\
(\% \text { change })\end{array}$ \\
\hline $\begin{array}{l}\text { Subject \# } 16 \\
341 \mathrm{mg} \text { strontium citrate }\end{array}$ & $+10.2 \%$ & Same \\
\hline $\begin{array}{l}\text { Subject \#1 } \\
681 \mathrm{mg} \text { strontium citrate }\end{array}$ & $+4.57 \%$ & $-4.17 \%$ \\
\hline $\begin{array}{l}\text { Subject \# } 13 \\
681 \mathrm{mg} \text { strontium citrate }\end{array}$ & $+8.99 \%$ & $+5.14 \%$ \\
\hline
\end{tabular}

Table 4-4: Bone Mineral Density Changes with Strontium Citrate.

Based on these three subjects, the average bone mineral density increase in the lumbar spine is $7.92 \%$ and in the hip the average increase is $2.57 \%$. These results are consistent with the bone mineral density increases observed with the studies involving strontium ranelate medication administration (Neuprez et al.,2008 and Hwang et al.,2009).

In the STRATOS, SOTI and TROPOS trials, a significance increase in bone mineral density 
was seen after a year of strontium ranelate. When strontium ranelate was orally administered to 160 postmenopausal women, in $1 \mathrm{~g}$ per day, along with $500 \mathrm{mg}$ of calcium supplementation, the investigators found that compared to the placebo, total neck and hip bone mineral density increases were $+3.21 \%$ and $+2.46 \%$, respectively. Similarly, when the investigators administered $2 \mathrm{~g}$ of strontium ranelate per day to postmenopausal osteoporotic women, compared to the placebo group, the average annual increase in lumbar bone mineral was $+7.3 \%$ (Neuprez et $a l, 2008)$. Interestingly, a similar study was performed on Asian women suffering from osteoporosis. In Taiwan, a 12 month randomized, double-blind placebo controlled study involving 125 women with osteoporosis, showed that the women who received $2 \mathrm{~g}$ of strontium ranelate daily showed a significant increase in bone mineral density in their hip, femur and spine, after a year. The bone mineral density in the total hip showed an average increase of $2.6 \%$, in the femoral neck: $2.6 \%$ and in the lumbar spine $5.9 \%$.

The consistency of the results observed for the three subjects (Table 4-4) with the bone mineral density results observed with the studies involving strontium ranelate medication could indicate that strontium citrate and other strontium supplements are able to exert beneficial on bone as strontium ranelate.

However, caution is necessary in interpreting bone mineral density increases because much of the bone mineral increases seen in the results presented in table 4-4 and the SOTI trial results Neuprez et al.,2008 and Hwang et al.,2009) is a technical artifact due to the replacement of some of the calcium in bone by strontium (Blake and Fogelman, 2007). Due to the high atomic number of strontium ( $\mathrm{Z}=38)$ compared to calcium $(\mathrm{Z}=20)$, when the bone mineral density is measured by dual-energy $\mathrm{x}$-ray absorptiometry (DEXA), strontium atoms will attenuate $\mathrm{x}$-rays 
more strongly than calcium causing patients' bone mineral density results to be overestimated (Blake and Fogelman, 2007). Neilson and colleagues (1999) studied this effect and suggested a $1 \%$ molar ratio of $[\mathrm{Sr} /[\mathrm{Ca}+\mathrm{Sr}]]$ or (strontium/ (calcium + strontium) $)$, caused a $10 \%$ overestimation of bone mineral density (Blake and Fogelman, 2007) where Neilsen and colleagues (1999) suggested the relationship, as cited by Heirwegh (2008):

$$
\frac{1.0 \mathrm{~mol}}{\mathrm{~mol} \% \mathrm{Sr}}=1.0\left(\frac{\mathrm{mols} S r}{\mathrm{mols}(\mathrm{Sr}+\mathrm{Ca})}\right) \times 100 \%
$$

Furthermore, Neilsen and colleagues (1999) proposed for in-vivo DEXA measurements taking into account overlying soft tissue, the bone mineral density may be adjusted as:

$$
B M D_{a d j}=\frac{B M D_{\text {scan }}}{1+C * S r L}
$$

where $\mathrm{BMD}_{\mathrm{adj}}$ is the adjusted bone mineral density, $\mathrm{BMD}_{\text {scan }}$ is the bone mineral density result obtained from the DEXA measurement, $\mathrm{C}$ is the correction factor of $10 \%$ and $\mathrm{SrL}$ is the molar percent strontium level with respect to calcium as illustrated in the above equation 4-1. Thus, in order to effectively correct for the bone mineral density, an accurate measurement of strontium concentration levels must be known. Thus, if bone strontium concentrations can be extracted from the IVXRF measurements, the correction formula (4-2) may be used to correct for bone mineral density in strontium supplementing individuals. 
In conclusion, the results presented in chapter three and four suggest two bone strontium mechanisms. First, an initial rapid uptake of strontium occurs, followed by further significant increases within the next 150 days. Over time, strontium levels increase more slowly, indicating strontium is retained in the bone crystal lattice. This second mechanism, know as ionic substitution, occurs as strontium is slowly migrated into the bone volume through an exchange with the calcium ion. Eventually, it is expected that strontium levels will plateau after three years, due to saturation of receptors in the GI tract. However, once an individual stops taking strontium supplements, elimination of bone strontium is expected to occur quickly. The elimination of strontium is expected to occur much faster in trabecular bone compared to cortical bone, due to higher bone turnover rate. As discussed in chapter one, the elimination of strontium, may be eliminated through: 1) clearance from the exchangeable pools of bone, 2) displacement of strontium by calcium, from sites within the apatite crystal by long term exchange processes and 3) by volume removal from the mineral phase and matrix by osteoclastic resorption (Neilsen, 2004).

The results also indicate that strontium supplementation may be a potential treatment in the treatment of osteoporosis and osteopenia, as well as prevention of bone loss in postmenopausal women. Thus, the IVXRF system may be a suitable clinical tool in monitoring bone strontium levels in individuals undergoing strontium supplementation as increases in bone strontium levels seems to correlate with the increases in bone mineral density. However, more work on continuing measurements of strontium supplementing individuals is required to fully address these preliminary observations. 


\section{Chapter 5 In-Vivo Measurement of Strontium Incorporation and}

\section{Retention in Human Bone Using an X-Ray Fluorescence System}

\subsection{Conclusions}

Strontium (Sr) is an element found in nature and the human skeleton. Of the human body burden, more than $99 \%$ of the strontium burden is found in bone (Marie et al., 2006a). Acquired through diet, strontium has been shown to exert beneficial and detrimental effects on bone health depending on levels. Previous studies in both animals and human involving strontium administration has shown strontium to increase bone mineral density and bone strength (Marie et al., 2006b, Cortet, 2009 and Boivin et al., 2009). However, its exact mechanism of therapeutic action is not yet fully understood. As cited by Zamburlini (2008), past studies have attempted to understand the pharmacological and biological role strontium plays in the human body, and interest in strontium had been garnered since the 1950's, when it was found that radioactive strontium, ${ }^{90} \mathrm{Sr}$, a by-product of nuclear fission found in nuclear fallouts, substituted for calcium in bone, thereby preventing its expulsion from the body. During the 1950's, animal studies showed that strontium exerted a positive beneficial effect in bone and an increase in bone density was reported suggesting strontium could potentially be used in the treatment of bone diseases such as osteoporosis (Zamburlini, 2008). Furthermore recent studies have shown positive and encouraging results with orally administered strontium ranelate, in both animals and humans and have given insight into how strontium behaves in bone (Neuprez et al., 2008). The recent large clinical trials: SOTI and TROPOS involving more than a hundred post-menopausal osteoporotic 
women demonstrated strontium ranelate to increase bone mineral density significantly at the lumbar spine, femoral neck and hip, even reversing the symptoms of osteoporosis (Neuprez et al.,2008). However, as encouraging as these studies have shown to be, one of the limitations included the measurement of strontium. The observations made in these studies involving both animals and human, depended on invasive measurement techniques such as bone biopsies of the iliac crest, and serum biomarker analysis which are not only invasive and painful but cannot be repeated over time. Thus, these methods are not feasible to study bone strontium levels frequently over time. Furthermore non-invasive techniques which included DPA measurements, has been limited in terms of the lack of sensitivity and the issue that DPA could only be used to measure bone sites immersed in a water vessel. Thus, the limited techniques available to measure strontium warrant the development of a non-invasive technique that was not only sensitive enough but could be used over time to measure strontium bone levels. Hence the development and optimization of the in-vivo $\mathrm{x}$-ray fluorescence (IVXRF) system by Pejović-Milić and colleagues (2004) followed by Zamburlini and colleagues (2007) and Heirwegh (2008) has shown it to be a promising diagnostic tool to measure bone strontium levels in humans. These initial pilot studies of our research group of healthy individuals demonstrated that the IVXRF system had enough sensitivity to measure strontium bone levels in varying individuals, being capable to distinguish between large differences of bone strontium concentrations. Further use of the IVXRF system by Heirwegh (2008) in the measurement of an osteoporotic woman brought up some interesting questions regarding the strontium behavior in bone.

The focus of this work has been on the measurement of bone strontium levels in humans over 
time. The purpose was not only to confirm the sensitivity of the IVXRF system, but to observe how strontium levels change in two bone sites over time. First, the issuc that was brought up by Heirwegh (2008) regarding improper subject and/or source positioning affecting the measurement errors of the bone strontium measurements was looked at. Second, the feasibility of using the portable mobile ultrasound system to determine soft-tissue thickncss was addressed in terms of its reproducibility. Third, individuals suffering from ostcoporosis and/or osterpenia were recruited and their bone strontium levels were measure with a minimum time commituncnt of one year. Of these individuals, although the focus was on the measurement of baseline individuals, those who have never taken strontium supplements before, individuals who were already taking strontium supplements were also invited to participate in the study. The measurement of these individuals presented information on strontium incorporation and retention as currently, to date, there are no published data on bone strontium in individuals sclfsupplementing with strontium supplements, such as strontium citrate, over time.

\subsubsection{Excitation Source Positioning and Mobile Litrasound System}

The effect of altering source positioning and the corresponding strontium signal observed way investigated and results are presented in chapter two of this work. This was looked at in order $t$ assess whether a change in subject positioning would greatly affect the strontium signal observed. The results indicated that coherent normalization to the ${ }^{124}$ I peak reduced the dependancy of the strontium signal observed. The largest discrepancy observed in the strontim signal occurred when the bone phantom to source distance was altered in the vertical; y-plarse (phantom height placement with respect to the source). Without romalizatign the strstsing 
signal discrepancy was determined to be $27.3 \%$ for the $\mathrm{k}$-alpha signal and with coherent normalization, this discrepancy was reduced to $2.64 \%$. Investigation of the other directions, showed that in the x-plane (phantom placement forward and backward relative to the source) and z-plane (phantom is moved left to right of the source) showed the strontium k-alpha signal discrepancy to be $3.08 \%$ and $3.35 \%$, respectively. The coherent normalization, once again, improved the strontium signal discrepancy to $1.15 \%$ and $1.16 \%$ respectively. Ultimately, though the coherent normalization improves the change of the strontium signal observed, care should be taken during a human measurement, especially for the finger bone site. This is due to the smaller bone size of the finger compared to the ankle. Therefore, careful and improved positioning of subjects would reduce the uncertainty associated with in-vivo bone strontium measurement using the IVXRF system.

The $10 \mathrm{MHz}$ portable mobile ultrasound system (Telemed EchoBlaster $128 \mathrm{EXT}-1 \mathrm{Z}$ kit with a linear HL 9.0/40/1Z8Z probe) was used in this work. Using this mobile ultrasound system, the average soft-tissue thickness of all individuals recruited in the research study was determined. At the finger, within the center of the middle phalanx, the average soft-tissue thickness was found to be $(0.28 \pm 0.04) \mathrm{cm}$ and at the ankle, within the most prominent part of the medial malleolus of the tibia, the average soft-tissue thickness was found to be $(0.26 \pm 0.05) \mathrm{cm}$. These results are in agreement with previous ultrasound measurements reported by Zamburlini (2008) in which the average soft-tissue thicknesses were reported to be $(0.26 \pm 0.04) \mathrm{cm}$ for the finger and $(0.25 \pm$ $0.07) \mathrm{cm}$, for the ankle. When reproducibility was assessed in an individual, taking into account re-positioning between ultrasound measurements over time and the use of a gel pad, the variance for the finger and ankle without the use of a gel pad was determined to be $0.71 \%$ and $0.49 \%$, 
respectively. Comparatively, with the use of a gel pad, the variances for the finger and ankle were determined to be $0.34 \%$ and $0.24 \%$. This result indicated that usage of the gel pad reduced the uncertainty associated with the ultrasound measurements and the lower variance obtained for the ankle could be attributed to the flatter bone surface at this site, compared to the finger, making it easier to do an ultrasound measurement. Additional errors introduced in an in-vivo measurement taking may be attributed to the erroneous determination of soft-tissue thickness that may occur if tendon is mistaken for the bone surface. Even though the $10 \mathrm{MHz}$ ultrasound system has been shown to have an estimated uncertainty of $3.2 \%$ as reported by Heirwegh (2008), compared to higher frequency ultrasound, if attention is given to minimize the amount of compression used in the acquisition of an ultrasound image, followed by careful analysis of where bone to tissue and tissue to air boundaries occur, then the uncertainty of error may be reduced, making the $10 \mathrm{MHz}$ mobile ultrasound an acceptable tool in the determination of softtissue thickness prior to the in-vivo bone strontium XRF measurement.

\subsubsection{Bone Strontium Levels in African Subject Measured with the IVXRF System}

Previously, using the IVXRF system, an initial pilot study in 2006 by Zamburlini and colleagues (2006) was performed. Twenty-two healthy individuals (11 females and 11 males) of both Caucasian and Asian ethnicities were measured at their finger and ankle bone sites. The results from the 2006 pilot study showed non-Continental Asians to have higher bone strontium signals at both bone sites compared to the Caucasian individuals. The average normalized strontium $\mathrm{k}$-alpha peak signal for the Caucasian individuals at the finger and ankle bones were $0.43 \pm 0.08$ and $0.40 \pm 0.13$, respectively. For the non-continental Asian individuals, the average 
normalized strontium $\mathrm{k}$-alpha peak signal at the finger and ankle bones were $(1.03 \pm 0.40)$ and $(1.09 \pm 0.30)$, respectively. Zamburlini and colleagues (2007a) suggested that genetics influence strontium levels observed. However, Zamburlini and colleagues (2007a) did not investigate this further to measure other races.

In this work, separate from the baseline and retention studies, a bone strontium measurement was performed using the same IVXRF system on an African male colleague. The results, presented in chapter three, showed that the African male had much higher bone strontium levels at both finger and ankle. In the African's finger bone measurement, the normalized k-alpha strontium signal was $1.93 \pm 0.08$ and in the ankle, the normalized $\mathrm{k}$-alpha strontium signal was $2.15 \pm 0.53$. The higher strontium level seen in the African male may also be attributed to geographical location and diet, as the African colleague originates from Nairobi, Kenya and states having a diet rich in vegetables and whole grains. Furthermore, high rubidium/strontium concentrations (in ppm) have been found in Kenya (Weis, 1987). However, more data is required to make any conclusive statements.

\subsubsection{Strontium Uptake and Incorporation}

Of the nineteen individuals recruited to participate in this study, one individual was healthy with no diagnosis of bone disease, whereas the rest of the participants were diagnosed with either osteoporosis, osteopenia or a combination of the two. The most common diagnosis was osteopenia of the hip which was seen in more than half of the total number of participants, followed by osteoporosis of the spine. The main reason participants joined the study was to be monitored on their bone strontium levels as they were taking the strontium supplements of their 
choice. Currently, all participants enrolled in the study are taking strontium citrate supplements, as this is the most popular type of supplement sold in North America. The reason participants were self-supplementing with strontium supplements was that either they had a bad experience with prescribed medications or they wanted to try an alternative treatment that has been believed to be promising in preventing or treating bone diseases. Individuals were measured as frequently as possible, on either a weekly, biweekly or monthly basis, and currently continue to be monitored.

Baseline individuals were those individuals without any prior history of strontium supplementation or strontium based drugs; therefore their bone strontium levels are reflective of their diet, race and/or geographical region they live in. A baseline measurement obtained corresponds to their natural strontium levels prior to taking strontium supplements. Continued measurements of baseline individuals at regular intervals over time, indicated some interesting results. After the very first intake of strontium supplements, there was an initial rapid increase of strontium levels at both bone sites, and, in agreement with previous studies, the ankle, predominantly made of trabecular bone, showed a higher strontium uptake compared to the finger bone, which is more representative of cortical bone. The average 24 hour increase, compared to day 0 , was found to be $47.2 \%$ and $63.2 \%$ for the finger and ankle, respectively. This was then followed by slower increases in bone strontium levels, followed by time intervals at which the levels seemed to plateau for a few weeks. Another significant increase in strontium levels, in which strontium levels were significantly higher varied among the individuals, but generally occurred within two to five months. The average strontium level compared to their average 
baseline levels generally indicated an increase of 4.3 times in the finger and 5.2 times in the ankle bone. The rapid initial increase in bone strontium levels off at approximately $72 \pm 32$ days for the finger bone and $83 \pm 36$ days for the ankle bone could coincide with the influence of strontium on the bone remodeling cycle, since one complete bone remodeling cycle takes approximately 120 days. This result indicates that once an individual begins strontium supplementation, there is an initial rapid uptake of strontium as a result of strontium being taken up by ionic exchange with calcium at the bone surface area, followed by the slower incorporation of strontium into the crystal lattice of the bone mineral. Since the bone remodeling cycle is influenced by a variety of factors, the uptake and incorporation of strontium depends on the rate of activity of bone remodeling, which in turn depends on osteoblastic activity.

\subsubsection{Strontium Retention}

Continued measurements of individuals over time indicate that strontium levels continue to increase even after a year of strontium supplementation. This is consistent with the findings in previous research trials in which the time taken for global bone strontium levels to plateau was reported to be three years (Neuprez et al., 2008). Interestingly in three individuals, who were measured in this study, bone strontium levels were significantly higher after three to four years. Compared to the control group, the average strontium level was 22 times higher in the finger and 65 times higher in the ankle of these three individuals. Due to detrimental effects strontium has on bone (rickets and osteomalacia), a potential toxic effect of strontium can suggestively be introduced at these bone levels. However, further measurements of these individuals are required to reach a conclusion whether these strontium levels are indicative of a plateau. It was also observed that after a year of strontium supplementation with strontium citrate, that bone mineral 
density scores increased. Of three individuals whose bone mineral density scores were made available to us, significant increases were seen at the lumbar spine measurement compared to the hip measurement. The average lumbar spine measurement increase was determined to be $+7.92 \%$ of the last annual $\mathrm{T}$-score, and in the hip the average bone mineral density increase was determined to be $+2.57 \%$ of the last annual T-score. The higher bone mineral density increases seen in the lumbar spine is attributed to the higher bone turnover, due to increased blood flow, at this site compared to the hip. Interestingly, these results are consistent with the bone mineral density increases observed with the studies involving strontium ranelate in which the bone mineral density increases at the lumbar spine and hip were reported to be increased to $7.3 \%$ and $2.46 \%$ (Neuprez et al.,2008), respectively. Hence, this indicates that strontium citrate and possibly other strontium supplements could have exerted the same or similar benefits in bone as strontium ranelate medication.

The results of this IVXRF study also showed that once an individual discontinued strontium supplementation, that there was a rapid decrease in strontium levels observed, most notably at the ankle bone site which showed an approximate decrease of $22 \%$ after the last intake of strontium supplementation, within two months. A smaller decrease of $11 \%$ in finger strontium levels was seen. Heirwegh (2008) suggested that the terminal half-life of bone strontium was $(193 \pm 72)$ days, in agreement with the reported biological half-life for osteoporotic individuals of 178 days (Smith et al, 1967). However, in this work, the biological half life was found to be longer: $(390 \pm 88)$ days for the ankle and $(515 \pm 65)$ days for the finger. This longer biological half-life is still shorter than the biological half-life of strontium from the bone matrix of 
(1118 \pm 450 ) days (Newton et al., 1977). This indicated that once strontium supplementation is discontinued, it is expected that a rapid decrease of strontium from the skeleton occurs followed by a slower phase of strontium elimination. The slower, second phase is likely attributed to the delayed mobilization of buried strontium not readily available for calcium ion exchange (Kendler et al, 2009).

Thus, based on the observations in the baseline individuals and retention studies, it can be suggested that once a person decides to take strontium supplements, there will be an initial rapid uptake of strontium due to ionic exchange at the bone surface, resulting in higher strontium signals observed at the ankle site, followed by the incorporation of strontium into the crystal lattice of the bone matrix. Moreover, this uptake and incorporation is likely to create a saturation of strontium at which time strontium levels in bone could plateau. However, due to the short length of this study, the plateau time was not yet observed after one year, but it is suggested to be within three years (Hwang et al., 2009). To maintain the effects, strontium supplementation will have to be continued, as discontinuing strontium will cause a rapid decline of bone strontium levels. But continuation of strontium supplementation in individuals should be monitored as overdose with strontium changes from the beneficial to detrimental effect. Thus the results indicate two different mechanisms of strontium uptake and incorporation, which is directly influenced by the bone remodeling cycle. However, more investigation and continuation of the study described here needs to be done in order to better understand strontium retention and/or elimination in human bone.

\subsubsection{Use of the Strontium K-alpha and K-beta peaks to Determine Bone Health}

The initial pilot study of twenty two individuals, as discussed in chapter four, was analyzed 
by Zamburlini et al (2007) in terms of the strontium k-alpha and k-beta ratio, in which the ratio was found to vary among individuals and produce values lower than the theoretical 5.2. Theoretically, since the probability of emission for a strontium k-alpha photon is seven times larger than the probability of emission for a strontium $k$-beta photon, then the theoretical $k$-alpla to $\mathrm{k}$-beta ratio is equal to seven. However, if it is assumed that strontium is uniformly distributed in hydrated cortical bone, then this ratio is lowered to 5.2 , considering that the bone thickness is infinite at this energy. However, smaller ratios were observed by Zamburlini (2008) and Heirwegh (2008) in the range of 2.6-3.2 as measured on cadaver fingers (overlying soft tissue intact). Among the twenty two control subjects, Zamburlini and colleagues (2007) determined finger bone and ankle bone ratios to be $(2.9 \pm 0.7)$ and $(2.7 \pm 1.0)$ respectively.

This observation agrees with the baseline ratios measured for the baseline individuals participating in this study. The baseline individuals indicated the ratio in the finger bone and ankle bone to be $(2.8 \pm 0.6)$ and $(2.8 \pm 0.7)$, respectively. It was further observed that at the time of rapid increase, the average ratio in the finger bone and ankle bone had increased to (4.8 0.6 ) and (4.6 \pm 0.3 ), respectively. This result suggested that strontium was uniformly distributed in bone and that it was superficially deposited on the outer bone surface. This result agreed within uncertainty, with the findings by Heirwegh (2008) who observed an average ratio for the finger bone and ankle bone of $(5.5 \pm 0.6)$ and $(5.2 \pm 0.2)$, respectively in one subject. Howerer, due to the variability of ratio over time, further investigation should be looking at the strontium ratios obtained for the baseline individuals over a longer period of time and whether this ratio may indicate the condition of bone health in an individual. 


\subsection{Future Work}

The development and optimization of the IVXRF system by Pejović-Milic et al (2004) and later by Zamburlini et al (2008), followed by evaluation of system performance and measurement reproducibility by Heirwegh (2008), have allowed for the successful bone strontium measurements of subjects participating in this work. However, in light of the experimental data obtained, and based on previous work, there are several improvements that can be made to the IVXRF system that would reduce the uncertainty associated with the measurements. Improvements include the positioning of individuals undergoing bone strontium measurement, the use of a different detector, the generation of a new set of calibration standards and in the interpretation of the strontium data obtained in terms of strontium kinetics and ratios of the k-alpha to k-beta peaks that may give more information on bone health and bone strontium incorporation.

\subsubsection{Improvement of Subject Positioning Undergoing the IVXRF Bone Strontium}

\section{Measurement}

In chapter two, the necessity of an improved positioning method was introduced. Considering that currently a measurement lasts thirty minutes per bone site, the comfort and positioning of individuals should also be taken into account when making improvements to the new positioning device. Presently, while the ankle measurement is easier to position due to the larger bone surface area, the finger measurement presents more of a challenge. Figure 5-1 shows the current positioning of a finger during the IVXRF measurement. 


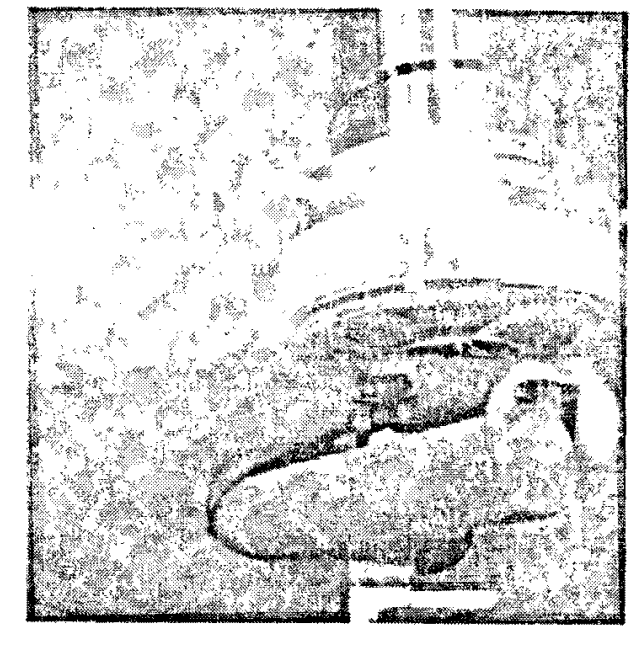

Figure 5-1: Human Finger Measurement (Heirwegh, 2008).

The limitation with this positioning method is that it is based on the operator's subjective positioning. Two possible proposed changes are considered. The first positioning changes would include the use of a laser pointer, side mirrors and a ruler track in addition to the current positioning system used.

The purpose of the laser would be similar to the positioning technique used for radiotherapy patient setup. A mark corresponding to the ultrasound measurement site would be made on both sides of the finger and the laser would help in positioning and aligning the finger with respect to the mark made. Side mirrors would help with visualizing the front of the finger that is currently obscured by the detector. In addition, a further immobilization clamp may be used such that would it would stabilize the top tip of the finger and help keep the finger straight during the measurement. A small beanbag may be used under the arm for the subject's comfort and support. A proposed diagram illustrating this idea is shown in Figure 5-2. 


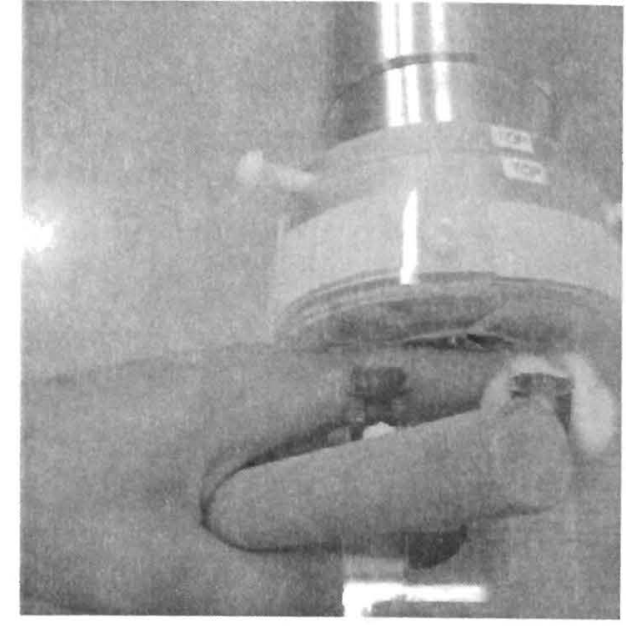

Figure 5-1: Human Finger

Measurement (Heirwegh, 2008).
The limitation with this positioning method is that it is based on the operator's subjective positioning. Two possible proposed changes are considered. The first positioning changes would include the use of a laser pointer, side mirrors and a ruler track in addition to the current positioning system used.

The purpose of the laser would be similar to the positioning technique used tor radiotherapy patient setup. A mark corresponding to the ultrasound

measurement site would be made on both sides of the finger and the laser would help in positioning and aligning the finger with respect to the mark made. Side mirrors would help with visualizing the front of the finger that is currently obscured by the detector. In addition, a further immobilization clamp may be used such that would it would stabilize the top tip of the finger and help keep the finger straight during the measurement. A small beanbag may be used under the arm for the subject's comfort and support. A proposed diagram illustrsting this idea is shown in Figure 5-2. 


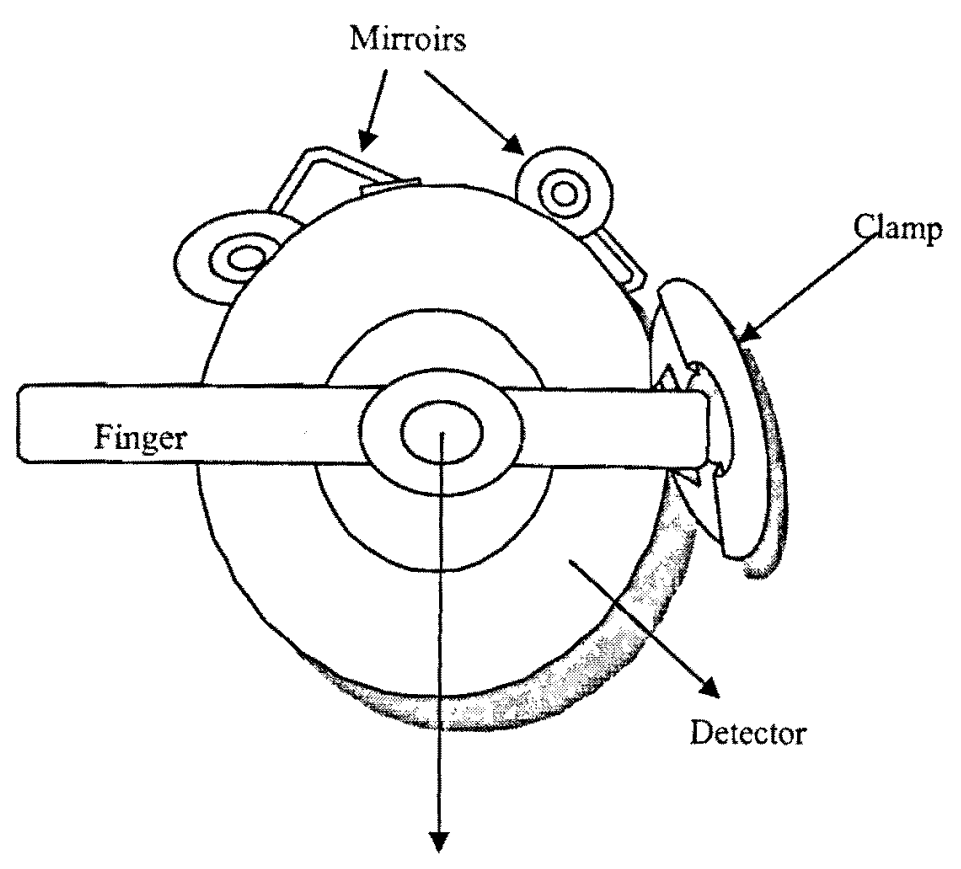

Aligned with portable laser

Figure 5-2: Proposed Finger Positioning (Front View) Additional Enhancements. The finger is represented by the yellow horizontal bar and two side mirrors are attached to the top of the detector. A clamp would further mobilize and keep the finger straight and may be adjustable to accommodate variances in finger thickness. The same wooden hand support base as shown in Figure 5-1, along with a bean bag may be used.

Likewise, the ankle would be positioned in a similar manner in which the middle of the ankle is first marked according to the ultrasound measurement, with lasers and side mirrors aiding in placement. However, for ankle immobilization, a shin support would be ideal to provide stability. This is illustrated in Figure 5-3. 


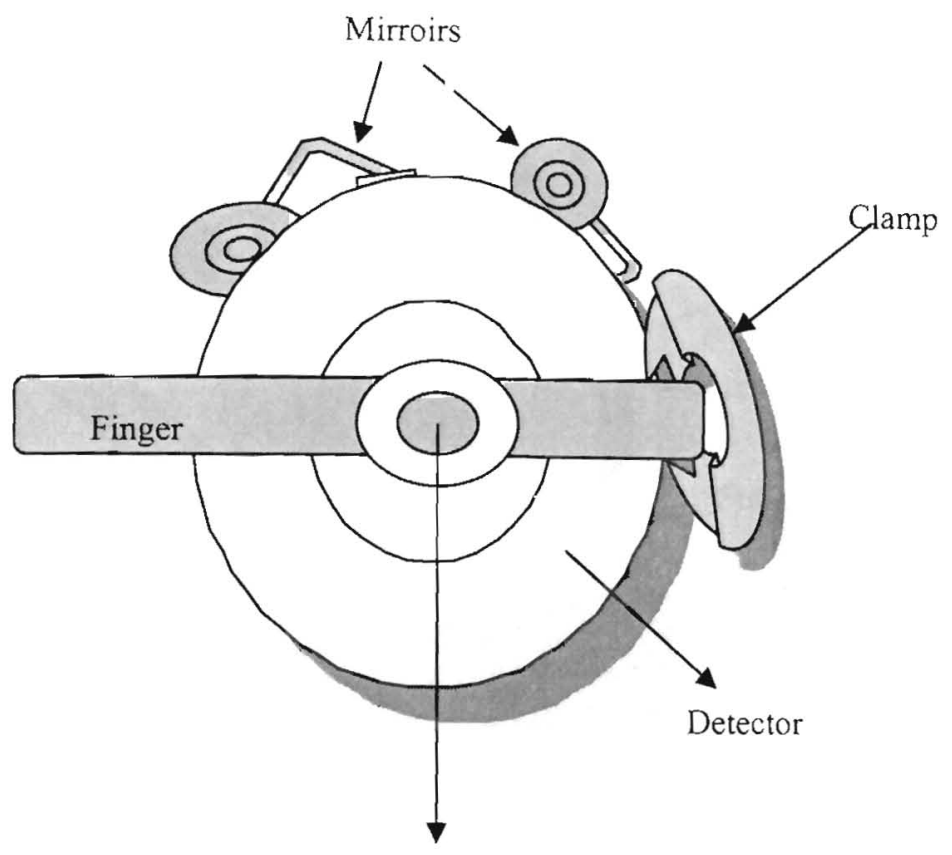

Aligned with portable laser

Figure 5-2: Proposed Finger Positioning (Front View) Additional Enhancements. The finger is represented by the yellow horizontal bar and two side mirrors are attached to the top of the detector. A clamp would further mobilize and keep the finger straight and may be adjustable to accommodate variances in finger thickness. The same wooden hand support base as shown in Figure 5-1, along with a bean bag may be used.

Likewise, the ankle would be positioned in a similar manner in which the middle of the ankle is first marked according to the ultrasound measurement, with lasers and side mirrors aiding in placement. However, for ankle immobilization, a shin support would be ideal to provide stability. This is illustrated in Figure 5-3. 


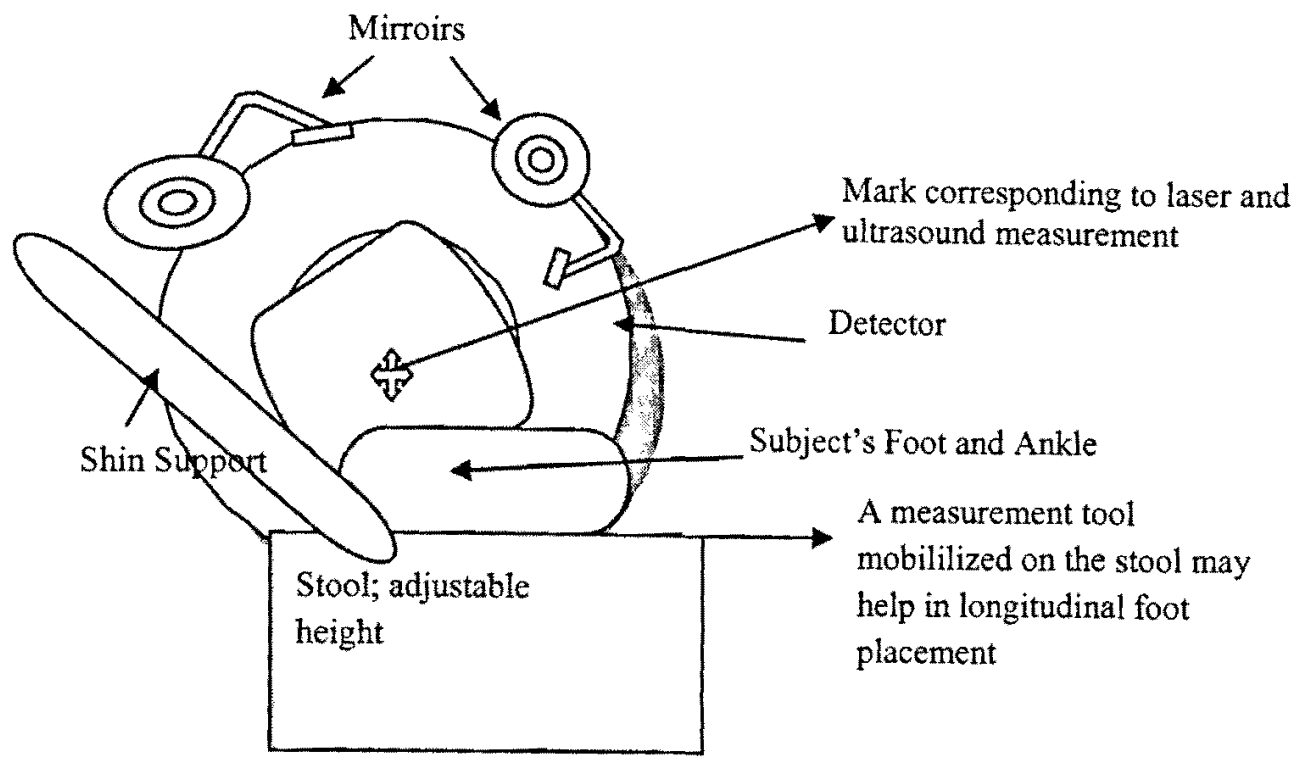

Figure 5-3: Proposed Ankle Positioning; Front View.

A search of other positioning methods which uses the x-ray fluorescence technique to analyze other elements in humans was performed in order to observe how other methods immobilized anatomical sites of interest. A finger bone lead measurement by Börjesson and Mattson, (2007), was found to be useful in terms of finger measurement and immobilization (Figure 5.4). 


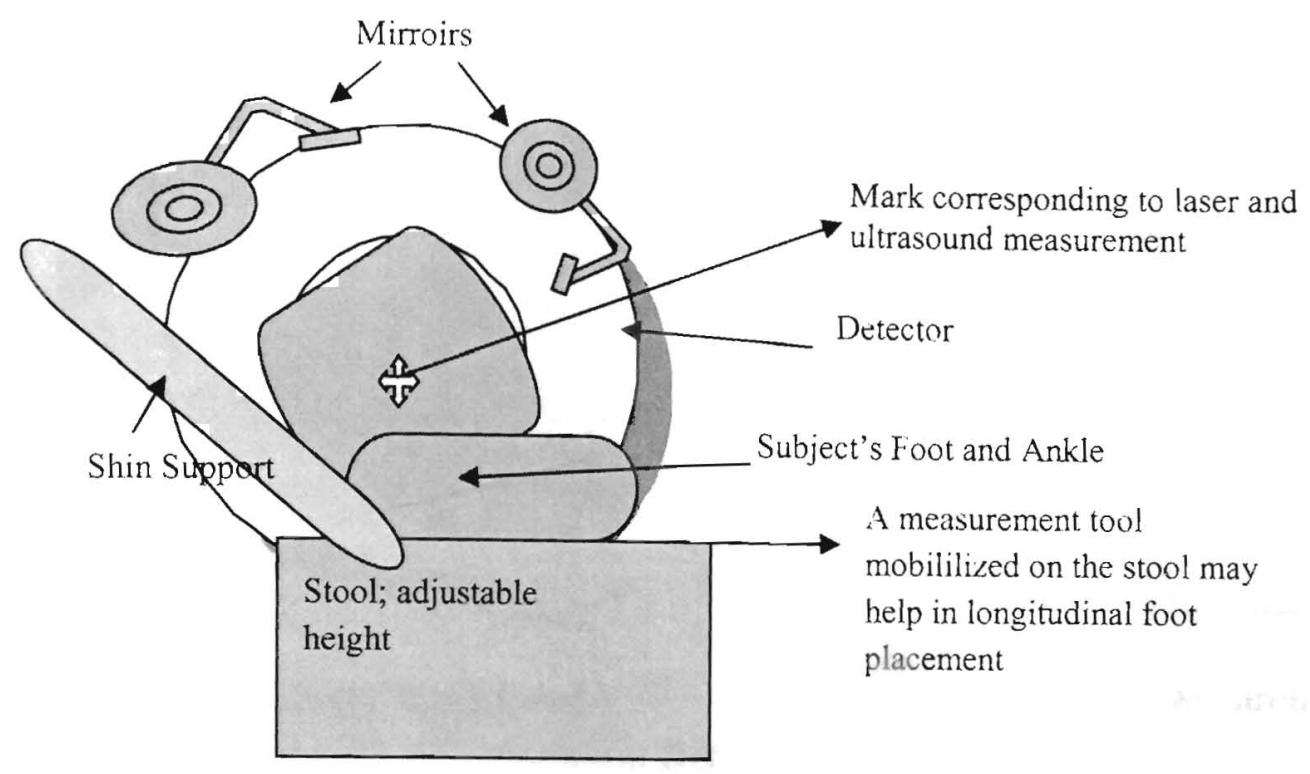

Figure 5-3: Proposed Ankle Positioning; Front View.

A search of other positioning methods which uses the $\mathrm{x}$-ray fluorescence technique to analyze other elements in humans was performed in order to observe how other methods immobilized anatomical sites of interest. A finger bone lead measurement by Börjesson and Mattson, (2007), was found to be useful in terms of finger measurement and immobilization (Figure 5.4). 


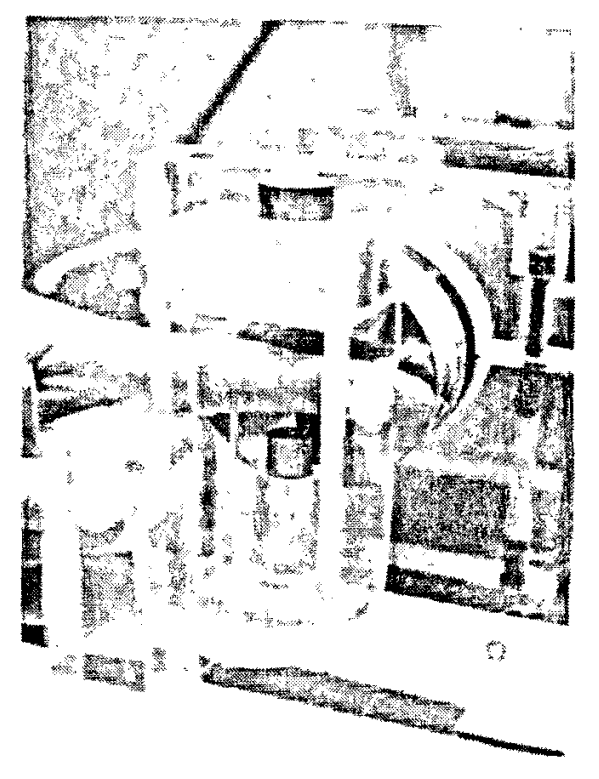

Figure 5-4: Finger Bone Lead Measurement with a Germanium Detector (16 mm) (Börjesson and Mattsson, 2007)
In the second proposed positioning system, the immobilization of the finger would be similar to that shown in Figure 5.4. However, with this proposed finger positioning, the issue of possible elemental contamination within the active collimator area must be considered as elements having close to similar emission lines as strontium may interfere and overlap with the two strontium alpha and beta peaks at $14.16 \mathrm{keV}$ and $15.8 \mathrm{keV}$, respectively. Table 5-1 lists some elements that have emission lines similar to strontium emission lines, and hence some of these elements may overlap with the strontium signal if present and should not be used.

\begin{tabular}{|c|c|}
\hline Element & Emission Line (KeV) \\
\hline Strontium (Sr) & $\mathrm{k}_{\alpha 1}: 14.1650 \quad \mathrm{k}_{\beta 1}: 15.8357$ \\
\hline Rubidium (Rb) & $\mathrm{k}_{\beta 1}: 14.9613$ \\
\hline Zirconium (Zr) & $\mathrm{k}_{\alpha 1}: 15.7751 \quad \mathrm{k}_{\alpha 2}: 15.6909$ \\
\hline Actinium (Ac) & $\mathrm{L}_{\beta 1}: 15.713$ \\
\hline Americium (Am) & $\mathrm{L}_{a 1}: 14.6172$ \\
\hline
\end{tabular}

Table 5-1: X-Ray Emission Lines (K-level and L-level) Similar to Strontium Alpha and Beta Peaks. Note that $k$-alpha is designated as $k_{\alpha}$ and $k$-beta is designated as $k_{\beta}$. (http://www.bedwani.ch/xrf/emission/XEmission.htm) 


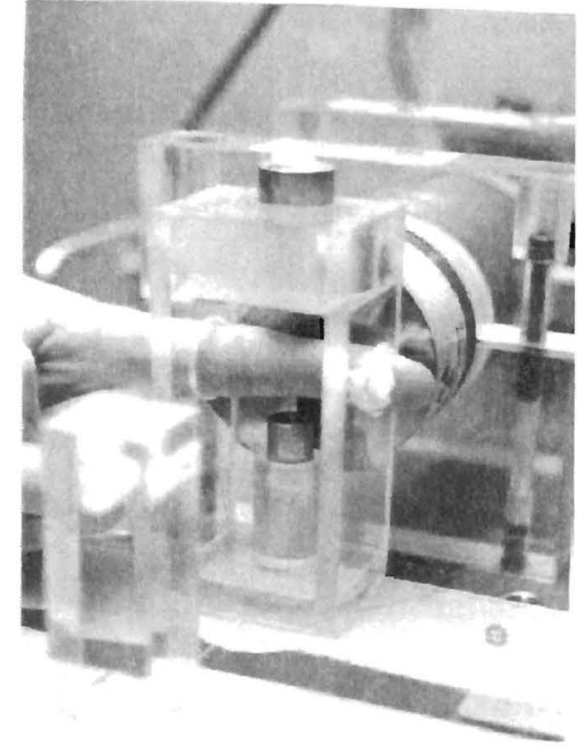

Figure 5-4: Finger Bone Lead

Measurement with a Germanium Detector

(16 mm) (Börjesson and Mattsson, 2007)
In the second proposed positioning system, the immobilization of the finger would be similar to that shown in Figure 5.4. However, with this proposed finger positioning, the issue of possible elemental contamination within the active collimator area must be considered as elements having close to similar emission lines as strontium may interfere and overlap with the two strontium alpha and beta peaks at $14.16 \mathrm{keV}$ and $15.8 \mathrm{keV}$, respectively. Table 5-1 lists some elements

that have emission lines similar to strontium emission lines, and hence some of these elements may overlap with the strontium signal if present and should not be used.

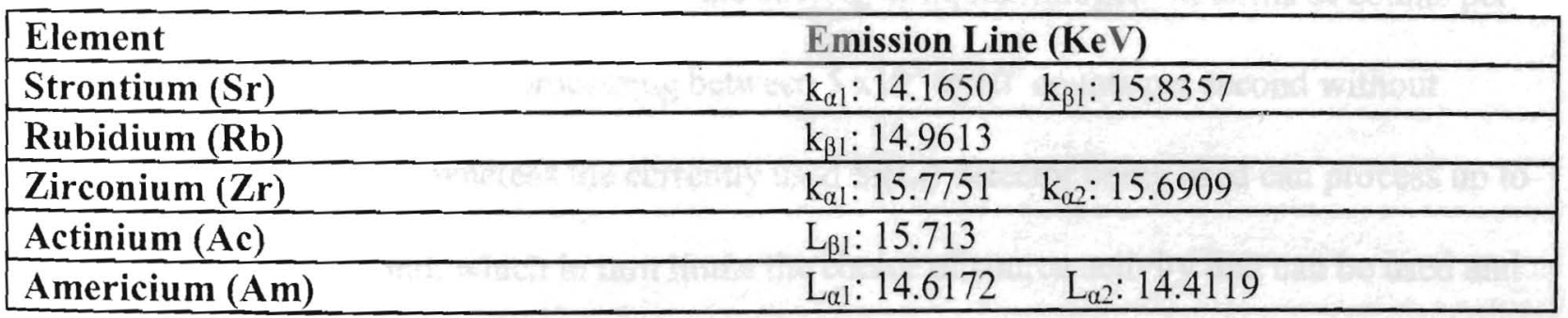

Table 5-1: X-Ray Emission Lines (K-level and L-level) Similar to Strontium Alpha and Beta Peaks. Note that $k$-alpha is designated as $k_{\alpha}$ and $k$-beta is designated as $k_{\beta}$. (http://www.bedwani.ch/xrf/emission/XEmission.htm) 


\subsubsection{New Generation of Silicon-Based Detectors and Optical X-Ray System for Bone}

\section{Strontium Measurements}

In addition to improving subject positioning, reducing the measurement time would make the strontium bone measurement more bearable from the subject's point of view, considering that the individual must not move his/her finger or ankle for the duration of thirty minutes. Furthermore, a reduction in measurement time would allow for repeated measurements to be taken so that an average of the strontium signal could be obtained which would not only reduce the uncertainty but allow for a better estimation of the strontium signal. One way to do this would be to change the excitation source to an $\mathrm{x}$-ray based optical system and consider the use of a different silicon based detector.

An X-ray optical system has recently been set-up at McMaster University along with the use of a brand new Ketek Silicon Drift Detector (SDD). The objective of this second generation of bone strontium IVXRF system is to replace the existing system and improve bone strontium measurements. The SDD has the advantage of being able to process more counts per second, being smaller in size, and does not require the cooling of liquid nitrogen. In terms of counts per second, the SDD is capable of processing between $5 \times 10^{5}$ to $10^{6}$ counts per second without losing energy resolution, whereas the currently used $\mathrm{Si}(\mathrm{Li})$ detector being used can process up to $4 \times 10^{4}$ counts per second, which in turn limits the choice of source activity that can be used and the sensitivity of the system (Zamburlini et al., 2007). Furthermore, compared to the current system, the new generation system has the advantage of decreasing the background under the strontium peaks, and thus simplifying the spectrum. Zamburlini (2008) theoretically determined that the use of a silver target $\mathrm{x}$-ray tube produced the best optimization conditions, as it would 
result in a collimated $22.16 \mathrm{keV}$ source of photons after passing through the optical focusing system. However, the SDD does present its disadvantages due to its low efficiency at the strontium energies. The work to date by Mira Sibai, as illustrated in figure 5-5 has included phantom simulations and preliminary measurements using the calibration phantoms with the SDD detector and further work is needed in terms of optimization.

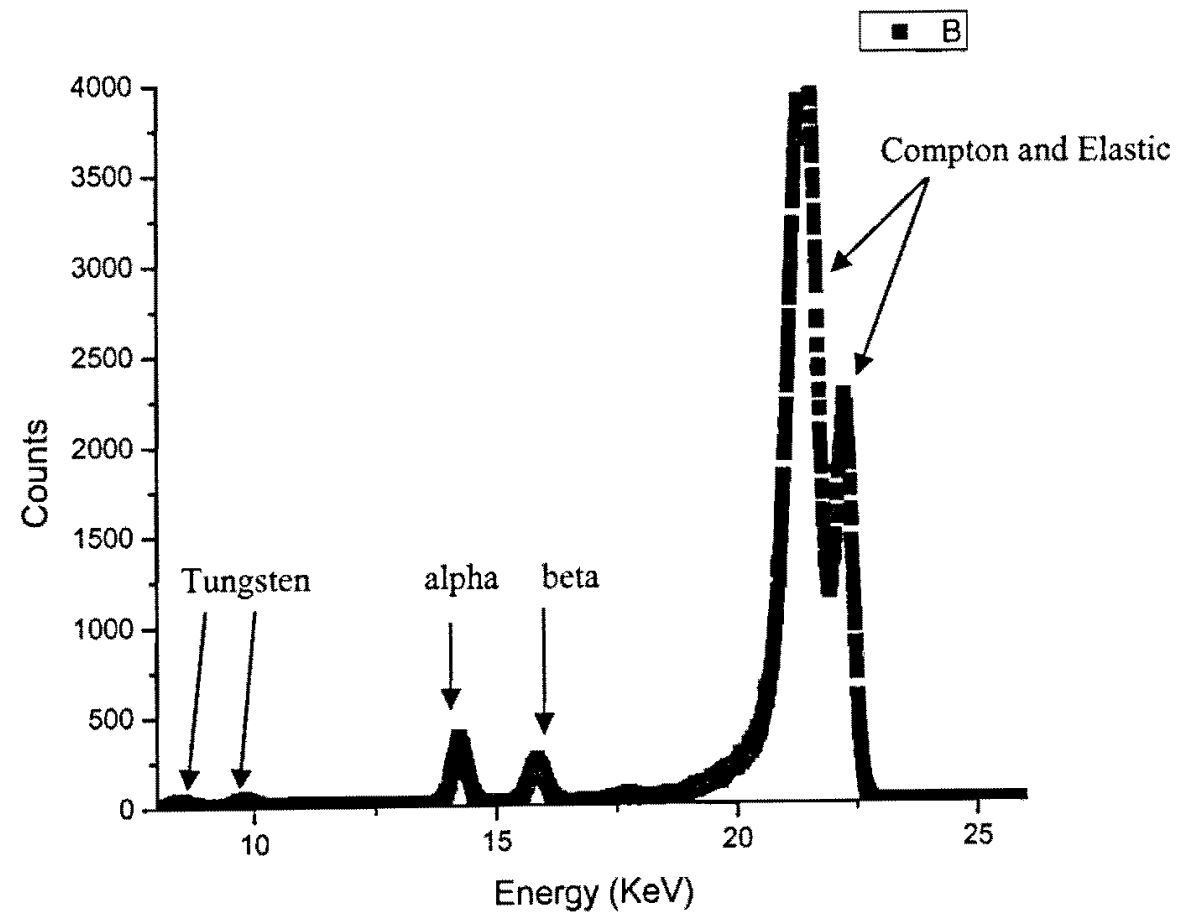

Figure 5-5: Optical system at $78.1 \mathrm{~cm}$ away from the $x$-ray tube. Note that coherent normalization is not done (Sibai, unpublished work).

In addition, as with the current $\mathrm{Si}(\mathrm{Li})$ detector system, if the SDD detector is to be used for bone strontium measurements, a new positioning system for subject positioning will have to be devised. 


\subsubsection{Creation of a New Set of Calibration Standard Phantoms for Bone Strontium Measurements}

As reported in the work by Heirwegh (2008), one of the problems with the current calibration phantom standards being used is the inherent strontium contamination associated with it. Currently, the present phantoms used in this work are made of Plaster of paris material of varying concentration (Table 5-2).

\begin{tabular}{|cccccc|}
\hline $\begin{array}{c}\text { Phantom } \\
\text { ID }\end{array}$ & $\begin{array}{c}\text { CaSO4.1/2H2O } \\
(\mathbf{g})\end{array}$ & $\mathbf{C a}(\mathrm{g})$ & Sr added $(\mathbf{m g})$ & ppm Sr/Ca & $\begin{array}{c}\mathbf{p p m} \\
\text { Sr/CaSO4.2H2O }\end{array}$ \\
\hline $\mathbf{1 / 6}$ & 5.0366 & 1.391 & 0.17 & 119.84 & 27.90 \\
\hline $\mathbf{1 / 3 \mathbf { a }}$ & 5.0571 & 1.396 & 0.33 & 238.72 & 55.57 \\
\hline $\mathbf{1 / 3 b}$ & 4.7827 & 1.321 & 0.33 & 252.41 & 58.76 \\
\hline $\mathbf{1 / 2}$ & 5.1601 & 1.425 & 0.5 & 350.93 & 81.69 \\
\hline $\mathbf{2 / 3}$ & 4.8979 & 1.352 & 0.67 & 492.95 & 114.75 \\
\hline $\mathbf{1}$ & 5.4569 & 1.507 & 1 & 663.68 & 154.49 \\
\hline $\mathbf{2}$ & 5.2677 & 1.455 & 2 & 1375.04 & 320.08 \\
\hline
\end{tabular}

Table 5-2: Plaster of Paris (poP) Phantoms used in IVXRF Measurements

As a result, the calibration curves obtained with these phantoms have resulted in a graph with a non-zero intercept. The resulting contamination present with the calibration standards can be determined by dividing the intercept of the calibration line by the slope of the calibration line. The estimated combined contamination from both the $\mathrm{k}$-alpha and $\mathrm{k}$-beta calibration lines was determined to be $363 \mu \mathrm{g}$ strontium/g calcium (Figure 5-6). 


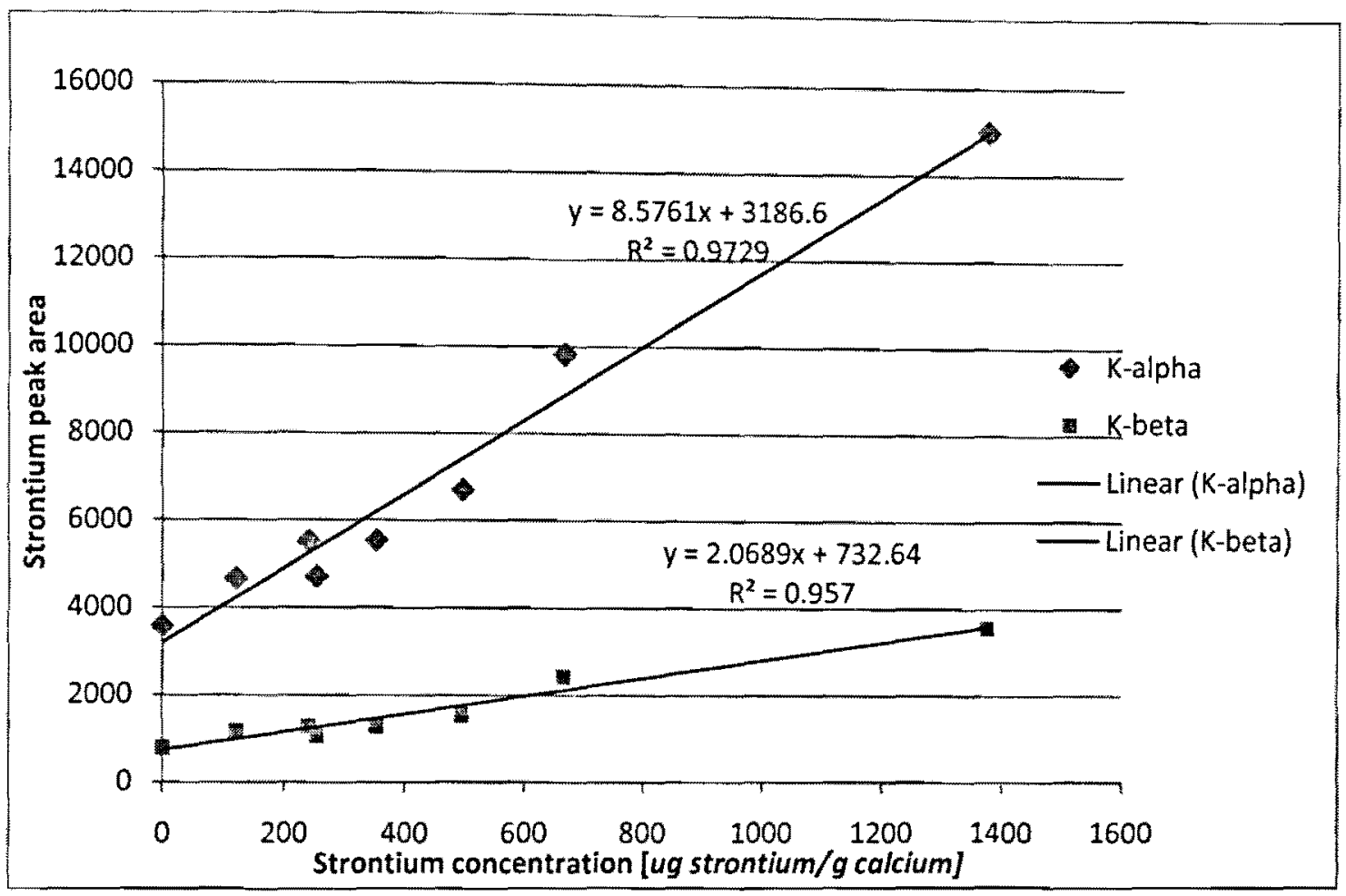

Figure 5-6: Calibration Curve of poP phantoms. The error relates to statistical uncertainty within the strontium peak area.

Hence, creation of a new set of calibration standards with smaller or no strontium contamination would improve the calibration curve obtained and solve the problem of the non-zero intercept. If this could be created, then the quantification of strontium concentration may be extracted from the calibration curve with reduced uncertainty. The new phantom calibration standards should be based of hydroxyapatite, which more closely resemble the mineral portion of bone. Thus, once a new set of calibration standards is achieved, the next step would be the attempt of quantifying and extracting strontium concentration to achieve absolute measurement of strontium in bone. Our research group is currently working on the creation of a new set of calibration standards. 


\subsubsection{Modeling of Bone Strontium Data}

In chapter three and four, the incorporation and retention of strontium was discussed. As individuals shared a common pattern of strontium uptake and retention, it would be worthwhile to kinetically model this data so that a relationship of strontium concentration with respect to time may be estimated. Bärenholdt and colleagues (2009) suggested that strontium retained in bone could be modeled according to Marshall's equation and the power function model, based on two important constants; the excretion rate, 'a', which could be obtained from the slope of the observed strontium data and the initial time, " $t_{0}$, which could be obtained from the altitude of the curve obtained from the strontium data (Bärenholdt et al., 2009).

According to Bärenholdt et al, (2009), since strontium is similar to calcium, in the assumption that long-term retention of strontium takes place mainly as a result of diffusion from bone surfaces into and from the calcified bone matrix, like calcium, the retention of strontium with time can also be described as a power function based on Marshall's equation, developed in 1969, which is given in Equation 5-1.

$$
R=t_{0} a\left(t+t_{0}\right)^{-a}=\left(\frac{t}{t_{0}+1}\right)^{-a}
$$

where $a$ is the excretion rate, $t$ is the treatment time and $t_{0}$ is the peak of the curve obtained. The retention curve after a single administration of strontium using the power function model, will be rectilinear in a log-log plot with a negative slope, $a$, which represents the excretion rate of strontium. 
As cited by Bärenholdt and colleagues (2009), the retention, R, of calcium at a time, t, may be determined from the method of whole body counting over thirty days $\left(t_{1 / 2}=4.53\right.$ days, gamma radiation energy $1.297 \mathrm{MeV}$ ) by means of an intravenous injection of ${ }^{47} \mathrm{CaCl}_{2}$. Taking into account, the physical decay $\mathrm{N}(\mathrm{t})$ of ${ }^{47} \mathrm{Ca}$ and the count rate $\mathrm{N}_{0}$, a log-log plot of whole bodycount rate against time, $t$, after injection may be plotted. From this plot, two important constants may be obtained. The first constant, $a$, is the value of the negative slope which represents the excretion rate of calcium and the second constant, $t_{0}$, represents the altitude of the curve. Using these two constants and equation 5-1, the retention of calcium may then be calculated. Assuming that strontium behaves the same way as calcium, the same principle is applied to determine the retention rate of strontium. Bärenholdt and colleagues (2009) estimated the retention of strontium ranelate over time and found that bone strontium uptake and retention data could be expressed with a power function model and that withdrawal of strontium ranelate treatment resulted in a decline in bone strontium but $73 \%$ and $67 \%$ strontium remained in the radius bone three and six months after strontium ranelate was discontinued.

Taking into account, the small molar concentrations of strontium relative to calcium, the single strontium atoms are assumed to act independently of each other. Thus, they estimated the effect of a constant daily intake, $m_{s}$, of 2 grams of strontium ranelate (which corresponds to a molar concentration of $8.5 \mathrm{mmol}$ strontium per day) during a treatment time, $t$, can be calculated as a linear summation of retented strontium from the single daily doses. Thus, if the total amount of calcium, denoted as $M_{c a}$ is $24,000 \mathrm{mmol}$ (for the present population assuming an average individual weight of $64 \mathrm{~kg}$, having a concentration of $375 \mathrm{mmol} \mathrm{Ca} \mathrm{kg}$ ), then the corresponding molar content of strontium can be expressed, in relation to the power function model as 
(Bärenholdt et al, 2009):

$$
\frac{M_{S r}(t)}{M_{C a}}=\int_{0}^{t} \frac{m_{S r} * A}{M_{C a}} *\left(\frac{t}{t_{0}}\right)^{-a} * d t=\frac{m_{S r} * A * t_{0}}{M_{C a} *(1-a)} *\left(\frac{t}{t_{0}}\right)^{1-a}
$$

Where $a$ is the excretion rate, $t$ is the treatment time, $t_{0}$ is the altitude of the curve and $A$ is the intestinal absorption. $\mathrm{M}_{\mathrm{ca}}$ is the total amount of calcium and is taken to be $24 \times 10^{3} \mathrm{mmol}$ and $m_{s r}$, refers to the daily strontium dosage in $\mathrm{mmol} / \mathrm{day}$.

However, once an individual stops taking strontium ranelate after a certain period of time, the retention of strontium at a time $t$ in the bones can be calculated as:

$\frac{M_{S r}(t)}{M_{C a}}=\frac{M_{S r^{*}} * t_{0}}{M_{C a}(1-a)} *\left\{\left(\frac{t}{t_{0}}\right)^{1-a}-\left(\frac{t-t_{S r}}{t_{0}}\right)^{1-a}\right\}$

where in addition to the same constants above, $\mathrm{t}_{\mathrm{sr}}$ refers to the time of treatment withdrawal. Hence, the shape of the corresponding strontium retention curve will depend not only on the excretion rate, $a$ but on the time of treatment withdrawal as well, $\mathrm{t}_{\mathrm{sr}}$. (Bärenholdt et $a l, 2009$ ). In another study by Cohn et al, a compartment model was used instead of Marshall's power function model and based on the injection of ${ }^{47} \mathrm{Ca}$ and ${ }^{85} \mathrm{Sr}$ in seven patients, using whole body counting 4-9 days after injection, for ${ }^{47} \mathrm{Ca} ; a=0.27$ and $\mathrm{t}_{0}=1.9$ days and for ${ }^{85} \mathrm{Sr}, a=0.45$ and $\mathrm{t}_{0}=1.5$ days. However, since these individuals were healthy individuals, the constant, $a$, is 
expected to be higher in older, osteoporotic individuals. Thus, it is possible, using the power function model to model the strontium data, if the two constants are optimally chosen. It is expected that the excretion rate, a, would be between $0.4-0.6$ as the data correlates to strontium levels in osteoporotic individuals. However, although the power function model seems a valid method to estimate strontium retention and strontium clearance, it presents with some issues, as brought up by Marie (2006b).

First, Marshall's equation was based on the intravenous administration of radium and wholebody counting, and there has been no reported evidence to date showing that strontium kinetically behaves the same way in bone as radium (Marie, 2006b). Second, the power function model does not take into account the time required for a complete bone cycle to occur (Marie, 2006b). Since strontium uptake and retention is influenced by the bone remodeling cycle, this time should be considered when modeling the data. Thus, if a baseline individual can be monitored for minimum time duration of three years, at which time strontium levels are expected to plateau then it may be possible to model the data for strontium uptake and retention in human bone. However, in addition to the power function model, most models are based on only one strontium intake (such as the intake of ${ }^{90} \mathrm{Sr}$ due to an accident), while this work deals with daily strontium intake. Indeed, using the strontium retention parameters, if the same individual stops taking strontium supplementation and is followed for a minimum of a year, a model may be based on strontium clearance but this work opens up the possibility to do a two compartment model (trabecular and cortical bone).

Thus if these issues of modeling the strontium data obtained from baseline data and looking at corresponding $\mathrm{k}$-alpha and $\mathrm{k}$-beta ratios are investigated, along with the improvement of subject 
positioning and the incorporation of a new generation system is made, then it may help us further understand the behavior of strontium in bone. While the recruitment of baseline individuals and continued measurement of subjects is currently still being done, further recruitment of healthy individuals and individuals from a variety of ethnic backgrounds may also help us answer the condition of osteoporosis that is becoming more and more prevalent, not only in the western countries but in the non-western countries as well. 


\section{APPENDIX I IVXRF Bone Strontium Measurements of Baseline}

\section{Subjects}

In this work, a total of 9 baseline subjects were measured. Representative results for these baseline individuals are discussed in chapter three (subjects 1 and 2). The remaining results for subjects 3 to 9 are illustrated in this Appendix I.
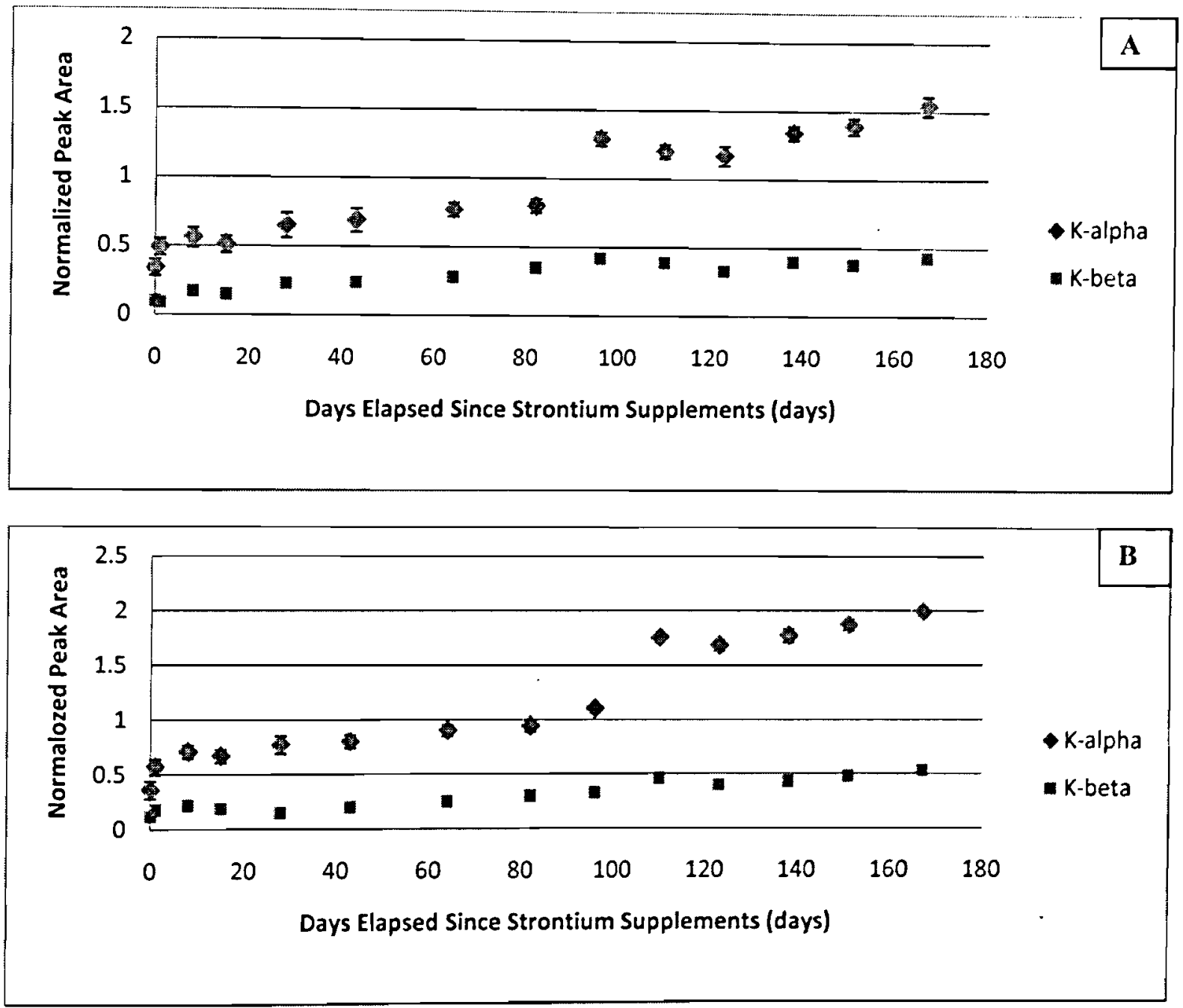

Figure AI-1: Strontium Measurement over Time Baseline Subject \#3 in A) Finger and B) Ankle. Subject is a $66 \mathrm{yr}$ old female, diagnosed with osteoporosis and osteopenia. Day zero represents the baseline measurement of subject's natural bone strontium level prior to strontium supplementation. Errors are associated with the statistical uncertainty. 

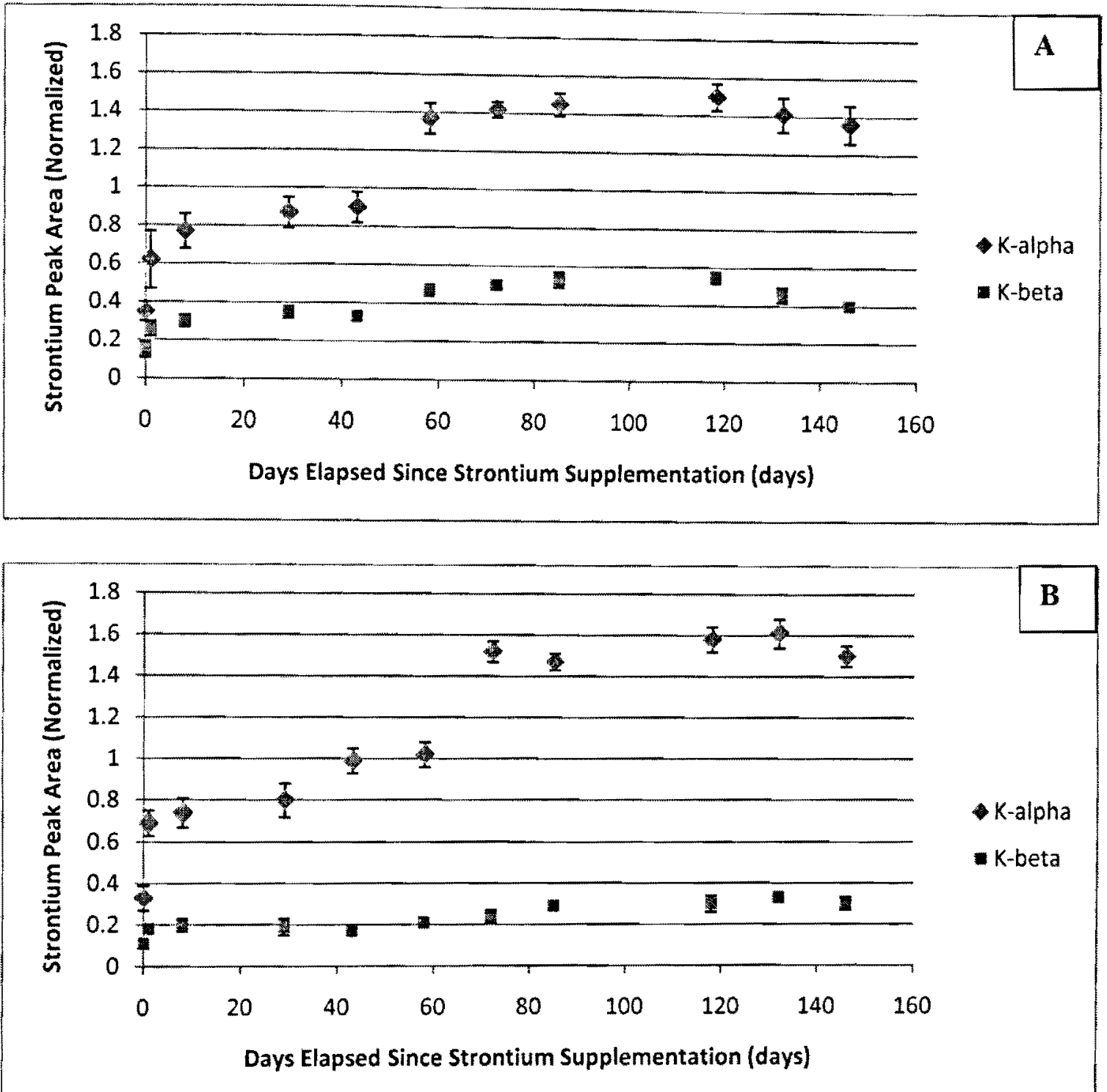

Figure AI-2: Strontium Measurement over Time Baseline Subject \#4 in A) Finger and B) Ankle. Subject is a $75 \mathrm{yr}$ old Caucasian female, diagnosed with osteoporosis of the spine and osteopenia of the neck. Day zero represents the baseline measurement of subject's natural bone strontium level prior to strontium supplementation. Errors are associated with the statistical uncertainty. 

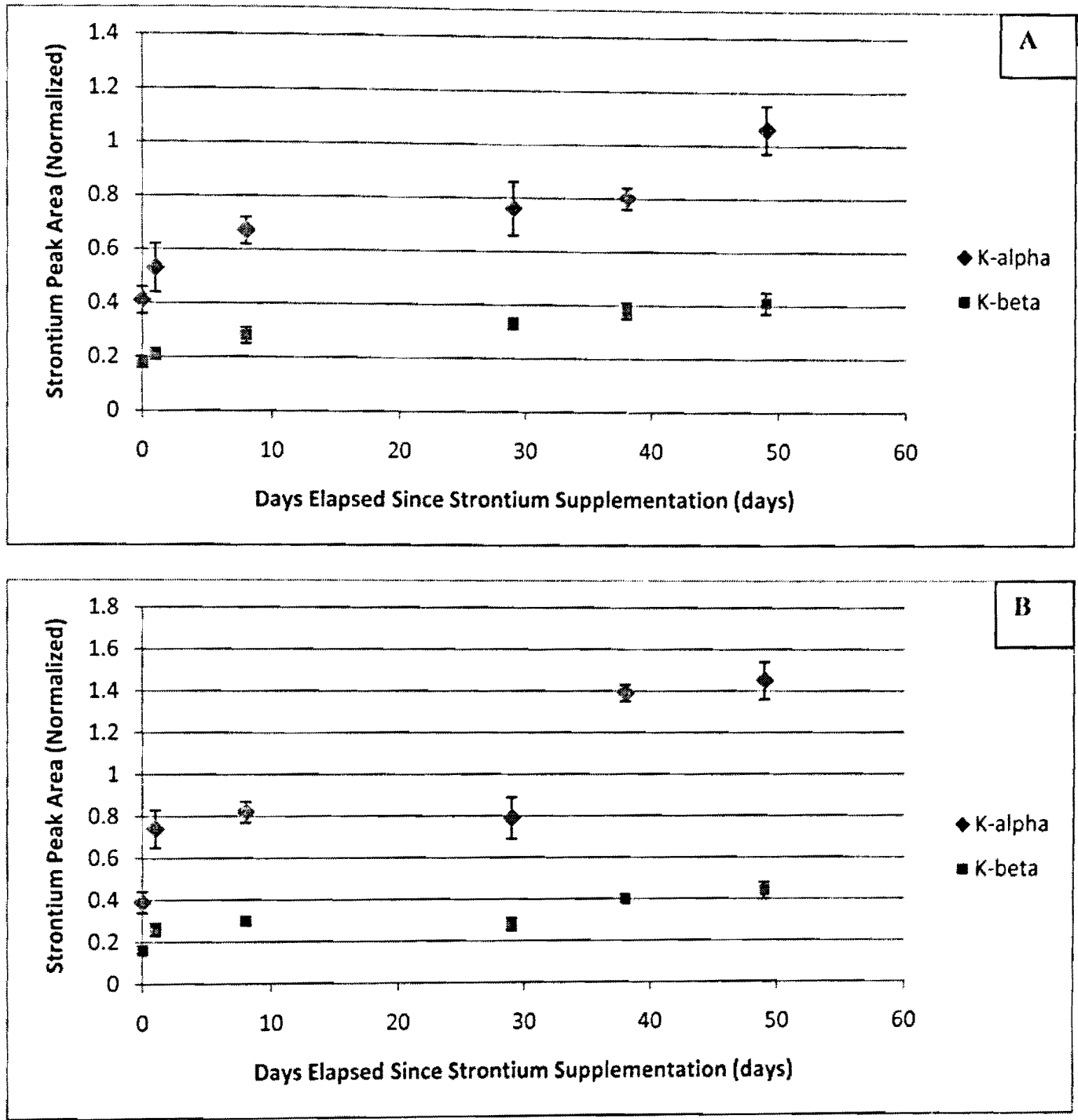

Figure AI-3: Strontium Measurement over Time Baseline Subject \#5 in A) Finger and B) Ankle. Subject is a $67 \mathrm{yr}$ old South American female, diagnosed with osteopenia of the hip. Note that normalized strontium peak area is proportional to the strontium signal observed. The error is associated with statistical uncertainty. 

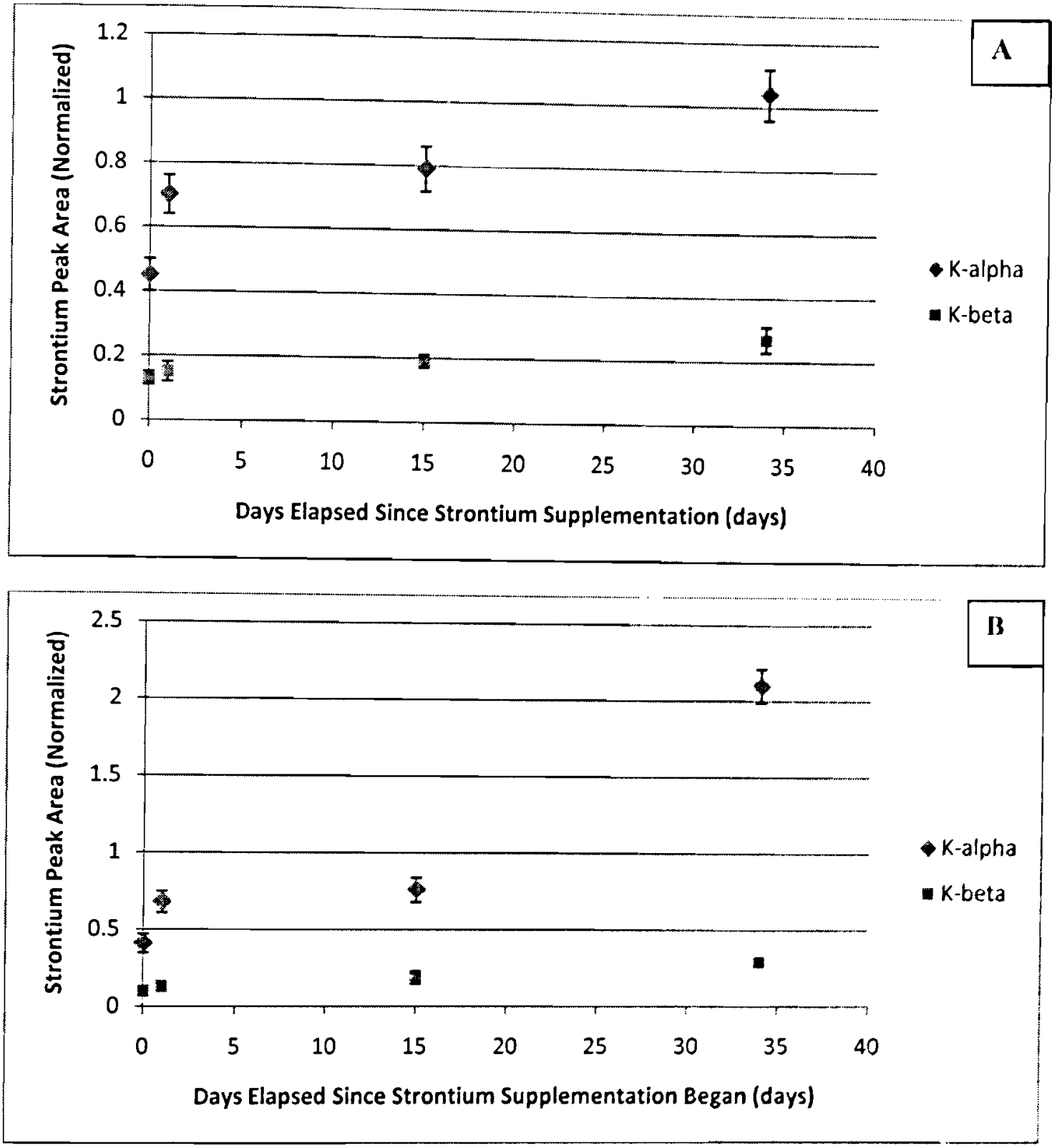

Figure AI-4: Strontium Measurement over Time Baseline Subject \#5 in A) Finger and B) Ankle. Subject is a 57 yr old Caucasian female, diagnosed with osteopenia of the spine. Note that normalized strontium peak area is proportional to the strontium signal observed. The error is associated with statistical uncertainty. 

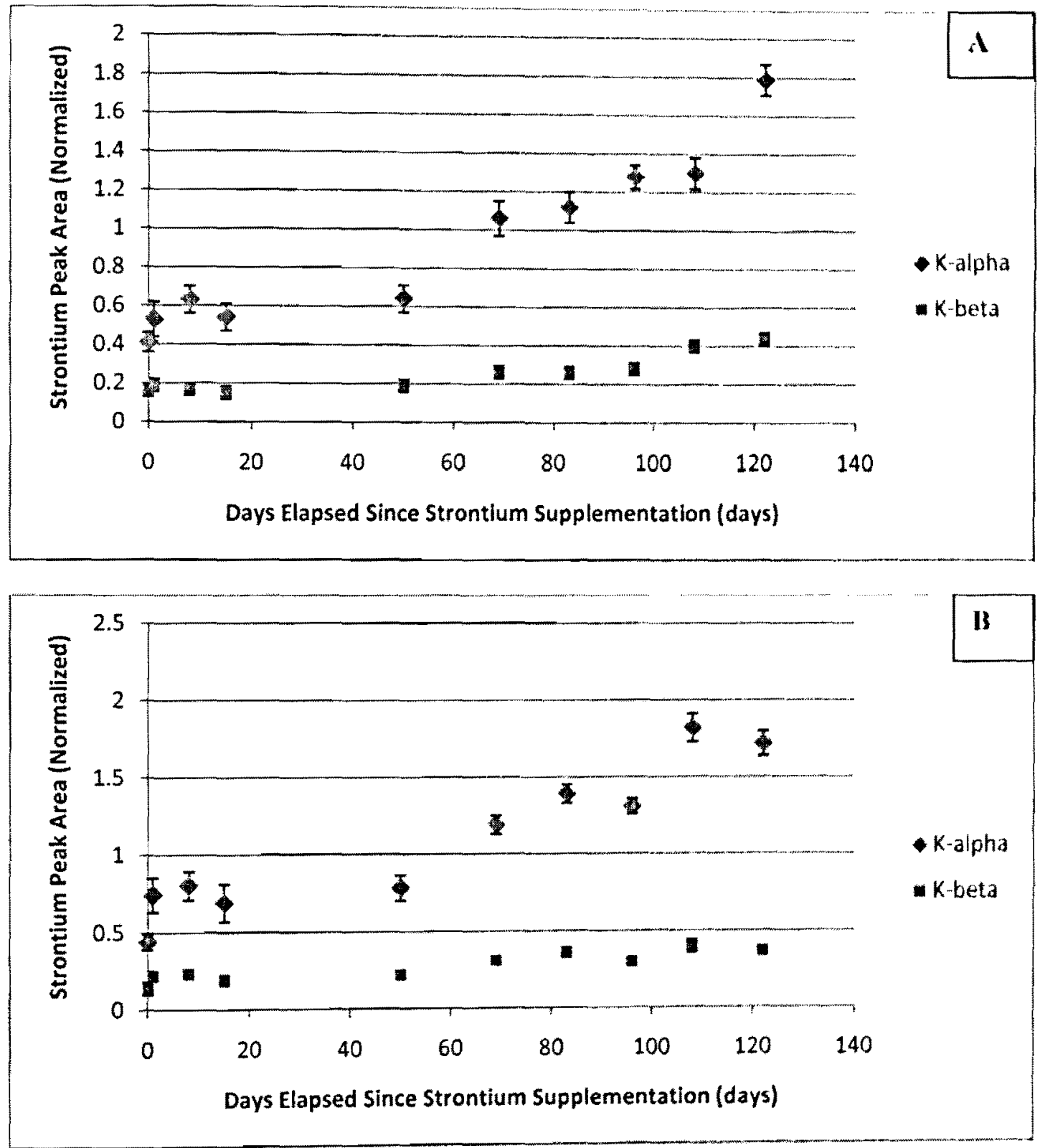

Figure AI-5: Strontium Measurement over Time Baseline Subject \#6 in A) Finger and B) Ankle. Subject is a 74 yr old Caucasian female, diagnosed with osteopenia of the spine, Note that normalized strontium peak area is proportional to the strontium signal oliserved. The error is associated with statistical uncertainty. 

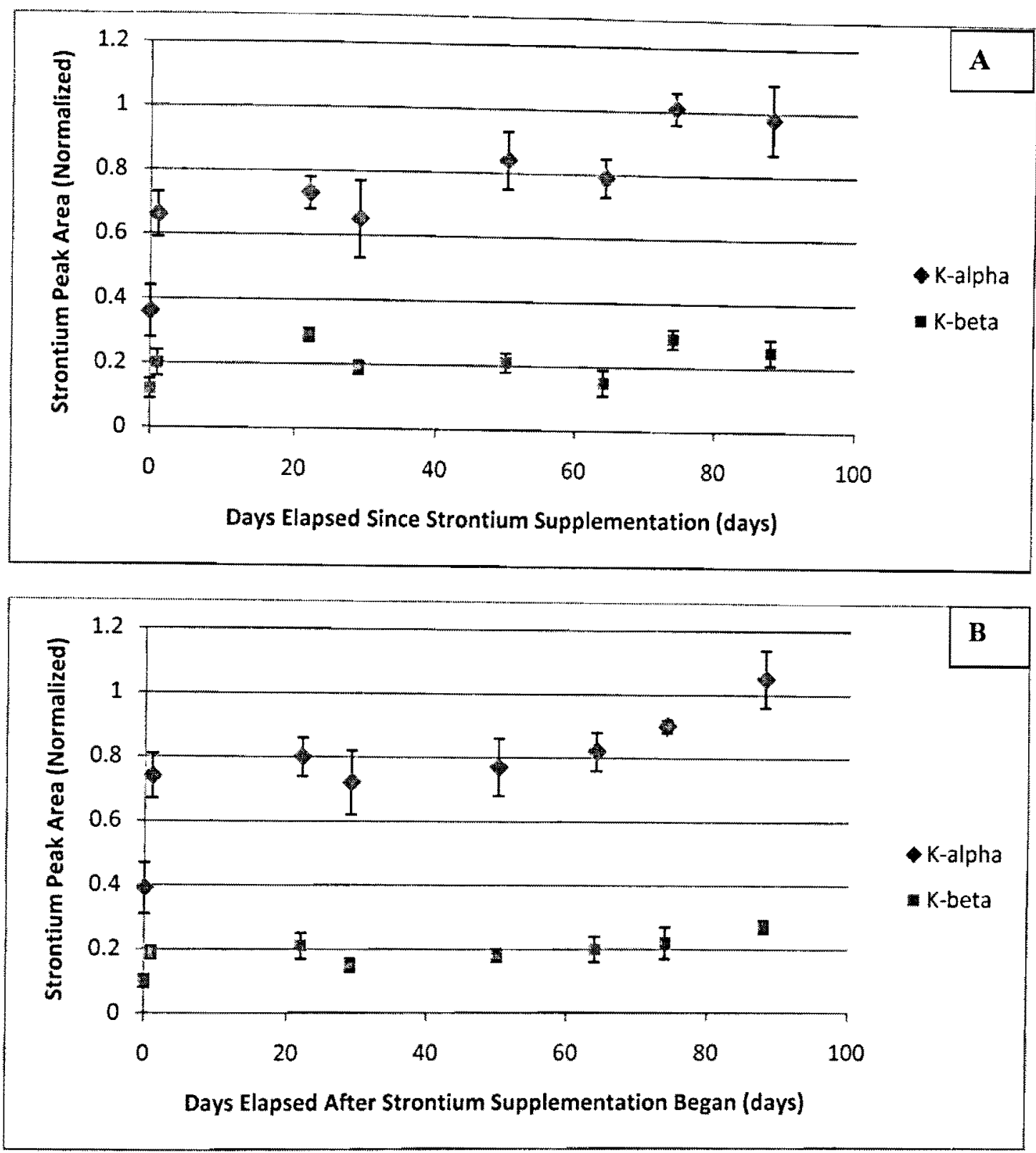

Figure AI-6: Strontium Measurement over Time Baseline Subject \#8 in A) Finger and B) Ankle. Subject is a 53 yr old Caucasian female, diagnosed with osteoporosis of the spine and osteopenia of the hip. Note that normalized strontium peak area is proportional to the strontium signal observed. The error is associated with statistical uncertainty. 

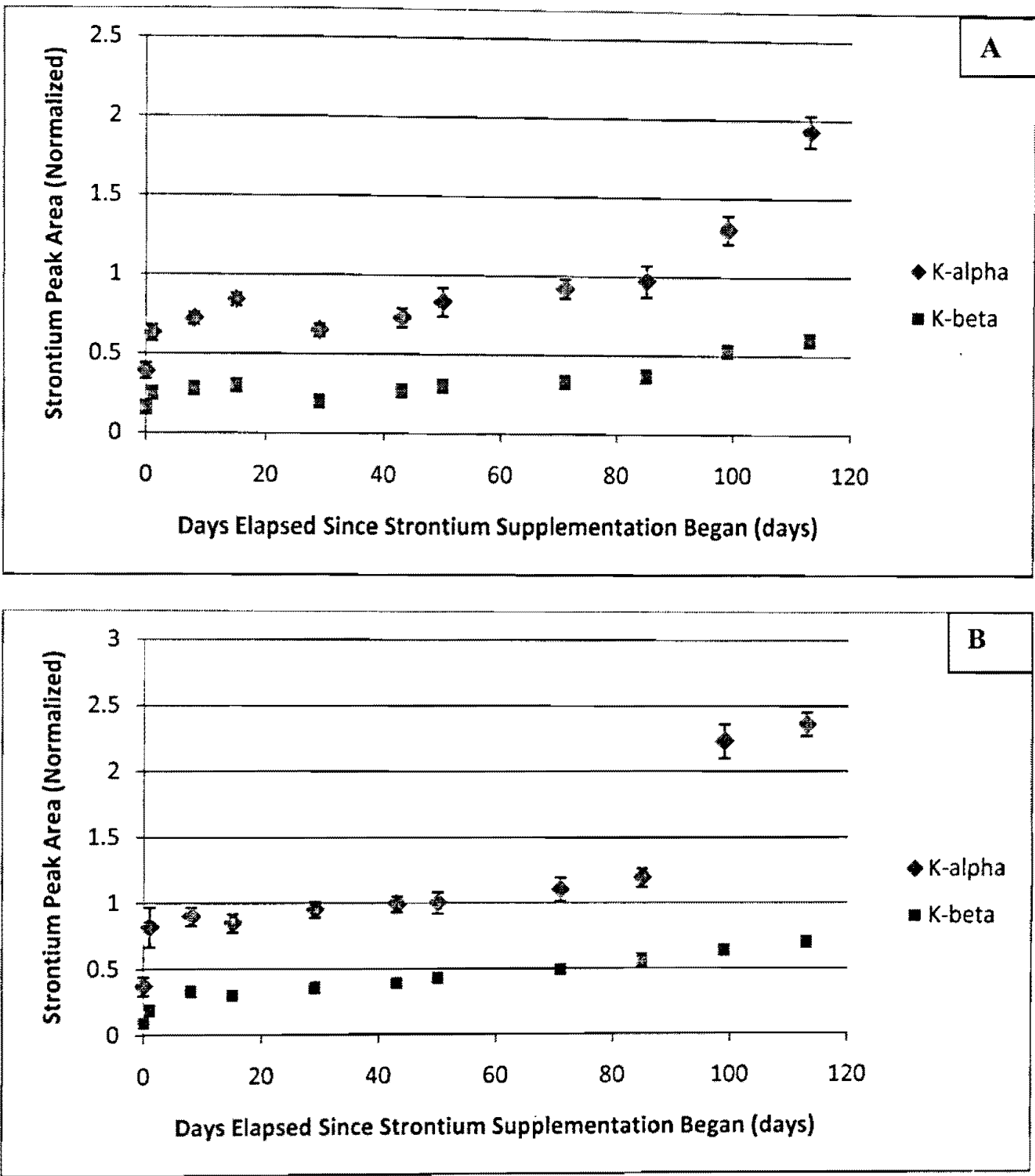

Figure AI-7: Strontium Measurement over Time Baseline Subject \#9 in A) Finger and B) Ankle. Subject is a 63 yr old Caucasian female, diagnosed with osteopenia of the spine and hip. Note that normalized strontium peak area is proportional to the strontium signal observed. The error is associated with statistical uncertainty. 


\section{APPENDIX II IVXRF Bone Strontium Measurements of Retention}

\section{Subjects}

In this work, a total of 10 retention subjects were measured. Representative results for these retention individuals are discussed in chapter four (subjects \#10 to 14). The remaining results for subjects 15 to 19 are illustrated in this Appendix II.
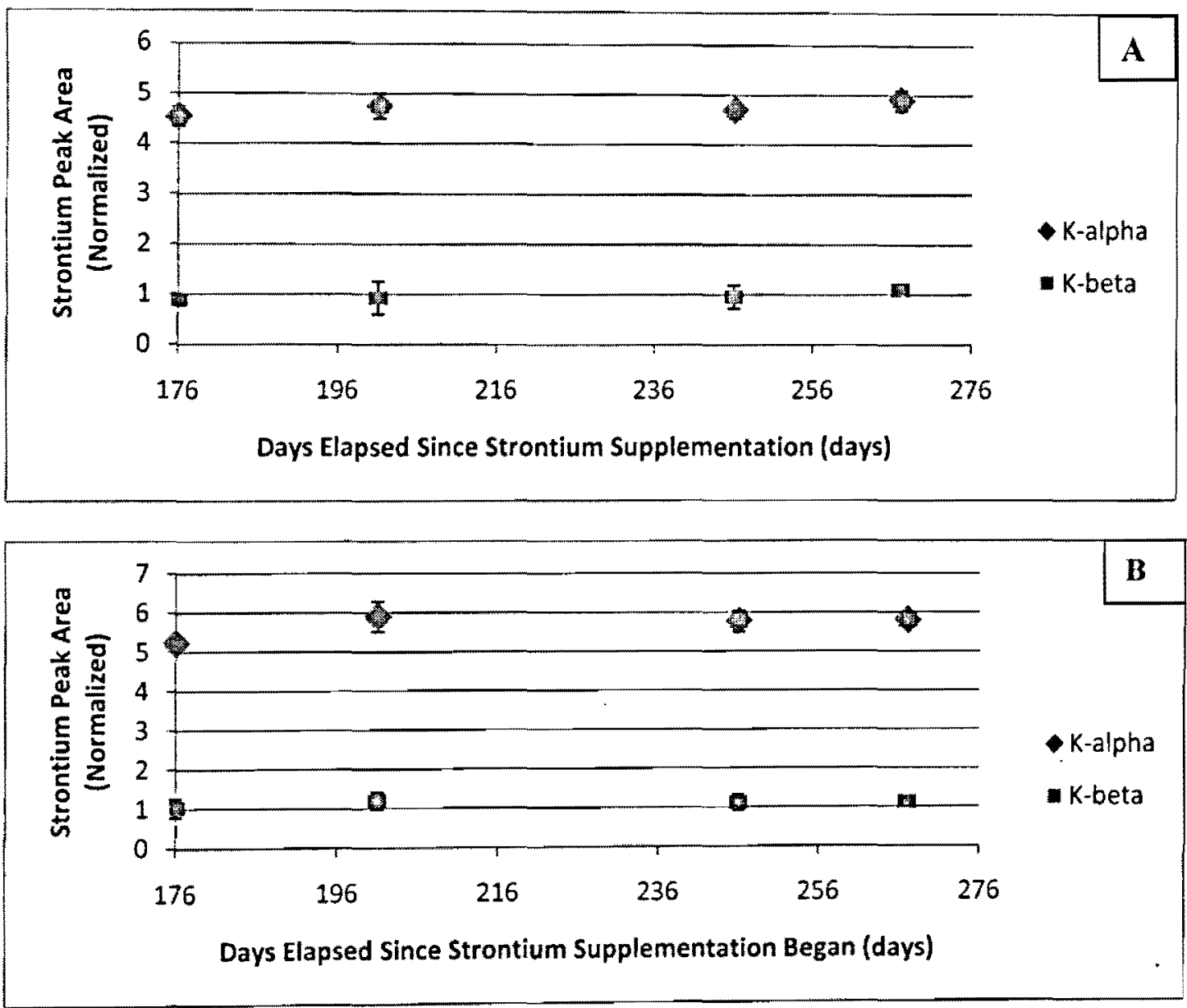

Figure AII-1: Strontium Measurement over Time Baseline Subject \#15 in A) Finger and B) Ankle. Subject is a 51 yr old Caucasian female, diagnosed with osteopenia of the spine. At time of first measurement, subject had been supplementing for 6 months (341 mg daily). Note that normalized strontium peak area is proportional to the strontium signal observed. The error is associated with statistical uncertainty. 

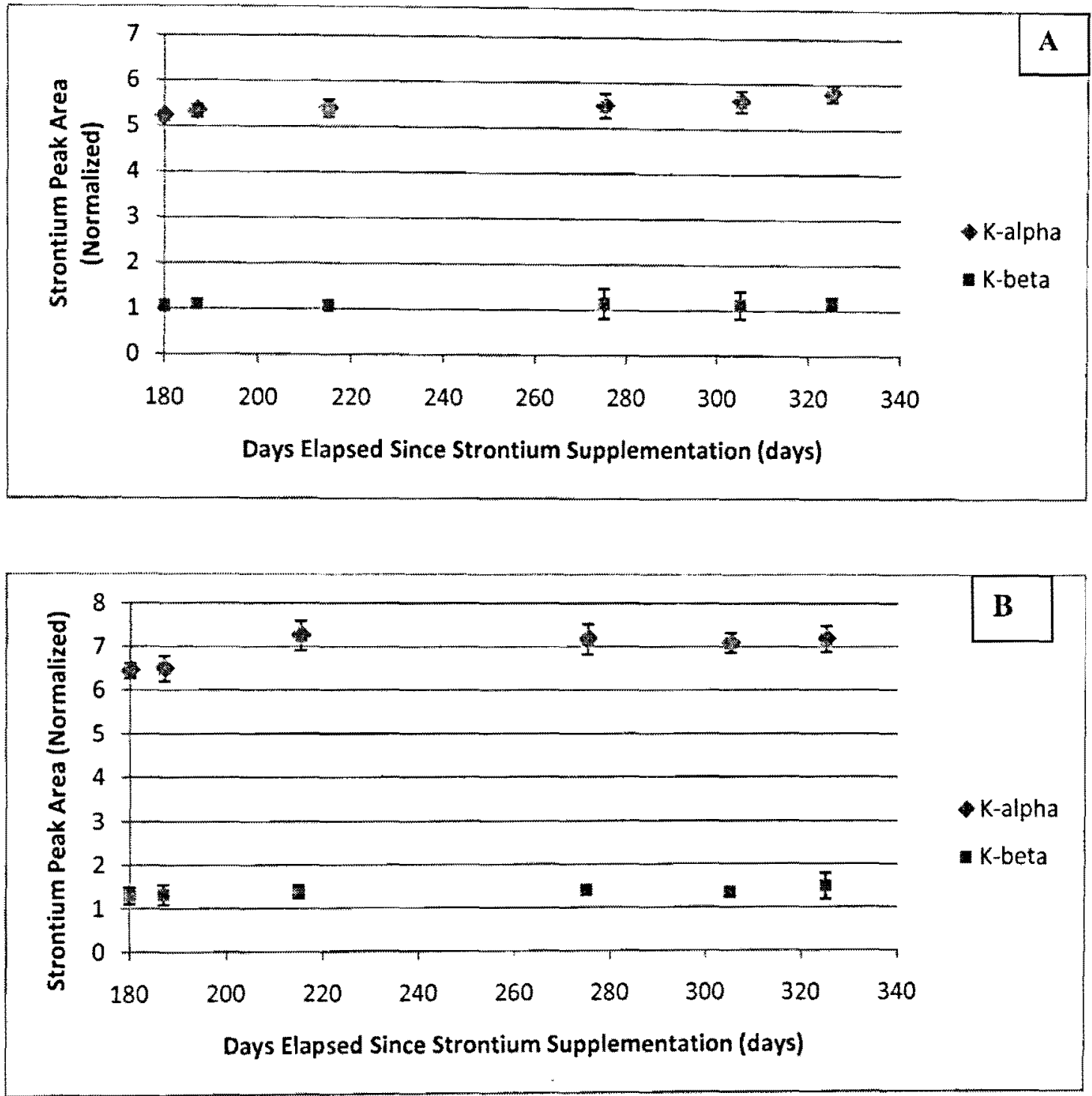

Figure AII-2: Strontium Measurement over Time Baseline Subject \#16 in A) Finger and B) Ankle. Subject is a 55 yr old Caucasian female, diagnosed with osteopenia of the spine. At time of first measurement, subject had been supplementing for 6 months ( $341 \mathrm{mg}$ daily). Note that normalized strontium peak area is proportional to the strontium signal observed. The error is associated with statistical uncertainty. 

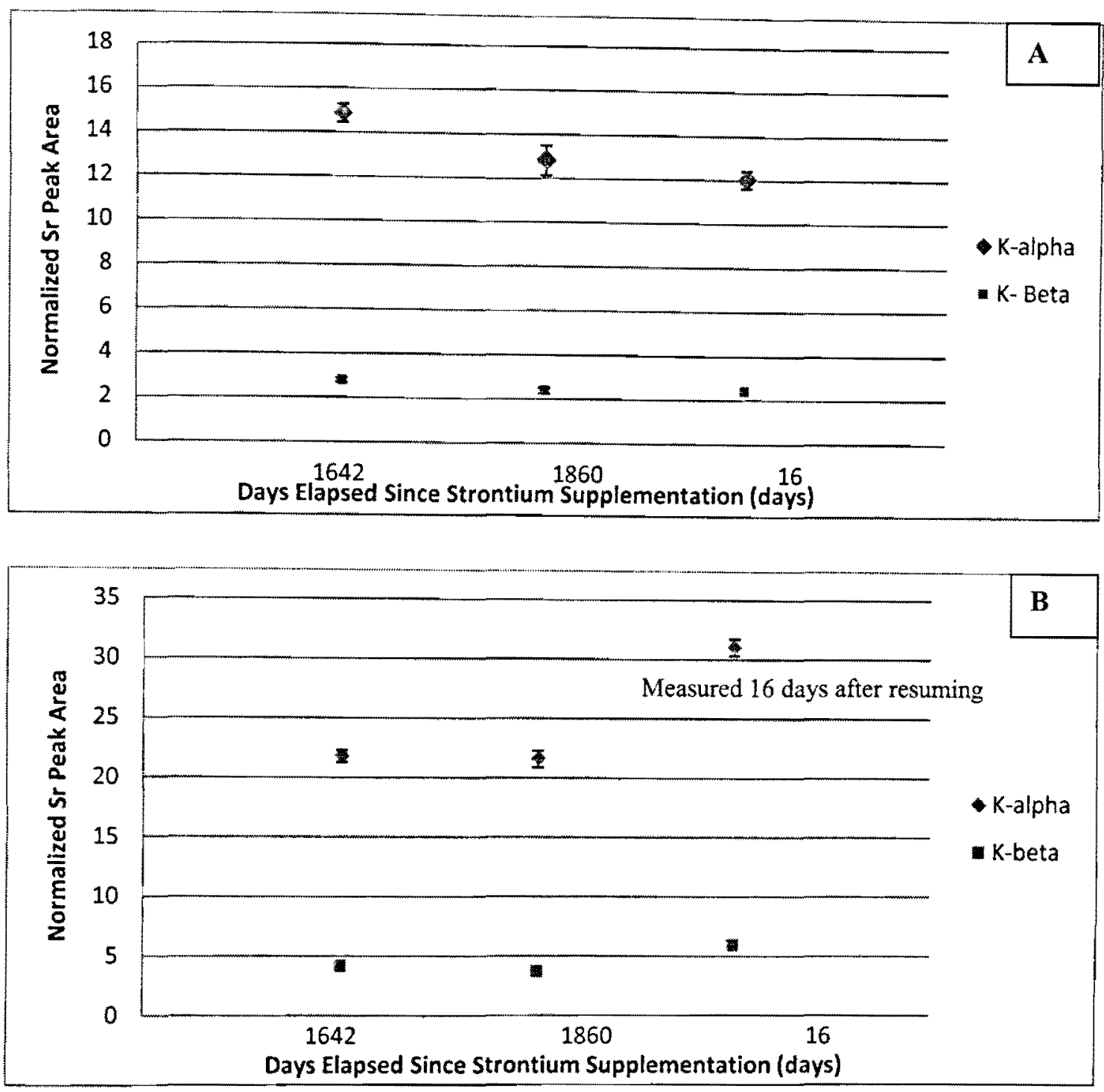

Figure AII-3: Strontium Measurement over Time Baseline Subject \#17 in A) Finger and B) Ankle. Subject is a 69 yr old Caucasian female, diagnosed with Osteopenia. Doses varied according to visit as: first visit; $1020 \mathrm{mg} / \mathrm{day}$, second visit: $680 \mathrm{mg} / \mathrm{day}$. She then discontinued strontium supplements after her second visit. A time lapse of 72 days occurred between visits and at the time of her third visit she had resumed strontium supplements to $341 \mathrm{mg} /$ day. Note that normalized strontium peak area is proportional to the strontium signal observed. The error is associated with statistical uncertainty. 

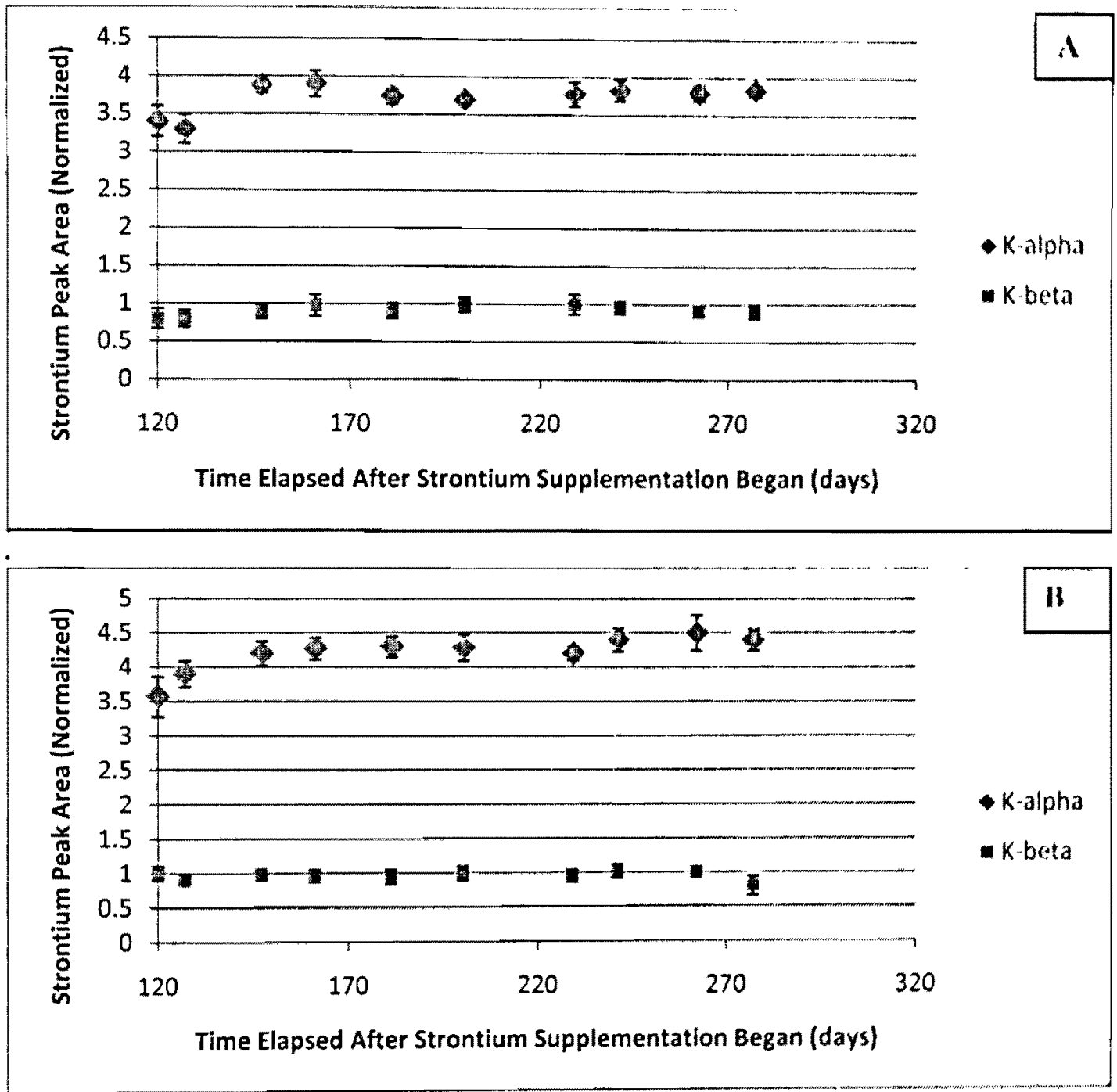

Figure AII-4: Subject \#19 in A) Finger and B) Ankle.. Subject is a 76 year old Caucasian female diagnosed with osteoporosis of the spine. Subject took one bottle of strontlum supplements before stopping 4 months (341mg daily) prior to joining the study. Note that normalized strontium peak area is proportional to the strontium signal observed. 'The Error is associated with statistical uncertainty. 
Subject \#18: Note for this subject, a onetime measurement was performed as subject joined study in June 2010. Subject is a 72 year old Caucasian female, diagnosed with osteopenia of the hip. At the time of measurement she had been taking strontium supplements $(341 \mathrm{mg}) 10$ months.

Subject \#18 Finger Bone Strontium Level: $5.18 \pm 0.20$

Subject \#18 Ankle Bone Strontium Level: $6.38 \pm 0.13$ 


\section{REFERENCES}

Bain SD, Jerome C, Shen V, Dupin-Roger I, Ammann P. (2009) Strontium ranelate improves bone strength in ovariectomized rat by positively influencing bone resistance determinants. Osteoporosis Int. 20: 1417-1428

Bärenholdt O, Kolthoff N, Neilsen SP. (2009) Effect of long-term treatment with strontium ranelate on bone strontium content. Bone. 45: 200-206

Barrett-Connor E, Siris ES, Wehren LE, Miller PD, Abbott TA, Berger ML, Santora AC, Sherwood LM (2005) Osteoporosis and fracture risk in women of different ethnic groups. $J$. Bone Miner. Res. 20: 185-194.

Belissa-Chatelain P, Dupin-Roger, Cournarie F. (2009) Re: "Effect of long-term treatment with strontium ranelate on bone strontium content" by Bärenholdt et al. (Bone 2009). Bone. 45 (Letter): 1024-1025

Bentley RA. (2006) Strontium Isotopes from the Earth to the Archaeological Skeleton: A review. Journal of Archaeological Method and Theory. 13 (3): 135-188

Berkow R, Beers MH, Fletcher AJ, Chir B. (1997) The Merck Manual of Medical Information (USA : Merck \& Co)

Blake GM, Fogelman I. (2007) Effect of bone strontium on bmd measurements. J Clinical Densitometry, 10: 34-38

Boivin G, Deloffre P, Perrat B, Panczer G, Boudeulle M, Mauras Y, Allain P, Tsouderos $Y$, Meunier PJ. (1996) Strontium distribution and interactions with bone mineral in monkey iliac bone after strontium salt (S 12911) administration. J. Bone Miner. Res. 11 (9): 1302-1311.

Boivin G, Farlay D, Khebbab T, Jaurand X, Delmas PD, Meunier PJ. (2009) In osteoporotic women treated with strontium ranelate, strontium is located in bone formed during treatment with a maintained degree of mineralization. Osteoporos Int. 10: 1-11.

Börjesson J, Mattsson S. (2007) Medical applications of x-ray fluorescence for trace.element research. JCPDS-International Centre for Diffraction data 2007. Retrieved July 2010 from: http://www.icdd.com/resources/axa/vol50/v50_01.pdf

Cabrera WE, Schrooten I, De Broe ME, D'Haese PC. (1999) Strontium and bone. J. Bone Miner. Res. 14 (5): 661-668. 
Canalis E, Hott M, Deloffre P, Tsouderos Y, Marie PJ. (1996) The divalent strontium salt S12911 enhances bone cell replication and bone formation in vitro. Bone. $18(6)$ : 517-523.

Christoffersen J, Christoffersen MR, Kolthoff N, Barenholdt O. (1997) Effects of strontium ions on growth and dissolution of hydroxyapatite and on bone mineral detection. Bone. 20 (1): 47-54.

Comar CL, Russell RS, Wasserman RH. (1957) Strontium-calcium movement from soil to man. Science. 126 (3272): 485-492.

Cortet B. (2009) Effects of bone anabolic agents on bone ultrastructure. Osteoporos Int. 20 (1): $1097-1100$

Dahl SG, Allain P, Marie PJ, Mauras Y, Boivin G, Ammann P, Tsouderos Y, Delmas PD, Christiansen C. (2001) Incorporation and distribution of strontium in bone. Bone. 28 (4): $446-453$.

Grynpas MD, Hamilton E, Cheung R, Tsouderos Y, Deloffre P, Hott M, Marie PJ. (1996) Strontium increases vertebral bone volume in rats at a low dose that does not induce detectable mineralization defect. Bone. 18 (3): 253-259

Heirwegh C. (2008) In vivo quantification of bone strontium using x-ray fluorescence. M.Sc. Thesis. McMaster University.

Heumann A, Davies G. (2002) U-Th Disequilibrium and Rb-Sr Age Constraints on the Magmatic Evolution of Peralkaline Rhyolites from Kenya. Journal of Petrology.43 (3): $557-577$

Hodges RM, MacDonald NS, Nusbaum R, Stearns R, Ezmirlian F, Spain P, McArthur C. (1950) The strontium content of human bones. J. Biol. Chem. 185 (2): 519-524.

Hwang JS, Chen JF, Yang TS, Wu DJ, Tsai KS, Ho C, Wu H, Su LS, Wang CJ, Tu ST. (2008) The effects of strontium ranelate in asian women with postmenopausal osteoporosis. Calcif Tissue Int. 83 (1): 308-314

Hurtel-Lemaire AS, Mentaverri, Caudrillier A, Cournarie F, Wattel A, Kamel S, Terwilliger EF, Brown EM, Brazier M. (2008) The calcium-sensing receptor is involved in strontium ranelate-induced osteoclasts apoptosis. J Biol. Chem. 284 (1): 575-584

Ilhan B, Uygur D, Ugurlu N, Ozakskit G. (2009) Strontium ranelate decreases plasma homocysteine levels in postmenopausal osteoporotic women. Rheumatol Int. 29 (1): 263-266 
International Commission on Radiological Protection (ICRP). (2002) Basic anatomical and physiological data for use in radiological protection: reference values. ICRP Publication 89. Pergamon Press, Oxford.

International Commission on Radiological Protection (ICRP). (1975) Report of the Task Group on Reference Man. ICRP Publication 23. Pergamon Press, Oxford.

JLab Education. (2010) The Element Strontium. Retreived July 2010 from: http://education.jlab.org/itselemental/ele038.html

Johns EH, Cunningham J. (1983) Physics of Radiology. Fourth Edition (USA, Thomas Books).

Kendler DL, Adachi JD, Josse RG, Slosman DO. (2009) Monitoring strontium ranelate therapy in patients with osteoporosis. Osteoporos Int. 20: 1101-1106

MacDonald NS, Ezmirlian F, Spain P, McArthur C. (1951) The ultimate site of skeletal deposition of strontium and lead. J. Biol. Chem. 189 (1): 387-399.

Marie PJ. (2006a) Strontium ranelate: a dual mode of action rebalancing bone turnover in favour of bone formation. Curr. Opin. Rheumatol. 18 (Suppl 1): S1 1-5.

Marie PJ. (2006b) Strontium ranelate: a physiological approach for optimizing bone formation and resorption. Bone. 38(Suppl 1): S10-S14

Marie PJ. (2008) Effective doses for strontium ranelate. Osteoporos Int. 19 (Letter): 19: 1813

Marie PJ, Ammann P, Boivin G, Rey C. (2001) Mechanisms of action and therapeutic potential of strontium in bone. Calcif. Tissue Int. 69 (3): 121-129.

Marie PJ, Garba MT, Hott M, Miravet L. (1985) Effect of low doses of stable strontium on bone metabolism in rats. Miner. Electrolyte Metab. 11 (1): 5-13.

Mayo Clinic Staff. Interpreting T-scores. Mayo Clinic. Retrieved July 2010 from http://www.mayoclinic.com

McCaslin FE, Jr. and Janes JM. (1959) The effect of strontium lactate in the treatment of osteoporosis. Proc. Staff Meet. Mayo Clin. 34 (13): 329-334.

Meunier PJ, Roux C, Seeman E, Ortolani S, Badurski JE, Spector TD, Cannata J, Balogh A, Lemmel EM, Nielsen SP, Rizzoli R, Genant HK, Reginster JY. (2004) The effects of strontium ranelate on the risk of vertebral fracture in women with postmenopausal osteoporosis. N. Engl. J. Med. 350 (5): 459-468. 
Neuprez A, Hiligsmann M, Scholtissen S, Bruyere O, Reginster JY. (2008) Strontium ranelate: the first agent of a new therapeutic class in osteoporosis. Adv Ther. 25 (12): 1235-1256

Nielsen SP, Barenholdt O, Barenholdt-Schioler C, Mauras Y, Allain P. (2004)

Noninvasive measurement of bone strontium. J. Clin. Densitom. 7 (3): 262-268.

Nielsen SP. (2004) Review: The biological role of strontium. Bone. 35 (3): 583-588.

Nielsen SP, Slosman D, Sorensen OH, Basse-Cathalinat B, De Cassin P, Roux C, Meunier PJ. (1999) Influence of strontium on bone mineral density and bone mineral content measurements by dual x-ray absorptiometry. J. Clin. Densitom. 2 (4): 371379.

OMeara JM, Chettle DR, McNeill FE, Webber CE. (1997) The feasibility of measuring bone uranium concentrations in vivo using source excited $\mathrm{K} x$-ray fluorescence. Phys. Med. Biol. 42 (6): 1109-1120.

Ozgur S, Sumer H, Kocoğlu G. (1996) Rickets and soil strontium. Arch. Dis. Child. 75 (6): 524-526.

Paula B, Marchesi E, Pagnoni A, Lambertini E, Franceschetti T, Penolazzi L, Piva R. (2009) Synthesis, characterization of strontium-bile acid salts and their bioactivity vs. the antiosteoporosis drug strontium ranelate. J. Inorganic Biochemistry. 103 (1): 891-897

Pecher C. (1941) Biological investigations with radioactive calcium and strontium. Proc Soc Exp Biol Med. 46 86-91.

Peel N. (2008) Bone remodeling and disorders of bone metabolism. Surgery. 27 (2): 70-74

Pejović-Milić A, Stronach IM, Gyorffy J, Webber CE, Chettle DR. (2004) Quantification of bone strontium levels in humans by in vivo x-ray fluorescence. Med. Phys. 31 (3): 528-538.

Pejović-Milić A, Brito JA, Gyorffy J, Chettle DR. (2002) Ultrasound measurements of overlying soft tissue thickness at four skeletal sites suitable for in vivo $\mathrm{x}$-ray fluorescence. Med. Phys. 29 (11): 2687-2691.

Pors Nielsen S. (2004) The biological role of strontium. Bone. 35 (3): 583-588.

Reginster JY, Felsenberg D, Boonen S, Diez-Perez A, Rizzoli R, Brandi ML, Spector TD, Brixen K, Goemaere S, Cormier C, Balogh A, Delmas PD, Meunier PJ. (2008) Effects of long-term strontium ranelate treatment on the risk of nonvertebral and vertebral fractures in postmenopausal osteoporosis: Results of a five-year, randomized, placebo-controlled trial. Arthritis Rheum. 58 (6): 1687-1695. 
Renaudin G, Jallot E, Nedelec JM. (2009) Effect of strontium substitution on the composition and microstructure of sol-gel derived calcium phosphates. J Sol-Gel Sci Technol. 51: 287-294

Rosenthal HL, Cochran OA, Eves MM. (1972) Strontium content of mammalian bone, diet and excreta. Environ. Res. 5 (2): 182-191.

ROCQ (2008) 80\% of women with osteoporosis-related fractures are neither diagnosed nor treated. Osteoporosis Canada Website. Retrieved June 2010 from: http://www.osteoporosis canada.ca

Schroeder HA, Tipton IH, Nason AP. (1972) Trace metals in man: strontium and barium. J. Chronic Dis. 25 (9): 491-517.

Schrooten I, Cabrera W, Goodman WG, Dauwe S, Lamberts LV, Marynissen R, Dorrine W, De Broe ME, DHaese PC. (1998) Strontium causes osteomalacia in chronic renal failure rats. Kidney Int. 54 (2): 448-456.

Shorr E and Carter AC. (1952) The usefulness of strontium as an adjuvant to calcium in the remineralization of the skeleton in man. Bull. Hosp. Joint Dis. 13 (1): 59-66. Smith DA, Speirs CF, Shimmins J. (1967) The long-term skeletal retention and recirculation of $85 \mathrm{Sr}$ in man. Calcif. Tissue Res. 1 (2): 144-152.

Snyder RE and Secord DC. (1982) The in situ measurement of strontium content in bone using X-ray fluorescence analysis. Phys. Med. Biol. 27 (4): 515-529.

Sutton R. (2009) .Practical Osteoporosis. Retrieved July 2010 from: http://www.bcrs.bc.ca/pdf/BMDWorkshopFinal18July_v2.pdf

Thurber DL, Kulp JL, Hodges E, Gast PW, Wampler JM. (1958) Common strontium content of the human skeleton. Science. 128 (3318): 256-257.

Turekian KK and Kulp JL. (1956) Strontium content of human bones. Science. 124 (3218): 405-407.

Valaciclovir. (2010) Strontium Ranelate CAS 135459-87-1. Chemical Register. Retrieved: July, 2010 from http://www.chemicalregister.com/Strontium_ranelate/suppliers/pid50978.htm

Verberckmoes SC, Behets GJ, Oste L, Bervoets AR, Lamberts LV, Drakopoulos M, Somogyi A, Cool P, Dorrine W, De Broe ME, D Haese PC. (2004) Effects of strontium on the physicochemical characteristics of hydroxyapatite. Calcif. Tissue Int. 75 (5): 405-415. 
Washington State Department of Health. Office of Radiation Protection-Sr 90 Fact Shect. Washington, USA. Retrieved: July 2010 from

http://www.doh.wa/gov/ehp/rp/factsheets/factshects-pdf/ fs24sr90.pdf

WHO. (1994) Study Group on Assessment of Fracture Risk and its Application to Screening for Postmenopausal Osteoporosis. Technical Report Serics (World IIcalth Organization). WHO, Geneva.

Wielopolski L, Vartsky D, Yasumura S, Cohn SH. (1983) Application of XRF to mcasure strontium in human-bone in vivo. Advances in X-Ray Analysis. 26 415-421.

Woodard HQ and White DR. (1986) The composition of body tissues. Br. J. Radiol. 59 (708): 1209-1218.

Woodard HQ. (1962) The elementary composition of human cortical bonc. /lealth Phys. 8 (0017-9078): 513-517.

Zaichick V. (2006) INAA of $\mathrm{Ca}, \mathrm{Cl}, \mathrm{K}, \mathrm{Mg}, \mathrm{Mn}, \mathrm{Na}, \mathrm{P}$, and Sr contents in the human cortical and trabecular bone. J. Radioanal. Nucl. 269 (3): 653-659.

Zamburlini M. (2008) In vivo measurement of bone strontium with $\mathrm{x}$-ray fluorescence. Ph.D. Dissertation. McMaster University.

Zamburlini M, Pejović-Milić A, Chettle DR. (2007b) Spectrometry mcthods for in vivo bone strontium measurements. X-Ray Spectrom. 37 (1): $42-50$.

Zamburlini M, Pejović-Milić A, Chettle DR. (2008) Coherent normalization of finger strontium XRF measurements: feasibility and limitations. Phys. Med. Biol. 53 (15): N307-N313.

Zamburlini M, Pejović-Milić A, Chettle DR, Webber CE, Gyorffy J. (2007a) In vivo study of an $\mathrm{x}$-ray fluorescence system to detect bone strontium non-invasively. Phys. Med. Biol. 52 (8): 2107-2122.

Zamburlini M, Pejović-Milić A, Chettle DR. (2006) Evaluation of geometries appropriatc for $\mathrm{I}-125$ in vivo bone strontium $\mathrm{x}$-ray fluorescence measurement. J. Radioanal. Nucl. 269 (3): 625-629. 